Oxygen Transport Membranes:

A Material Science and Process Engineering Approach

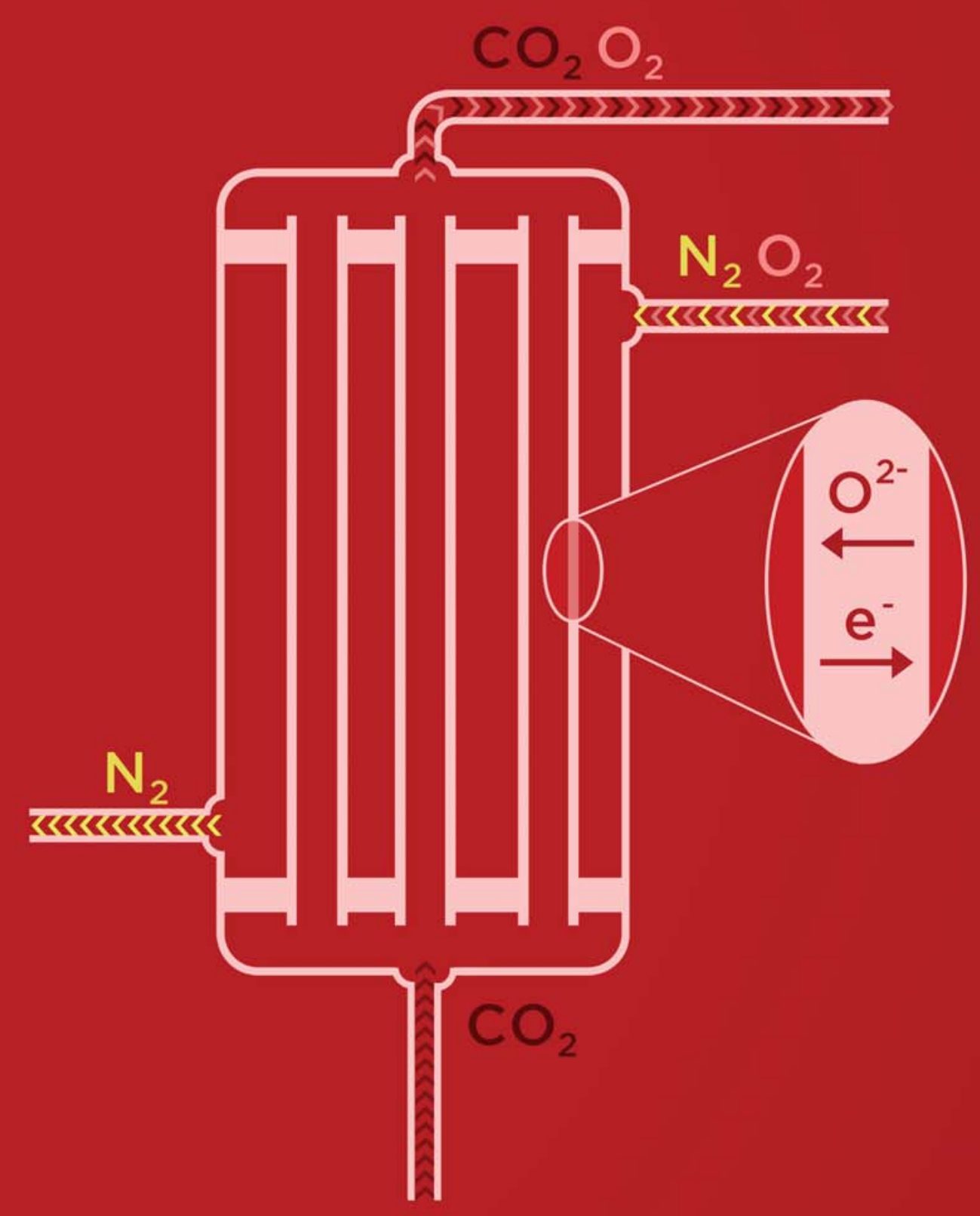

Wei Chen 


\section{Oxygen transport membranes:}

A material science and process engineering approach

\section{Wei Chen}




\section{Graduation committee}

Chairman:

Prof. dr. G. Mul

University of Twente

Promotors:

Prof. dr. ir. A. Nijmeijer

University of Twente

Prof. dr. A. J. A. Winnubst

University of Science and Technology of China /

University of Twente

Committee members:

Prof. dr. J. Caro

Leibniz University of Hanover

Prof. dr. C-S. Chen

University of Science and Technology of China

Prof. dr. ir. M. van Sint-Annaland

Eindhoven University of Technology

Prof. dr. ing. A. J. H. M. Rijnders

University of Twente

Dr. ir. A. G. J. van der Ham

University of Twente

The research described in this thesis was carried out in the Inorganic Membranes group and the MESA+ Institute for Nanotechnology at the University of Twente, Enschede, the Netherlands.

Cover design by Jonathan Bennink, www.tingle.nl

Oxygen transport membranes: A material science and process engineering approach

Wei Chen, $\mathrm{PhD}$ thesis, University of Twente, The Netherlands

ISBN: 978-90-365-3660-8

DOI: $10.3990 / 1.9789036536608$

URL: http:// dx.doi.org/10.3990/1.9789036536608

Printed by Gildeprint, Enschede, the Netherlands

(C) Copyright 2014 Wei Chen 


\title{
OXYGEN TRANSPORT MEMBRANES: \\ A MATERIAL SCIENCE AND PROCESS \\ ENGINEERING APPROACH
}

\section{DISSERTATION}

\author{
to obtain \\ the degree of doctor at the University of Twente, \\ on the authority of the rector magnificus, \\ prof. dr. H. Brinksma,
}

on account of the decision of the graduation committee,

to be publicly defended

on Friday, $16^{\text {th }}$ of May, 2014 at 14:45

by

\section{Wei Chen}

born on $19^{\text {th }}$ of December, 1982

in Biyang county, Henan Province, P.R. China 
This dissertation has been approved by promotors:

Prof. dr. ir. A. Nijmeijer

Prof. dr. A.J.A. Winnubst 


\section{Table of contents}

Table of contents $\quad$ i

Chapter 1 Introduction 1

$1.1 \mathrm{CO}_{2}$ capture and storage $\quad 2$

1.1.1 Post-combustion $\mathrm{CO}_{2}$ capture 3

1.1.2 Oxy-fuel combustion 4

1.1.3 Pre-combustion $\mathrm{CO}_{2}$ capture 5

1.2 Oxygen transport membranes integrated in oxy-fuel combustion $\quad 7$

1.2.1 Oxygen transport through a dense ceramic membrane 7

1.2.2 Integration of oxygen transport membranes in the oxy-fuel combustion $\begin{array}{ll}\text { process } & 10\end{array}$

1.3 State of the art membranes for oxy-fuel combustion 12

1.4 Scope of the thesis 14

$\begin{array}{ll}\text { References } & 15\end{array}$

Chapter 2 Oxygen Non-stoichiometry Determination of Perovskite Materials by $\begin{array}{ll}\text { a carbonation process } & 19\end{array}$

$\begin{array}{ll}2.1 \text { Introduction } & 20\end{array}$

$\begin{array}{ll}2.2 \text { Experimental } & 21\end{array}$

$\begin{array}{ll}2.3 \text { Results } & 23\end{array}$

2.4 Discussion

2.5 Conclusion 32

$\begin{array}{ll}\text { References } & 33\end{array}$

Chapter 3 A description of oxygen transport in a bench-scale oxygen permeation set-up using computing fluid dynamics 35

3.1 Introduction 36

3.2 Experimental and methodological procedure 39 
3.2.1 Membrane fabrication and oxygen permeation experiments

3.2.2 Oxygen transport through a MIEC membrane $\quad 40$

3.2.3 Design of a numerical model for the oxygen permeation set-up

3.2.4 Calculation of oxygen ionic conductivity from oxygen permeation data43

3.3 Results and discussion

3.3.1 Oxygen permeation results

3.3.2 Oxygen ionic conductivity of SCF

3.3.3 Parameters influencing the distribution at the permeate side of the membrane

3.4 Conclusions

3.5 Appendix

3.5.1 Calculation of the diffusion coefficient of a gas mixture

3.5.2 Calculation of the viscosity of single and mixed gases

3.5.3 Calculation of the viscosity of mixed gases

Chapter 4 Ta-doped $\mathrm{SrCo}_{0.8} \mathrm{Fe}_{0.2} \mathrm{O}_{3-\delta}$ membranes: Phase stability and oxygen permeation in $\mathrm{CO}_{2}$ atmosphere

4.1 Introduction

4.2 Experimental

4.3 Results and Discussion $\quad 63$

4.3.1 Phase composition and thermal expansion 63

4.3.2 Effect of Ta-doping on the reaction between SCF powders and $\mathrm{CO}_{2} \quad 65$

4.3.3 Oxygen permeation $\quad 69$

$\begin{array}{ll}4.4 \text { Conclusion } & 70\end{array}$

$\begin{array}{ll}\text { References } & 70\end{array}$

Chapter 5 Oxygen-selective membranes integrated with oxy-fuel combustion 73

5.1 Introduction 
5.2 Experimental procedure and methodology $\quad 75$

$\begin{array}{ll}\text { 5.2.1 Sample preparation } & 75\end{array}$

5.2.2 Thermal-gravimetric analysis (TGA) 76

5.2.3 X-ray photoelectron spectroscopy analysis 76

$\begin{array}{ll}\text { 5.2.4 Oxygen permeation measurements } & 77\end{array}$

$\begin{array}{ll}\text { 5.2.5 Membrane area calculation } & 78\end{array}$

5.3 Results and discussion $\quad 82$

5.3.1 Thermal-gravimetric analysis 82

5.3.2 XPS analysis 84

5.3.3 Oxygen permeation measurements 85

5.3.4 Process design and membrane area calculation $\quad 87$

5.4 Conclusion $\quad 89$

$\begin{array}{ll}\text { References } & 90\end{array}$

Chapter 6 Membrane-integrated oxy-fuel combustion: process design and simulation 93

6.1 Introduction 96

6.2 Coal-fired power plant without $\mathrm{CO}_{2}$ capture 98

6.3 Oxy-fuel combustion process 101

6.4 Membrane-integrated oxy-fuel combustion process 103

6.4.1 Membrane module 103

$\begin{array}{ll}\text { 6.4.2 Process design } & 108\end{array}$

$\begin{array}{ll}\text { 6.4.3 Process simulation } & 110\end{array}$

6.4.4 Specific energy demand for $\mathrm{CO}_{2}$ capture and oxygen production 111

6.4.5 Parametric study 112

6.4.6 Process modification 118

$\begin{array}{ll}\text { 6.5 Conclusion } & 120\end{array}$ 
$\begin{array}{ll}\text { References } & 121\end{array}$

$\begin{array}{ll}\text { 6.6 Appendix } & 124\end{array}$

$\begin{array}{ll}\text { Chapter } 7 \text { Conclusions and Recommendations } & 127\end{array}$

$\begin{array}{ll}7.1 \text { Incomplete gas mixing in a lab-scale permeation set-up } & 128\end{array}$

7.2 Chemical stability of MIEC membranes in a $\mathrm{CO}_{2}$-containing atmosphere 129

7.3 Evaluation of the membrane-integrated oxy-fuel combustion process 131

7.4 Some recommendations for future work 132

$\begin{array}{ll}\text { References } & 133\end{array}$

$\begin{array}{ll}\text { Summary } & 135\end{array}$

$\begin{array}{ll}\text { Samenvatting } & 139\end{array}$

$\begin{array}{ll}\text { Acknowledgements } & 145\end{array}$

$\begin{array}{ll}\text { Curriculum Vitae } & 147\end{array}$ 
Chapter 1 Introduction 


\section{1 $\mathrm{CO}_{2}$ capture and storage}

A general consensus exists that the earth is experiencing rapid climate changes, which may cause a redistribution of the global climates. Although it is unknown whether this is beneficial or disastrous for human beings, it will undoubtedly affect human civilization. For example, global warming may cause ice melting in Antarctica and Greenland, which leads to a rise of the sea level and eventually some low altitude cities and countries may disappear.

Although there is no universal agreement about the cause of global warming, many climate scientists assume that the anthropogenic emission of carbon dioxide $\left(\mathrm{CO}_{2}\right)$ into the atmosphere is one of the main reasons. In order to reduce $\mathrm{CO}_{2}$ emissions, it is recommended to apply $\mathrm{CO}_{2}$ capture and storage (CCS) techniques at large $\mathrm{CO}_{2}$ point sources. An example of such a source is a fossil fuel-fired power plant. Combined, these fossil fuel-fired power plants account for some $30 \%$ of the worldwide $\mathrm{CO}_{2}$ emissions. A way of CCS is to compress (100 bar - 150 bar) and transport $\mathrm{CO}_{2}$ to a storage site, where it is deposited into an underground geological formation for permanent storage. A simple scheme of this process is shown in Figure 1.1 .

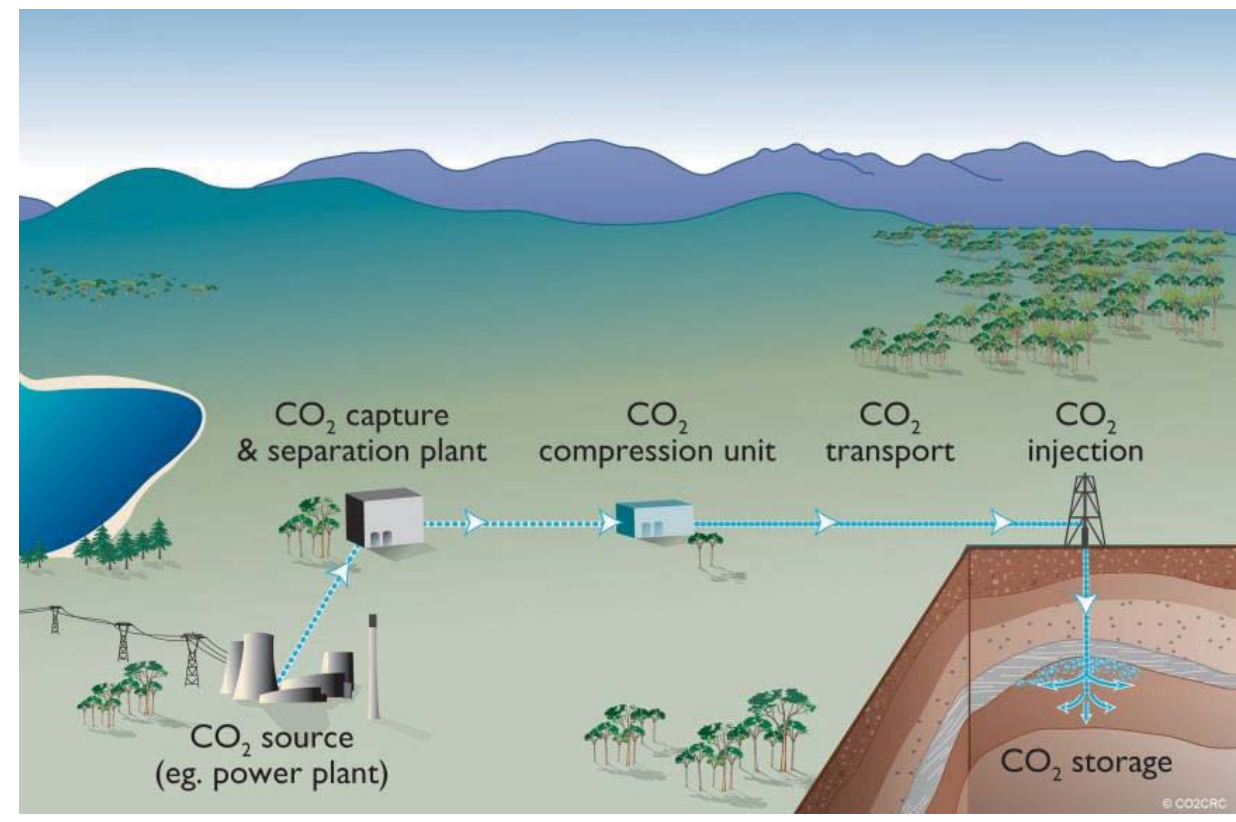

Figure 1.1. Overview of $\mathrm{CO}_{2}$ capture and storage. 
In the past twenty years, many techniques have been developed and demonstrated for $\mathrm{CO}_{2}$ capture in fossil fuel-fired power plants. Generally, these techniques can be divided into three categories: post-combustion $\mathrm{CO}_{2}$ capture, oxyfuel combustion and pre-combustion $\mathrm{CO}_{2}$ capture.

\subsubsection{Post-combustion $\mathrm{CO}_{2}$ capture}

Post-combustion $\mathrm{CO}_{2}$ capture involves the removal of $\mathrm{CO}_{2}$ from the flue gas of a combustion process. The advantage of post-combustion $\mathrm{CO}_{2}$ capture is that it can be implemented to an existing combustion process (as e.g. in a power plant) without making many changes to the plant layout. A disadvantage is that the $\mathrm{CO}_{2}$ concentration in the flue gas is very low (usually less than 15 mole \%) because the main component is $\mathrm{N}_{2}$ and that the flue gas is at near atmospheric pressure. Several techniques are developed for the separation of $\mathrm{CO}_{2}$ from the flue gas such as absorption/desorption, membrane separation and cryogenic distillation [1-4].

The most mature technique in the post-combustion $\mathrm{CO}_{2}$ capture area is the absorption/desorption method as schematically shown in Figure 1.2. $\mathrm{CO}_{2}$, as present in the flue gas, is chemically bound to a solvent between $40{ }^{\circ} \mathrm{C}$ and $60{ }^{\circ} \mathrm{C}$. The $\mathrm{CO}_{2}$ enriched solvent is pumped to a stripper where the temperature is increased to 110 $130{ }^{\circ} \mathrm{C}$ in order to remove the absorbed $\mathrm{CO}_{2}$. After desorption the lean solvent is cooled and recycled to the absorption stage via a lean-rich solvent heat exchanger and a cooler to bring the temperature down to the optimal absorption temperature. Many candidates are available to be used as solvent in this process. Monoethanolamine (MEA) is already for many years one of the mostly used solvent to separate $\mathrm{CO}_{2}$ on an industrial scale. However, with a MEA solution containing 70 $\mathrm{wt} \%$ of water with high specific heat capacity and latent heat, the $\mathrm{CO}_{2}$ absorption (at $40{ }^{\circ} \mathrm{C}$ ) and desorption (at $120^{\circ} \mathrm{C}$ ) cycles with the MEA solvent are not very energy efficient. The overall energy consumption in this process is $\sim 450 \mathrm{kWh} / \mathrm{t}_{\mathrm{CO}_{2}}$ (including the $\mathrm{CO}_{2}$ compression), which accounts to a drop of $\sim 30 \%$ in net 
efficiency of the power plant.

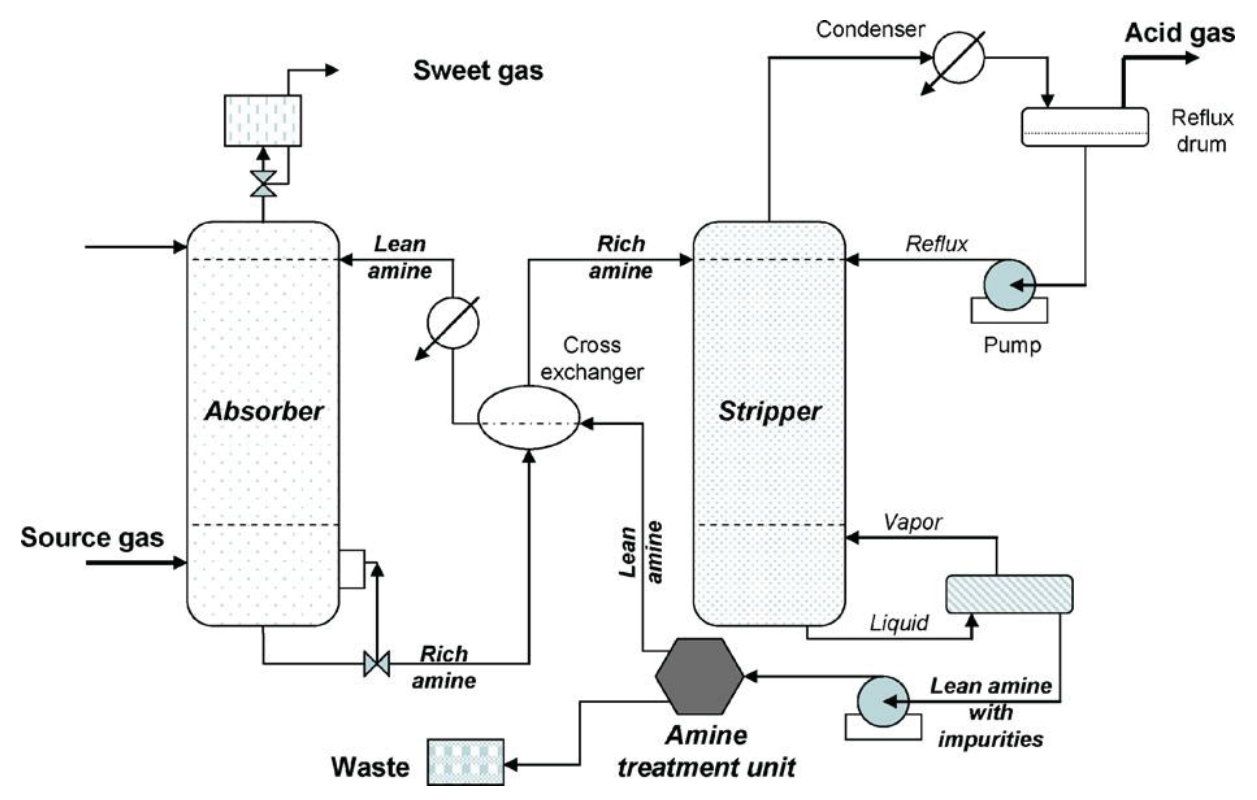

Figure 1.2. A typical monoethanolamine (MEA) absorption process for $\mathrm{CO}_{2}$ capture from the flue gas [5].

\subsubsection{Oxy-fuel combustion}

The separation of $\mathrm{CO}_{2}$ from $\mathrm{N}_{2}$ as described in section on post-combustion $\mathrm{CO}_{2}$ capture is avoided in an oxy-fuel combustion process, because here pure oxygen instead of air is used to combust the fossil fuel (see Figure 1.3). In this way the flue gas mainly consists of $\mathrm{CO}_{2}$ and water vapor. This water vapor is removed by cooling and knocking out the free water, after which the flue gas contains $80-98 \% \mathrm{CO}_{2}$, resulting in an efficient $\mathrm{CO}_{2}$ capture process. Since the combustion of fossil fuel with pure oxygen can generate temperatures up to $3500{ }^{\circ} \mathrm{C}$, which is too high for typical power plant burners, pure oxygen is usually mixed with a part of the flue gas to decrease the oxygen concentration in the burner. It is reported that a composition of $35 \%(\mathrm{v} / \mathrm{v})$ oxygen with $65 \%(\mathrm{v} / \mathrm{v}) \mathrm{CO}_{2}$ is needed in order to have a similar flame temperature as when air is used [6]. 


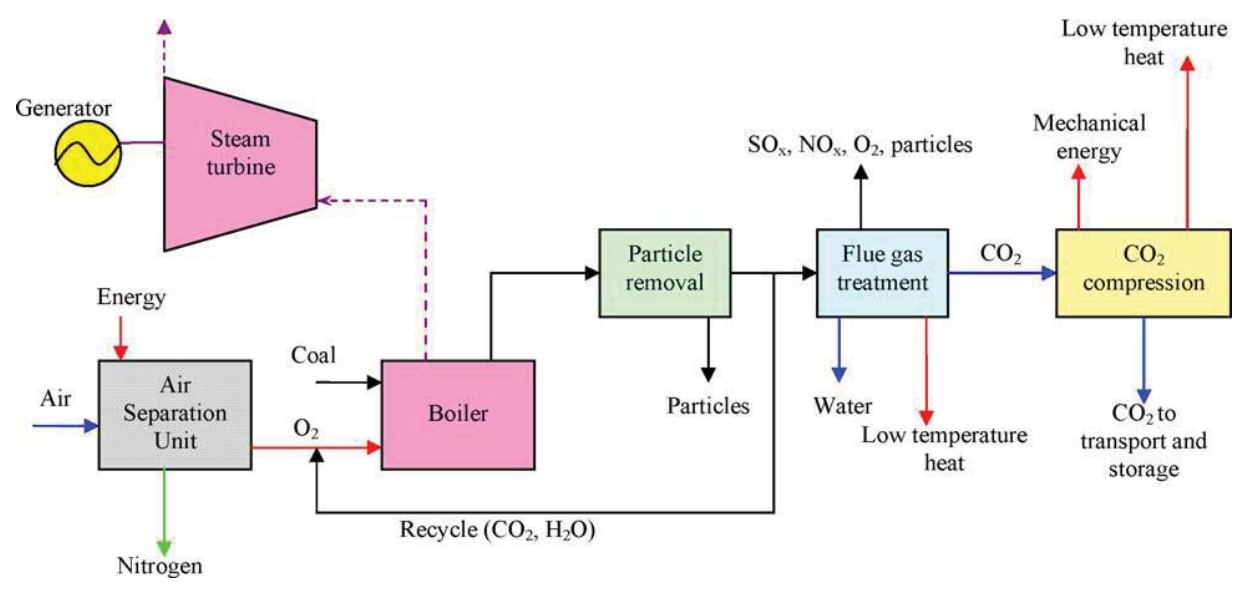

Figure 1.3. Basic principle of oxy-fuel technology [7].

In most cases the oxygen, required for an oxy-fuel combustion process is produced by cryogenic distillation of air, as this technique currently is the only mature way for air separation on a large scale. The energy consumption for oxygen production by means of cryogenic distillation is reported to be $200-240 \mathrm{kWh} / \mathrm{t}_{\mathrm{O}_{2}}$ (gaseous oxygen at 1 atmosphere and $15{ }^{\circ} \mathrm{C}$ ) [8]. This amount of energy results in a decrease of $\sim 10 \%$ in the net efficiency of the power plant. This efficiency drop is much less than that in the MEA based post-combustion $\mathrm{CO}_{2}$ capture process.

\subsubsection{Pre-combustion $\mathrm{CO}_{2}$ capture}

Pre-combustion $\mathrm{CO}_{2}$ capture is a process that produces a carbon-free fuel before combustion. This process comprises two main steps: fuel reforming and $\mathrm{H}_{2} / \mathrm{CO}_{2}$ separation, as shown in Figure 1.4.

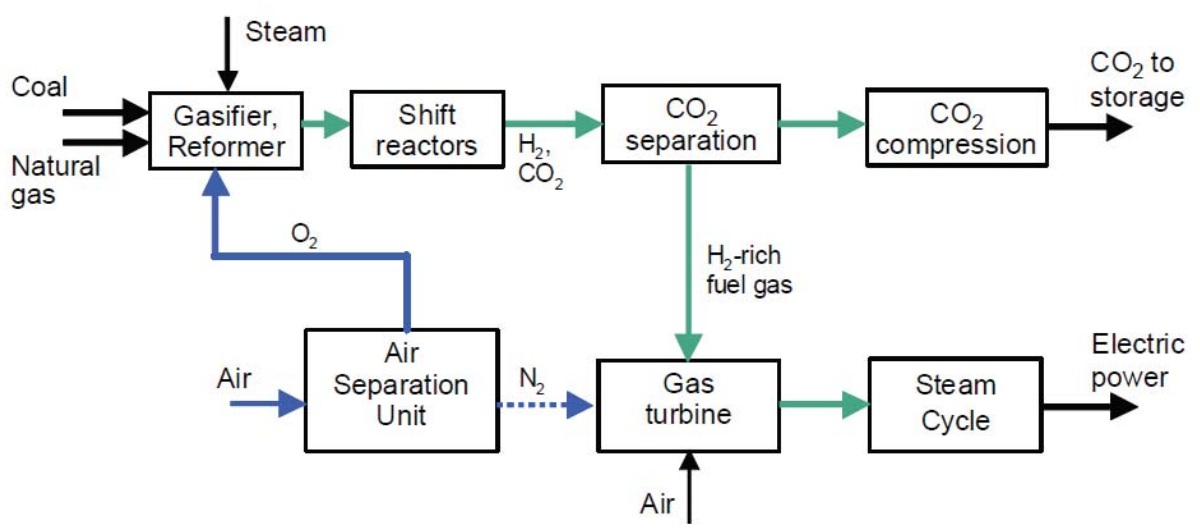

Figure 1.4. Basic principle of pre-combustion process [9].

In the first step fuel is reformed by steam or oxygen or both, and a mixture of $\mathrm{H}_{2}$ 
and CO (syngas) is obtained, as shown in eq. (1.1) to (1.3) for methane or coal (assuming that there is only carbon present in the coal). In any case, the produced syngas undergoes a water gas shift reaction where $\mathrm{CO}$ is converted to $\mathrm{CO}_{2}$ and more $\mathrm{H}_{2}$ is produced, as shown in eq. (1.4).

Steam reforming of methane

$$
\mathrm{CH}_{4}+\mathrm{H}_{2} \mathrm{O} \leftrightarrow \mathrm{CO}+3 \mathrm{H}_{2} \quad \Delta H_{\mathrm{r}}^{\circ}=250 \mathrm{~kJ} / \mathrm{mol}
$$

Partial oxidation of methane

$$
\mathrm{CH}_{4}+\mathrm{O}_{2} \leftrightarrow \mathrm{CO}+2 \mathrm{H}_{2} \quad \Delta H_{\mathrm{r}}^{\mathrm{o}}=-36 \mathrm{~kJ} / \mathrm{mol}
$$

Coal gasification

$$
4 \mathrm{C}+2 \mathrm{H}_{2} \mathrm{O}+\mathrm{O}_{2} \leftrightarrow 4 \mathrm{CO}+2 \mathrm{H}_{2} \quad \Delta H_{\mathrm{r}}^{\mathrm{o}}=130 \mathrm{~kJ} / \mathrm{mol}
$$

Water gas shift reaction

$$
\mathrm{CO}+\mathrm{H}_{2} \mathrm{O} \leftrightarrow \mathrm{CO}_{2}+\mathrm{H}_{2} \quad \Delta H_{\mathrm{r}}^{\mathrm{o}}=2.8 \mathrm{~kJ} / \mathrm{mol}
$$

After these reactions $\mathrm{H}_{2}$ must be separated from $\mathrm{CO}_{2}$. This separation can either be done by a conventional $\mathrm{CO}_{2}$ absorption (solvent based) or adsorption (pressure swing adsorption) method or by using $\mathrm{H}_{2}-$ or $\mathrm{CO}_{2}$ selective membranes. In the case of membrane separation, the separation process can be coupled with the water gas shift reaction in one membrane reactor. In this way the reaction, as shown in eq. (1.4), can be shifted to the right by simultaneously removing the produced $\mathrm{H}_{2}$ or $\mathrm{CO}_{2}$.

After the gas separation step, the produced $\mathrm{H}_{2}$ is combusted with air in a gas turbine to generate electricity, and the exhaust gas is used to heat a steam turbine cycle for further electricity generation. This process is called integrated gasification combined cycle (IGCC) with $\mathrm{CO}_{2}$ capture if coal is used as the fuel, and natural gas combined cycle (NGCC) with $\mathrm{CO}_{2}$ capture if natural gas is used as the fuel.

One may note that an air separation unit is also needed in some of the precombustion $\mathrm{CO}_{2}$ capture line-ups, which is similar to an oxy-fuel combustion process. The difference between these two processes is that the amount oxygen needed, e.g., the oxygen necessary for partial oxidation of methane to $\mathrm{CO}$ and $\mathrm{H}_{2}$ is 
only $25 \%$ of that in a complete oxidation of methane to $\mathrm{CO}_{2}$ and $\mathrm{H}_{2} \mathrm{O}$.

\subsection{Oxygen transport membranes integrated in oxy-fuel combustion}

As mentioned above, the oxygen needed for the oxy-fuel combustion process is produced by cryogenic distillation of air, which is an energy-intensive process. In order to reduce the energy consumption for oxygen production, it has been proposed to use dense ceramic oxygen transport membranes and it is assumed that the energy consumption in this process can be significantly reduced [10].

\subsubsection{Oxygen transport through a dense ceramic membrane}

A dense ceramic oxygen transport membrane comprises different metal oxides. A key feature of these metal oxides is that they are not stoichiometric at room or elevated temperature. Some of the oxygen sites in the crystal structure are not occupied, which are called oxygen vacancies. The lattice oxygen around the oxygen vacancies may hop randomly from their original sites to the oxygen vacancies if they possess sufficient thermal energy to overcome the energy barrier.

If the two sides of the membrane are exposed to different oxygen partial pressures $\left(P_{\mathrm{O}_{2}}\right)$, the random hopping of oxygen ions has a statistical direction from the high $P_{\mathrm{O}_{2}}$ side to the low $P_{\mathrm{O}_{2}}$ side. Since oxygen ions are negatively charged, a counter-transport of electronic charge carriers is required to maintain charge neutrality in the membrane. This electronic current can be realized either by an external circuit if the membrane material is purely ionic conducting or by simultaneous transport of electrons if the membrane material is mixed ionicelectronic conducting. These two routes are schematically shown in Figure 1.5. Some research is performed on the first configuration $[11,12]$, but most studies on oxygen transport membranes are focused on the second configuration, because here no external electrical circuit is required, resulting in a far more simple membrane system [13]. In this thesis, the discussion on oxygen transport is based on these mixed ion- 
electron conducting (MIEC) membranes without further notation.
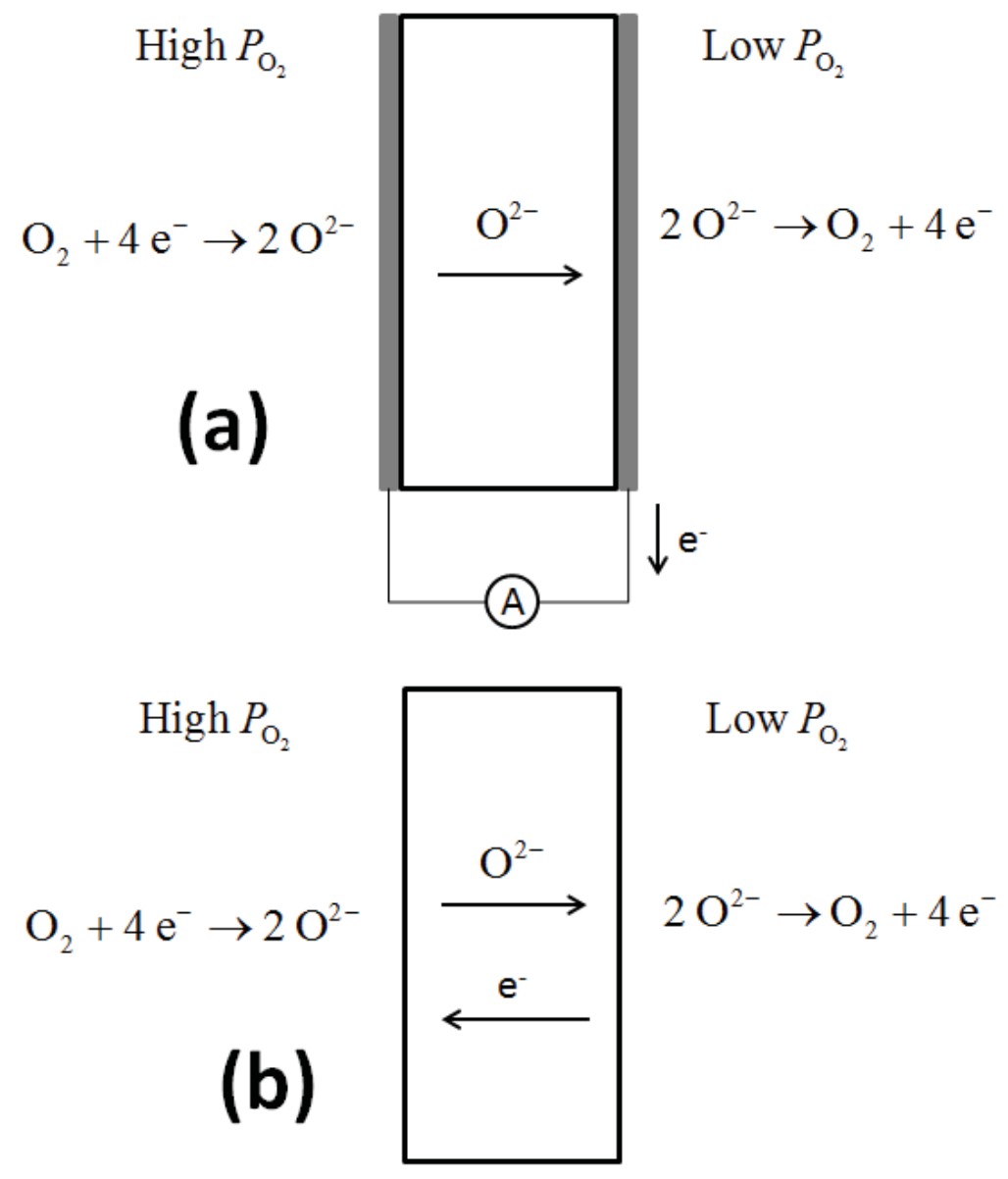

Figure 1.5. Configuration of oxygen transport membrane with (a) and without (b) an external circuit.

The oxygen transport through a MIEC membrane comprises of 3 steps, i.e.: (1) the surface-exchange reaction on the membrane surface at the high $P_{\mathrm{O}_{2}}$ side; (2) the simultaneous diffusion of charged species in the bulk phase and (3) the surfaceexchange reaction on the membrane surface at the low $P_{\mathrm{O}_{2}}$ side. The slowest of these three steps determines the overall oxygen flux, which is called rate limiting step. The rate limiting step depends on membrane material, operating conditions and membrane geometry. Bouwmeester et al. [14] use the concept of critical thickness $\left(L_{\mathrm{c}}\right)$ to distinguish the rate limiting steps: 


$$
L_{\mathrm{c}}=\frac{D_{\mathrm{i}}}{k}
$$

where $D_{\mathrm{i}}$ is the self-diffusion coefficient of oxygen anions and $\mathrm{k}$ is the surface exchange coefficient. When the membrane thickness $(L)$ is much higher than $L_{\mathrm{c}}$, bulk diffusion dominates oxygen transport; when $L$ is much lower than $L_{\mathfrak{c}}$, surfaceexchange reactions are important.

If the oxygen transport through the membrane is controlled by bulk diffusion, the oxygen flux can be described by the Wagner equation [15]:

$$
j_{\mathrm{O}_{2}}=-\frac{R T}{(4 F)^{2} L} \int_{\ln P_{\mathrm{O}_{2}}^{\prime}}^{\ln P_{\mathrm{O}_{2}}^{\prime \prime}} \frac{\sigma_{\mathrm{el}} \sigma_{\text {ion }}}{\sigma_{\mathrm{el}}+\sigma_{\mathrm{ion}}} d \ln P_{\mathrm{O}_{2}}
$$

where $j_{\mathrm{O}_{2}}$ is the oxygen permeation flux, $\mathrm{R}$ the gas constant, $T$ absolute temperature, $F$ Faraday constant, $L$ membrane thickness, $\sigma_{\text {ion }}$ oxygen ionic conductivity, $\sigma_{\mathrm{el}}$ electronic conductivity and $P_{\mathrm{O}_{2}}$ is the oxygen partial pressure. For most MIEC membranes, the electronic conductivity $\sigma_{\mathrm{el}}$ is often two orders of magnitude higher than $\sigma_{\text {ion }}$. Therefore eq. 1.6 can be rewritten as:

$$
j_{\mathrm{O}_{2}}=-\frac{R T}{(4 F)^{2} L} \int_{\ln P_{\mathrm{O}_{2}}^{\prime}}^{\ln P_{\mathrm{O}_{2}}^{n}} \sigma_{\text {ion }} \mathrm{d} \ln P_{\mathrm{O}_{2}}
$$

If the oxygen surface exchange is the rate limiting step, i.e. $L<<L_{\mathfrak{c}}$, only some empirical relations have been found to predict the oxygen flux [16], namely:

$$
J_{\mathrm{O}_{2}}=\alpha\left(P_{\mathrm{O}_{2}}^{\prime 5 / 8}-P_{\mathrm{O}_{2}}^{\prime \prime 5 / 8}\right)
$$

or

$$
J_{\mathrm{O}_{2}}=\alpha\left(P_{\mathrm{O}_{2}}^{\prime 1 / 4}-P_{\mathrm{O}_{2}}^{\prime \prime 1 / 4}\right)
$$

These equations have been successfully used to describe the oxygen flux within the erbia-stabilized bismuth oxide system although physical meaning is not very clear [16]. 
1.2.2 Integration of oxygen transport membranes in the oxy-fuel combustion process

The integration of oxygen transport membranes in the oxy-fuel combustion process can be applied in two ways, as illustrated in Figure 1.6. In the first way (Figure 1.6a), air is used as the feed gas, nitrogen is retained and pure oxygen is produced. There are three gas streams in this operation mode, and thus it is called 3end mode. In the second way (Figure 1.6b), a sweep gas is used to carry away the permeated oxygen, and there are four gas streams in this operation mode, so it is called 4-end mode. 

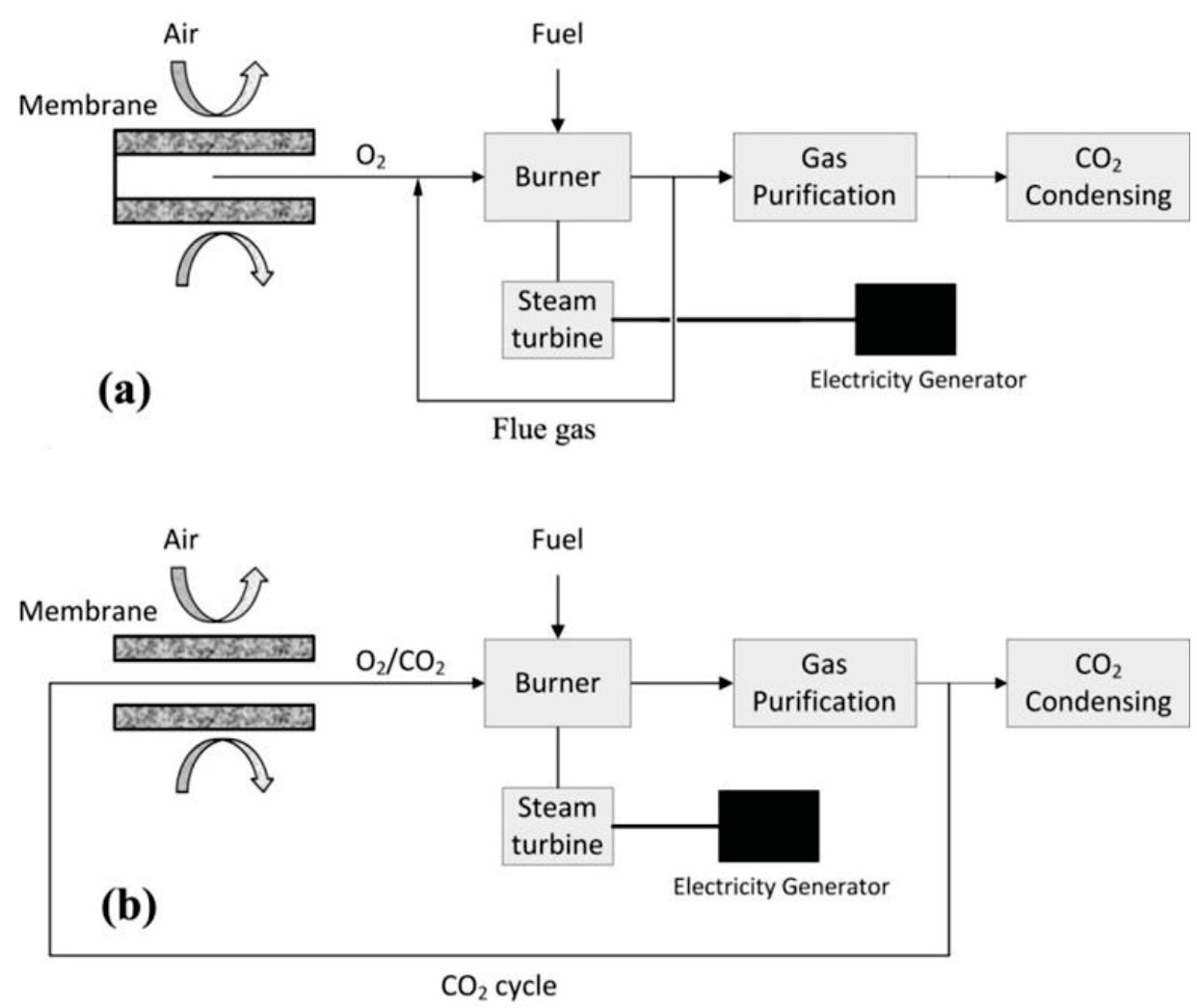

Figure 1.6. Illustration of membrane-integrated oxy-fuel combustion process in 3-end (a) and 4-end mode (b).

In the 3-end mode either the feed (air) side of the membrane is compressed or at the permeate side of the membrane a vacuum is applied or a combination of these two methods. In this way a $P_{\mathrm{O}_{2}}$ gradient is created across the membrane. Pure oxygen, as separated by the membrane, is diluted by recycled flue gas to avoid extremely high temperatures during of fuel combustion.

In the 4-end mode, a sweep gas is used to carry the permeated oxygen and also to decrease the $P_{\mathrm{O}_{2}}$ at the sweep side for creating a $P_{\mathrm{O}_{2}}$ gradient across the membrane. In this 4-end mode a higher $P_{\mathrm{O}_{2}}$ gradient can be created if compared with the 3-end mode. For example, assume, for both modes, that the total pressure is 10 bar at the feed side (air) and 1 bar at the permeate side of the membrane. The $P_{\mathrm{O}_{2}}$ at 
the feed side is identical for both cases, i.e. $\sim 2.1$ bar. While the $P_{\mathrm{O}_{2}}$ at the permeate side is different. In the 3 -end mode, the $P_{\mathrm{O}_{2}}$ is equal to the total pressure, i.e. 1 bar. In the 4-end mode the $P_{\mathrm{O}_{2}}$ is lower than the total pressure because there is also sweep gas. Assume that the oxygen mole fraction is 0.5 , then the $P_{\mathrm{O}_{2}}$ is only 0.5 bar. Thus the $P_{\mathrm{O}_{2}}$ difference in 3-end mode is 1.1 bar, while 1.6 bar in the 4-end mode. This difference leads to a fact that the required pressure for air compression is lower in the 4-end mode, which is one of the biggest advantages of the 4-end mode.

\subsection{State of the art membranes for oxy-fuel combustion}

There are two general requirements for the membranes to be used in the oxy-fuel combustion process: stability and permeability.

In the 3-end mode membranes are only exposed to nitrogen and oxygen, and most of the MIEC membranes are chemically stable in these gases. Besides chemical stability phase stability has to be considered when using MIEC membranes. The phase stability is affected by temperature and $P_{\mathrm{O}_{2}} \cdot \mathrm{Ba}_{0.5} \mathrm{Sr}_{0.5} \mathrm{Co}_{0.8} \mathrm{Fe}_{0.2} \mathrm{O}_{3-\delta}$ (BSCF) and $\mathrm{SrCo}_{0.8} \mathrm{Fe}_{0.2} \mathrm{O}_{3-\delta}$ (SCF) are considered for air separation application because of their high oxygen fluxes [17-20]. Oxygen flux values for BSCF are reported as high as $\sim 1.6 \mathrm{ml} / \mathrm{min}$ under a $P_{\mathrm{O}_{2}}$ gradient of $0.21 / 0.05$ bar at $950{ }^{\circ} \mathrm{C}$, with a membrane thickness of $1.5 \mathrm{~mm}$ [20]. Similar oxygen flux data are given for SCF. BSCF suffers from a slow phase transition from a pure cubic structure to a mixture of a cubic and a hexagonal structure below $\sim 825{ }^{\circ} \mathrm{C}[21,22]$, which causes a decline in oxygen flux with time. For SCF a transition from the cubic perovskite to the lower conducting orthorhombic brownmillerite phase has been found when the temperature is below $790{ }^{\circ} \mathrm{C}$ and the $P_{\mathrm{O}_{2}}$ is less than $10^{-2}$ bar $[18,23,24]$. Therefore, in order to use these membranes, the operation temperature should be above the phase transition temperature, i.e. $825^{\circ} \mathrm{C}$ and $790{ }^{\circ} \mathrm{C}$ for resp. $\mathrm{BSCF}$ and $\mathrm{SCF}$. An alternative way is to 
stabilize the high-conducting perovskite phase to a lower temperature by doping. Yakovlev et al. reported that doping of $3 \mathrm{~mol} \% \mathrm{Zr}$ - at the $\mathrm{B}$-site $(\mathrm{Co} / \mathrm{Fe}$ site) of $\mathrm{BSCF}$ can stabilize the cubic structure down to $800{ }^{\circ} \mathrm{C}$ [25]. Chen et al. [26] have also found that $\sim 4 \mathrm{~mol} \% \mathrm{Zr}$-doping at the B-site can stabilize $\mathrm{SCF}$ to $\sim 700{ }^{\circ} \mathrm{C}$ in a $P_{\mathrm{O}_{2}}$ of $10^{-4}$ bar.

For membranes, to be used in the 4-end mode, one of the options is to use $\mathrm{CO}_{2}$, which is known as an acid gas, as the sweep gas. As most of the MIEC oxides contain alkaline-earth elements $(\mathrm{Ca}, \mathrm{Sr}$ or $\mathrm{Ba})$ a carbonation reaction occurs when these membranes are exposed to a $\mathrm{CO}_{2}$-containing atmosphere. This reaction results in the formation of an alkaline-earth carbonate layer, which is impermeable for oxygen, on the membrane surface, resulting in a decline in oxygen flux or even to a non-permeating membrane. Changing the sweep gas from helium to $\mathrm{CO}_{2}$ results in an immediate stagnation of the oxygen flux for BSCF membranes [27]. It is also found that the oxygen flux of SCF membrane decreases to almost zero in 80 hours when $\mathrm{CO}_{2}$ is used as sweep [28]. In recent years, more and more research has been focused on the development of $\mathrm{CO}_{2}$-resistant membranes. Kilner et al. reported that $\mathrm{La}_{0.6} \mathrm{Sr}_{0.4} \mathrm{Co}_{0.2} \mathrm{Fe}_{0.8} \mathrm{O}_{3-\delta}$ (LSCF) membranes have a high $\mathrm{CO}_{2}$ resistance [29]. In [30] it is reported that LSCF-based hollow fibre membranes (membrane thickness $\sim 200 \mu \mathrm{m}$ ) show a stable oxygen flux of $\sim 0.8 \mathrm{ml} / \mathrm{min}$ at $950{ }^{\circ} \mathrm{C}$ when $\mathrm{CO}_{2}$ is used as sweep gas. Wei et al. have developed $\mathrm{K}_{2} \mathrm{NiF}_{4}$-type $\left(\mathrm{Pr}_{0.9} \mathrm{La}_{0.1}\right)_{2}\left(\mathrm{Ni}_{0.74} \mathrm{Cu}_{0.21} \mathrm{Ga}_{0.05}\right) \mathrm{O}_{4+\delta}(\mathrm{PLNCG})$ membranes which show good $\mathrm{CO}_{2}$ resistance and similar oxygen flux as LSCF membranes [31, 32]. Chen et al. fabricated several dual phase membranes such as $\mathrm{La}_{0.8} \mathrm{Sr}_{0.2} \mathrm{MnO}_{3-\delta}(\mathrm{LSM})-\mathrm{Zr}_{0.84} \mathrm{Y}_{0.16} \mathrm{O}_{1.92}$ (YSZ) and $\mathrm{LSM}-\mathrm{Ce}_{0.8} \mathrm{Sm}_{0.2} \mathrm{O}_{2-\delta}$ (SDC) [33, 34], which show excellent $\mathrm{CO}_{2}$ resistance but rather low oxygen flux.

Besides the membrane stability, the oxygen permeability of the membranes is also important. A summary on oxygen flux data of different membranes has been given by Sunarso et al [13]. In principle, the higher of the oxygen permeability, the less membrane area is needed for a certain air separation duty, thus the cost for air 
separation will be reduced. Generally, there are two ways to increase the oxygen flux if the membrane material has already been chosen, i.e. decrease the membrane thickness or increase the surface exchange rate. According to eq. 1.6, the oxygen flux is inversely proportional to the membrane thickness if bulk diffusion predominates the oxygen transport. For example, a supported BSCF thin film (70 $\mu \mathrm{m}$ thick) shows an oxygen flux of $\sim 6 \mathrm{ml} / \mathrm{min}$ at $950{ }^{\circ} \mathrm{C}$ [35], which is much higher than that of a 1.5 $\mathrm{mm}$ thick BSCF membrane $(\sim 1.6 \mathrm{ml} / \mathrm{min})$ [20]. One may notice that the decrease in thickness by a factor of $\sim 20$ only results in an increase in oxygen flux by a factor of $\sim 4$. This relative small increase in oxygen flux is possibly caused by the change in the rate limiting step. At a membrane thickness of $70 \mu \mathrm{m}$, or maybe even at a higher thickness, oxygen transport is controlled by the surface exchange reaction. So there is a limit in increasing the oxygen flux by decreasing the membrane thickness. If the flux is controlled by the oxygen surface exchange rate, a porous layer can be applied on the dense membrane to increase the total surface area and thus increase the surface exchange rate. The coated layer can be the same material as the membrane or a different, dedicated, material. In the latter case materials with a higher oxygen exchange rate are usually considered.

\subsection{Scope of the thesis}

The objective of the research, as described in this thesis, is to investigate the feasibility of integrating MIEC membranes into the oxy-fuel combustion process for $\mathrm{CO}_{2}$ capture. This includes the fabrication of appropriate membrane materials and the design of a membrane-integrated oxy-fuel process.

Chapter 2 and 3 are focused on the characterization of the membrane properties. In chapter 2, a novel, simple and easy way to determine the oxygen nonstoichiometry of the perovskite materials by a carbonation process is developed. Chapter 3 presents a numerical method to more accurately measure the oxygen ionic conductivity of the MIEC membranes, using data obtained from a standard laboratory permeation set-up. In chapter $4, \mathrm{a} \mathrm{CO}_{2}$ resistant SCF membrane has been 
developed by partial substitution of $\mathrm{Co} / \mathrm{Fe}$ by $\mathrm{Ta}$, but at the cost of a reduction in oxygen flux by $\sim 30 \%$. In chapter 5 it is found that the $\mathrm{CO}_{2}$ resistance of SCF membranes is greatly affected by the ambient $P_{\mathrm{O}_{2}}$, and it is possible to avoid $\mathrm{CO}_{2}$ poisoning of the membrane by increasing the ambient $P_{\mathrm{O}_{2}}$, rather than by doping. Chapter 6 gives a design of a MIEC membrane based oxy-fuel combustion process as simulated in UniSim ${ }^{\circledR}$. Finally, in chapter 7, recommendations and outlook for future research work are given.

\section{References}

[1] M.J. Tuinier, M. van Sint Annaland, J.A.M. Kuipers, A novel process for cryogenic $\mathrm{CO}_{2}$ capture using dynamically operated packed beds-An experimental and numerical study, Int J Greenh Gas Con, 5 (2011) 694-701.

[2] T.C. Merkel, H. Lin, X. Wei, R. Baker, Power plant post-combustion carbon dioxide capture: An opportunity for membranes, Journal of Membrane Science, 359 (2010) 126-139.

[3] M.J. Tuinier, M. van Sint Annaland, G.J. Kramer, J.A.M. Kuipers, Cryogenic capture using dynamically operated packed beds, Chem Eng Sci, 65 (2010) 114-119.

[4] J. Blamey, E.J. Anthony, J. Wang, P.S. Fennell, The calcium looping cycle for large-scale $\mathrm{CO}_{2}$ capture, Progress in Energy and Combustion Science, 36 (2010) 260-279.

[5] L. Dumée, C. Scholes, G. Stevens, S. Kentish, Purification of aqueous amine solvents used in post combustion $\mathrm{CO}_{2}$ capture: A review, Int J Greenh Gas Con, 10 (2012) 443-455.

[6] E. Croiset, K. Thambimuthu, A. Palmer, Coal combustion in $\mathrm{O}_{2} / \mathrm{CO}_{2}$ mixtures compared with air, The Canadian Journal of Chemical Engineering, 78 (2000) 402-407.

[7] I. Hadjipaschalis, G. Kourtis, A. Poullikkas, Assessment of oxyfuel power generation technologies, Renewable and Sustainable Energy Reviews, 13 (2009) 2637-2644.

[8] A. Darde, R. Prabhakar, J.-P. Tranier, N. Perrin, Air separation and flue gas compression and purification units for oxy-coal combustion systems, Energy Procedia, 1 (2009) 527-534.

[9] N.A. Røkke, Ø. Langørgen, Enabling pre-combustion plants - the DECARBit project, Energy Procedia, 1 (2009) 1435-1442.

[10] P.N. Dyer, R.E. Richards, S.L. Russek, D.M. Taylor, Ion transport membrane technology for oxygen separation and syngas production, Solid State Ionics, 134 (2000) 21-33.

[11] K. Zhang, L. Liu, Z. Shao, R. Xu, J.C. Diniz da Costa, S. Wang, S. Liu, Robust ion-transporting ceramic membrane with an internal short circuit for oxygen production, Journal of Materials 
Chemistry A, 1 (2013) 9150-9156.

[12] K. Zhang, Z. Shao, C. Li, S. Liu, Novel $\mathrm{CO}_{2}$-tolerant ion-transporting ceramic membranes with an external short circuit for oxygen separation at intermediate temperatures, Energ Environ Sci, 5 (2012) 5257-5264.

[13] J. Sunarso, S. Baumann, J.M. Serra, W.A. Meulenberg, S. Liu, Y.S. Lin, J.C.D. da Costa, Mixed ionic-electronic conducting (MIEC) ceramic-based membranes for oxygen separation, Journal of Membrane Science, 320 (2008) 13-41.

[14] H.J.M. Bouwmeester, H. Kruidhof, A.J. Burggraaf, Importance of the surface exchange kinetics as rate limiting step in oxygen permeation through mixed-conducting oxides, Solid State Ionics, 72 (1994) 185-194.

[15] H.J.M. Bouwmeester, A.J. Burggraaf, The CRC Handbook of Solid State Electrochemistry, 1 ed., CRC Press, 1996.

[16] H.J.M. Bouwmeester, H. Kruidhof, A.J. Burggraaf, P.J. Gellings, Oxygen semipermeability of erbia-stabilized bismuth oxide, Solid State Ionics, 53-56, Part 1 (1992) 460-468.

[17] Z.P. Shao, W.S. Yang, Y. Cong, H. Dong, J.H. Tong, G.X. Xiong, Investigation of the permeation behavior and stability of a $\mathrm{Ba}_{0.5} \mathrm{Sr}_{0.5} \mathrm{Co}_{0.8} \mathrm{Fe}_{0.2} \mathrm{O}_{3-\delta}$ oxygen membrane, Journal of Membrane Science, 172 (2000) 177-188.

[18] L. Qiu, T.H. Lee, L.M. Liu, Y.L. Yang, A.J. Jacobson, Oxygen Permeation Studies of $\mathrm{SrCo}_{0.8} \mathrm{Fe}_{0.2} \mathrm{O}_{3-\delta}$, Solid State Ionics, 76 (1995) 321-329.

[19] J. Tong, W. Yang, B. Zhu, R. Cai, Investigation of ideal zirconium-doped perovskite-type ceramic membrane materials for oxygen separation, Journal of Membrane Science, 203 (2002) 175-189.

[20] Z. Shao, G. Xiong, H. Dong, W. Yang, L. Lin, Synthesis, oxygen permeation study and membrane performance of a $\mathrm{Ba}_{0.5} \mathrm{Sr}_{0.5} \mathrm{Co}_{0.8} \mathrm{Fe}_{0.2} \mathrm{O}_{3-\delta}$ oxygen-permeable dense ceramic reactor for partial oxidation of methane to syngas, Sep Purif Technol, 25 (2001) 97-116.

[21] S. Svarcova, K. Wiik, J. Tolchard, H.J.M. Bouwmeester, T. Grande, Structural instability of cubic perovskite $\mathrm{Ba}_{\mathrm{x}} \mathrm{Sr}_{1-\mathrm{x}} \mathrm{Co}_{1-\mathrm{y}} \mathrm{Fe}_{\mathrm{y}} \mathrm{O}_{3-\delta}$, Solid State Ionics, 178 (2008) 1787-1791.

[22] M. Arnold, T.M. Gesing, J. Martynczuk, A. Feldhoff, Correlation of the Formation and the Decomposition Process of the BSCF Perovskite at Intermediate Temperatures, Chem Mater, 20 (2008) 5851-5858.

[23] H. Kruidhof, H.J.M. Bouwmeester, R.H.E. v. Doorn, A.J. Burggraaf, Influence of order-disorder transitions on oxygen permeability through selected nonstoichiometric perovskite-type oxides, Solid State Ionics, 63-65 (1993) 816-822.

[24] A.A. Yaremehenko, V.V. Kharton, M. Avdeev, A.L. Shaula, F.M.B. Marques, Oxygen permeability, thermal expansion and stability of $\mathrm{SrCo}_{0.8} \mathrm{Fe}_{0.2} \mathrm{O}_{3-\delta}-\mathrm{SrAl}_{2} \mathrm{O}_{4}$ Composites, Solid State Ionics, 178 (2007) 1205-1217. 
[25] S. Yakovlev, C.-Y. Yoo, S. Fang, H.J.M. Bouwmeester, Phase transformation and oxygen equilibration kinetics of pure and $\mathrm{Zr}$-doped $\mathrm{Ba}_{0.5} \mathrm{Sr}_{0.5} \mathrm{Co}_{0.8} \mathrm{Fe}_{0.2} \mathrm{O}_{3-\delta}$ perovskite oxide probed by electrical conductivity relaxation, Applied Physics Letters, 96 (2010) -.

[26] W. Chen, Y.B. Zuo, C.S. Chen, A.J.A. Winnubst, Effect of $\mathrm{Zr}^{4+}$ doping on the oxygen stoichiometry and phase stability of $\mathrm{SrCo}_{0.8} \mathrm{Fe}_{0.2} \mathrm{O}_{3-\delta}$ oxygen separation membrane, Solid State Ionics, 181 (2010) 971-975.

[27] M. Arnold, H.H. Wang, A. Feldhoff, Influence of $\mathrm{CO}_{2}$ on the oxygen permeation performance and the microstructure of perovskite-type $\left(\mathrm{Ba}_{0.5} \mathrm{Sr}_{0.5}\right)\left(\mathrm{Co}_{0.8} \mathrm{Fe}_{0.2}\right) \mathrm{O}_{3-\delta}$ membranes, Journal of Membrane Science, 293 (2007) 44-52.

[28] Q. Zeng, Y.B. Zu, C.G. Fan, C.S. Chen, $\mathrm{CO}_{2}$-tolerant oxygen separation membranes targeting $\mathrm{CO}_{2}$ capture application, Journal of Membrane Science, 335 (2009) 140-144.

[29] S.J. Benson, D. Waller, J.A. Kilner, Degradation of $\mathrm{La}_{0.6} \mathrm{Sr}_{0.4} \mathrm{Fe}_{0.8} \mathrm{Co}_{0.2} \mathrm{O}_{3-\delta}$ in carbon dioxide and water atmospheres, J Electrochem Soc, 146 (1999) 1305-1309.

[30] X. Tan, N. Liu, B. Meng, J. Sunarso, K. Zhang, S. Liu, Oxygen permeation behavior of $\mathrm{La}_{0.6} \mathrm{Sr}_{0.4} \mathrm{Co}_{0.8} \mathrm{Fe}_{0.2} \mathrm{O} 3$ hollow fibre membranes with highly concentrated $\mathrm{CO}_{2}$ exposure, Journal of Membrane Science, 389 (2012) 216-222.

[31] Y.Y. Wei, J. Tang, L.Y. Zhou, J. Xue, Z. Li, H.H. Wang, Oxygen separation through U-shaped hollow fiber membrane using pure $\mathrm{CO}_{2}$ as sweep gas, Aiche J, 58 (2012) 2856-2864.

[32] Y. Wei, O. Ravkina, T. Klande, H. Wang, A. Feldhoff, Effect of $\mathrm{CO}_{2}$ and $\mathrm{SO}_{2}$ on oxygen permeation and microstructure of $\left(\mathrm{Pr}_{0.9} \mathrm{La}_{0.1}\right)_{2}\left(\mathrm{Ni}_{0.74} \mathrm{Cu}_{0.21} \mathrm{Gaa}_{0.05}\right) \mathrm{O}_{4+\delta}$ membranes, Journal of Membrane Science, 429 (2013) 147-154.

[33] W. Li, T.-F. Tian, F.-Y. Shi, Y.-S. Wang, C.-S. Chen, $\mathrm{Ce}_{0.8} \mathrm{Sm}_{0.2} \mathrm{O}_{2-\delta}-\mathrm{La}_{0.8} \mathrm{Sr}_{0.2} \mathrm{MnO}_{3-\delta}$ Dual-Phase Composite Hollow Fiber Membrane for Oxygen Separation, Ind Eng Chem Res, 48 (2009) 57895793.

[34] W. Li, J.J. Liu, C.S. Chen, Hollow fiber membrane of yttrium-stabilized zirconia and strontiumdoped lanthanum manganite dual-phase composite for oxygen separation, Journal of Membrane Science, 340 (2009) 266-271.

[35] S. Baumann, J.M. Serra, M.P. Lobera, S. Escolástico, F. Schulze-Küppers, W.A. Meulenberg, Ultrahigh oxygen permeation flux through supported $\mathrm{Ba}_{0.5} \mathrm{Sr}_{0.5} \mathrm{Co}_{0.8} \mathrm{Fe}_{0.2} \mathrm{O}_{3-\delta}$ membranes, Journal of Membrane Science, 377 (2011) 198-205. 
Chapter 1 


\title{
Chapter 2 Oxygen non-stoichiometry determination of perovskite materials by a carbonation process
}

\begin{abstract}
:
A new and easy method is developed to determine the oxygen non-stoichiometry of perovskite materials under equilibrium conditions. The method is based on the complete decomposition of the powder to stoichiometric metal oxides and/or metal carbonates by using $\mathrm{CO}_{2}$ as reacting gas. The oxygen non-stoichiometry is calculated from the mass change caused by this reaction. Its applicability is demonstrated by using $\mathrm{SrCoO}_{3-\delta}, \mathrm{BaCoO}_{3-\delta}, \mathrm{BaFeO}_{3-\delta}$ and $\mathrm{BaCeO}_{3-\delta}$ as representative materials. The oxygen non-stoichiometry $(\delta)$ values at $950{ }^{\circ} \mathrm{C}$ in air were determined as $0.48,0.36$, 0.43 and 0.03 respectively. These values can be used as reference points for oxygen non-stoichiometry analysis at other temperatures.
\end{abstract}

This chapter has been published as:

W. Chen, A. Nijmeijer, L. Winnubst, Oxygen non-stoichiometry determination of perovskite materials by a carbonation process, Solid State Ionics, 229 (2012) 54-58. 


\subsection{Introduction}

An important issue in defect chemistry is the study of the oxygen nonstoichiometry of metal oxides, especially for materials with high oxygen deficiency [1-3]. Examples are several perovskite systems with general formula $\mathrm{ABO}_{3-\delta}$, where $\delta$ represents the oxygen non-stoichiometry value. Several methods are developed to measure this oxygen non-stoichiometry as function of temperature and oxygen partial pressure [4]. All these methods are based on the analysis of the change in oxygen non-stoichiometry $\Delta(\delta)$ as function of temperature or oxygen partial pressure, which are briefly reviewed as following.

For the measurement of $\Delta(\delta)$ thermal gravimetric analysis (TGA) is the most popular and frequently used method [5]. In this method it is assumed that the only reason for mass change is the release or incorporation of oxygen at varying temperatures or oxygen partial pressures. The mass change of the sample can then easily be converted to $\Delta(\delta)$. Another technique to measure $\Delta(\delta)$ is coulometric titration [4], where samples are placed in a sealed vessel made from yttria-stabilized zirconia (YSZ). One part of the YSZ (connected with electrolytes) is used as an oxygen pump, while another separate part is used as oxygen sensor. A defined amount of oxygen is pumped out/in quantitatively by applying a fixed electrical potential over the pump part of the vessel. The change in oxygen partial pressure in the vessel is not only related to the amount of oxygen removed by pumping, because oxygen is also released from the powder sample during pumping. From the difference between the measured oxygen partial pressure in the vessel and the amount of oxygen pumped out $\Delta(\delta)$ can be calculated. A method similar to coulometric titration is solid electrolyte coulometry (SEC). The difference however is that in the latter case the experiment can be done in open systems or in a gas flowing mode. Details can be found in Teske, Bode and Vashook's work [6-8].

It should be mentioned that in order to determine the absolute oxygen nonstoichiometry for both the TGA and the coulometric titration method, an absolute 
value of $\delta$ at a fixed temperature and oxygen partial pressure is necessary (called reference point). A traditional way to obtain such a reference point is iodometric titration [9]. Here samples are dissolved in $\mathrm{HCl}$ with the presence of an excess of $\mathrm{KI}$ and heated in an oxygen-free (nitrogen) environment. During this process, the transition metal ions (such as $\mathrm{Co}^{3+}, \mathrm{Co}^{4+}, \mathrm{Fe}^{3+}, \mathrm{Fe}^{4+}$ ) were reduced, and $\mathrm{I}^{-}$was oxidized to $I_{2}$. The amount of $I_{2}$ released is quantitatively determined by redox titration using $\mathrm{Na}_{2} \mathrm{~S}_{2} \mathrm{O}_{3}$ as the titrant agent. The oxygen non-stoichiometry was calculated based on the amount of $I_{2}$ formed. Another way to measure the reference point is hydrogen reduction [10], by making use of the phenomenon that at elevated temperatures $\left(\sim 700{ }^{\circ} \mathrm{C}\right)$ several cations in oxides will react with hydrogen to the metallic state or to the metal oxides, and the absolute content of oxygen in these oxides is determined by monitoring the mass loss of the sample in a hydrogen containing gas with a TGA setup, while the final products are determined by X-Ray Diffraction (XRD).

In this paper a new and convenient method is reported to measure the absolute oxygen content $(3-\delta)$ of perovskite materials at a thermodynamic equilibrium state. Since several metal oxides, especially perovskite structured oxides, contain alkaline earth metals, which are very sensitive to $\mathrm{CO}_{2}$, these materials easily decompose at elevated temperature in a $\mathrm{CO}_{2}$ containing atmosphere [11]. After complete reaction and obtaining stoichiometric products the oxygen non-stoichiometry can easily be calculated. To demonstrate this method, $\mathrm{SrCoO}_{3-\delta}, \mathrm{BaCoO}_{3-\delta}, \mathrm{BaFeO}_{3-\delta}$ and $\mathrm{BaCeO}_{3-\delta}$ were chosen as representative materials in this study, because of their relative simple compositions, while products after reaction with $\mathrm{CO}_{2}$ can easily be identified. However, it is expected that this method can also successfully be applied for other perovskite materials with well-defined reaction products.

\subsection{Experimental}

$\mathrm{SrCoO}_{3-\delta}, \mathrm{BaCoO}_{3-\delta}, \mathrm{BaFeO}_{3-\delta}$ and $\mathrm{BaCeO}_{3-\delta}$ were synthesized using an EDTA complexation/pyrolysis process as described in detail in [12]. In this work metal 
nitrates were dissolved in demineralized water under stirring at a stoichiometric ratio. EDTA, dissolved in ammonia, was added and after chelating for several minutes citric acid was added. The molar ratio of total metal ions : citric acid : EDTA was $1.0: 1.5: 1.0$. The $\mathrm{pH}$ value of the solution was adjusted to 6 by adding ammonia. Subsequently $\mathrm{NH}_{4} \mathrm{NO}_{3}$ was added as an ignition aid at an amount of $100 \mathrm{~g} \mathrm{NH}_{4} \mathrm{NO}_{3}$ per 0.1 mole of metal ions. This final solution was heated at $120-150{ }^{\circ} \mathrm{C}$ under stirring to evaporate water until it changed into a viscous gel, which was transferred to a stainless steel vessel and heated on a hot plate at a temperature of around $500{ }^{\circ} \mathrm{C}$, while a vigorous combustion took place, resulting in a fluffy powder. The powder was collected and calcined in a room furnace at $950{ }^{\circ} \mathrm{C}$ for 5 hours at a heating and cooling rate of $3{ }^{\circ} \mathrm{C} / \mathrm{min}$.

Isothermal gravimetric analyses were carried out on a Netzsch TG 449 F3 Jupiter®. About $20 \mathrm{mg}$ of powder was weighed in an alumina crucible and placed in the TGA setup. The temperature was increased to $950{ }^{\circ} \mathrm{C}$ in flowing air $(79 \mathrm{ml} / \mathrm{min}$ $\mathrm{N}_{2}$ and $21 \mathrm{ml} / \mathrm{min} \mathrm{O}_{2}$ ) at a heating rate of $10{ }^{\circ} \mathrm{C} / \mathrm{min}$. The system was isothermally hold in air at $950{ }^{\circ} \mathrm{C}$ for 1 hour in order to reach a steady equilibrium state, indicated by a constant mass of the sample at this holding. Subsequently the gas was switched to a $\mathrm{CO}_{2} / \mathrm{N}_{2}$ mixture $\left(80 \mathrm{ml} / \mathrm{min} \mathrm{CO}_{2}\right.$ and $20 \mathrm{ml} / \mathrm{min} \mathrm{N}_{2} ; \mathrm{N}_{2}$ is used as protective gas for the setup). After completion of the reaction between powder and $\mathrm{CO}_{2}$ (when no mass change was observed), the system was cooled to room temperature in the same $\mathrm{CO}_{2} / \mathrm{N}_{2}$ mixture at a cooling rate of $10{ }^{\circ} \mathrm{C} / \mathrm{min}$. All TGA experiments were based on a correction file measured with a blank crucible to exclude background data. After TGA measurements the samples were ground with a mortar and the phase composition was analyzed by X-ray diffraction (Bruker D2 PHASER with $\mathrm{Cu} \mathrm{K} \mathrm{K}_{\alpha}$ radiation, accelerate voltage $30 \mathrm{KV}$, current $10 \mathrm{~mA}$, step size 0.02 , time per step $1 \mathrm{~s}$ ). For comparison the X-ray diffraction patterns of freshly synthesized powders (after calcination) were analyzed as well.

After obtaining the oxygen non-stoichiometry value $(\delta)$ in air at $950{ }^{\circ} \mathrm{C}$ the 
values of $\delta$ at other temperatures were determined by simple TGA experiments in air. In these experiments the temperature was stepwise increased from $550{ }^{\circ} \mathrm{C}$ to $950{ }^{\circ} \mathrm{C}$ in flowing air $\left(79 \mathrm{ml} / \mathrm{min} \mathrm{N}_{2}\right.$ and $\left.21 \mathrm{ml} / \mathrm{min}_{2}\right)$ and hold at intervals of $100{ }^{\circ} \mathrm{C}$. Based on the reference point at $950{ }^{\circ} \mathrm{C}$, oxygen non-stoichiometry at other temperatures was calculated.

\subsection{Results}

Isothermal gravimetric analysis is a convenient way to study quantitatively the reaction between perovskite materials and $\mathrm{CO}_{2}$ [13], and the results are given in Figure 2.1. It can be seen that the reactions are very fast for all four materials, resulting in a final increase in weight of respectively $119.04 \%, 114.18 \%, 108.92 \%$ and $113.67 \%$. In order to make sure that the reactions were completely finished, the systems were hold for a longer time at $950{ }^{\circ} \mathrm{C}$ before cooling. During this cooling procedure in the same $\mathrm{CO}_{2} / \mathrm{N}_{2}$ atmosphere no mass change was observed.
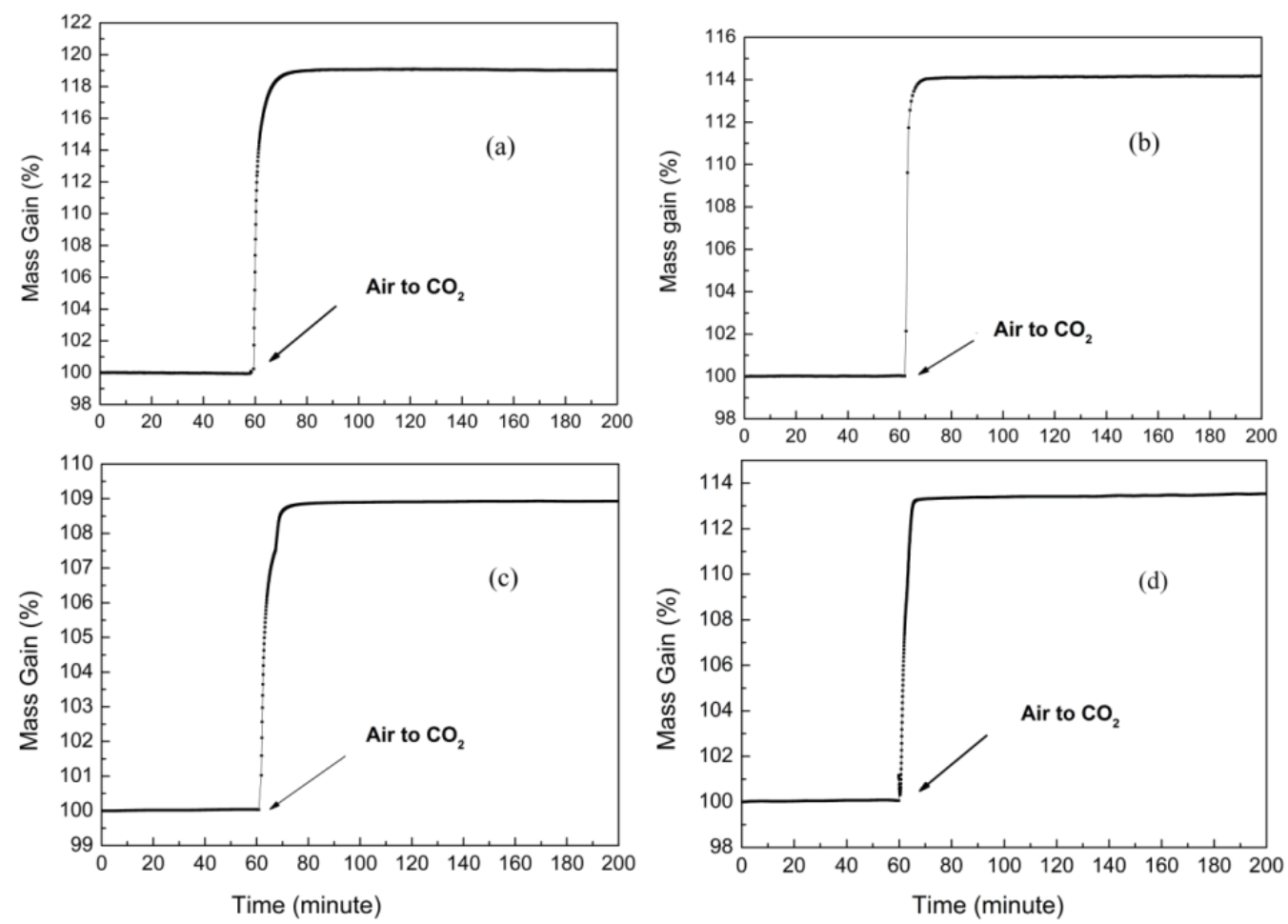

Figure. 2.1. Normalized plot of mass change of (a) $\mathrm{SrCoO}_{3-\delta \delta}$, (b) $\mathrm{BaCoO}_{3-\delta}$, (c) $\mathrm{BaFeO}_{3-\delta}$ and (d) $\mathrm{BaCeO}_{3-8}$ in air $/ \mathrm{CO}_{2}$ at $950^{\circ} \mathrm{C}$

The phase composition of powder samples before and after TGA experiments 
were examined by X-Ray diffraction and the results are shown in Figure 2.2. From this figure it can be seen that the characteristic peaks of the perovskite materials were not present any more after $\mathrm{CO}_{2}$ exposure, indicating that the decomposition reaction is complete. By indexing the XRD patterns of $\mathrm{CO}_{2}$-treated powders, products of the carbonation reactions can be determined.
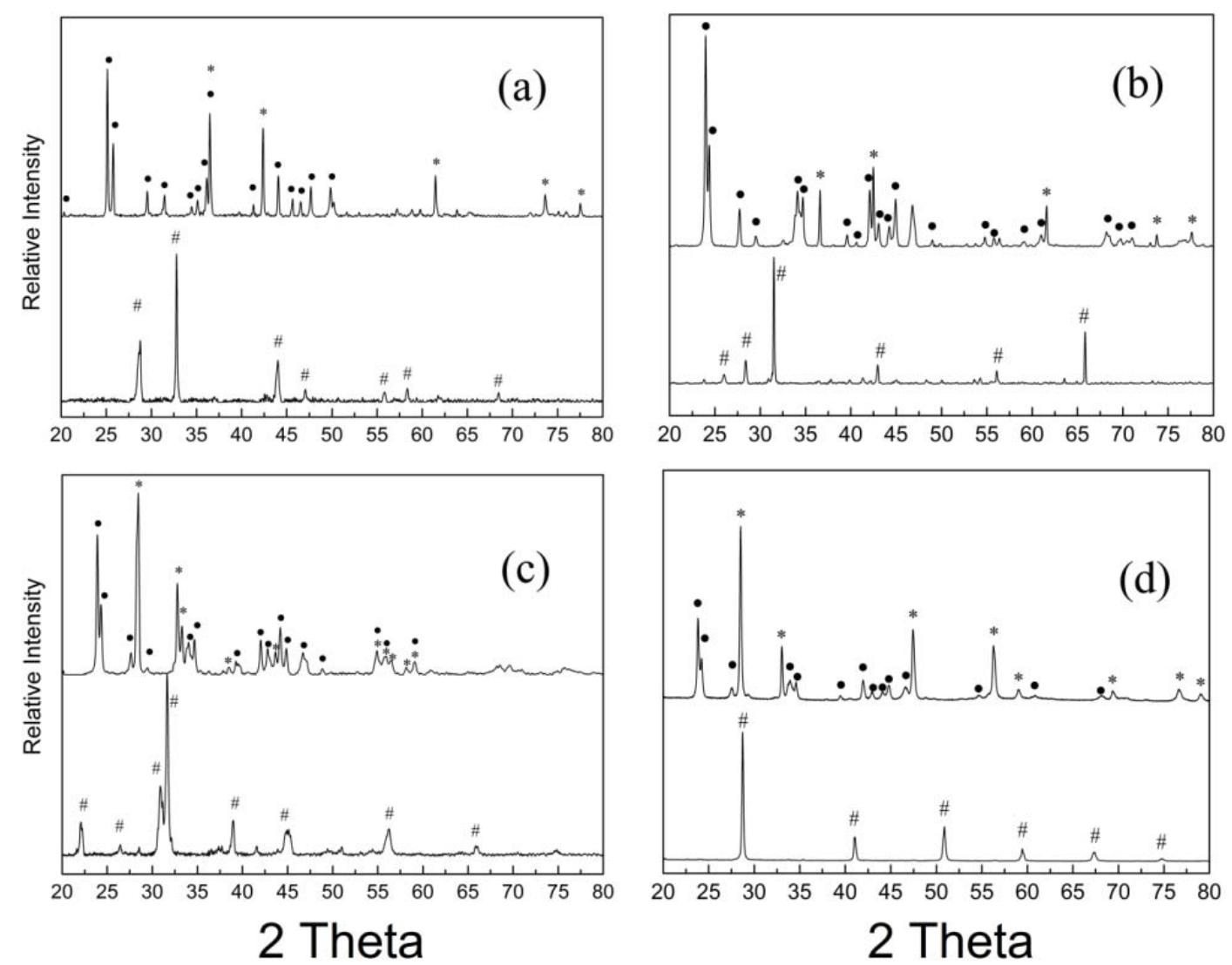

Figure. 2.2. X-Ray Diffraction pattern of (a) $\mathrm{SrCoO}_{3-\delta}$, (b) $\mathrm{BaCoO}_{3-\delta}$, (c) $\mathrm{BaFeO}_{3-\delta}$ and (d) $\mathrm{BaCeO}_{3-\delta}$ before (lower) and after (upper) $\mathrm{CO}_{2}$ treatment at $950{ }^{\circ} \mathrm{C}$. \#: As prepared samples;

- in (a): $\mathrm{SrCO}_{3} ; \bullet$ in (b-d): $\mathrm{BaCO}_{3} ; *$ in (a-d): $\mathrm{CoO}, \mathrm{CoO}, \mathrm{BaFe}_{2} \mathrm{O}_{4}$, and $\mathrm{CeO}_{2}$

Tables 2.1-2.4 summarize the XRD data to prove the degree of matching of the XRD signals of standard materials with those of the products after reaction. In these tables only characteristic peaks are given, however full indexing of the XRD data was performed in this work. From these data it is concluded that the diffraction angles (20) match very well. The slight deviations in intensities for some signals might be caused by the overlap of different peaks for the products obtained after the decomposition reaction. For example, in the case of $\mathrm{SrCoO}_{3-\delta}$ after reaction with $\mathrm{CO}_{2}$ 
(figure 2.2c), the characteristic peaks of $\mathrm{CoO}(111)$ and $\mathrm{SrCO}_{3}$ (112) are so close to each other that it is impossible to separate them, which makes the intensity of $\mathrm{CoO}$ (111) even higher than that of $\mathrm{CoO}$ (200) (see table 2.1).

Table 2.1 Comparison of XRD patterns of $\mathrm{SrCoO}_{3-\delta}$ after reaction with $\mathrm{CO}_{2}$ at $950^{\circ} \mathrm{C}$ with standard XRD peaks ( $\mathrm{Cu} \mathrm{K} \alpha$ radiation)

\begin{tabular}{|c|c|c|c|c|c|}
\hline Materials & $\begin{array}{c}\text { XRD } \\
\text { peaks } \\
(2 \theta)\end{array}$ & $\begin{array}{c}\text { Normalized } \\
\text { peak } \\
\text { intensity } \\
(\text { Area, \%) }\end{array}$ & $\begin{array}{c}\text { Characteristic } \\
\text { peaks for pure } \\
\text { material }(2 \theta)\end{array}$ & $\begin{array}{c}\text { Peak } \\
\text { intensity } \\
\text { for pure } \\
\text { material } \\
(\%)\end{array}$ & $(\mathrm{h} \mathrm{k} \mathrm{1)}$ \\
\hline & & \multicolumn{4}{|c|}{ ICDD PDF No.: 78-0431 } \\
\hline \multirow[t]{6}{*}{$\mathrm{CoO}$} & 36.51 & 117 & 36.49 & 68 & (111) \\
\hline & 42.40 & 100 & 42.38 & 100 & $(200)$ \\
\hline & 61.50 & 56 & 61.49 & 45 & $(220)$ \\
\hline & 73.65 & 35 & 73.66 & 16 & (311) \\
\hline & 77.55 & 25 & 77.52 & 11 & $(222)$ \\
\hline & & \multicolumn{4}{|c|}{ ICDD PDF No.: 05-0418 } \\
\hline \multirow[t]{7}{*}{$\mathrm{SrCO}_{3}$} & 25.16 & 100 & 25.17 & 100 & $(111)$ \\
\hline & 25.80 & 46 & 25.80 & 70 & $(021)$ \\
\hline & 36.17 & 35 & 36.18 & 34 & (112) \\
\hline & 36.51 & 75 & 36.53 & 40 & $(130)$ \\
\hline & 44.09 & 24 & 44.08 & 50 & $(221)$ \\
\hline & 47.69 & 20 & 47.69 & 35 & $(132)$ \\
\hline & 49.89 & 34 & 49.92 & 31 & (113) \\
\hline
\end{tabular}


Table 2.2 Comparison of XRD patterns of $\mathrm{BaCoO}_{3-\delta}$ after reaction with $\mathrm{CO}_{2}$ at $950^{\circ} \mathrm{C}$ with standard $\mathrm{XRD}$ peaks ( $\mathrm{Cu} \mathrm{K} \alpha$ radiation)

\begin{tabular}{|c|c|c|c|c|c|}
\hline Materials & $\begin{array}{l}\text { XRD } \\
\text { peaks } \\
(2 \theta)\end{array}$ & $\begin{array}{c}\text { Normalized } \\
\text { peak } \\
\text { intensity } \\
\text { (Area, \%) }\end{array}$ & $\begin{array}{c}\text { Characteristic } \\
\text { peaks for pure } \\
\text { material }(2 \theta)\end{array}$ & $\begin{array}{c}\text { Peak } \\
\text { intensity for } \\
\text { pure } \\
\text { material } \\
(\%)\end{array}$ & (h k l) \\
\hline $\mathrm{CoO}$ & $\begin{array}{l}36.59 \\
42.49 \\
61.58 \\
73.75 \\
77.61\end{array}$ & $\begin{array}{c}54 \\
100 \\
54 \\
19 \\
27\end{array}$ & $\begin{array}{c}\text { ICDD PDF I } \\
36.49 \\
42.38 \\
61.49 \\
73.66 \\
77.52\end{array}$ & $\begin{array}{c}\mathbf{7 8 - 0 4 3 1} \\
68 \\
100 \\
45 \\
16 \\
11\end{array}$ & $\begin{array}{l}(111) \\
(200) \\
(220) \\
(311) \\
(222)\end{array}$ \\
\hline $\mathrm{BaCO}_{3}$ & $\begin{array}{l}23.98 \\
24.39 \\
34.13 \\
34.70 \\
42.09 \\
44.94 \\
46.78 \\
\end{array}$ & $\begin{array}{l}100 \\
48 \\
25 \\
23 \\
27 \\
22 \\
19 \\
\end{array}$ & $\begin{array}{c}\text { ICDD PDF I } \\
23.90 \\
24.31 \\
34.10 \\
34.61 \\
42.00 \\
44.92 \\
46.80 \\
\end{array}$ & $\begin{array}{c}\mathbf{7 1 - 2 3 9 4} \\
100 \\
52 \\
21 \\
25 \\
28 \\
23 \\
18 \\
\end{array}$ & $\begin{array}{l}(111) \\
(021) \\
(112) \\
(130) \\
(221) \\
(132) \\
(113) \\
\end{array}$ \\
\hline
\end{tabular}


Table 2.3 Comparison of $\mathrm{XRD}$ patterns of $\mathrm{BaFeO}_{3-\delta}$ after reaction with $\mathrm{CO}_{2}$ at $950^{\circ} \mathrm{C}$ with standard $\mathrm{XRD}$ peaks $(\mathrm{Cu} \mathrm{K} \alpha$ radiation)

\begin{tabular}{|c|c|c|c|c|c|}
\hline Materials & $\begin{array}{l}\text { XRD } \\
\text { peaks } \\
(2 \theta)\end{array}$ & $\begin{array}{c}\text { Normalized } \\
\text { peak } \\
\text { intensity } \\
\text { (Area, \%) }\end{array}$ & $\begin{array}{l}\text { Characteristic } \\
\text { peaks for pure } \\
\text { material }(2 \theta)\end{array}$ & $\begin{array}{c}\text { Peak } \\
\text { intensity for } \\
\text { pure } \\
\text { material } \\
(\%)\end{array}$ & $(\mathrm{h} \mathrm{k} 1)$ \\
\hline \multirow{6}{*}{$\mathrm{BaFe}_{2} \mathrm{O}_{4}$} & & \multicolumn{4}{|c|}{ ICDD PDF No.: 25-1191 } \\
\hline & 28.27 & 99 & 28.22 & 54 & $(402)$ \\
\hline & 28.47 & 100 & 28.41 & 100 & $(212)$ \\
\hline & 32.79 & 80 & 32.70 & 56 & $(610)$ \\
\hline & 33.32 & 38 & 33.22 & 27 & $(020)$ \\
\hline & 44.19 & 50 & 44.12 & 21 & $(422)$ \\
\hline \multirow{8}{*}{$\mathrm{BaCO}_{3}$} & & \multicolumn{4}{|c|}{ ICDD PDF No.: 71-2394 } \\
\hline & 23.90 & 100 & 23.90 & 100 & $(111)$ \\
\hline & 24.33 & 57 & 24.31 & 52 & $(021)$ \\
\hline & 34.05 & 28 & 34.10 & 21 & (112) \\
\hline & 34.64 & 19 & 34.61 & 25 & $(130)$ \\
\hline & 42.03 & 27 & 42.00 & 28 & $(221)$ \\
\hline & 44.88 & 22 & 44.92 & 23 & (132) \\
\hline & 46.70 & 31 & 46.80 & 18 & (113) \\
\hline
\end{tabular}


Table 2.4 Comparison of XRD Patterns of $\mathrm{BaCeO}_{3-\delta}$ after reaction with $\mathrm{CO}_{2}$ at $950^{\circ} \mathrm{C}$ with Standard XRD Peaks ( $\mathrm{Cu} \mathrm{K} \alpha$ radiation)

\begin{tabular}{|c|c|c|c|c|c|}
\hline Materials & $\begin{array}{l}\text { XRD } \\
\text { peaks } \\
(2 \theta)\end{array}$ & $\begin{array}{c}\text { Normalized } \\
\text { peak } \\
\text { intensity } \\
\text { (Area, \%) }\end{array}$ & $\begin{array}{c}\text { Characteristic } \\
\text { peaks for pure } \\
\text { material }(2 \theta)\end{array}$ & $\begin{array}{c}\text { Peak } \\
\text { intensity for } \\
\text { pure } \\
\text { material } \\
(\%) \\
\end{array}$ & (h k l) \\
\hline $\mathrm{CeO}_{2}$ & $\begin{array}{l}28.55 \\
33.08 \\
47.49 \\
56.33 \\
76.66\end{array}$ & $\begin{array}{l}100 \\
26 \\
53 \\
48 \\
15\end{array}$ & $\begin{array}{c}\text { ICDD PDF I } \\
28.55 \\
33.08 \\
47.48 \\
56.34 \\
76.70\end{array}$ & $\begin{array}{c}\mathbf{4 3 - 1 0 0 2} \\
100 \\
27 \\
46 \\
34 \\
12\end{array}$ & $\begin{array}{l}(111) \\
(200) \\
(220) \\
(311) \\
(331)\end{array}$ \\
\hline $\mathrm{BaCO}_{3}$ & $\begin{array}{l}23.89 \\
24.27 \\
34.02 \\
34.68 \\
42.01 \\
44.95 \\
46.65 \\
\end{array}$ & $\begin{array}{l}100 \\
73 \\
35 \\
15 \\
21 \\
20 \\
17\end{array}$ & $\begin{array}{c}\text { ICDD PDF I } \\
23.90 \\
24.31 \\
34.10 \\
34.61 \\
42.00 \\
44.92 \\
46.80 \\
\end{array}$ & $\begin{array}{c}\mathbf{7 1 - 2 3 9 4} \\
100 \\
52 \\
21 \\
25 \\
28 \\
23 \\
18 \\
\end{array}$ & $\begin{array}{l}(111) \\
(021) \\
(112) \\
(130) \\
(221) \\
(132) \\
(113) \\
\end{array}$ \\
\hline
\end{tabular}

According to the XRD results, the reactions between $\mathrm{SrCoO}_{3-\delta}, \mathrm{BaCoO}_{3-\delta}$, $\mathrm{BaFeO}_{3-\delta}, \mathrm{BaCeO}_{3-\delta}$ and $\mathrm{CO}_{2}$ at $950{ }^{\circ} \mathrm{C}$ can be described as follow:

$$
\begin{gathered}
\mathrm{SrCoO}_{3-\delta}+\mathrm{CO}_{2} \rightarrow \mathrm{SrCO}_{3}+\mathrm{CoO}+\frac{1-\delta}{2} \mathrm{O}_{2} \\
\mathrm{BaCoO}_{3-\delta}+\mathrm{CO}_{2} \rightarrow \mathrm{BaCO}_{3}+\mathrm{CoO}+\frac{1-\delta}{2} \mathrm{O}_{2} \\
2 \mathrm{BaFeO}_{3-\delta}+\mathrm{CO}_{2} \rightarrow \mathrm{BaFe}_{2} \mathrm{O}_{4}+\mathrm{BaCO}_{3}+\frac{1-2 \delta}{2} \mathrm{O}_{2} \\
\mathrm{BaCeO}_{3-\delta}+\mathrm{CO}_{2} \rightarrow \mathrm{BaCO}_{3}+\mathrm{CeO}_{2}-\frac{\delta}{2} \mathrm{O}_{2}
\end{gathered}
$$

As shown by $\mathrm{XRD}$, in our case the products $\left(\mathrm{CoO}, \mathrm{SrCO}_{3}, \mathrm{BaCO}_{3}, \mathrm{CeO}_{2}\right.$ and 
$\mathrm{BaFe}_{2} \mathrm{O}_{4}$ ) are stoichiometric and the reactions are complete. The following equation, describing the mass change during the reaction, can then be established:

$$
\frac{m_{1}}{\mathrm{MW}_{\mathrm{ABCoO}_{3-\delta}}}=\frac{m_{2}}{\mathrm{MW}_{\mathrm{ss}}}
$$

where $m_{1}$ and $\mathrm{MW}_{\mathrm{ABCOO}-\delta}$ represent the mass and molecular weight of the samples before the reaction with $\mathrm{CO}_{2} ; m_{2}$ and $\mathrm{MW}_{\mathrm{SS}}$ are the mass and the sum of the molecular weights of the products after reaction. For example, $\mathrm{MW}_{\mathrm{SS}}$ for reaction (1) is the sum of mole weight of $\mathrm{SrCO}_{3}$ and $\mathrm{CoO}$. Since MW $\mathrm{SS}$ is known and $m_{1}$ and $m_{2}$ can be determined from the TGA results, the molecular weight of $\mathrm{ABO}_{3-\delta}$ can be calculated according to eq. (2.5) and subsequently the oxygen non-stoichiometry $(\delta)$ is determined to be as 0.48, 0.36, 0.43 and 0.03 for $\mathrm{SrCoO}_{3-\delta}, \mathrm{BaCoO}_{3-\delta}, \mathrm{BaFeO}_{3-\delta}$ and $\mathrm{BaCeO}_{3-\delta}$ respectively, which is in agreement with literature [14-16].

Based on the reference point measured at $950{ }^{\circ} \mathrm{C}$ in air, oxygen nonstoichiometry $(\delta)$ at other temperatures can be acquired according to eq. (2.6).

$$
\frac{\mathrm{m}_{T}}{\mathrm{MW}_{T}}=\frac{\mathrm{m}_{950}}{\mathrm{MW}_{950}}
$$

where $m_{T}$ and $\mathrm{MW}_{T}$ represent the mass and molecular weight of $\mathrm{ABO}_{3-\delta}$ at temperature $T, m_{950}$ and $\mathrm{MW}_{950}$ are the mass and molecular weight at $950{ }^{\circ} \mathrm{C}$. In this study, the temperature was stepwise increased to $950^{\circ} \mathrm{C}$ in air, and at each measuring point $\left(550{ }^{\circ} \mathrm{C}, 650{ }^{\circ} \mathrm{C}, 750{ }^{\circ} \mathrm{C}, 850{ }^{\circ} \mathrm{C}\right.$, and $\left.950{ }^{\circ} \mathrm{C}\right)$ the temperature was kept constant until a steady state was reached. The results, as given in Figure 2.3, clearly indicate that equilibrium was really obtained during these holding temperatures as no weight loss is observed prior to the next heating step. The oxygen non-stoichiometry was calculated according to eq. (2.6) and results are shown in Figure 2.4. For $\mathrm{BaCeO}_{3-\delta}$, due to extremely small mass change during heating, we could not do the same analysis as above with our equipment, so the result for $\mathrm{BaCeO}_{3-\delta}$ was not given in this study. 

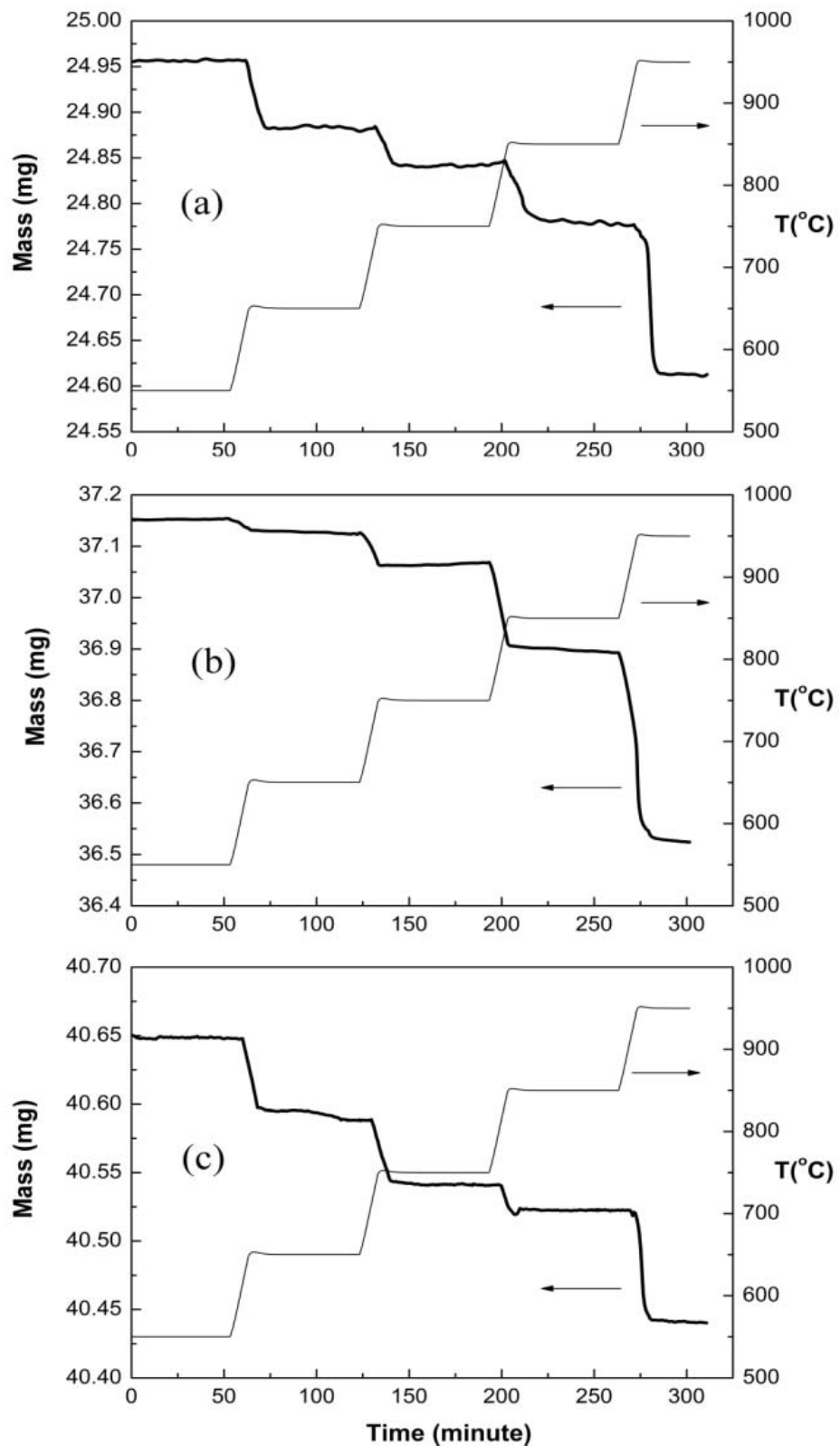

Figure. 2.3. Mass change of powder sample in air as function of temperature; (a) $\mathrm{SrCoO}_{3-\delta}$, (b) $\mathrm{BaCoO}_{3-\delta}$ and (c) $\mathrm{BaFeO}_{3-\delta}$ 


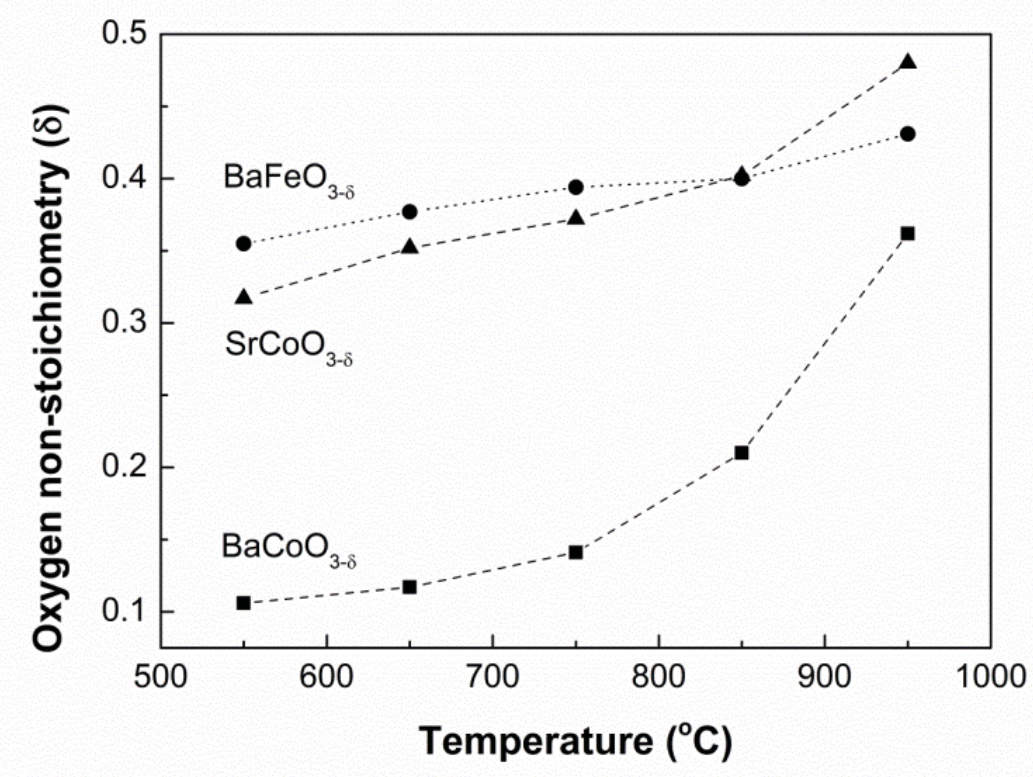

Figure. 2.4. Temperature dependence of oxygen non-stoichiometry $(\delta)$ in $\operatorname{SrCoO}_{3-\delta}(\boldsymbol{\Delta})$, $\mathrm{BaCoO}_{3-\delta}(\boldsymbol{\bullet})$ and $\mathrm{BaFeO}_{3-\delta}(\bullet)$ in air; Dashed lines are guides to the eye

\subsection{Discussion}

The principle of this method is similar to the hydrogen reduction method, because in both cases the perovskite materials react with a sweeping gas resulting in stoichiometric products; subsequently the oxygen non-stoichiometry is calculated from the mass change. However, the reaction mechanism is completely different, one is reduction and another one is carbonation. Due to this difference, some materials that do not react with $\mathrm{CO}_{2}$ may react with hydrogen, and some materials that do not react with hydrogen may react with $\mathrm{CO}_{2}$, which gives the idea that we can choose appropriate method for certain material. For example, $\mathrm{BaCeO}_{3-\delta}$ is a well-known perovskite material for hydrogen separation and it is very stable in hydrogen containing atmosphere, indicating that we cannot use hydrogen reduction method to determine its oxygen non-stoichiometry, however this material is very sensitive to $\mathrm{CO}_{2}$ and we can analyze the oxygen non-stoichiometry by $\mathrm{CO}_{2}$ method.

An accurate analysis of the phase composition of the reaction products is of great importance, which in this work was examined by room-temperature XRD. It should 
be pointed out that there might be some phase transitions during the cooling process, meaning that the phase composition at $950{ }^{\circ} \mathrm{C}$ could be different. However, as in this work no mass change was observed during cooling, the assumption can be made that the products of the reactions (1-4) at $950{ }^{\circ} \mathrm{C}$ are the same as those analyzed at room temperature and can be used to calculate the oxygen non-stoichiometry by eq. (2.5). Nevertheless, high temperature $\mathrm{XRD}$ in a $\mathrm{CO}_{2}$ atmosphere is the best way to identify the phase composition. This might be possible, because $\mathrm{CO}_{2}$ is not explosive and toxic and it is therefore safe to conduct XRD experiments under such conditions, which is not the case for the explosive properties of hydrogen at the higher temperatures of interest.

Evaluation of the accuracy of the method is also important, especially when the oxygen non-stoichiometry change is very small, like for $\mathrm{BaCeO}_{3-\delta}$. The cumulative error of this method may arise from different steps in the experiment, but the most important one is weighing part. In this study, the weighing error of our TGA equipment is around $0.01 \%$ (20 50 mg powder was used), and it will cause 0.01 deviation in the oxygen non-stoichiometry calculation. Generally, there are two ways to increase the accuracy of this method. The first one is to increase the accuracy of the TGA setup, however this is limited, due to current technology; e.g.: the best accuracy for an electronic balance is $0.001 \mathrm{mg}$. Alternatively, one can use more powder to increase the accuracy as well. In some other studies, around $1 \mathrm{~g}$ or even $3 \sim 4 \mathrm{~g}$ was used for TGA measurements [17, 18]. If for example in this study $200 \mathrm{mg}$ powder was used and weighed with the same accuracy, the deviation of $3-\delta$ would be reduced to 0.001 .

\subsection{Conclusion}

A new method to determine the oxygen non-stoichiometry of perovskite materials under equilibrium state has been developed and demonstrated by using $\mathrm{SrCoO}_{3-\delta}, \mathrm{BaCoO}_{3-\delta}, \mathrm{BaFeO}_{3-\delta}$ and $\mathrm{BaCeO}_{3-\delta}$ as representative materials. The oxygen non-stoichiometry $(\delta)$ of these 4 materials at $950^{\circ} \mathrm{C}$ in air was measured to be 0.48 , 
$0.36,0.43$ and 0.03 respectively. Based on these reference points, the oxygen nonstoichiometry at other temperatures was also measured, while this method is expected to be successful for other perovskite materials as well. This method is not only restricted for analysis of $\delta$ in air, large variations in oxygen partial pressures can also be used, because the equilibrium state for all partial pressures can easily be attained at (sufficient) high temperatures.

\section{References}

[1] T. Nagai, W. Ito, T. Sakon, Solid State Ionics 177 (2007) (39-40) 3433.

[2] V.G. Milt, M.A. Ulla, E.E. Miro, Applied Catalysis B-Environmental 57 (2005) (1) 13.

[3] J. Suntivich, H.A. Gasteiger, N. Yabuuchi, H. Nakanishi, J.B. Goodenough, Y. Shao-Horn, Nat Chem 3 (2011) (7) 546.

[4] M.V. Patrakeev, I.A. Leonidov, V.L. Kozhevnikov, J Solid State Electr 15 (2011) (5) 931.

[5] A.N. Petrov, V.A. Cherepanov, O.F. Kononchuk, L.Y. Gavrilova, Journal of Solid State Chemistry 87 (1990) (1) 69.

[6] B. M., T. K., U. H., Fachzeitschrift fuer das Laboratorium 38 (1994) 6.

[7] K. Teske, H. Ullmann, D. Rettig, Journal of Nuclear Materials 116 (1983) (2-3) 260.

[8] V.V. Vashook, M.V. Zinkevich, H. Ullmann, J. Paulsen, N. Trofimenko, K. Teske, Solid State Ionics 99 (1997) (1-2) 23.

[9] M. Karppinen, M. Matvejeff, K. Salomaki, H. Yamauchi, J Mater Chem 12 (2002) (6) 1761.

[10] S. McIntosh, J.F. Vente, W.G. Haije, D.H.A. Blank, H.J.M. Bouwmeester, Solid State Ionics 177 (2006) (19-25 SPEC. ISS.) 1737.

[11] J. Yi, M. Schroeder, T. Weirich, J. Mayer, Chem Mater 22 (2010) (23) 6246.

[12] H. Patra, S.K. Rout, S.K. Pratihar, S. Bhattacharya, Powder Technology 209 (2011) (1-3) 98.

[13] Q. Zeng, Y.B. Zu, C.G. Fan, C.S. Chen, Journal of Membrane Science 335 (2009) (1-2) 140.

[14] J. Rodríguez, J.M. González-Calbet, Mater Res Bull 21 (1986) (4) 429.

[15] A.J. Jacobson, J.L. Hutchison, Journal of the Chemical Society, Chemical Communications (1976) (3).

[16] H.J.V. Hook, The Journal of Physical Chemistry 68 (1964) (12) 3786.

[17] S. Kim, R. Merkle, J. Maier, Surface Science 549 (2004) (3) 196.

[18] M. Oishi, K. Yashiro, K. Sato, J. Mizusaki, N. Kitamura, K. Amezawa, T. Kawada, Y. Uchimoto, Solid State Ionics 179 (2008) (15-16) 529. 
Chapter 2 


\title{
Chapter 3 A description of oxygen transport in a bench-scale oxygen permeation set-up using computing fluid dynamics
}

\begin{abstract}
Measuring the oxygen permeability of dense ceramic membranes is usually performed with a lab-scale oxygen permeation set-up, in which feed and sweep gas are directly flushed to the membrane surface. Due to concentration gradients within the experimental setup, the oxygen partial pressure $\left(P_{\mathrm{O}_{2}}\right)$ measured at the outlet of the set-up is not the same as the $P_{\mathrm{O}_{2}}$ on the membrane surface, which leads to an inaccurate calculation of the oxygen ionic conductivity (a measure of oxygen permeability) of the membranes. In order to overcome this problem, a computational fluid dynamics (CFD) model is developed to describe the oxygen transport in such a set-up and special attention is paid to the exact oxygen partial pressures on the membrane surface. With this CFD model, the oxygen ionic conductivity of a selected model membrane, $\mathrm{SrCo}_{0.8} \mathrm{Fe}_{0.2} \mathrm{O}_{3-\delta}$ ( $\mathrm{SCF}$ ), is calculated. In addition, the influence of several parameters such as the distance from sweep gas inlet to the membrane surface, the sweep gas flow rate and the type of sweep gas on the oxygen partial pressure distribution in the setup is studied.
\end{abstract}




\subsection{Introduction}

Dense ceramic membranes made from mixed ionic-electronic conducting (MIEC) oxides have attracted considerable attention in the past decades due to their potential application in oxygen separation from air. The major advantage of oxygen separation by these membranes over other techniques, such as cryogenic distillation and pressure swing adsorption (PSA), lies in their infinite selectivity, i.e. only oxygen can go through the membranes. In addition, the oxygen separation can easily be coupled with other chemical processes where oxygen is required, for example, partial oxidation of methane or oxy-fuel combustion for $\mathrm{CO}_{2}$ capture [1-3].

The research on MIEC membranes was initiated by Teraoka et al. [4] in the 1980's. After that, a lot of work has been done to improve the performance of the MIEC membranes, for example, to increase the oxygen permeability. A commonly used method to measure the oxygen permeability of a MIEC membrane is a high temperature oxygen permeation experiment, which usually makes use of a benchscale set-up as schematically shown in Figure 3.1. In most cases air is used as feed gas and an inert gas such as helium or argon is used as sweep gas. The oxygen flux through the membranes can be calculated by analyzing the oxygen concentration at the exit of the set-up, usually by using an oxygen sensor or a gas chromatograph (GC). 


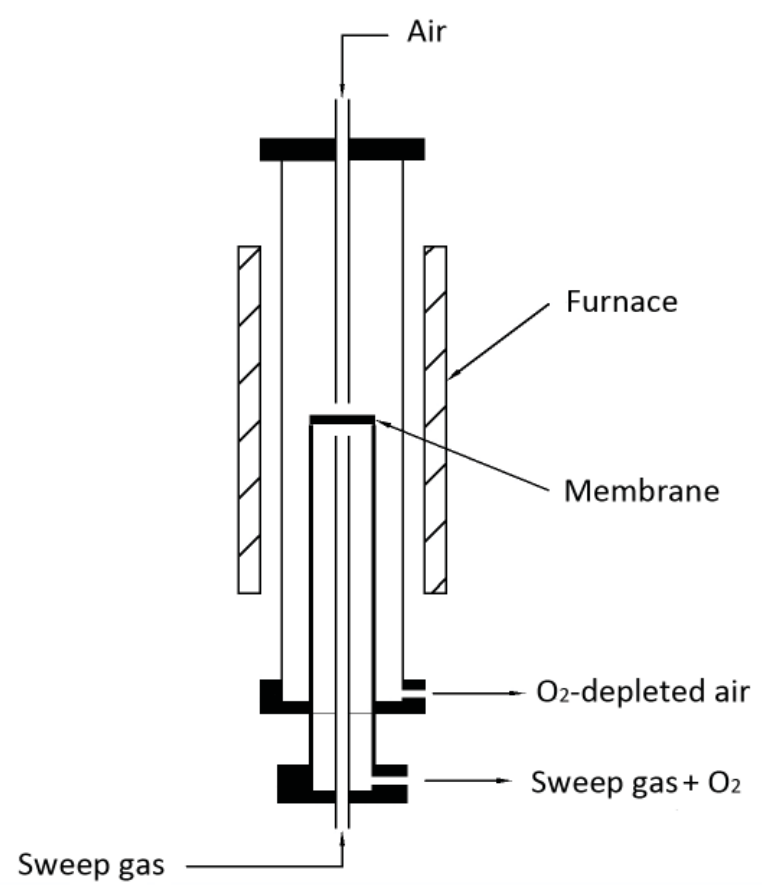

Figure 3.1. Schematic diagram of the high temperature oxygen permeation set-up.

The oxygen flux through a MIEC membrane reflects the oxygen permeability through the membrane. However, the oxygen flux is affected by many parameters, such as membrane thickness, operating temperature and feed/sweep gas flow rate. A better way to evaluate a MIEC membrane is to determine the oxygen ionic conductivity, which is an intrinsic material property of the membrane and can be obtained from the oxygen permeation data by using the following equation, as proposed by Chen et al. [5].

$$
\sigma_{\text {ion }}\left(P_{\mathrm{O}_{2}}^{\prime \prime}\right)=-\frac{4^{2} F^{2} L}{R T}\left[\frac{d j_{\mathrm{O}_{2}}}{d \ln P_{\mathrm{O}_{2}}^{\prime \prime}}\right]_{P_{\mathrm{O}_{2}}^{\prime}=\text { constant }}
$$

where $j_{\mathrm{O}_{2}}$ is oxygen flux, $R$ the gas constant, $T$ absolute temperature, $\mathrm{F}$ the Faraday constant, $L$ the membrane thickness, $\sigma_{\text {ion }}$ the oxygen ionic conductivity, $P_{\mathrm{O}_{2}}^{\prime}$ the oxygen partial pressure at the feed side and $P_{\mathrm{O}_{2}}^{\prime \prime}$ the oxygen partial pressure at the sweep side of the membrane. 
For calculating $\sigma_{\text {ion }}$ of a membrane from oxygen flux data, it is in most cases assumed that the oxygen partial pressure $\left(P_{\mathrm{O}_{2}}\right)$ at the outlet (= "sweep gas $+\mathrm{O}_{2}$ " in Figure 5.1) has the same value as the oxygen partial pressure at the surface $\left(=P_{\mathrm{O}_{2}}^{\prime \prime}\right)$. In other words it is assumed that the oxygen permeation set-up, as shown in Figure 3.1, works as a Continuous Ideally Stirred-Tank Reactor (CISTR), which means a perfect mixing of both nitrogen/oxygen in the feed (air) compartment and sweep gas/oxygen in the permeate compartment. However, the validity of the CISTR assumption depends on the reactor geometry as well as operating parameters. Very often this CISTR assumption is not true and the gas mixing is incomplete [6], i.e. the $P_{\mathrm{O}_{2}}$ measured at the outlet of the permeation set-up is not equal to the $P_{\mathrm{O}_{2}}$ on the membrane surface, hence the calculation of $\sigma_{\text {ion }}$ based on the CISTR assumption is not accurate. In order to obtain a more accurate value of $\sigma_{\text {ion }}$ for a membrane, it is necessary to know the exact $P_{\mathrm{O}_{2}}$ on the membrane surface. However, direct measuring of $P_{\mathrm{O}_{2}}$ on the membrane surface is experimentally very difficult in such a small device and any probing in the permeation set-up will inevitably affect the flow field.

In this work, a method is developed to determine $\sigma_{\text {ion }}$ of a MIEC membrane more accurately from oxygen permeation experiments with the aid of computational fluid dynamics modeling (CFD). It is also intended to understand the oxygen gradient in the above mentioned reactor and its effect on the oxygen flux through the membrane. For this purpose the COMSOL Multiphysics ${ }^{\circledR}$ program was applied as modeling tool while $\mathrm{SrCo}_{0.8} \mathrm{Fe}_{0.2} \mathrm{O}_{3-\delta}$ was used as membrane material in this study. 


\subsection{Experimental and methodological procedure}

\subsubsection{Membrane fabrication and oxygen permeation experiments}

$\mathrm{SrCo}_{0.8} \mathrm{Fe}_{0.2} \mathrm{O}_{3-\delta}(\mathrm{SCF})$ was synthesized using an EDTA complexation/pyrolysis process. Metal nitrates were dissolved in demineralized water under stirring at a stoichiometric ratio. EDTA, dissolved in ammonia, was added and after chelating for several minutes citric acid was added. The molar ratio of total metal ions : EDTA : citric acid was $1.0: 1.0: 1.5$. The $\mathrm{pH}$ of the solution was adjusted to 6 by adding ammonia. Subsequently $\mathrm{NH}_{4} \mathrm{NO}_{3}$ was added as an ignition aid at an amount of $100 \mathrm{~g}$ $\mathrm{NH}_{4} \mathrm{NO}_{3}$ per 0.1 mole of metal ions. This final solution was heated at $120-150{ }^{\circ} \mathrm{C}$ under stirring to evaporate water until it changed into a viscous gel and was transferred to a stainless steel vessel and heated on a hot plate at a temperature of around $500{ }^{\circ} \mathrm{C}$, while a vigorous combustion took place, resulting in a fluffy powder. The powder was collected and calcined in a room furnace at $950{ }^{\circ} \mathrm{C}$ for 5 hours at a heating and cooling rate of $3{ }^{\circ} \mathrm{C} / \mathrm{min}$. The calcined powders were uniaxially pressed at $4 \mathrm{MPa}$ into disk shapes, subsequently cold isostatically pressed at $400 \mathrm{Mpa}$ for 6 minutes and sintered in ambient air at $1200{ }^{\circ} \mathrm{C}$ for 10 hours.

The experimental set-up for oxygen permeation measurements is schematically shown in Figure 3.1. Disk-shaped samples with a diameter of $15 \mathrm{~mm}$ and a relative density $>90 \%$ were polished to a thickness of $1 \mathrm{~mm}$ and ultrasonically cleaned in ethanol. The membranes were sealed to one end of a quartz tube (diameter $12 \mathrm{~mm}$ ) using gold paste as sealant. After sealing at $1000{ }^{\circ} \mathrm{C}$ for 2 hours the temperature was lowered to $950{ }^{\circ} \mathrm{C}$, and air was fed to one side of the sample $(100 \mathrm{ml} / \mathrm{min})$, while helium was led at $50 \mathrm{ml} / \mathrm{min}$ over the permeate side as sweep gas to carry away the permeated oxygen. The composition of the effluent stream at the permeate side was analyzed by an oxygen sensor (Systech ZR893). A gas chromatograph (Varian CP 4900 equipped with a $5 \AA$ molecular sieve column using helium as carrier gas) was used to check the leakage of the sealing. If there is no nitrogen peak in the GC 
spectrum of the permeate gas, it is assumed that the sealing is gas tight.

\subsubsection{Oxygen transport through a MIEC membrane}

The oxygen flux through a dense ceramic MIEC membrane is generally described by Wagner's equation, assuming bulk oxygen diffusion to be the rate limiting step [7]:

$$
j_{\mathrm{O}_{2}}=-\frac{R T}{(4 F)^{2} d} \int_{\mathrm{ln} p \mathrm{O}_{2}^{\prime}}^{\ln p \mathrm{O}_{2}^{\prime \prime}} \frac{\sigma_{\mathrm{el}} \sigma_{\mathrm{ion}}}{\sigma_{\mathrm{el}}+\sigma_{\mathrm{ion}}} d \ln p \mathrm{O}_{2}
$$

For most MIEC membranes, the electronic conductivity $\sigma_{\mathrm{el}}$ is two orders of magnitude higher than $\sigma_{\text {ion }}$ and therefore eq. (3.2) can be rewritten as:

$$
j_{\mathrm{O}_{2}}=-\frac{R T}{(4 F)^{2} d} \int_{\ln P_{\mathrm{O}_{2}}^{\prime}}^{\ln P_{0_{2}}^{\prime \prime}} \sigma_{\text {ion }} \mathrm{d} \ln P_{\mathrm{O}_{2}}
$$

If $\sigma_{\text {ion }}$ is dependent of $P_{\mathrm{O}_{2}}$, the following empirical power law is used to describe the oxygen ionic conductivity $\sigma_{\text {ion }}$ as function of $P_{\mathrm{O}_{2}}$ [7]:

$$
\sigma_{\text {ion }}=\sigma_{\text {ion }}^{0}\left(P_{\mathrm{O}_{2}}\right)^{n}
$$

where $\sigma^{\circ}$ ion is the conductivity at standard state $\left(P_{\mathrm{O}_{2}}=1\right.$ bar). By integrating eq. (3.3) with (3.4), the following equation for the oxygen flux is obtained

$$
j_{\mathrm{O}_{2}}=\frac{R T \sigma_{\text {ion }}^{0}}{(4 F)^{2} n d}\left(P_{\mathrm{O}_{2}}^{\prime n}-P_{\mathrm{O}_{2}}^{\prime \prime n}\right)
$$

3.2.3 Design of a numerical model for the oxygen permeation set-up 


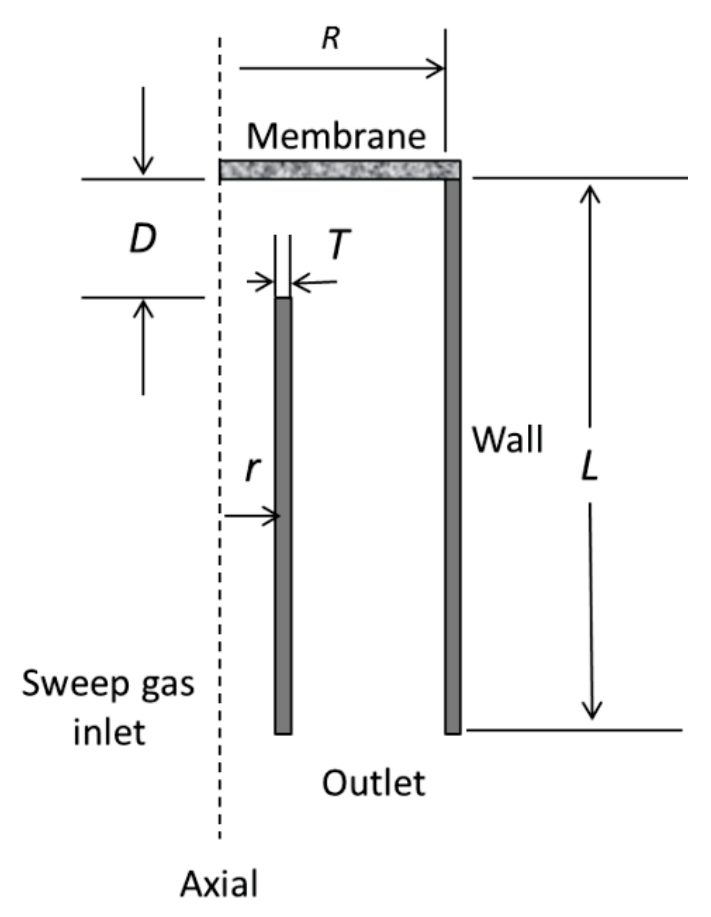

Figure 3.2. Schematic representation of the oxygen permeation set-up as used for the simulation.

The model used for the Computational Fluid Dynamics (CFD) simulation is schematically shown in Figure 3.2 and the dimensions of this model are given in Table 3.1. It should be noted that the incomplete gas mixing may occur at both the feed side and permeate side of the membrane. The change in $P_{\mathrm{O}_{2}}$ in the feed side, however, is expected to be rather small, because in most cases a large flow rate is used and only a small part of the oxygen is consumed [6]. Therefore, in this study $P_{\mathrm{O}_{2}}$ is assumed to be constant in the feed compartment of the set-up ( 0.21 bar), while in the permeate compartment of the reactor a gradient in $P_{\mathrm{O}_{2}}$ is expected.

The $P_{\mathrm{O}_{2}}$ distribution in the permeate compartment is obtained by simultaneously solving the Navier-Stokes and Maxwell-Stefan diffusion equations with the boundary conditions as given in Table 3.2. It should be noted that the laminar flow model is selected for the flow field calculation. This was allowed because Reynold's number is $<50$ in the smallest diameter of the system (sweep gas inlet tube) for sweep gas 
flow rates up to $90 \mathrm{ml} / \mathrm{min}$.

Meshing is an important factor that can affect the accuracy of a CFD simulation. In general, finer meshing usually ensures a higher accuracy, but it also increases computation work. In this study, we gradually refined the mesh by reducing the element size until the simulation results remained the same. The total number of elements, used in this study, is $\sim 20,000$.

Table 3.1. Geometry of the permeation set-up

\begin{tabular}{lll}
\hline Variable & Value & Units \\
\hline Membrane radius, $R_{\mathrm{m}}$ & 6 & $\mathrm{~mm}$ \\
Membrane thickness & 1 & $\mathrm{~mm}$ \\
Sweep gas inlet tube (inner radius), $r$ & 1.5 & $\mathrm{~mm}$ \\
Distance of sweep gas inlet to membrane, $D$ & 3.6 & $\mathrm{~mm}$ \\
Sweep gas tube thickness, $T$ & 1 & $\mathrm{~mm}$ \\
Pressure & 1.0 & $\mathrm{~atm}$ \\
Simulated length, $L$ & 15 & $\mathrm{~mm}$ \\
\hline
\end{tabular}


Table 3.2. Boundary conditions for simulation

\begin{tabular}{ll}
\hline Boundary conditions (convection) & Type \\
\hline Sweep gas inlet & Mass flow \\
Membrane inlet & Pointwise mass flow** \\
Sweep gas outlet & Pressure (1 bar) \\
Axis & Axial symmetry \\
Membrane & Non-slip \\
Wall & Non-slip \\
& \\
\hline Boundary conditions (diffusion) & Type \\
\hline Sweep gas inlet & Oxygen mole fraction $(0.001)$ \\
Sweep gas outlet & Convective flow \\
Axis & Axial symmetry \\
Membrane & Inward flux \\
Wall & No flux \\
\hline
\end{tabular}

** The inward flux is calculated by eq. (3.5).

3.2.4 Calculation of oxygen ionic conductivity from oxygen permeation data

As can be seen form eq. (3.5), the oxygen ionic conductivity of a MIEC membrane is dependent on $P_{\mathrm{O}_{2}}$. The calculation of $\sigma_{\text {ion }}^{\circ}$ and $n$ from oxygen permeation measurements was done in 2 steps. The first step is to estimate $\sigma^{\circ}$ ion and $n$ under the CISTR assumption, so by assuming that the $P_{\mathrm{O}_{2}}$ measured at the outlet of the set-up is identical to that on the membrane surface $\left(P_{\mathrm{O}_{2}}^{\prime \prime}\right)$. By using eq. (3.1) a data set of $\sigma_{\text {ion }} \sim P_{\mathrm{O}_{2}}^{\prime \prime}$ is obtained in this way. This data set is used to fit the eq. (3.4) by applying a least-square algorithm. In this way the two parameters, $\sigma_{\text {ion }}^{\circ}$ and $n$, are obtained but still assuming a CISTR approach of the permeation set-up. 
In the second step, the estimated $\sigma_{\text {ion }}^{\circ}$ and $n$ from the first step are used as input parameters for the COMSOL model, where there is no CISTR assumption. The fitting program with COMSOL is illustrated in Figure 3.3. With a given set of ${\sigma^{\circ}}_{\text {ion }}$ and $n$ the $P_{\mathrm{O}_{2}}$ on the membrane surface and at the outlet of the permeation set-up are calculated with COMSOL. During iteration, $\sigma_{\text {ion }}^{\circ}$ and $n$ were adjusted until the calculated $P_{\mathrm{O}_{2}}$ at the outlet of the permeation set-up is in agreement with the $P_{\mathrm{O}_{2}}$ measured in experiments.

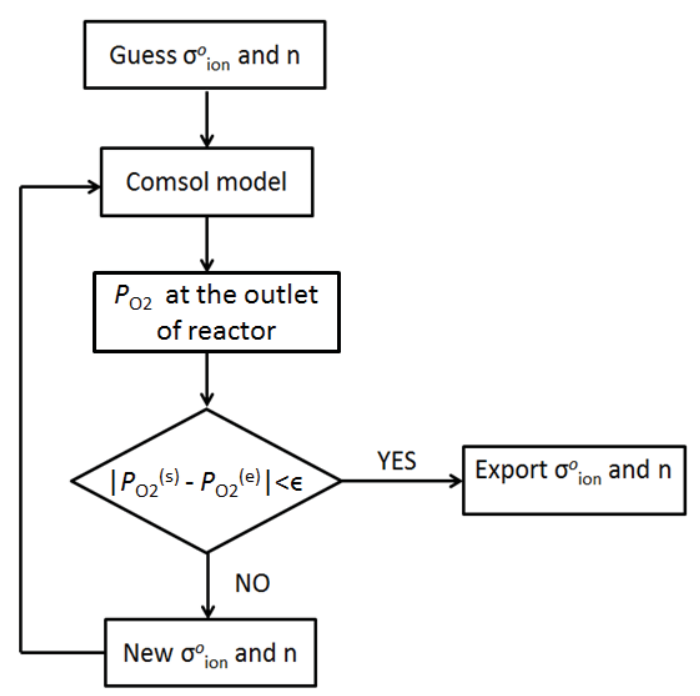

Figure 3.3. Fitting procedure for calculation of the oxygen ionic conductivity. $P_{\mathrm{O} 2}{ }^{\mathrm{s}}$ and $P_{\mathrm{O} 2}{ }^{\mathrm{e}}$ are the oxygen partial pressure at the outlet of the reactor, respectively calculated using the COMSOL Multiphysics ${ }^{\circledR}$ program model and the experimentally determined one.

\subsection{Results and discussion}

\subsubsection{Oxygen permeation results}

Table 3.3 gives the oxygen flux of SCF membranes at different temperature and at different sweep flow rates. As we can see, the oxygen permeation flux increases with sweep gas flow rate, which is because of the overall $P_{\mathrm{O}_{2}}$ at the permeate side of the membrane is decreased when a higher sweep gas flow rate is used, leading to an increase of the driving force. The oxygen flux decrease with decreasing sweep flow 
rate as observed at $800{ }^{\circ} \mathrm{C}$ is explained by the phase transition of SCF from the cubic to the orthorhombic structure [8-9], which latter has a lower oxygen permeability. The phase transition of SCF occurs at around $790{ }^{\circ} \mathrm{C}$, and is affected by the $P_{\mathrm{O}_{2}}$. At lower $P_{\mathrm{O}_{2}}$ (meaning in this case a higher sweep-gas flow rate) the phase transition is more likely to occur.

Table 3.3. Oxygen flux of SCF membranes at different temperatures and different sweep gas flow rates

\begin{tabular}{ccccc}
\hline $\begin{array}{c}\text { Helium flow } \\
\text { rate } \\
(\mathrm{ml} / \mathrm{min})\end{array}$ & $800^{\circ} \mathrm{C}$ & $850^{\circ} \mathrm{C}$ & $900^{\circ} \mathrm{C}$ & $950^{\circ} \mathrm{C}$ \\
\hline 31.19 & 3.13 & 5.99 & 7.88 & 9.86 \\
47.69 & 3.03 & 6.19 & 8.40 & 10.74 \\
73.49 & 3.07 & 6.65 & 9.22 & 12.03 \\
95.89 & 3.00 & 6.71 & 9.56 & 12.58 \\
\hline
\end{tabular}

\subsubsection{Oxygen ionic conductivity of SCF}

Fitting results of $\sigma_{\text {ion }}^{\circ}$ and $n$ without (= initial values, using eq. (3.1) and (3.4)) and with (= fitted values, using COMSOL) CISTR assumption are given in Table 3.4. As can be seen, both $\sigma^{\circ}$ ion and $n$ tend to be smaller if a CISTR assumption is made and the difference is getting more pronounced at a higher temperature.

Table 3.4. Oxygen ionic conductivity $\sigma^{o}$ ion and power index $n$ obtained from fitting experimental results.

\begin{tabular}{lccccc}
\hline & & $800^{\circ} \mathrm{C}$ & $850^{\circ} \mathrm{C}$ & $900^{\circ} \mathrm{C}$ & $950^{\circ} \mathrm{C}$ \\
\hline \multirow{2}{*}{ Initial } & $\sigma_{\text {ion }}^{\circ}(\mathrm{S} / \mathrm{cm})$ & 0.83 & 1.26 & 1.47 & 1.79 \\
values & $n$ & 0.34 & 0.28 & 0.24 & 0.22 \\
\hline
\end{tabular}




$\begin{array}{lccccc}\text { Fitted } & \sigma_{\text {ion }}^{\circ}(\mathrm{S} / \mathrm{cm}) & 0.82 & 1.30 & 1.53 & 1.87 \\ \text { values } & n & 0.57 & 0.43 & 0.36 & 0.32\end{array}$

From an Arrhenius plot of $\log \left(\sigma_{\text {ion }}^{\circ}\right)$ versus 1000/T (Figure 3.4, non-CISTR), suggesting a thermal activation process for $\sigma^{\circ}$ ion, an activation energy of $25 \pm 4$ $\mathrm{kJ} /$ mole is calculated, which is similar to the result as reported by Qiu et al. [9]. The $n$ value increases with decreasing temperature, suggesting that the ionic conductivity is more sensitive to $P_{\mathrm{O}_{2}}$ at lower temperature.

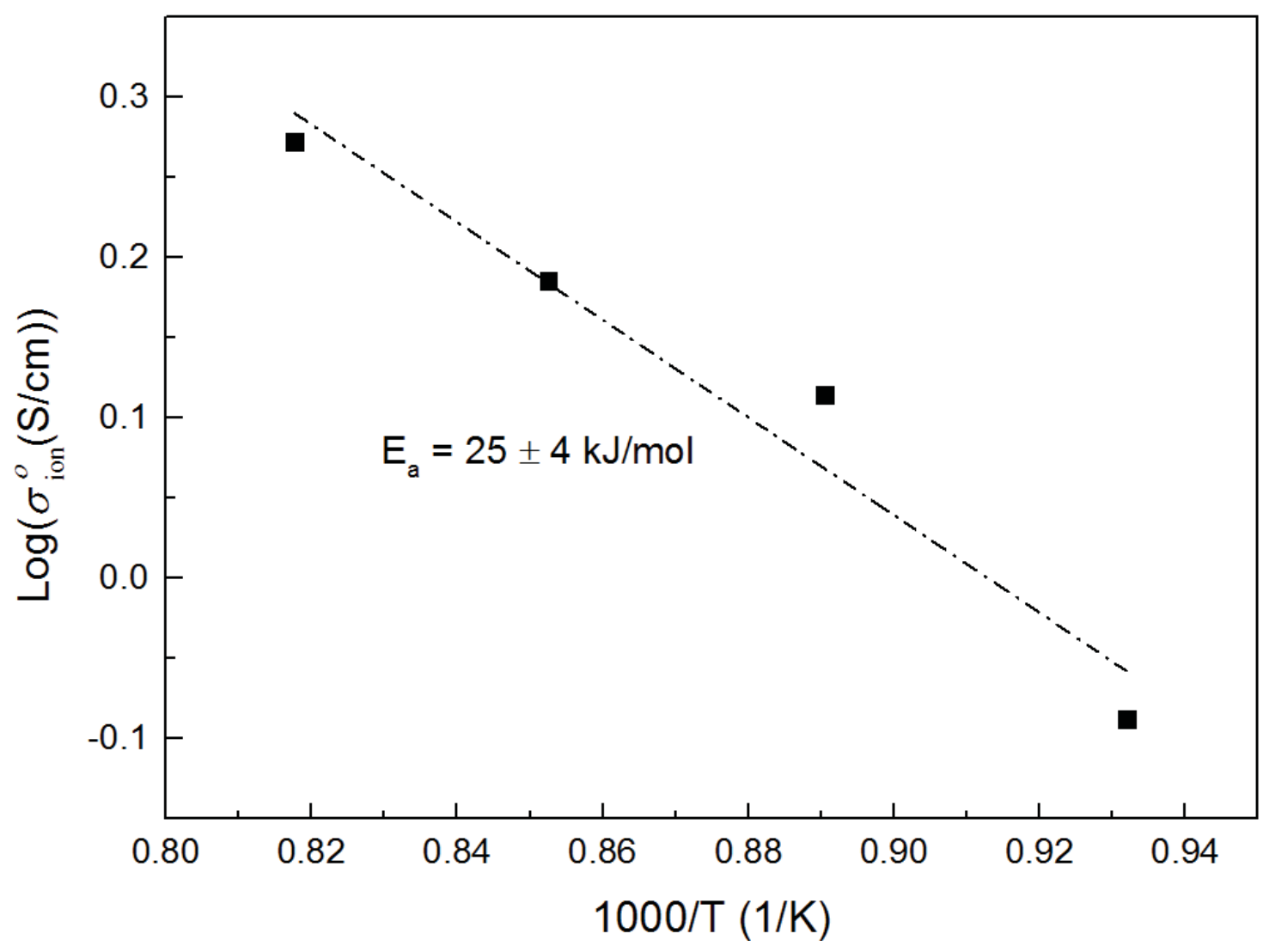

Figure 3.4. Temperature dependence of $\sigma_{\text {ion }}^{0}$ for SCF membrane. 
3.3.3 Parameters influencing the $P_{\mathrm{O}_{2}}$ distribution at the permeate side of the membrane

In order to compare the influence of different parameters on the $P_{\mathrm{O}_{2}}$ at the permeate side of the membrane, a reference case is required. In this reference case the following assumptions are made: (1) the distance between sweep gas inlet and membrane surface is $3 \mathrm{~mm}$; (2) helium is chosen as sweep gas with a flow rate of 60 $\mathrm{ml}$ (STP)/min; (3) the operating temperature is $900^{\circ} \mathrm{C}$; (4) oxygen ionic conductivity data are taken from Table $3.4\left(\sigma_{\text {ion }}{ }=1.53 \mathrm{~S} / \mathrm{cm}\right.$ and $\left.n=0.36\right)$. Other parameters are kept identical as given in Table 3.1. In the parametric study, the following cases had been investigated:

(1) The distance $D$ between sweep gas inlet and the membrane (Figure 3.2) was varied from 1 to $5 \mathrm{~mm}$ with a step size of $2 \mathrm{~mm}$.

(2) The sweep gas flow rate was varied from 30 to $90 \mathrm{ml} / \mathrm{min}$ (STP) with a step size of $30 \mathrm{ml} / \mathrm{min}$ (STP).

(3) When different sweep gases are used, the oxygen concentration profile in the reactor might be different because the diffusion coefficient between oxygen and the respective sweep gases is different (see table A3.1 in the appendix). In this parametric study, helium, argon, nitrogen and carbon dioxide were used as sweep gas.

\section{Effect of reactor geometry}

Due to direct flushing and the high velocity of the sweep gas in the inlet tube ( $1 \mathrm{~m} / \mathrm{s}$ at $900{ }^{\circ} \mathrm{C}$ when a flow rate of $60 \mathrm{ml} / \mathrm{min}$ is used), the $P_{\mathrm{O}_{2}}$ on the membrane surface is found to be higher at the edge (at the wall of the set-up) and lower at the center. Besides, the $P_{\mathrm{O}_{2}}$ on the membrane surface is higher than that far away from the surface. Both cases are strongly affected by the distance between the sweep gas inlet tube and the membrane surface $(D)$. As can be seen from Figure 3.5, a large $D$ 
seems to lead to a more homogenous oxygen partial pressure distribution.
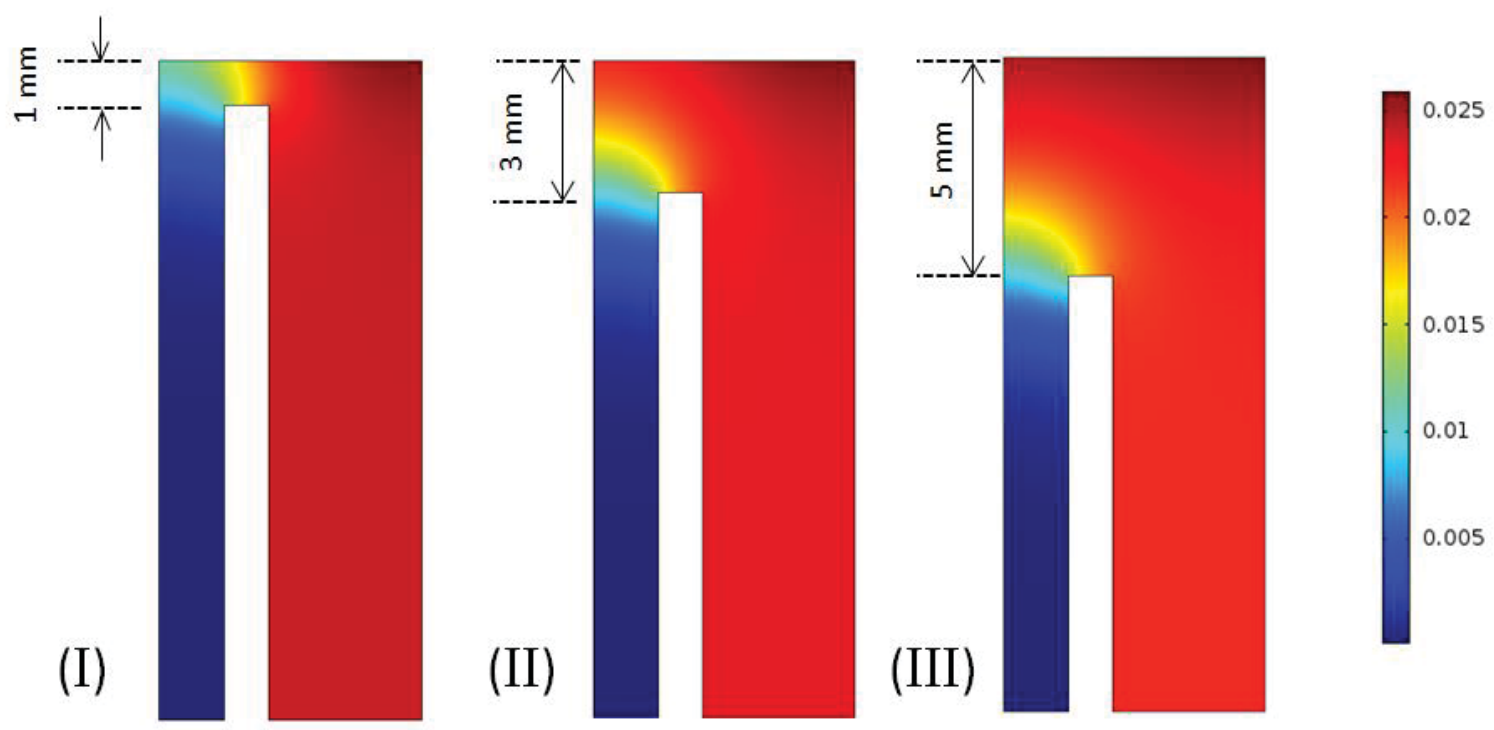

Figure 3.5. $P_{\mathrm{O}_{2}}$ (bar) in the permeation set-up as a function of $D$ (distance from sweep gas inlet to membrane surface), I, II and III resp.: $D=1,3$ and $5 \mathrm{~mm}$. Helium is used as sweep gas with a flow rate of $60 \mathrm{ml} / \mathrm{min}$.
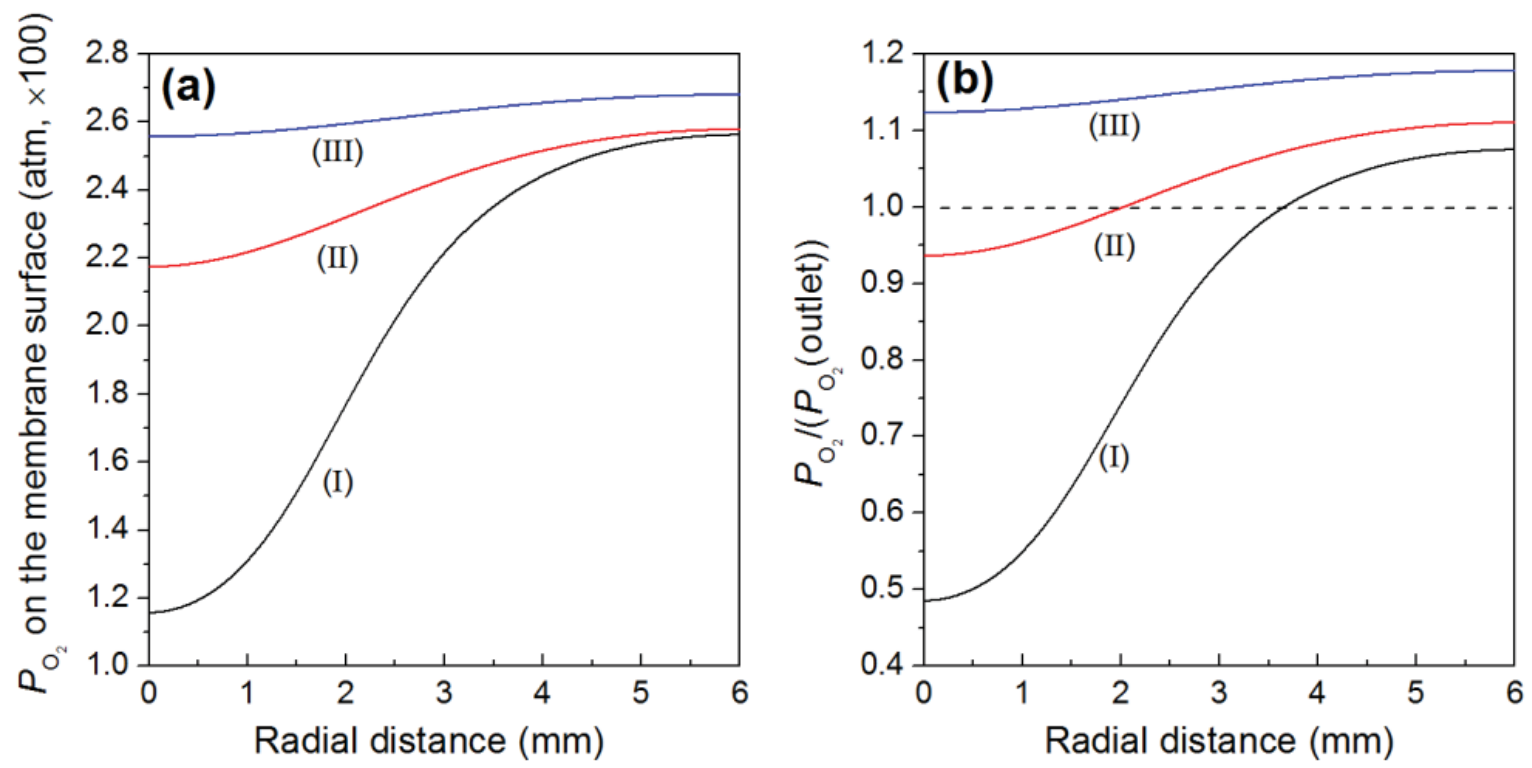

Figure 3.6. Influence of $D$ (distance from sweep gas inlet to membrane surface) on: (a) $P_{\mathrm{O}_{2}}$ on the membrane surface; (b) ratio of $P_{\mathrm{O}_{2}}$ on the membrane surface to that at the outlet of the set-up. I, II and III resp.: $D=1,3$ and $5 \mathrm{~mm}$. Helium is used as sweep gas with a flow rate of $60 \mathrm{ml} / \mathrm{min}$. Radial distance: distance from membrane center to edge.

For a quantitative description of the $P_{\mathrm{O}_{2}}$ profile on the membrane surface, a plot 
of $P_{\mathrm{O}_{2}}$ on the membrane surface against the radial distance (from membrane center to edge) is given in Figure 3.6a. It should be mentioned that the $P_{\mathrm{O}_{2}}$ on the membrane surface is defined as the $P_{\mathrm{O}_{2}}$ in the first mesh element layer from the membrane surface, which is around $3 \mu \mathrm{m}$. It can be seen from Figure 3.6a that the $P_{\mathrm{O}_{2}}$ on the membrane surface is more homogenous when a small $D(1 \mathrm{~mm})$ is used, for example, when $D$ is $1 \mathrm{~mm}$, the $P_{\mathrm{O}_{2}}$ at the edge of the membrane is $\sim 2.2$ times of that in the center, compared to a ratio of 1.04 when $D$ is $5 \mathrm{~mm}$.

Due to the lower gas velocities at the membrane surface in case of a large $\mathrm{D}$, the $\mathrm{O}_{2}$-concentration profile is more governed by the diffusive transport of the permeating oxygen than by the convective influence of the sweep gas and concentration polarization occurs In contrast, a small D causes higher sweep gas velocities at the membrane surface and therefore leads to a good transport of the permeating oxygen away from the surface. This affects also the permeation rate. When $D$ is chosen to be 1,3 and $5 \mathrm{~mm}$, the oxygen flux is calculated to be $1.30,1.26$ and $1.23 \mathrm{ml} / \mathrm{cm}^{2} / \mathrm{min}$, and it is obvious that a small $D$ increases the oxygen flux due to more effective sweeping.

Compared to the measured oxygen partial pressure at the outlet of the setup, we can see from Figure $3.6 \mathrm{~b}$, that when a large $D(5 \mathrm{~mm})$ is used, the $P_{\mathrm{O}_{2}}$ on the membrane surface is higher than that at the outlet of the setup, regardless of the radial distance; while, for smaller $D(1$ and $3 \mathrm{~mm})$, the $P_{\mathrm{O}_{2}}$ on the membrane surface is partly higher (at the membrane edge) and partly lower (membrane center) than that at the outlet of the setup. The average of this ratio is calculated to be $0.85,1.03$ and 1.15 for $D=1,3$ and $5 \mathrm{~mm}$, respectively, which suggests both large and small $D$ leads to a large deviation between $P_{\mathrm{O}_{2}}$ on the membrane surface and the value measured at the outlet of the set-up, while $D=3 \mathrm{~mm}$ seems to be a good selection in 
this study and in that case the CISTR assumption is rather realistic.

\section{Effect of sweep gas flow rate}

The effect of sweep gas flow rate on the $P_{\mathrm{O}_{2}}$ profile in the reactor is shown in Figure 3.7.

(I)

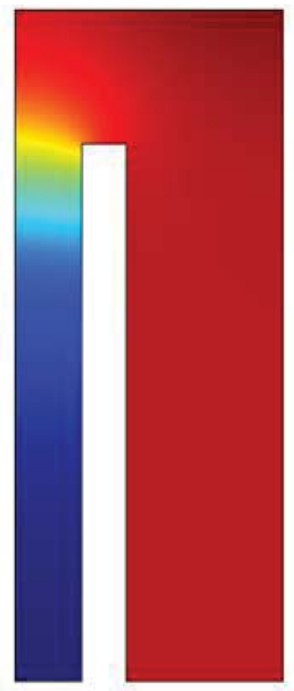

(II)

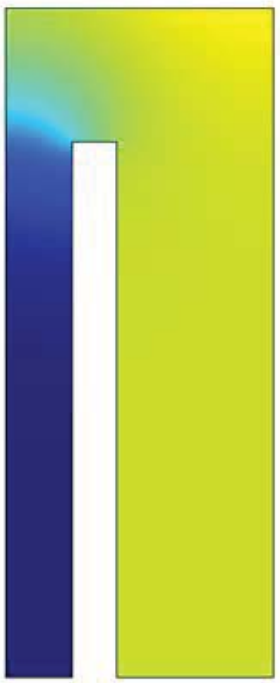

(III)

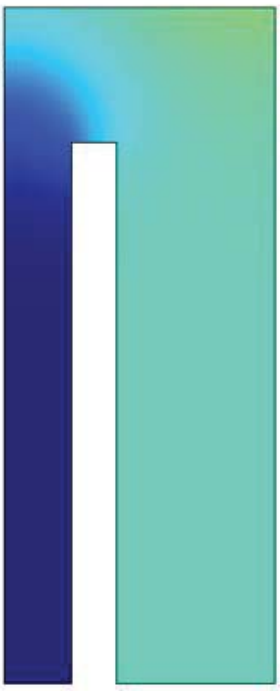

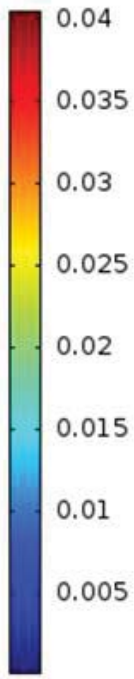

Figure 3.7. $P_{\mathrm{O}_{2}}$ (bar) in the permeation set-up as a function of helium flow rate, (I to III) helium flow rate: 30,60 and $90 \mathrm{ml} / \mathrm{min}$.
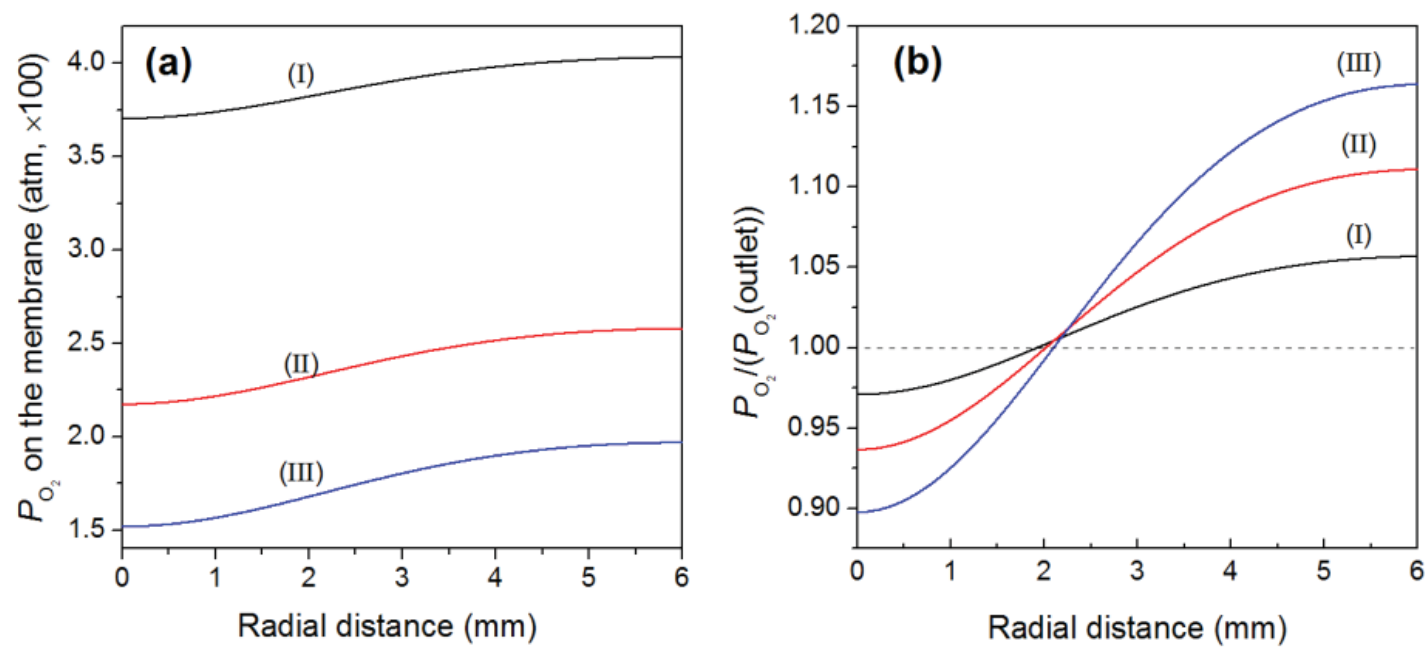

Figure 3.8. Influence of helium flow rate on: (a) $P_{\mathrm{O}_{2}}$ on the membrane surface; (b) ratio of $P_{\mathrm{O}_{2}}$ on the membrane surface to that at the outlet of the set-up. I, II and III resp.: 30, 60 and $90 \mathrm{ml} / \mathrm{min}$. Radial distance: distance from membrane center to edge. 
In the present study, helium is used as sweep gas. It can be seen that increasing the helium flow rate decreases the overall $P_{\mathrm{O}_{2}}$ within the reactor and therefore also on the membrane surface. It can be deduced from Figure $3.8 \mathrm{a}$ that $P_{\mathrm{O}_{2}}$ on the membrane surface is reduced from 3.7-4.0 bar to 1.5-1.9 bar when the helium flow rate increases from 30 to $90 \mathrm{ml} / \mathrm{min}$. A decrease in $P_{\mathrm{O}_{2}}$ on the membrane surface leads to an increase in driving force for oxygen flux, meaning a higher oxygen flux. As can be seen from Figure 3.8b, the difference of $P_{\mathrm{O}_{2}}$ at the membrane surface and at the outlet of the reactor is getting bigger when a higher helium flow rate is applied.

\section{Effect of sweep gas type}

In most cases inert gases such as helium, argon, nitrogen or non-inert gases like $\mathrm{CO}_{2}$ are used as sweep gas to study the oxygen permeation of dense membranes [2, 10-12]. One must be aware of the fact that diffusion of oxygen into the sweep gas is different for different gases. According to the Chapman-Enskog's theory (see appendix), the diffusion coefficient for binary gas system is mainly affected by the molecular weight differences between the gases (see eq. (3.7) in appendix). For example, the diffusion coefficients of oxygen in helium $\left(7.20 \times 10^{-4} \mathrm{~m}^{2} / \mathrm{s}\right)$ at $900{ }^{\circ} \mathrm{C}$ is more than 3 times higher than that of oxygen in argon $\left(2.12 \times 10^{-4} \mathrm{~m}^{2} / \mathrm{s}\right)$, indicating that diffusion of oxygen into helium is much faster than oxygen into argon. Therefore a faster mixing between the oxygen/helium is expected than that between the oxygen/argon. Figures 3.9 and 3.10 give the simulation results when different sweep gases are used. It is clear that the gas mixing, as well as the $P_{\mathrm{O}_{2}}$ homogeneousness on the membrane surface, is strongly affected by the sweep gas type. For example, when argon is used as sweep gas, the $P_{\mathrm{O}_{2}}$ at the edge of the membrane is $111 \%$ higher than that in the center, compared to only $18 \%$ when helium is used as sweep gas. When helium is used as sweep gas, the ratio of $P_{\mathrm{O}_{2}}$ on the membrane surface versus $P_{\mathrm{O}_{2}}$ at 
the outlet of the permeation set-up is the smallest, indicating best mixing. Due to the faster diffusive oxygen transport away from the membrane surface with higher binary diffusion coefficients concentration polarization decreases. The permeation rate therefore reaches its highest value when using He as sweep gas $\left(1.26 \mathrm{ml} / \mathrm{cm}^{2} / \mathrm{min}\right)$, compared with $1.23,1.23$ and $1.22 \mathrm{ml} / \mathrm{cm}^{2} / \mathrm{min}$ for $\mathrm{N}_{2}, \mathrm{Ar}$ and $\mathrm{CO}_{2}$ as sweep gas, respectively.

(I)

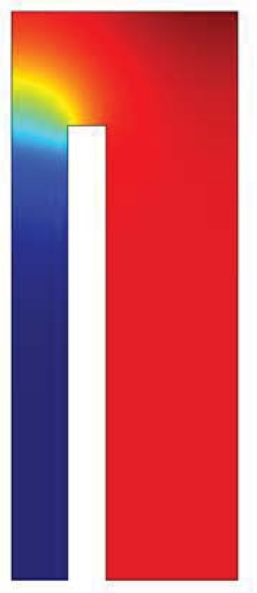

(II)

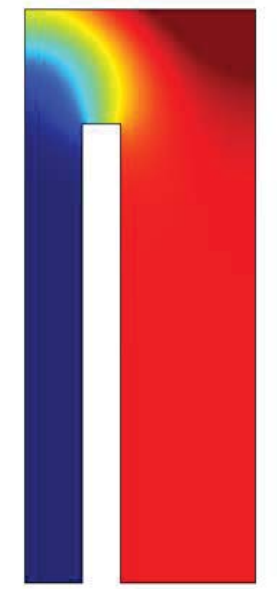

(III)

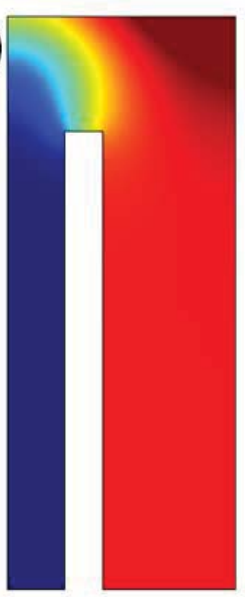

(IV)

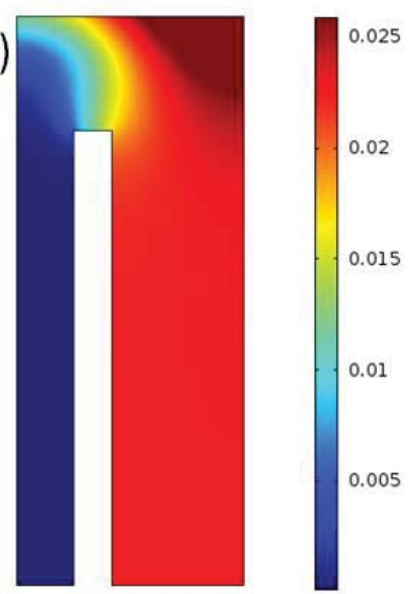

Figure 3.9. $P_{\mathrm{O}_{2}}$ (bar) in the permeation set-up when different sweep gas is used, I, II, III and IV resp.: $\mathrm{He}, \mathrm{N}_{2}$, Ar and $\mathrm{CO}_{2}$. Sweep gas flow rate: $60 \mathrm{ml} / \mathrm{min}$.
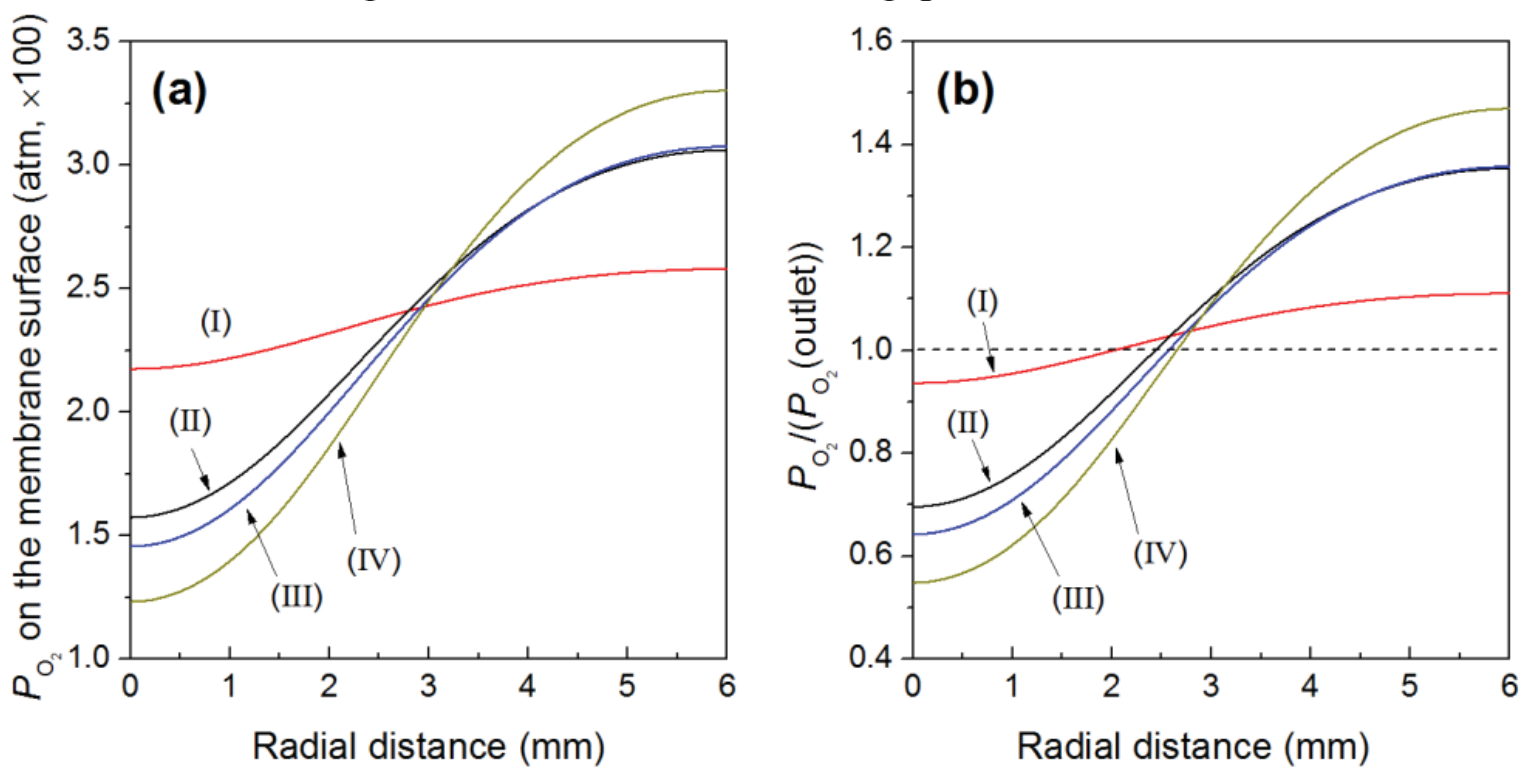

Figure 3.10. Influence of different sweep gases on: (a) $P_{\mathrm{O}_{2}}$ on the membrane surface; (b) ratio of $P_{\mathrm{O}_{2}}$ on the membrane surface to that at the outlet of the set-up. I, II and III resp.: 
$\mathrm{He}, \mathrm{N}_{2}, \mathrm{Ar}$ and $\mathrm{CO}_{2}$. Sweep gas flow rate: $60 \mathrm{ml} / \mathrm{min}$. Radial distance: distance from membrane center to edge.

\subsection{Conclusions}

A CFD model is developed to describe the oxygen transport in a commonly used lab-scale oxygen permeation set-up. The oxygen ionic conductivity of the SCF membranes is obtained by fitting the oxygen permeation data with the aid of a CFD model, while no CISTR assumption is required. It is found from the CFD simulation that the $P_{\mathrm{O}_{2}}$ directly on the membrane surface differs from that obtained by measuring the $P_{\mathrm{O}_{2}}$ at the outlet. Furthermore, the fact that the $P_{\mathrm{O}_{2}}$ on the membrane surface is not homogeneous emphasizes the difficulty of using the CISTR assumption for determining the ionic conductivity from permeation measurements. Using the membrane's surface partial pressures determined by CFD simulations leads to a smaller oxygen ionic conductivity as when calculating the ionic conductivity under the CISTR assumption.

The influence of different parameters, such as the distance from sweep gas inlet to the membrane surface, the sweep gas flow rate and the sweep gas type, has been studied, and the following results were found:

(1) The distance from sweep gas inlet to the membrane surface affects the $P_{\mathrm{O}_{2}}$ in both radial direction and axial direction. At increasing distance the $P_{\mathrm{O}_{2}}$ on the membrane surface becomes more homogenous due to the lower sweep gas velocity at the surface, causing less convection. However, when the distance is too large, the overall $P_{\mathrm{O}_{2}}$ on the membrane surface will be much higher than that measured at the outlet of the set-up.

(2) The binary diffusion coefficient in the oxygen-sweep gas mixture has a strong influence on the concentration distribution in the setup. Higher diffusion coefficients lead to a better mixing and therefore a faster transport of the oxygen away from the 
membrane surface. Faster mixing leads to a more homogeneous oxygen partial pressure distribution in the setup. Helium as sweep gas gives the highest diffusion coefficient and results in the most homogeneous oxygen partial pressure distribution in the setup, if compared with gases like $\mathrm{N}_{2}, \mathrm{Ar}$ of $\mathrm{CO}_{2}$.

(3) A higher sweep gas flow rate decreases the overall $P_{\mathrm{O}_{2}}$ at the permeate side of the membrane, thus increasing the oxygen flux, which makes the $P_{\mathrm{O}_{2}}$ on the membrane surface less homogenous. This influence is relatively small compared with the geometry change of the setup and sweep gas composition. 


\subsection{Appendix}

3.5.1 Calculation of the diffusion coefficient of a gas mixture

For a binary gas system, the diffusion coefficient can be estimated by ChapmanEnskog's equation:

$$
D=\frac{1.86 \times 10^{-3} T^{3 / 2} \sqrt{\frac{1}{M_{1}}+\frac{1}{M_{2}}}}{P \sigma_{12}^{2} \Omega}
$$

where $D$ is the diffusion coefficient for the gas mixture; $\mathrm{M}_{i}$ the molar mass for gas $i$; $\sigma_{12}=\frac{\sigma_{1}+\sigma_{2}}{2}$ the average collision diameter (Lennard-Jones characteristic length); $\mathrm{T}$ the temperature; $\mathrm{P}$ the pressure and $\Omega$ a dimensionless temperature-dependent collision integral. Results of several diffusion coefficients, using this equation, are given in table A3.1.

Table A3.1. Calculated gas diffusion coefficient at 1 bar. Values for $\sigma_{12}$ and $\Omega$ can be found in Hirschfelder's book [13].

\begin{tabular}{ccccc}
\hline & \multicolumn{4}{c}{ Diffusion coefficient $\left(\mathrm{m}^{2} / \mathrm{s}, \times 10^{-4}\right)$} \\
Temperature (K) & $\mathrm{He}-\mathrm{O}_{2}$ & $\mathrm{~N}_{2}-\mathrm{O}_{2}$ & $\mathrm{Ar}-\mathrm{O}_{2}$ & $\mathrm{CO}_{2}-\mathrm{O}_{2}$ \\
\hline 1073 & 6.21 & 1.77 & 1.71 & 1.24 \\
1123 & 6.70 & 1.91 & 1.84 & 1.34 \\
1173 & 7.20 & 2.05 & 1.98 & 1.44 \\
1223 & 7.71 & 2.19 & 2.12 & 1.55 \\
1273 & 8.25 & 2.35 & 2.26 & 1.65 \\
\hline
\end{tabular}

3.5.2 Calculation of the viscosity of single and mixed gases

Calculation of the viscosity of a single gas

The viscosity of a single gas at a certain temperature and pressure is usually easy 
to find in handbooks. There is a small change in viscosity with pressure but a relative larger change in viscosity with temperature. The relationship between viscosity and temperature can be described by Sutherland's law[14]:

$$
\mu=\mu_{0} \frac{T_{0}+C}{T+C}\left(\frac{T}{T_{0}}\right)^{3 / 2}
$$

This in turn is equal to

$$
\mu=\lambda \frac{T^{3 / 2}}{T+C}
$$

where $\lambda=\frac{\mu_{0}\left(T_{0}+C\right)}{T_{o}^{3 / 2}}$ is a constant for the gas.

Table A3.2. Sutherland's constant, reference values and $\lambda$ values for some gases [15]:

\begin{tabular}{ccccc}
\hline Gas & $C[\mathrm{~K}]$ & $T_{0}[\mathrm{~K}]$ & $\mu_{0}[\mu \mathrm{Pa} \mathrm{s}]$ & $\lambda\left[\mu \mathrm{Pa} \mathrm{s} \mathrm{K}^{-1 / 2}\right]$ \\
\hline air & 120 & 291.15 & 18.27 & 1.51 \\
$\mathrm{~N}_{2}$ & 111 & 300.55 & 17.81 & 1.41 \\
$\mathrm{O}_{2}$ & 127 & 292.25 & 20.18 & 1.69 \\
$\mathrm{CO}_{2}$ & 240 & 293.15 & 14.8 & 1.57 \\
$\mathrm{CO}$ & 118 & 288.15 & 17.2 & 1.43 \\
$\mathrm{H}_{2}$ & 72 & 293.85 & 8.76 & 0.64 \\
$\mathrm{NH}_{3}$ & 370 & 293.15 & 9.82 & 1.30 \\
$\mathrm{SO}_{2}$ & 416 & 293.65 & 12.54 & 1.77 \\
$\mathrm{He}$ & 79.4 & 273 & 19 & 1.48 \\
\hline
\end{tabular}

\subsubsection{Calculation of the viscosity of mixed gases}

The viscosity of a gas mixture can be calculated according to Sutherland-Thiesen equation [16]: 


$$
\mu_{\mathrm{m}}=\sum_{i=1}^{n} \frac{\mu_{i}}{1+\frac{1.385 \mu_{1}}{x_{i} \rho_{i}} \sum_{\substack{j=1 \\ j \neq i}}^{n} \frac{x_{i}}{D_{i j}}}
$$

In case of a binary gas system, eq. (3.9) can be written:

$$
\mu_{\mathrm{m}}=\frac{\mu_{1}}{1+\frac{x_{1}}{x_{2}} \frac{1.385 \mu_{1}}{D_{12} \rho_{1}}}+\frac{\mu_{2}}{1+\frac{x_{2}}{x_{1}} \frac{1.385 \mu_{2}}{D_{12} \rho_{2}}}
$$

where $\mu_{i}$ is the viscosity of gas $i ; x_{i}$ is the mole fraction of gas $i$; $\mathrm{D}_{i j}$ is the diffusion coefficient between gas $i$ and $j$; $\rho_{i}$ is the density of gas $i$ and $\mu_{\mathrm{m}}$ is the viscosity of the gas mixture.

\section{References}

[1] J.J. Liu, S.Q. Zhang, W.D. Wang, J.F. Gao, W. Liu, C.S. Chen, Partial oxidation of methane in a $\mathrm{Zr}_{0.84} \mathrm{Y}_{0.16} \mathrm{O}_{1.92}-\mathrm{La}_{0.8} \mathrm{Sr}_{0.2} \mathrm{Cr}_{0.5} \mathrm{Fe}_{0.5} \mathrm{O}_{3-\delta}$ hollow fiber membrane reactor targeting solid oxide fuel cell applications, J Power Sources, 217 (2012) 287-290.

[2] W. Chen, C.-S. Chen, L. Winnubst, Ta-doped $\mathrm{SrCo}_{0.8} \mathrm{Fe}_{0.2} \mathrm{O}_{3-\delta}$ membranes: Phase stability and oxygen permeation in $\mathrm{CO}_{2}$ atmosphere, Solid State Ionics, 196 (2011) 30-33.

[3] B. Metz, O. Davidson, H.d. Coninck, M. Loos, L. Meyer, IPCC Special Report on Carbon Dioxide Capture and Storage, Intergovernmental Panel on Climate Change, (2005).

[4] Y. Teraoka, H.-M. Zhang, S. Furukawa, N. Yamazoe, Oxygen permeation through perovskite-type oxides, Chemistry Letter, 14 (1985) 1743-1746.

[5] C.H. Chen, H. Kruidhof, H.J.M. Bouwmeester, A.J. Burggraaf, Ionic conductivity of perovskite $\mathrm{LaCoO}_{3}$ measured by oxygen permeation technique, Journal of Applied Electrochemistry, 27 (1997) 71-75.

[6] J.M. Gozálvez-Zafrilla, A. Santafé-Moros, S. Escolástico, J.M. Serra, Fluid dynamic modeling of oxygen permeation through mixed ionic-electronic conducting membranes, Journal of Membrane Science, 378 (2011) 290-300.

[7] H.J.M. Bouwmeester, A.J. Burggraaf, The CRC Handbook of Solid State Electrochemistry, 1 ed., CRC Press, 1996.

[8] W. Chen, Y.B. Zuo, C.S. Chen, A.J.A. Winnubst, Effect of $\mathrm{Zr}^{4+}$ doping on the oxygen stoichiometry and phase stability of $\mathrm{SrCo}_{0.8} \mathrm{Fe}_{0.2} \mathrm{O}_{3-\delta}$ oxygen separation membrane, Solid State Ionics, 181 (2010) 971-975.

[9] L. Qiu, T.H. Lee, L.M. Liu, Y.L. Yang, A.J. Jacobson, Oxygen Permeation Studies of 
$\mathrm{SrCo}_{.8} \mathrm{Fe}_{0.2} \mathrm{O}_{3-\delta}$, Solid State Ionics, 76 (1995) 321-329.

[10] G. Etchegoyen, T. Chartier, P. Del-Gallo, An architectural approach to the oxygen permeability of a La0.6 $\mathrm{Sr}_{0.4} \mathrm{Fe}_{0.9} \mathrm{Ga}_{0.1} \mathrm{O}_{3-\delta}$ perovskite membrane, J Eur Ceram Soc, 26 (2006) 2807-2815.

[11] V. Esposito, M. Søgaard, P.V. Hendriksen, Chemical stability of $\mathrm{La}_{0.6} \mathrm{Sr}_{0.4} \mathrm{CoO}_{3-\delta}$ in oxygen permeation applications under exposure to $\mathrm{N}_{2}$ and $\mathrm{CO}_{2}$, Solid State Ionics, 227 (2012) 46-56.

[12] M.P. Lobera, J.M. Serra, S.P. Foghmoes, M. Søgaard, A. Kaiser, On the use of supported ceria membranes for oxyfuel process/syngas production, Journal of Membrane Science, 385-386 (2011) 154-161.

[13] J.O.Hirschfelder, C.F.Curtiss, R.B.Bird, Molecular Theory of Gases and Liquids, Molecular Theory of Gases and Liquids, (1954).

[14] W. Sutherland, LII. The viscosity of gases and molecular force, Philosophical Magazine Series 5, 36 (1893) 507-531.

[15] M. White, Viscous fluid flow, McGraw-Hill, Inc., 1991.

[16] J.W. Buddenberg, C.R. Wilke, Calculation of Gas Mixture Viscosities, Industrial \& Engineering Chemistry, 41 (1949) 1345-1347. 


\title{
Chapter 4 Ta-doped $\mathrm{SrCo}_{0.8} \mathrm{Fe}_{0.2} \mathrm{O}_{3-\delta}$ membranes: Phase stability and oxygen permeation in $\mathrm{CO}_{2}$ atmosphere
}

\begin{abstract}
:
The chemical and structural stability of perovskite-derived $\mathrm{SrCo}_{0.8} \mathrm{Fe}_{0.2} \mathrm{O}_{3-\delta}$ (SCF) and $\mathrm{Sr}\left(\mathrm{Co}_{0.8} \mathrm{Fe}_{0.2}\right)_{0.9} \mathrm{Ta}_{0.1} \mathrm{O}_{3-\delta}$ (SCFTa) were investigated by both isothermal gravimetric analysis (TGA) and X-Ray diffraction (XRD). It was shown that the reaction between $\mathrm{SCF}$ and $\mathrm{CO}_{2}$ at elevated temperature is almost negligible when $\mathrm{Ta}$ is doped to SCF. XPS analysis shows that the basicity of SCFTa is less than that of SCF, which may be contributed to the enhanced stability of SCFTa in $\mathrm{CO}_{2}$ atmosphere. $\mathrm{Ta}^{5+}$ also increases the perovskite phase stability of SCF in low oxygen partial pressure $\left(\mathrm{pO}_{2}<10^{-2} \mathrm{~atm}\right)$, which was proven by the disappearance of a strong shrinkage signal during thermal expansion measurements. In the oxygen permeation measurement, the oxygen flux of SCFTa was slightly lower than that of SCF when an air-helium gradient was applied over the membrane, but it remained almost the same when pure $\mathrm{CO}_{2}$ was introduced as sweep gas, while, the oxygen flux of SCF dropped drastically at first and decreased to zero after 60 hours in the $\mathrm{CO}_{2}$ atmosphere.
\end{abstract}

This chapter has been published as:

W. Chen, C.-S. Chen, L. Winnubst, Ta-doped $\mathrm{SrCo}_{0.8} \mathrm{Fe}_{0.2} \mathrm{O}_{3-\delta}$ membranes: Phase stability and oxygen permeation in $\mathrm{CO}_{2}$ atmosphere, Solid State Ionics, 196 (2011) 30-33. 


\subsection{Introduction}

One of the reasons for global warming is the massive anthropogenic emission of $\mathrm{CO}_{2}$, which arises mainly from use of fossil fuels. It has been proposed that burning fossil fuels with $\mathrm{CO}_{2}$-diluted $\mathrm{O}_{2}$ produces a concentrated $\mathrm{CO}_{2}$ gas stream and thus enables efficient $\mathrm{CO}_{2}$ capture $[1,2]$. To improve the economic competiveness of this oxy-fuel combustion technique, there are substantial efforts in developing ceramic oxygen separation membranes that have a potential to reduce the oxygen production cost by one third over the present cryogenic air separation process [3]. It is reported that the $\mathrm{O}_{2} / \mathrm{CO}_{2}$ mixture, necessary for combustion, could be supplied by using $\mathrm{CO}_{2}$ as sweep gas for the transport of oxygen through a Mixed Ionic and Electronic Conductor (MIEC) membrane [4-6]. The MIEC usually has the oxygen deficient perovskite structure $\left(\mathrm{ABO}_{3-\delta}\right)$, in which oxygen ions are transported via hopping of oxygen vacancies, while electrons are conducted along the B-O-B network. Several new materials have been explored from which $\mathrm{SrCo}_{0.8} \mathrm{Fe}_{0.2} \mathrm{O}_{3-\delta}$ (SCF) is regarded as one of the most promising material. However, SCF has been reported to undergo a phase transition from cubic perovskite to orthorhombic brownmillerite below $790^{\circ} \mathrm{C}$. Moreover, because of the presence of the alkaline-earth element Sr, SCF is very sensitive to acidic gasses like $\mathrm{CO}_{2}$. Yi et al. showed that exposure of SCF to an atmosphere containing $5 \% \mathrm{CO}_{2}$ at $810^{\circ} \mathrm{C}$ resulted in the decomposition and partial failure of the membrane [7]. Zeng et al. also found that SCF completely decomposed after annealing in $\mathrm{CO}_{2}$ at $950^{\circ} \mathrm{C}[8]$.

Recently, high valence ions such as $\mathrm{Ti}^{4+}$ and $\mathrm{Ta}^{5+}$ have been reported to have positive effect on the phase stability and $\mathrm{CO}_{2}$ tolerance of some MIECs. Zeng et al. have found that Ti doping considerably decreased the reaction between $\mathrm{CO}_{2}$ and SCF [8], while Wang's group has been reported that introduction of Ta into $\mathrm{SrCoO}_{3-\delta}$ improves phase stability and reversibility in air [9], and $\mathrm{Ta}$ containing $\mathrm{BaCo}_{0.7} \mathrm{Fe}_{0.2} \mathrm{Ta}_{0.1} \mathrm{O}_{3-\delta}$ also exhibits high stability, high permeability and a low thermal expansion coefficient [10]. Bi et al. also found that partial substitution of $\mathrm{Ce}$ by $\mathrm{Ta}$ 
strongly increased the chemical stability of $\mathrm{BaCe}_{0.8} \mathrm{Y}_{0.2} \mathrm{O}_{3-\delta}$ against $\mathrm{CO}_{2}$ [11], and they claimed that the relatively high electronegativity of Ta decreased the basicity of $\mathrm{BaCe}_{0.8} \mathrm{Y}_{0.2} \mathrm{O}_{3-8}$, and consequently increased the chemical stability in a $\mathrm{CO}_{2}$ environment. So it is reasonable to make the assumption that partial substitution of the B-site $\mathrm{Co}$ and $\mathrm{Fe}$ in SCF by Ta may increase its phase stability and $\mathrm{CO}_{2}$ tolerance.

In this work, $10 \%$ of the Co and Fe cations in SCF were substituted by Ta, aiming to increase to the stability of SCF in $\mathrm{CO}_{2}$ atmosphere. Both isothermal gravimetric and XRD were used to study the effect of Ta doping on phase stability, while oxygen permeation measurements were performed to examine permeation performance under operating conditions.

\subsection{Experimental}

$\mathrm{SrCo}_{0.8} \mathrm{Fe}_{0.2} \mathrm{O}_{3-\delta} \quad(\mathrm{SCF})$ and $\mathrm{Sr}\left(\mathrm{Co}_{0.8} \mathrm{Fe}_{0.2}\right)_{0.9} \mathrm{Ta}_{0.1} \mathrm{O}_{3-\delta} \quad$ (SCFTa) powders were synthesized using an EDTA complexation/pyrolysis process [12]. Required quantity of $\mathrm{SrCO}_{3}$ were dissolved in diluted nitric acid and appropriate amounts of $\mathrm{Co}\left(\mathrm{NO}_{3}\right)_{2}$, $\mathrm{Fe}\left(\mathrm{NO}_{3}\right)_{3}$ solutions and EDTA (metal-cation: EDTA=1:1) were added. The $\mathrm{pH}$ of the solution was adjusted to 2 with ammonia and finally $\mathrm{Ta}_{2} \mathrm{O}_{5}$ was added. The mixture was evaporated at $80^{\circ} \mathrm{C}$ while stirring until a viscous resin was obtained and subsequently heated on a hot plate, resulting in a rapid and vigor auto-ignition. The resultant powder was calcined at $1000^{\circ} \mathrm{C}$ for $5 \mathrm{~h}$. The calcined powders were pressed uni-axially at $4 \mathrm{MPa}$ into disk shapes, subsequently cold isostatically pressed at $300 \mathrm{Mpa}$, and sintered in ambient air at $1200^{\circ} \mathrm{C}(\mathrm{SCF})$ or $1237^{\circ} \mathrm{C}(\mathrm{SCFTa})$ for $15 \mathrm{~h}$.

Densities of the sintered samples were determined using Archimedes method in mercury. The phase composition was analyzed using XRD (Philips X'Pert Pro Super, $\mathrm{Cu} \mathrm{K} \alpha$ ). The O1s XPS spectra of as-calcined powders were measured using an ESCALAB MK II, VG equipment, and analyzed with the Gaussian peaks software. Isothermal gravimetric analyses were carried out in a home-built apparatus equipped with an analytical balance. About $1 \mathrm{~g}$ of powder was placed in a quartz sample holder suspended from the bottom of the balance with a hooked quartz stick, and was heated 
in flowing air to $900^{\circ} \mathrm{C}$. When the sample mass reached a constant value at $900^{\circ} \mathrm{C}$, a $\mathrm{CO}_{2}$ stream was introduced instead of air and the mass change was recorded and sampled by a computer.

Thermal expansion measurements were conducted using a dilatometer (NETZSCH DIL 402C) at a heating/cooling rate $3{ }^{\circ} \mathrm{C}$. First, sintered SCF and SCFTa samples were heated to $1000^{\circ} \mathrm{C}$ in nitrogen $\left(p \mathrm{O}_{2} \sim 10^{-4} \mathrm{~atm}\right)$ and then cooled to room temperature also in nitrogen. After that, the as-annealed samples were heated to $1000^{\circ} \mathrm{C}$ again in nitrogen and the thermal expansion was recorded.

The experimental setup for oxygen permeation measurements is schematically shown in Figure 4.1. Disk-shaped samples with a diameter of $15 \mathrm{~mm}$ and a relative density $>90 \%$ were polished to a thickness of $1 \mathrm{~mm}$ and ultrasonically cleaned in ethanol. The membranes were sealed to one end of an alumina tube at $1020^{\circ} \mathrm{C}$ using a glass ring as sealant. After sealing, the temperature was lowered to $900^{\circ} \mathrm{C}$, and air was fed to one side of the sample $(100 \mathrm{ml} / \mathrm{min})$, while $\mathrm{He}$ or $\mathrm{CO}_{2}(50 \mathrm{ml} / \mathrm{min})$ was led over the other (permeate) side to carry away the permeated oxygen. The composition of the effluent stream at the permeate side was analyzed by an online gas chromatograph (Ke Xiao instrument China GC-1690T). The oxygen flux was corrected for any oxygen leakage through the glass sealant or imperfection in the pellet by measuring the concentration of nitrogen in the effluent stream. The amount of leakage oxygen is typically less than $5 \%$ of the total amount of the permeated oxygen. 


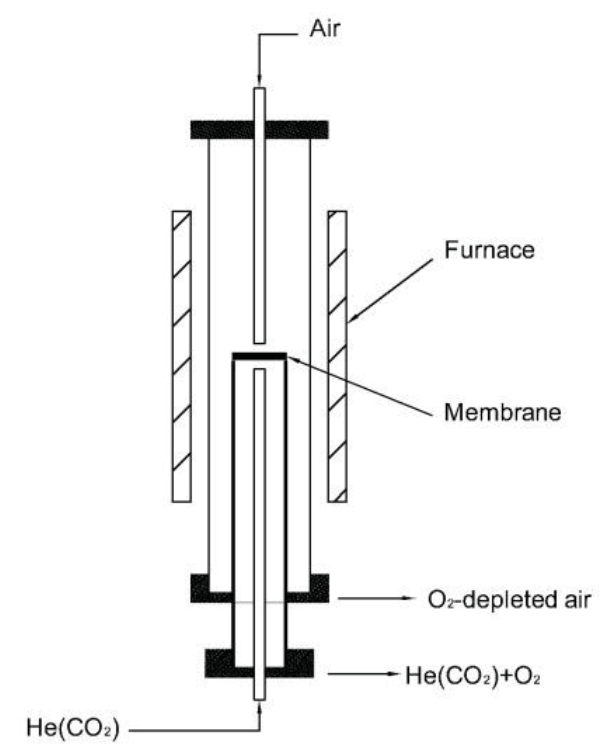

Figure 4.1. Schematic diagram of the high temperature permeation setup

\subsection{Results and Discussion}

\subsubsection{Phase composition and thermal expansion}

Figure 4.2 shows the room temperature XRD patterns of as-calcined SCF and SCFTa powders. The XRD patterns can be indexed as cubic perovskite, and there is no evidence of second phase, indicating that a phase pure perovskite structure can be obtained by the synthesis method described above. 


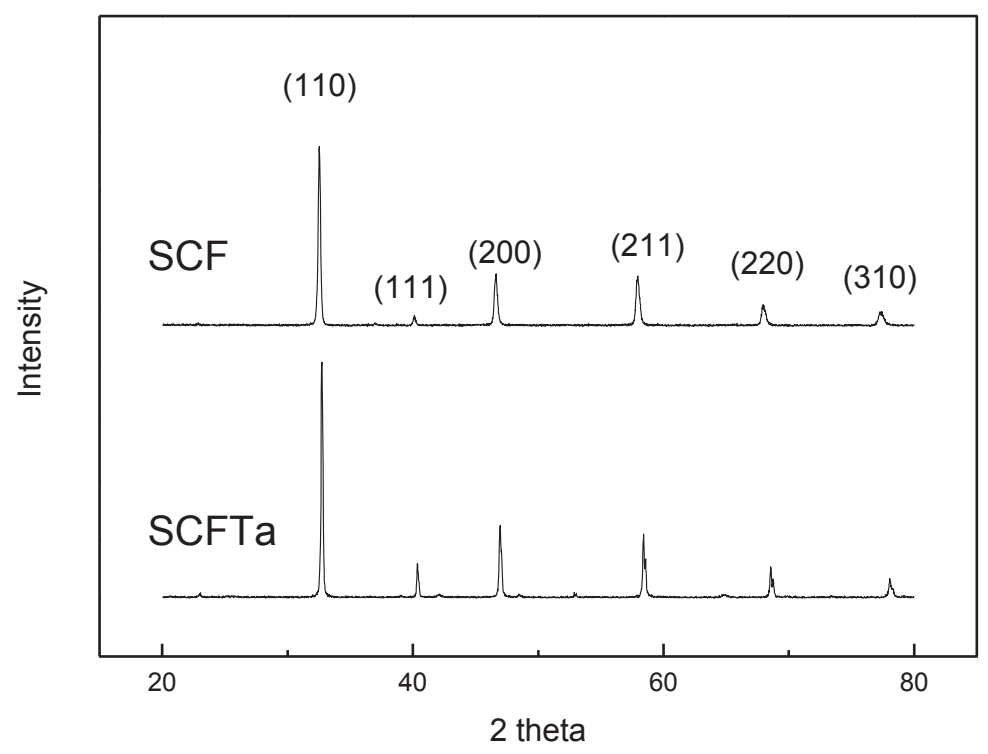

Figure 4.2. XRD patterns of as-calcined SCF and SCFTa. All peaks are indexed in cubic setting

For SCF, it is well known that, during heating, a phase transition from the brownmillerite to the perovskite crystal structure occurs around $790^{\circ} \mathrm{C}$ when $p \mathrm{O}_{2}$ is less than $10^{-2}$ atm [13-16], accompanied by a sudden volume decrease of more than $1 \%$ which may result in cracking of the membrane. Because of the sudden expansion during the formation of the perovskite crystal structure, analyzing the thermal expansion as function of temperature is a simple tool for detecting whether a membrane experiences this phase transition. Such a sudden expansion is even better visible when the derivative of the expansion as function of temperature is depicted. Thermal expansion measurements for both SCF and SCFTa were conducted and the results are shown in Figure 4.3. A sudden large shrinkage for un-doped SCF at around $760^{\circ} \mathrm{C}$ is observed which can be identified as the phase transition from the orthorhombic brownmillerite to the cubic perovskite structure. In previous work [17], we have found that addition of $\mathrm{Zr}$ increases the phase stability of SCF in a nitrogen atmosphere and decreases the volume change. However, still a small change in thermal expansion occurs when $4 \% \mathrm{Zr}$ (the solubility limit in SCF) was added. While, no such shrinkage is observed for SCFTa (see Figure 4.3), suggesting that Ta 
doping can completely prevent the phase transition.

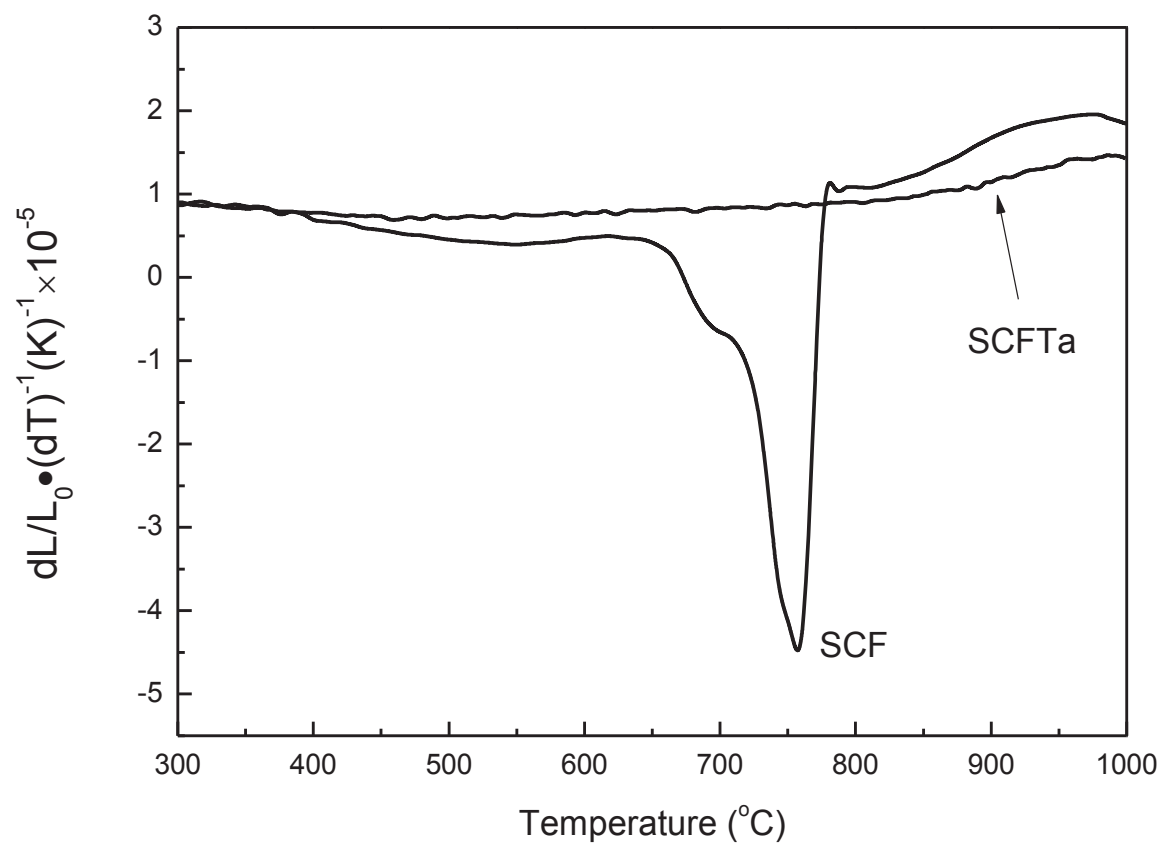

Figure 4.3. Derivative of the expansion as function of temperature of SCF and SCFTa (in nitrogen)

\subsubsection{Effect of Ta-doping on the reaction between SCF powders and $\mathrm{CO}_{2}$}

Isothermal gravimetric analysis of SCF and SCFTa powders in $\mathrm{CO}_{2}$ atmosphere at $900^{\circ} \mathrm{C}$ are given in Figure 4.4. The mass of the SCF powder immediately increased upon exposure to pure $\mathrm{CO}_{2}$ at $900^{\circ} \mathrm{C}$, resulting in a mass gain of $14.5 \%$ after 18 hours. While the Ta-doped SCF powder showed a slight increase in mass of only $1.7 \%$ after 17 hours of $\mathrm{CO}_{2}$ exposure. Obviously, the reaction between $\mathrm{SCF}$ and $\mathrm{CO}_{2}$ is largely restrained by the doping of Ta to SCF. After the isothermal gravimetric analysis, the samples were cooled to room temperature in $\mathrm{CO}_{2}$ atmosphere and $\mathrm{X}$-ray powder diffraction measurements were conducted to study the phase composition. The results given in Figure 4.5 show that the SCF sample completely decomposed into strontium carbonates and iron/cobalt oxides, which is in accordance with the work of Rui [18] and Yang [19]. For the Ta-doped SCF, only a small amount of $\mathrm{SrCO}_{3}$ was present but this could be regarded as an extremely small amount, while 
the perovskite structure of SCFTa was largely preserved.

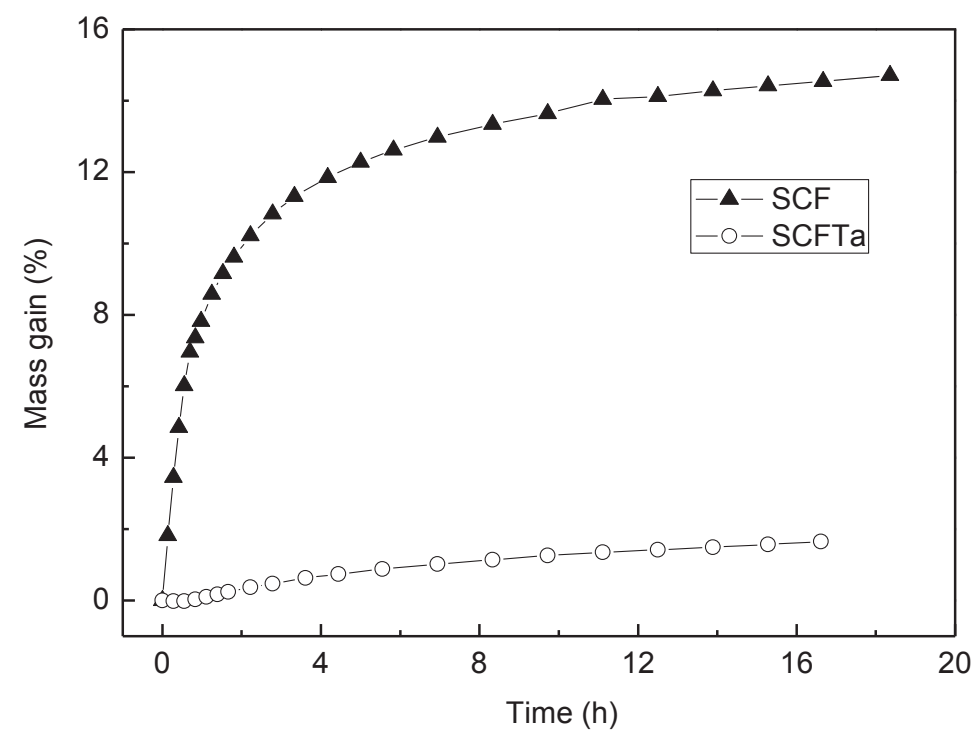

Figure 4.4. Mass change of SCF and SCFTa powder samples upon exposure to $\mathrm{CO}_{2}$ at $900^{\circ} \mathrm{C}$

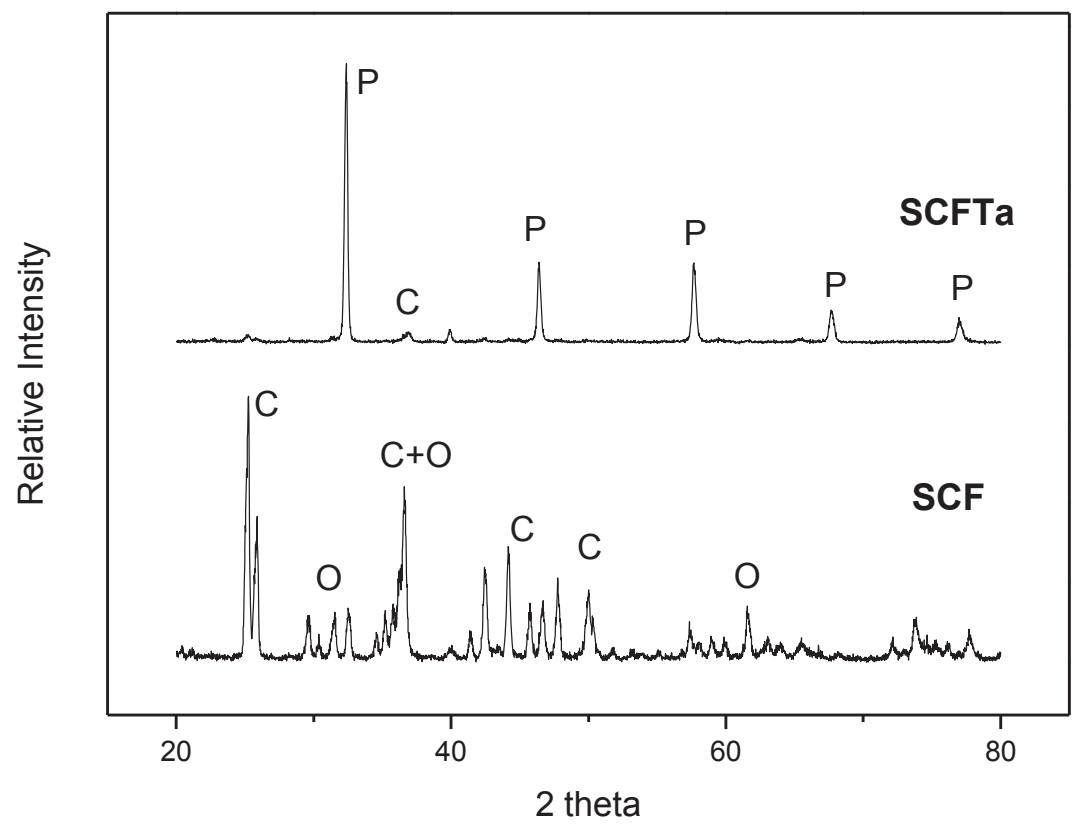

Figure 4.5. XRD patterns of SCF and SCFTa after isothermal gravimetric analysis in $\mathrm{CO}_{2}$ atmosphere at $900^{\circ} \mathrm{C}$ for 19 and 17 hours respectively and subsequently cooled to room temperature in $\mathrm{CO}_{2}$. P: perovskite; $\mathrm{C}: \mathrm{SrCO}_{3}$; O: metal-oxides 
The general reaction between SCF or SCFTa and $\mathrm{CO}_{2}$ can be written as follow [20]:

$$
\begin{aligned}
& \mathrm{SrCo}_{0.8} \mathrm{Fe}_{0.2} \mathrm{O}_{3-\delta}+\mathrm{CO}_{2} \leftrightarrow \\
& \mathrm{SrCO}_{3}+0.1 \mathrm{Fe}_{2} \mathrm{O}_{3}+0.8 \mathrm{CoO}+\frac{0.9-\delta}{2} \mathrm{O}_{2} \\
& \mathrm{Sr}\left(\mathrm{Co}_{0.8} \mathrm{Fe}_{0.2}\right)_{0.9} \mathrm{Ta}_{0.1} \mathrm{O}_{3-\delta}+\mathrm{CO}_{2} \leftrightarrow \\
& \mathrm{SrCO}_{3}+0.09 \mathrm{Fe}_{2} \mathrm{O}_{3}+0.72 \mathrm{CoO}+0.05 \mathrm{Ta}_{2} \mathrm{O}_{5}+\frac{0.76-\delta}{2} \mathrm{O}_{2}
\end{aligned}
$$

If $\delta$ is assumed to be 0.5 [21], as mentioned in, it can be calculated from these chemical reactions in combination with the mass loss as determined by isothermal gravimetric analysis (Figure 4.2) that over $85 \%$ (mole) of SCF has decomposed, while this decomposition less than $8 \%$ for SCFTa. Generally, the chemical reactions as given in eq. (4.1) and (4.2) can be regarded as a Lewis acid-base reaction, where $\mathrm{CO}_{2}$ acts as the acid while the metal oxides represent the solid base [11]. The intensity of this reaction is determined by the basicity of the metal oxides, and it is well known that the basicity of a metal oxide is defined as the ability of these species to donate electrons to an adsorbed molecule (in this case $\mathrm{CO}_{2}$ ). In general, the $\mathrm{O} 1 \mathrm{~s}$ binding energy $(\mathrm{O} 1 \mathrm{~s} \mathrm{BE})$, which is related to the charge density around the oxide ions, is usually used as a measure for the basicity of metal oxides [22, 23]. A higher $\mathrm{O} 1 \mathrm{~s} \mathrm{BE}$ means a lower charge density and consequently it is harder for the oxides to donate electrons to the adsorbed molecule. In this work, the O1s BE of SCF and SCFTa were measured by X-ray Photoelectron Spectroscopy (XPS). The XPS spectra of the O1s BE signals are shown in Figure 4.6, and all specific data are summarized in table 4.1 . 


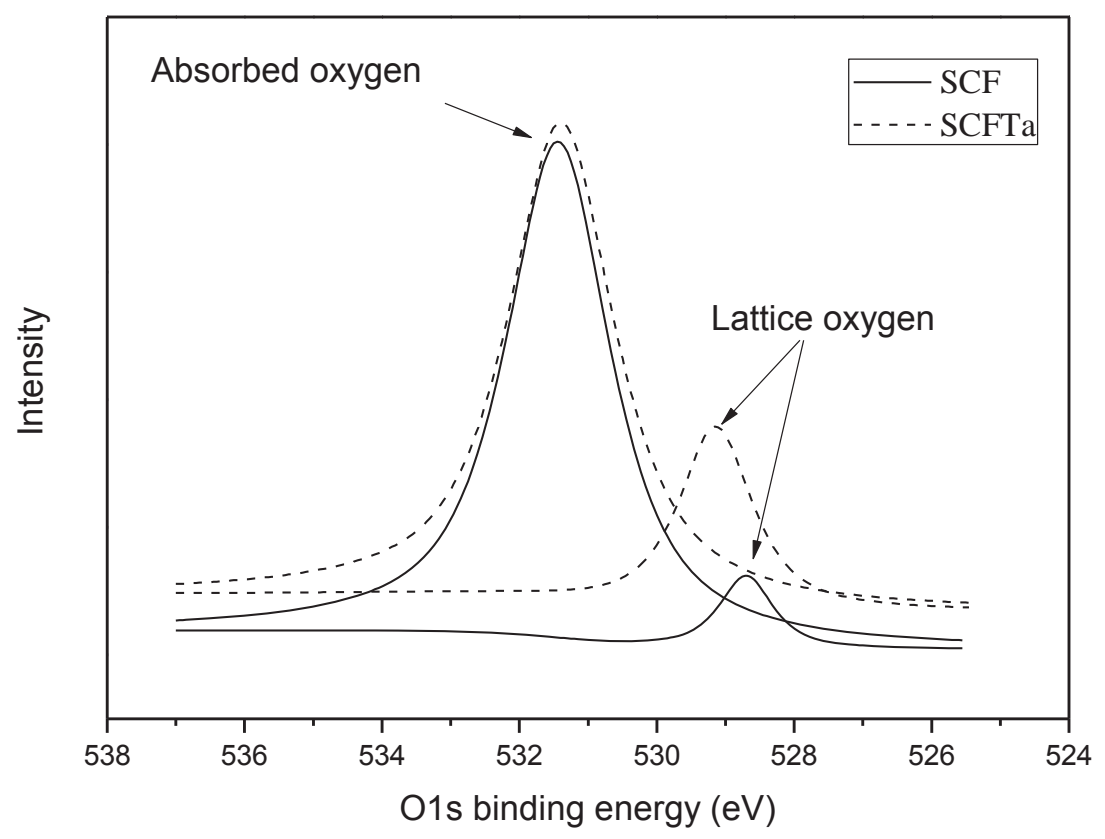

Figure 4.6. O1s binding energy of lattice oxide ions and absorbed oxygen of SCF and SCFTa powders as determined by XPS

Table 4.1. O1s binding energies of SCF and SCFTa

\begin{tabular}{lcc}
\hline & Absorbed oxygen $(\mathrm{eV})$ & Lattice oxygen $(\mathrm{eV})$ \\
\hline SCF & 531.4 & 528.7 \\
SCFTa & 531.4 & 529.1 \\
\hline
\end{tabular}

The peak at $531.4 \mathrm{eV}$ is assigned to oxygen absorbed on the particle surface [8], which is identical for both SCF and SCFTa. However, the peak for lattice oxygen of SCFTa in XPS shifts to a higher value by $0.4 \mathrm{eV}$ compared with pure SCF, indicating that the electron donating capacity of SCFTa is less and consequently its basic character is weaker than that of SCF. One possible reason for the lower basicity of SCFTa is that the Ta-O bond strength of $799.1 \mathrm{~kJ} / \mathrm{mol}$ is much higher than that of Co$\mathrm{O}(384.5 \mathrm{~kJ} / \mathrm{mol})$ and the $\mathrm{Fe}-\mathrm{O}$ bond $(390.4 \mathrm{~kJ} / \mathrm{mol})$ [24]. So, partial substitution of $\mathrm{Co}$ and $\mathrm{Fe}$, as present on the B-sites of SCF, by Ta increases the average $\mathrm{B}-\mathrm{O}$ bond strength and consequently decreases the surface charge density, leading to a decrease of the basicity of SCF. 


\subsubsection{Oxygen permeation}

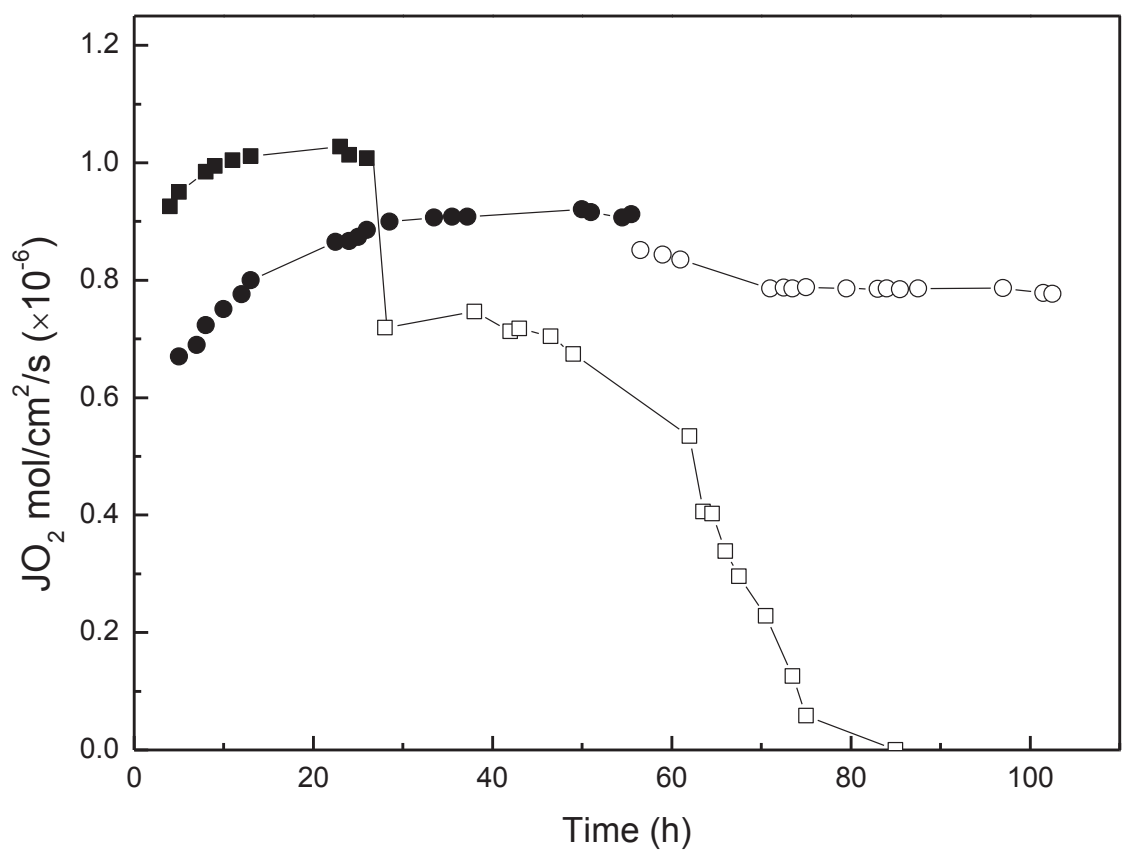

Figure 4.7. Time dependence of oxygen permeation flux through $1 \mathrm{~mm}$ membranes at $900 \mathrm{oC}$; Sweep gas flow rate (He, $\mathrm{CO} 2): 50 \mathrm{ml} / \mathrm{min}$

п: SCF in He; $\square$ : SCF in CO2; •: SCFTa in He; ०: SCFTa in $\mathrm{CO} 2$

To examine the oxygen permeation performance of SCF and SCFTa membranes under operating conditions, i.e. in a $\mathrm{CO}_{2}$ atmosphere, long term oxygen permeation measurements were performed at $900^{\circ} \mathrm{C}$ under air $/ \mathrm{CO}_{2}$ gradient (air flow rate 100 $\mathrm{ml} / \mathrm{min}$ ). The results, as given in Figure 4.7 , showed a permeability of around $1 \times 10^{-6}$ $\mathrm{mol} / \mathrm{cm}^{2} / \mathrm{s}$ for SCF when helium $(50 \mathrm{ml} / \mathrm{min})$ was used as sweep gas, which is in accordance with literature [15]. However, when $\mathrm{CO}_{2}(50 \mathrm{ml} / \mathrm{min})$ was introduced, the flux suddenly dropped to $7.2 \times 10^{-7} \mathrm{~mol} / \mathrm{cm}^{2} / \mathrm{s}$, followed by a decrease to almost zero after 57 hours of $\mathrm{CO}_{2}$ exposure at the sweep side of the membrane. For SCFTa, it took almost 30 hours to achieve a steady oxygen permeation flux in helium, which has also been found by Zhu and Yi in their work $[25,26]$. This could be due to readjusting of the lattice structure from the as-prepared state to a steady state under permeation conditions or to a reduction of the initial surface oxygen desorption rate. 
When $\mathrm{CO}_{2}$ was introduced as sweep gas instead of helium, the oxygen permeation flux dropped from $9 \times 10^{-7} \mathrm{~mol} / \mathrm{cm}^{2} / \mathrm{s}$ to $8.5 \times 10^{-7} \mathrm{~mol} / \mathrm{cm}^{2} / \mathrm{s}$. This drop in permeation is much lower than that of SCF. Even more important is that the flux remained almost constant during the following 50 hours $\left(7.8 \times 10^{-7} \mathrm{~mol} / \mathrm{cm}^{2} / \mathrm{s}\right.$ after 50 hours $)$. Overall, it is worthwhile to get a stable membrane at the expense of sacrificing a little of permeability because stability is of top importance in industry. The good performance of SCFTa undoubtedly suggests that SCFTa should be a promising material for oxygen production in the oxy-fuel process.

\subsection{Conclusion}

The phase transition from perovskite to brownmillerite at low oxygen partial pressure $\left(p \mathrm{O}_{2}<10^{-2} \mathrm{~atm}\right)$ can effectively be restrained by substitution of $\mathrm{Co}$ and $\mathrm{Fe}$ with $10 \% \mathrm{Ta}$ at the $\mathrm{B}$ site of $\mathrm{SrCo}_{0.8} \mathrm{Fe}_{0.2} \mathrm{O}_{3-\delta}$ (SCF). Oxygen permeation measurements were conducted and the results showed that the Ta-doped SCF possessed much better long-term stability in a $\mathrm{CO}_{2}$ atmosphere than pure SCF. A possible reason is that Ta doping decreases the basicity of SCF, which restrains the acid-base reaction of $\mathrm{CO}_{2}$ with SCF. Actually, the decrease of basicity has been proven by XPS analysis. To sum up, the good performance of SCFTa in reducing atmosphere as well as in $\mathrm{CO}_{2}$ atmosphere makes this material an interesting candidate as membrane in the oxy-fuel combustion process.

\section{References}

[1] B.J.P. Buhre, L.K. Elliott, C.D. Sheng, R.P. Gupta, T.F. Wall, Oxy-fuel combustion technology for coal-fired power generation, Progress in Energy and Combustion Science, 31 (2005) 283-307.

[2] H.M. Kvamsdal, K. Jordal, O. Bolland, A quantitative comparison of gas turbine cycles with $\mathrm{CO}_{2}$ capture, Energy, 32 (2007) 10-24.

[3] P.A. Armstrong, E.P. Foster, H.H. Gunardson, ITM oxygen for gasification, in, 2005, pp. B17B22.

[4] S.G. Sundkvist, T. Griffin, N.P. Thorshaug, AZEP-Development of an Integrated Air Separation Membrane-Gas Turbine, Second Nordic Minisymposium on Carbon Dioxide Capture and Storage, (2001). 
[5] T. Griffin, S.G. Sundkvist, K. Asen, T. Bruun, Advanced zero emissions gas turbine power plant, J Eng Gas Turb Power, 127 (2005) 81-85.

[6] S.G. Sundkvist, H. Eklund, AZEP -an EC funded project for development of a CCGT power plant without $\mathrm{CO}_{2}$ emissions, $4^{\text {th }}$ Nordic Minisymposium on $\mathrm{CO}_{2}$ Capture and Storage, (2005).

[7] J.X. Yi, S.J. Feng, Y.B. Zuo, W. Liu, C.S. Chen, Oxygen permeability and stability of $\mathrm{Sr}_{0.95} \mathrm{Co}_{0.8} \mathrm{Fe}_{0.2} \mathrm{O}_{3-\delta}$ in a $\mathrm{CO}_{2}$ - and $\mathrm{H}_{2} \mathrm{O}$-containing atmosphere, Chem Mater, 17 (2005) 5856-5861.

[8] Q. Zeng, Y.B. Zu, C.G. Fan, C.S. Chen, $\mathrm{CO}_{2}$-tolerant oxygen separation membranes targeting $\mathrm{CO}_{2}$ capture application, Journal of Membrane Science, 335 (2009) 140-144.

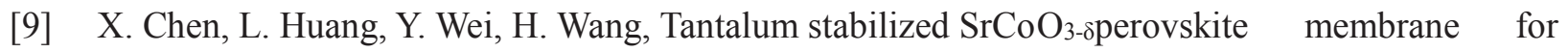
oxygen separation, Journal of Membrane Science, 368 (2011) 159-164.

[10] H.X. Luo, B.B. Tian, Y.Y. Wei, H.H. Wang, H.Q. Jiang, J. Caro, Oxygen Permeability and Structural Stability of a Novel Tantalum-Doped Perovskite $\mathrm{BaCo}_{.7} \mathrm{Fe}_{0.2} \mathrm{Ta}_{0.1} \mathrm{O}_{3-\delta}$, Aiche J, 56 (2010) 604-610.

[11] L. Bi, S. Zhang, S. Fang, Z. Tao, R. Peng, W. Liu, A novel anode supported $\mathrm{BaCe}_{0.7} \mathrm{Ta}_{0.1} \mathrm{Y}_{0.2} \mathrm{O}_{3-\delta}$ electrolyte membrane for proton-conducting solid oxide fuel cell, Electrochem Commun, 10 (2008) 1598-1601.

[12] M. Liu, R. Wang, D.F. Li, D.T. Liang, A novel combustion route for the preparation of perovskitetype oxygen permeable materials, Materials Chemistry and Physics, 102 (2007) 132-139.

[13] W.T.A. Harrison, T.H. Lee, Y.L. Yang, D.P. Scarfe, L.M. Liu, A.J. Jacobson, A Neutron-Diffraction Study of 2 Strontium Cobalt Iron-Oxides, Mater Res Bull, 30 (1995) 621-630.

[14] L.M. Liu, T.H. Lee, L. Qiu, Y.L. Yang, A.J. Jacobson, A thermogravimetric study of the phase diagram of strontium cobalt iron oxide, $\mathrm{SrCo}_{.8} \mathrm{Fe}_{0.2} \mathrm{O}_{3-\delta}$, Mater Res Bull, 31 (1996) 29-35.

[15] L. Qiu, T.H. Lee, L.M. Liu, Y.L. Yang, A.J. Jacobson, Oxygen Permeation Studies of $\mathrm{SrCo}_{0.8} \mathrm{Fe}_{0.2} \mathrm{O}_{3-\delta}$, Solid State Ionics, 76 (1995) 321-329.

[16] S. McIntosh, J.F. Vente, W.G. Haije, D.H.A. Blank, H.J.M. Bouwmeester, Structure and oxygen stoichiometry of $\mathrm{SrCo}_{0.8} \mathrm{Fe}_{0.2} \mathrm{O}_{3-\delta}$ and $\mathrm{Ba}_{0.5} \mathrm{Sr}_{0.5} \mathrm{Co}_{0.8} \mathrm{Fe}_{0.2} \mathrm{O}_{3-\delta}$, Solid State Ionics, 177 (2006) 17371742.

[17] W. Chen, Y.B. Zuo, C.S. Chen, A.J.A. Winnubst, Effect of Zr4+ doping on the oxygen stoichiometry and phase stability of $\mathrm{SrCo}_{0.8} \mathrm{Fe}_{0.2} \mathrm{O}_{3-\delta}$ oxygen separation membrane, Solid State Ionics, 181 (2010) 971-975.

[18] Z.B. Rui, J.J. Ding, Y.D. Li, Y.S. Lin, $\mathrm{SrCo}_{0.8} \mathrm{Fe}_{0.2} \mathrm{O}_{3-\delta}$ sorbent for high-temperature production of oxygen-enriched carbon dioxide stream, Fuel, 89 (2010) 1429-1434.

[19] Q. Yang, Y.S. Lin, M. Bülow, High temperature sorption separation of air for producing oxygenenriched $\mathrm{CO}_{2}$ stream, Aiche J, 52 (2006) 574-581.

[20] H.J. Freund, M.W. Roberts, Surface chemistry of carbon dioxide, Surf Sci Rep, 25 (1996) 225- 
273.

[21] S. McIntosh, J.F. Vente, W.G. Haije, D.H.A. Blank, H.J.M. Bouwmeester, Structure and oxygen stoichiometry of $\mathrm{SrCo}_{0.8} \mathrm{Fe}_{0.2} \mathrm{O}_{3-\delta}$ and $\mathrm{Ba}_{0.5} \mathrm{Sr}_{0.5} \mathrm{Co}_{0.8} \mathrm{Fe}_{0.2} \mathrm{O}_{3-\delta}$, Solid State Ionics, 177 (2006) 17371742.

[22] V. Dimitrov, T. Komatsu, Correlation between O1s binding energy and metal binding energy in XPS spectra of oxide glasses, Phys Chem Glasses, 44 (2003) 401-408.

[23] H. Fan, G. Wang, L. Hu, Infrared, Raman and XPS spectroscopic studies of $\mathrm{Bi}_{2} \mathrm{O}_{3}-\mathrm{B}_{2} \mathrm{O}_{3}-\mathrm{Ga}_{2} \mathrm{O}_{3}$ glasses, Solid State Sci, 11 (2009) 2065-2070.

[24] I. CRC Press, Handbook of Chemistry and Physics, Handbook of Chemistry and Physics, (2000).

[25] J.X. Yi, Y.B. Zuo, W. Liu, L. Winnubst, C.S. Chen, Oxygen permeation through a $\mathrm{Ce}_{0.8} \mathrm{Sm}_{0.2} \mathrm{O}_{2-\delta^{-}}$ $\mathrm{La} 0.8 \mathrm{Sr}_{0.2} \mathrm{CrO}_{3-\delta}$ dual-phase composite membrane, Journal of Membrane Science, 280 (2006) 849855.

[26] X.F. Zhu, W.S. Yang, Composite membrane based on ionic conductor and mixed conductor for oxygen permeation, AIChE, 54 (2008) 665-672. 


\title{
Chapter 5 Oxygen-selective membranes integrated with oxy-fuel combustion
}

\begin{abstract}
:
The perovskite-type oxide $\mathrm{SrCo}_{0.8} \mathrm{Fe}_{0.2} \mathrm{O}_{3-\delta}$ (SCF), a highly oxygen-permeable material, is restricted for application in the membrane-integrated oxy-fuel combustion process by its low tolerance to $\mathrm{CO}_{2}$. In the present work, we found that the $\mathrm{CO}_{2}$ tolerance of SCF is improved by increasing the oxygen partial pressure in the $\mathrm{CO}_{2}$-containing gas. Long term oxygen permeation experiments, at $950{ }^{\circ} \mathrm{C}$, showed that mixing $5 \%$ of oxygen into the $\mathrm{CO}_{2}$ sweep gas effectively prevents degradation of the SCF membrane. X-ray photoelectron spectroscopy it was indicates that the increase in $\mathrm{CO}_{2}$ tolerance of $\mathrm{SCF}$ is caused by a decrease in basicity of the material with increasing oxygen partial pressure. Based on these experimental results, a modified oxy-fuel combustion process is proposed. Calculation of the required membrane area for operating a $50 \mathrm{MW}$ coal-fired power plant showed that the modified process comprises a viable option.
\end{abstract}

This chapter has been published as:

W. Chen, C.-S. Chen, H.J.M. Bouwmeester, A. Nijmeijer, L. Winnubst, Oxygen-selective membranes integrated with oxy-fuel combustion, Journal of Membrane Science, 463(2014) 166-172. 


\subsection{Introduction}

Oxy-fuel combustion is a promising technique for $\mathrm{CO}_{2}$ capture in a fossil fuelfired power plant. In a typical oxy-fuel combustion process, pure oxygen instead of air is used for fuel combustion, resulting in a concentrated $\mathrm{CO}_{2}$ gas stream, thus enabling efficient $\mathrm{CO}_{2}$ capture. In most cases pure oxygen is separated from air via the cryogenic distillation or the pressure swing adsorption (PSA) process. Both processes are energy intensive, which limits further development of the oxy-fuel combustion technique $[1,2]$. It is proposed that oxygen can be produced by using mixed ionic-electronic conducting (MIEC) ceramic membranes, through which (neutral) oxygen transport at elevated temperatures (usually higher than $700{ }^{\circ} \mathrm{C}$ ) $[3$, 4]. A general scheme of this process is given in Figure 5.1. The oxygen, as separated from air by the membrane, is carried by the sweep gas $\mathrm{CO}_{2}$, while the $\mathrm{CO}_{2} / \mathrm{O}_{2}$ gas mixture is used to combust the fossil fuel. After combustion and purification, the exhaust gas mainly consists of $\mathrm{CO}_{2}(>95 \%)$. Part of the $\mathrm{CO}_{2}$ is recycled as sweep gas and the rest is compressed for delivery and storage.

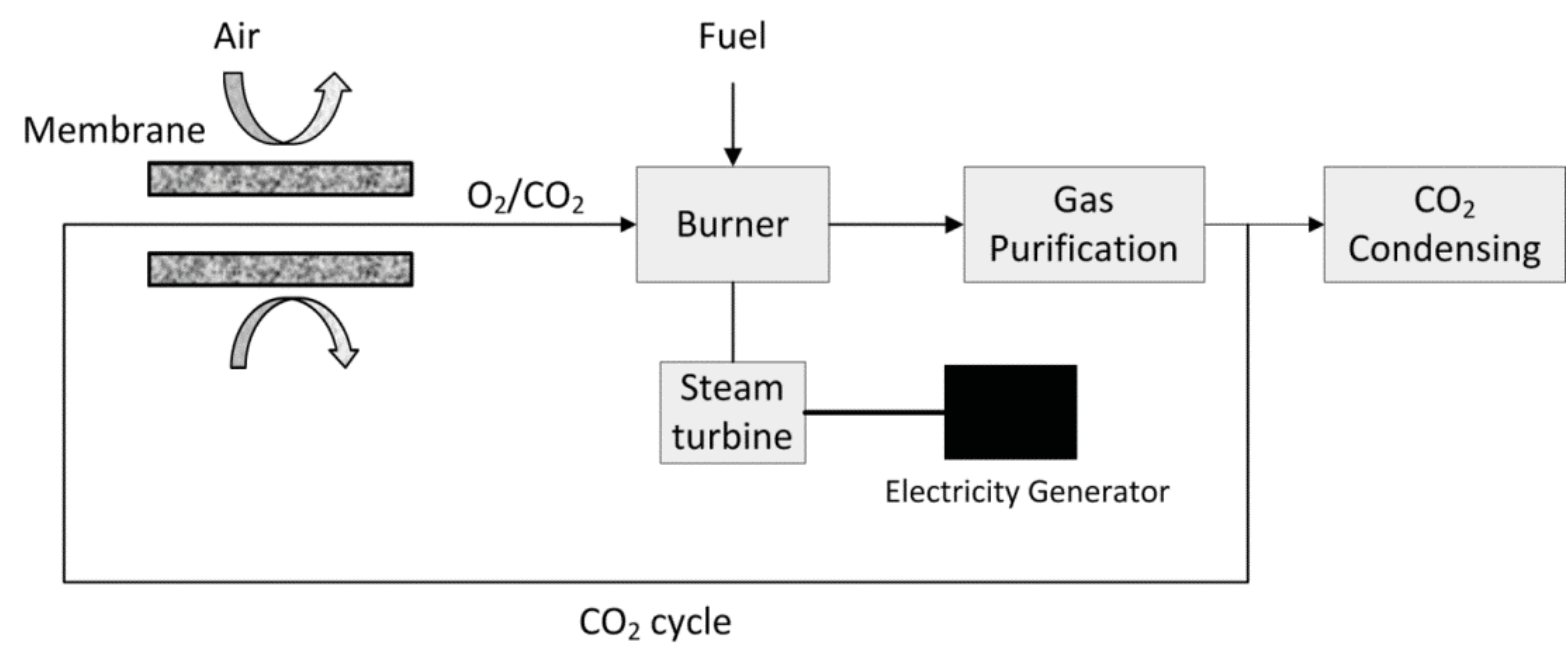

Figure 5.1. Scheme for membrane integrated oxy-fuel combustion process.

Most MIEC materials have the perovskite crystal structure and contain alkalineearth elements like $\mathrm{Ca}, \mathrm{Sr}$ or $\mathrm{Ba}$. Due to the presence of these elements, a carbonation reaction tends to occur when these membranes are exposed to a $\mathrm{CO}_{2}$-containing atmosphere. This reaction results in the formation of an alkaline-earth carbonate 
layer on the membrane surface, which is impermeable for oxygen, resulting in a decline in oxygen flux or even to a non-permeating membrane. For example, $\mathrm{SrCo}_{0.8} \mathrm{Fe}_{0.2} \mathrm{O}_{3-\delta}$ (SCF), a highly oxygen-permeable material, showed a decrease in oxygen flux to almost zero within 100 hours when using $\mathrm{CO}_{2}$ as sweep gas [5]. In order to increase the $\mathrm{CO}_{2}$ tolerance of SCF membranes, $\mathrm{Sr}^{2+}$ was partially substituted with $\mathrm{La}^{3+}[6]$, or $\mathrm{Co} / \mathrm{Fe}$ with $\mathrm{Ti}^{4+}, \mathrm{Zr}^{4+}, \mathrm{Ta}^{5+}$ or $\mathrm{Nb}^{5+}$ [7, 8]. However, this improvement in $\mathrm{CO}_{2}$ tolerance was at the expense of a decrease in oxygen flux [9].

Besides partial substitution, there are other parameters that affect the $\mathrm{CO}_{2}$ tolerance of $\mathrm{SCF}$, for example, temperature and $\mathrm{CO}_{2}$ partial pressure $\left(p \mathrm{CO}_{2}\right)$. Yi et al. [10] found that SCF is more stable at higher temperature and lower $p \mathrm{CO}_{2}$ (balanced with helium), and suggested SCF membranes should be operated above $900{ }^{\circ} \mathrm{C}$. In the present study we examined another possible parameter: the oxygen partial pressure $\left(p \mathrm{O}_{2}\right)$, which has not been reported before to the best of our knowledge, as a way to improve the $\mathrm{CO}_{2}$ tolerance of alkaline-earth containing perovskite materials. In this study thermal-gravimetric analysis (TGA) was used to investigate the effect of $p \mathrm{O}_{2}$ on the stability of the SCF perovskite system in a $\mathrm{CO}_{2}$-containing atmosphere. $\mathrm{X}$-ray photoelectron spectroscopy (XPS) was used to examine the oxygen bonding energy of SCF at different oxygen partial pressures. Oxygen permeation experiments were performed to test the $\mathrm{CO}_{2}$ tolerance of SCF membranes under operating conditions by adding $0 \%$ or $5 \%$ of oxygen to the sweep gas $\left(\mathrm{CO}_{2}\right)$. Finally, we propose a modified oxy-fuel combustion process and estimated the SCF membrane area needed in a combustion process for a $50 \mathrm{MW}$ coal-fired power plant.

\subsection{Experimental procedure and methodology}

\subsubsection{Sample preparation}

$\mathrm{SrCo}_{0.8} \mathrm{Fe}_{0.2} \mathrm{O}_{3-\delta}$ (SCF) was synthesized using an EDTA complexation/pyrolysis process. Metal nitrates were dissolved at a stoichiometric ratio in demineralized water under stirring. EDTA, dissolved in ammonium hydroxide, was added for 
chelating and after several minutes citric acid was added as well. The molar ratio of total metal ions : citric acid : EDTA was $1.0: 1.5: 1.0$. The $\mathrm{pH}$ of the solution was adjusted to 6 by adding ammonium hydroxide. Subsequently $\mathrm{NH}_{4} \mathrm{NO}_{3}$ was added as an ignition aid at an amount of $100 \mathrm{~g} \mathrm{NH}_{4} \mathrm{NO}_{3}$ per 0.1 mole of metal ions. The final solution was heated at $120-150{ }^{\circ} \mathrm{C}$ under stirring to evaporate water until the system changed into a viscous gel, which was transferred to a stainless steel vessel and heated on a hot plate at a temperature of around $500{ }^{\circ} \mathrm{C}$, while a vigorous combustion took place, resulting in a fluffy powder. The powder was collected and calcined at $950{ }^{\circ} \mathrm{C}$ for 5 hours at a heating and cooling rate of $3{ }^{\circ} \mathrm{C} / \mathrm{min}$. The calcined powders were uniaxially pressed at $4 \mathrm{Mpa}$ into disk-shaped membranes, subsequently cold isostatically pressed at $400 \mathrm{Mpa}$ for 6 minutes, and sintered in ambient air at $1200{ }^{\circ} \mathrm{C}$ for 10 hours at a heating rate of $3{ }^{\circ} \mathrm{C} / \mathrm{min}$ and a cooling rate of $2{ }^{\circ} \mathrm{C} / \mathrm{min}$.

\subsubsection{Thermal-gravimetric analysis (TGA)}

Isothermal gravimetric analyses were carried out on a Netzsch TG 449 F3 Jupiter $^{\circledR}$. About $20 \mathrm{mg}$ of powder was weighed in an alumina crucible and placed in the TGA setup. The system was heated to $950{ }^{\circ} \mathrm{C}$ in flowing 'synthetic' air (95 $\mathrm{ml} / \mathrm{min} \mathrm{N}_{2}$ and $25 \mathrm{ml} / \mathrm{min} \mathrm{O}_{2}$; all gas flow rates are given under standard temperature and pressure without further notation) at a heating rate of $10{ }^{\circ} \mathrm{C} / \mathrm{min}$. The system was isothermally held for 1 hour in order to attain equilibrium, indicated by a constant weight of the sample. Subsequently the sweep gas was changed to a $\mathrm{CO}_{2} / \mathrm{O}_{2} / \mathrm{N}_{2}$ mixture (total flow rate $120 \mathrm{ml} / \mathrm{min}$ with a $\mathrm{CO}_{2}$ flow rate $80 \mathrm{ml} / \mathrm{min} ; \mathrm{O}_{2}$ flow rate is variable and $\mathrm{N}_{2}$ is used as balance). After 5 hours, the system was cooled down at $10{ }^{\circ} \mathrm{C} / \mathrm{min}$ in the same flowing gases. All TGA data were processed with a correction file of a blank crucible using the same temperature program, to exclude background data of the equipment.

\subsubsection{X-ray photoelectron spectroscopy analysis}

For X-ray photoelectron spectroscopy (XPS: ESCALAB MK II, VG equipment) 
analysis SCF bars $(8 \mathrm{~mm} \times 4 \mathrm{~mm} \times 3 \mathrm{~mm})$ were prepared using the same procedure as for the disk-shaped membranes. After sintering and polishing to the desired dimensions, the samples were annealed in nitrogen $\left(p \mathrm{O}_{2}=10^{-4}\right.$ bar $)$ or oxygen $\left(p \mathrm{O}_{2}=\right.$ 1.0 bar) at $950{ }^{\circ} \mathrm{C}$ for 20 hours and quenched to room temperature within a few seconds. Afterwards, the bars were broken and only the center part of the cross section was analyzed by XPS using an X-ray beam size of $250 \mu \mathrm{m}$ and a step size of $0.05 \mathrm{eV}$.

5.2.4 Oxygen permeation measurements

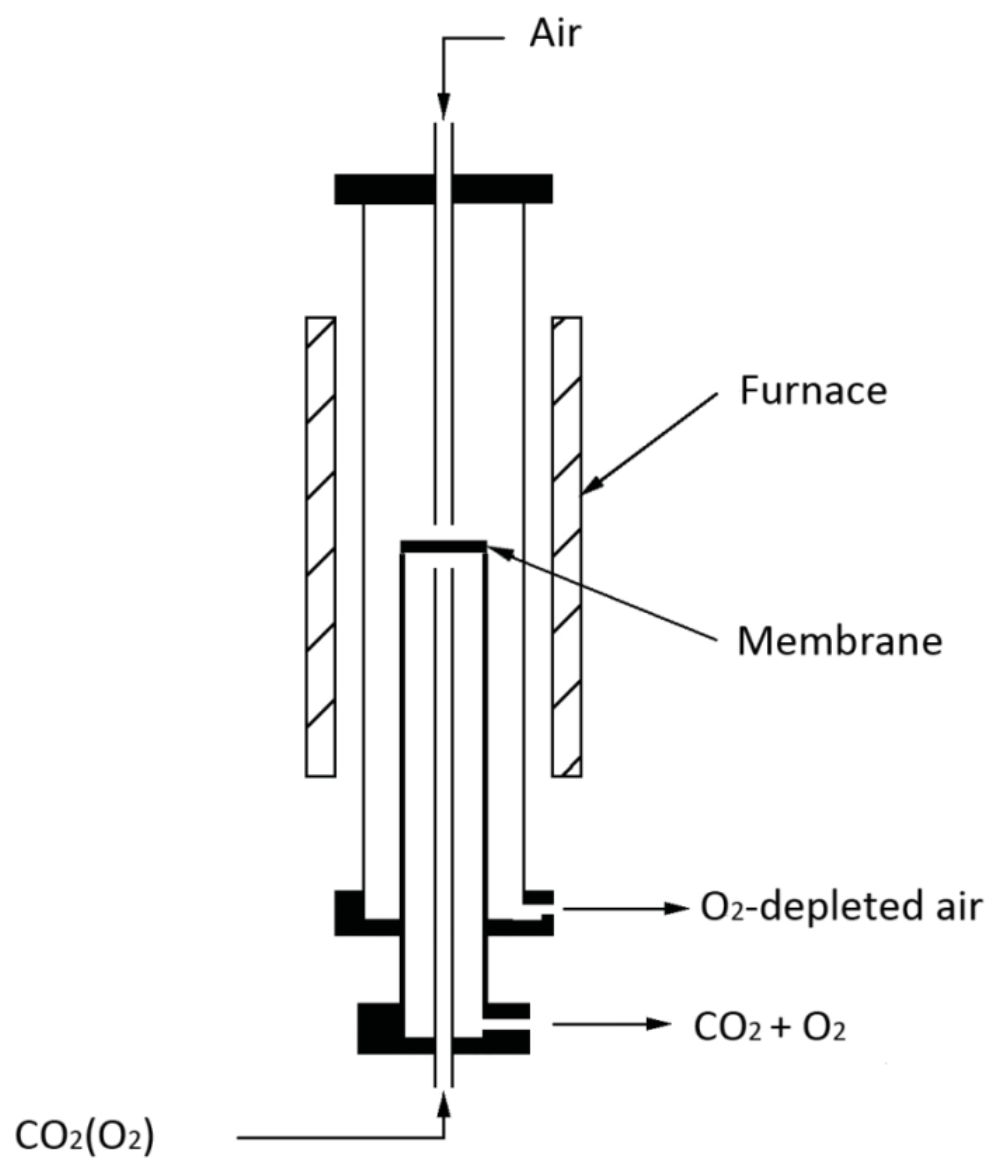

Figure 5.2. Schematic diagram of the high temperature permeation setup.

The experimental setup for oxygen permeation measurements is schematically shown in Figure 5.2. Disk-shaped membranes with a diameter of $15 \mathrm{~mm}$ and a relative density $>90 \%$ were polished to a thickness of $1 \mathrm{~mm}$ and ultrasonically 
cleaned in ethanol. The membranes were sealed to one end of a quartz tube (diameter $12 \mathrm{~mm}$ ) using gold paste and a sealing temperature of $1000{ }^{\circ} \mathrm{C}$. After sealing, the temperature was lowered to $950{ }^{\circ} \mathrm{C}$, and air was applied as feed gas to one side of the membrane $(100 \mathrm{ml} / \mathrm{min})$, while $\mathrm{CO}_{2}(50 \mathrm{ml} / \mathrm{min})$ or a $\mathrm{CO}_{2} / \mathrm{O}_{2}$ gas mixture (50 $\mathrm{ml} / \mathrm{min}$ ) was applied to the other side to sweep away the permeated oxygen. The composition of the effluent gas at the permeate side was analyzed by an oxygen sensor (Systech ZR893). A gas chromatograph (Varian CP 4900 equipped with $5 \AA$ molecular sieve column using He as carrier gas) was used to check for any leakage of the sealing. If there was no nitrogen peak in the spectrum for the permeate gas stream, it was assumed that the sealing was sufficient and oxygen permeation due to leakage was neglected.

\subsubsection{Membrane area calculation}

The aim of this calculation is to estimate the membrane area needed for a 50 MW coal-fired power plant. This was done in two steps: 1) calculation of the oxygen produced by a single membrane tube and 2) determination of the total required membrane area, necessary for the power plant, based on the calculation for a single tube. 


\section{Oxygen production by a single membrane tube}

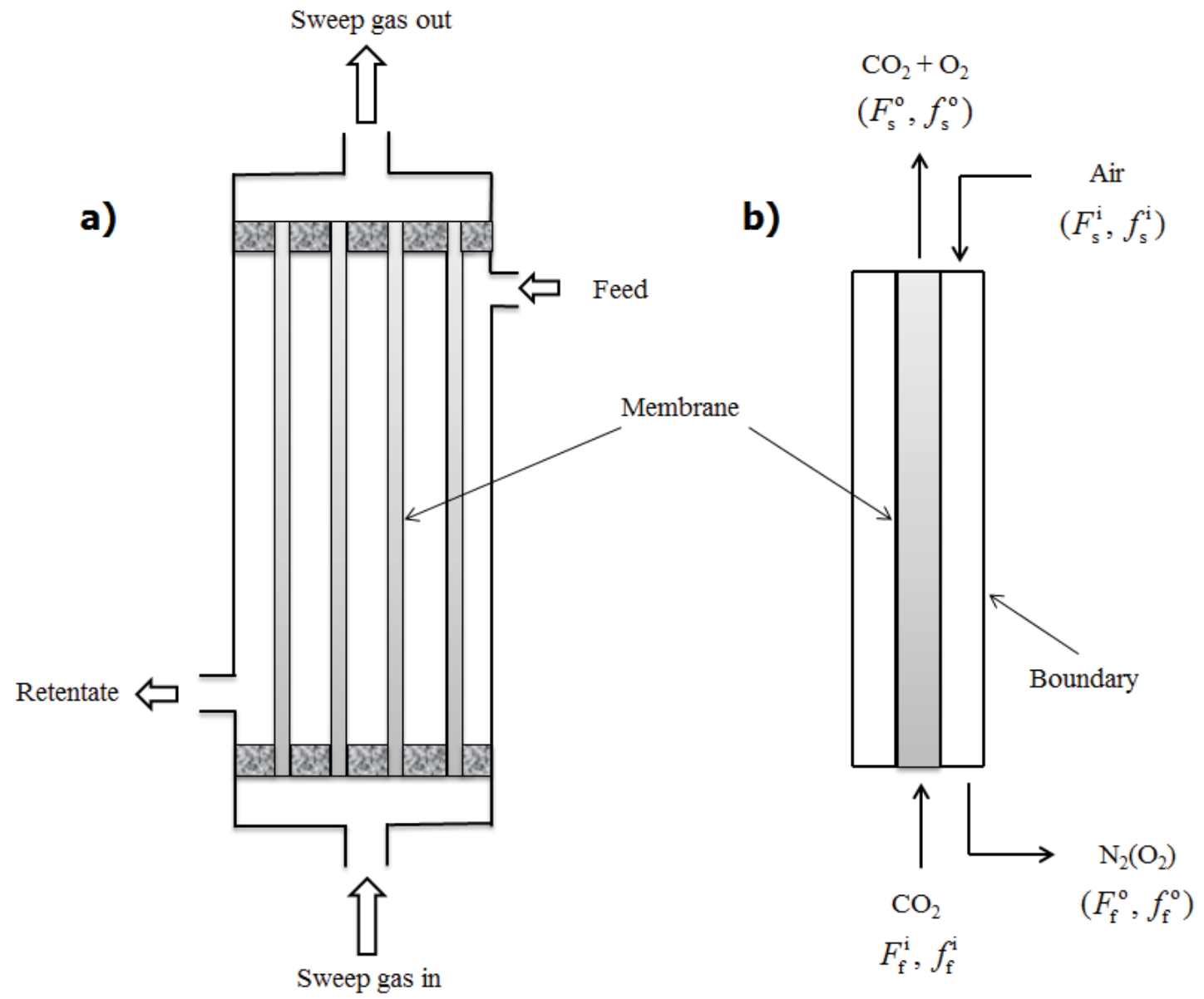

Figure 5.3. Schematic drawing of (a) a membrane module and (b) a membrane tube.

Tubular membranes were chosen in this study and a simple scheme of the membrane module and a membrane tube is shown in Figure 5.3. For the calculation the oxygen production by a single membrane tube, the following assumptions are made: (1) oxygen is transported from the shell side to the core side of the membrane tube; (2) the sweep and feed gas flows are in a counter-current mode; (3) there is no oxygen concentration polarization in the radial direction; (4) the absolute pressure drop in the membrane module is neglected; (5) the oxygen transport in both core and shell side of the membrane is described by a convection diffusion and a reaction model (eq. (5.1) - (5.2)) [11]; (6) the oxygen flux is governed by Wagner's equation (eq. (5.3)) [12], in which the electronic conductivity of the membranes is predominant and the ionic conductivity constant. 


$$
\begin{gathered}
D_{\mathrm{s}} \frac{\mathrm{d}^{2} f_{\mathrm{s}}}{\mathrm{d} z^{2}}-\frac{\mathrm{d}}{\mathrm{d} z}\left(\vec{v}_{\mathrm{s}} f_{\mathrm{s}}\right)+\frac{2 V_{\mathrm{m}}}{R_{1}} \vec{J}_{\mathrm{O}_{2}}=0 \\
D_{\mathrm{f}} \frac{\mathrm{d}^{2} f_{\mathrm{f}}}{\mathrm{d} z^{2}}-\frac{\mathrm{d}}{\mathrm{d} z}\left(\vec{v}_{\mathrm{f}} f_{\mathrm{f}}\right)+\frac{2 R_{1} V_{\mathrm{m}}}{R_{2}^{2}-R_{1}^{2}} \vec{J}_{\mathrm{O}_{2}}=0
\end{gathered}
$$

where

$$
\left\{\begin{array}{l}
\vec{J}_{\mathrm{O}_{2}}=\frac{R T}{\left(4 F_{a}\right)^{2} d} \sigma_{\text {ion }} \ln \left(\frac{P_{\mathrm{f}} f_{\mathrm{f}}}{P_{\mathrm{s}} f_{\mathrm{s}}}\right) \\
\vec{v}_{\mathrm{s}}=\frac{\vec{F}_{\mathrm{s}}}{\pi R_{1}^{2}} \\
\vec{v}_{\mathrm{f}}=\frac{\vec{F}_{\mathrm{f}}}{\pi\left(R_{2}^{2}-R_{1}^{2}\right)}
\end{array}\right.
$$

with Danckwerts boundary conditions [13],

$$
\begin{cases}\vec{v}_{\mathrm{s}} f_{\mathrm{s}}^{\mathrm{i}}=\vec{v}_{\mathrm{s}} f_{\mathrm{s}}-D_{\mathrm{s}} \frac{\mathrm{d} f_{\mathrm{s}}}{\mathrm{d} z}, & z=0 \\ \frac{\mathrm{d} f_{\mathrm{s}}}{\mathrm{d} z}=0, & z=\mathrm{L} \\ \frac{\mathrm{d} f_{\mathrm{f}}}{\mathrm{d} z}=0, & z=0 \\ \vec{v}_{\mathrm{f}} f_{\mathrm{f}}^{\mathrm{i}}=\vec{v}_{\mathrm{f}} f_{\mathrm{f}}-D_{\mathrm{f}} \frac{\mathrm{d} f_{\mathrm{f}}}{\mathrm{d} z}, & z=\mathrm{L}\end{cases}
$$

Where $f, D, P, F$ and $\vec{v}$ are $\mathrm{O}_{2}$ mole fractions, $\mathrm{O}_{2}$ diffusion coefficients in the gas phase, absolute pressure, volume flow rate and velocity of the sweep (with subscript $\mathrm{s}$ ) gas or feed (with subscript $\mathrm{f}$ ) gas; $R$ gas constant, $z$ the coordinates along the membrane tube, $T$ absolute temperature, $V_{\mathrm{m}}$ molar volume of oxygen in the gas phase oxygen at given temperature and pressure, $F_{a}$ Faraday constant, $d$ membrane thickness, $\sigma_{\text {ion }}$ oxygen ionic conductivity, $R_{1}$ the radius of the tube membrane 
(average of outer and inner diameter) and $R_{2}$ the distance from center of the tube membrane to the wall boundary (Figure 5.3). $f_{\mathrm{s}}^{\mathrm{i}}, f_{\mathrm{f}}^{\mathrm{i}} f_{\mathrm{s}}^{\mathrm{i}}$ and $f_{\mathrm{f}}^{\mathrm{i}}$ are the $\mathrm{O}_{2}$ mole fractions at the inlet (with superscript i) and outlet (with superscript o) of sweep gas and feed gas and $\mathrm{L}$ the length of the membrane tube.

Eq. (5.1)-(5.2), in combination with the boundary conditions as given in eq. (5.4), can be numerically solved if sweep/feed gas flow rates $(F)$ and their $\mathrm{O}_{2}$ mole fractions $(f)$ at the inlet of the membrane tube are known $\left(F_{\mathrm{s}}^{\mathrm{i}}, F_{\mathrm{f}}^{\mathrm{i}}, f_{\mathrm{s}}^{\mathrm{i}}, f_{\mathrm{f}}^{\mathrm{i}}\right)$. From these results gas flow rates and $\mathrm{O}_{2}$ mole fractions at the outlet of the membrane tube can be calculated $\left(F_{\mathrm{s}}^{0}, F_{\mathrm{f}}{ }^{0}, f_{\mathrm{s}}^{0}, f_{\mathrm{f}}{ }^{0}\right)$. In most cases, $f_{\mathrm{s}}^{\mathrm{i}}$ and $f_{\mathrm{f}}^{\mathrm{i}}$ are fixed, while $F_{\mathrm{s}}^{\mathrm{i}}$ and $F_{\mathrm{f}}^{\mathrm{i}}$ can be adjusted if necessary. For example, if a certain $\mathrm{O}_{2}$ mole fractions $\left(f_{\mathrm{s}}^{0}, f_{\mathrm{f}}^{0}\right)$ in the sweep/feed gas at the outlet of the membrane tube is required, appropriate $F_{s}^{\mathrm{i}}$ and $F_{\mathrm{f}}^{\mathrm{i}}$ values have to be chosen. In this study. In this work $f_{\mathrm{s}}^{0}$ is fixed at a value of 0.35 because it has been reported that a composition of approximately $35 \% \mathrm{O}_{2}$ and $65 \%$ of $\mathrm{CO}_{2}(\mathrm{v} / \mathrm{v})$ is needed in an oxy-fuel combustion process to ensure the flame temperature and heat capacity of gases to match fuel combustion in air [14]. Besides, $f_{\mathrm{f}}^{0}$ is kept at a value of 0.02 which means that around $92 \%$ of oxygen in the air is recovered.

As the increase of sweep gas flow rate is caused by the permeated oxygen, the amount of moles of oxygen produced by a single membrane tube, $F_{\mathrm{O}_{2}}$, can be calculated with eq. (5.5):

$$
F_{\mathrm{O}_{2}}=F_{\mathrm{s}}^{0}-F_{\mathrm{s}}^{\mathrm{i}}
$$

\section{Total membrane area calculation}

The total membrane area is based on a $50 \mathrm{MW}$ coal-fired power plant. In this power plant, the combustion of coal is described by reaction (6) assuming coal 
contains $100 \%$ of carbon.

$$
\mathrm{C}+\mathrm{O}_{2} \rightarrow \mathrm{CO}_{2}
$$

If it is further assumed that the heat density of coal is $30 \mathrm{MJ} / \mathrm{kg}$ (HHV) and the overall efficiency of the power plant is $30 \%$ [15], the total amount of coal needed for one hour operation of this power plant is

$$
N_{\text {coal }}=\frac{50 \mathrm{MW} \times 3600 \mathrm{~s}}{30 \mathrm{MJ} / \mathrm{kg} \times 0.3 \times 12 \mathrm{~kg} / \mathrm{kmole}} \approx 1667 \mathrm{kmole}
$$

The oxygen needed for the combustion of coal has the same mole number. Since the oxygen produced by a single tube membrane is known (eq. (5.5)), the number of tubular membranes, $N_{\mathrm{m}}$, and also the total membrane area, $A$, can be calculated:

$$
\begin{gathered}
N_{\mathrm{m}}=\frac{F_{\mathrm{O}_{2}}^{\mathrm{T}}}{F_{\mathrm{O}_{2}}} \\
A=2 \pi R_{1} \mathrm{~L} \times N_{\mathrm{m}}
\end{gathered}
$$

where $F_{\mathrm{O}_{2}}^{\mathrm{T}}$ is the amount of total oxygen needed and $F_{\mathrm{O}_{2}}$ is the amount of oxygen produced by a single membrane tube.

\subsection{Results and discussion}

\subsubsection{Thermal-gravimetric analysis}

The calcined SCF powder was checked to have a phase pure perovskite crystal structure by means of XRD. The reaction between $\mathrm{SCF}$ and $\mathrm{CO}_{2}$ was studied by isothermal gravimetric experiments TGA. In Figure 5.4a, the results of TGA experiments at $950{ }^{\circ} \mathrm{C}$ are described under varying $p \mathrm{O}_{2}$ by adjusting the $\mathrm{N}_{2} / \mathrm{O}_{2}$ ratio and keeping the $p \mathrm{CO}_{2}$ constant at 0.67 bar. The weight of the SCF powder samples immediately increases upon exposure to a $\mathrm{CO}_{2}$-containing gas mixture, while the rate of weight gain is different when the experiments were performed at different $p \mathrm{O}_{2}\left(10^{-}\right.$ ${ }^{4}, 0.05,0.10$ and 0.20 bar); a higher $p \mathrm{O}_{2}$ leads to a lower reaction rate of $\mathrm{CO}_{2}$ with the SCF powder sample. After 5 hours, the weight of the samples increased by $15.4 \%$, 
$10.4 \%, 8.6 \%$ and $6.2 \%$ respectively. Clearly, the reaction between $\mathrm{SCF}$ and $\mathrm{CO}_{2}$ at $950{ }^{\circ} \mathrm{C}$ is strongly affected by $p \mathrm{O}_{2}$.
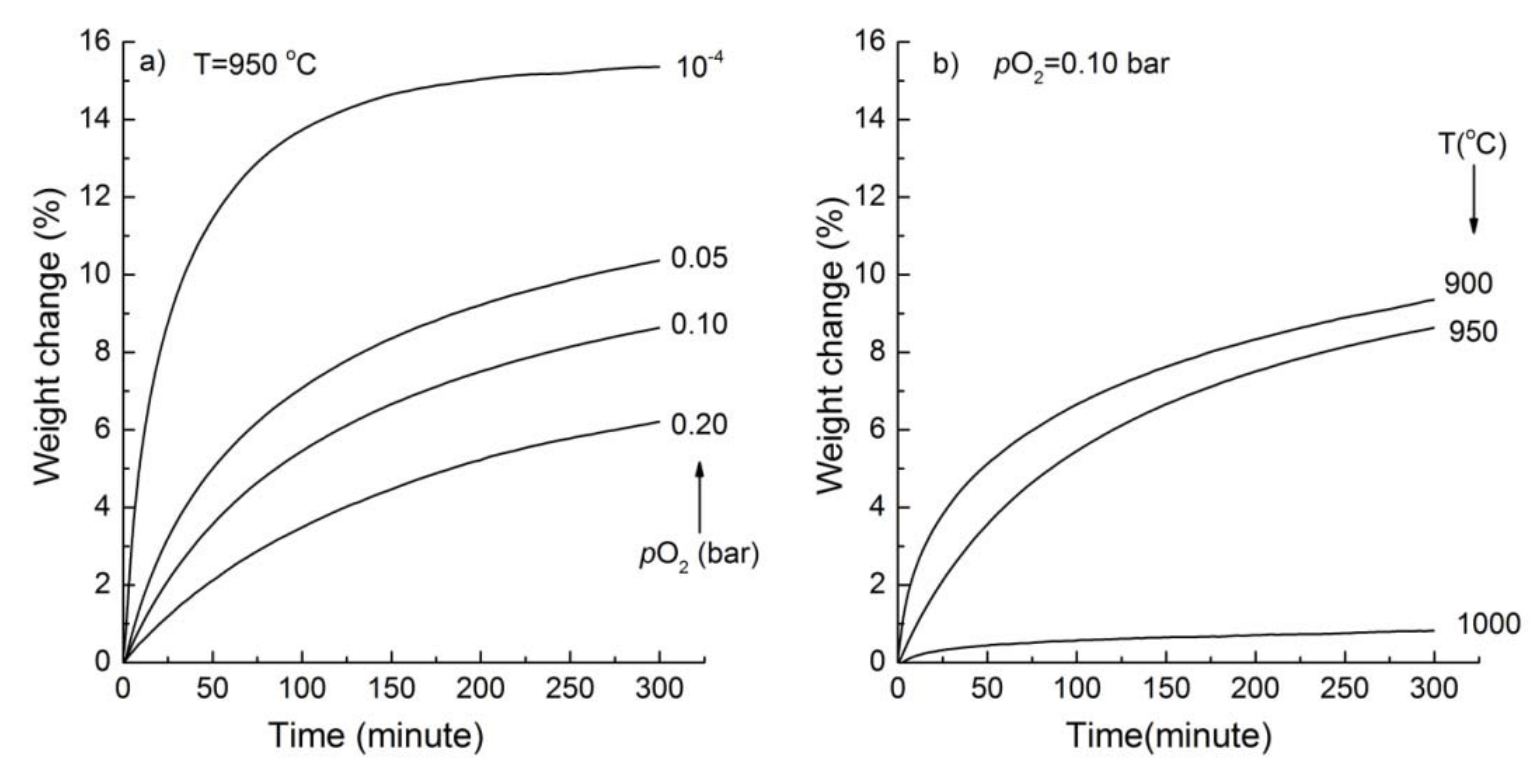

Figure 5.4. Weight change of SCF powder samples under different conditions; a) variation in $\left.p \mathrm{O}_{2} ; \mathrm{b}\right)$ variation in temperature. $\left(p \mathrm{CO}_{2}=0.67\right.$ bar in all cases; balance: $\left.\mathrm{N}_{2}\right)$.

Another parameter that can influence the reaction between $\mathrm{SCF}$ and $\mathrm{CO}_{2}$ is the temperature. At $1000{ }^{\circ} \mathrm{C}$, the reaction was very slow, and after 5 hours, the weight only increased by $0.8 \%$, compared to $9.4 \%$ and $8.6 \%$ for $900{ }^{\circ} \mathrm{C}$ and $950{ }^{\circ} \mathrm{C}$, respectively, when using a $p \mathrm{O}_{2}$ of 0.1 bar. A higher temperature leads to a lower reaction rate (Figure 5.4b), which indicates that SCF is more stable at higher temperatures. This result is in accordance with previous data of Yi et al. [10]. A similar trend has been found for other perovskite structures like $\mathrm{BaCe}_{0.9} \mathrm{Y}_{0.1} \mathrm{O}_{3-\delta}$ [16]. A thermodynamic analysis has been performed by Brandão et al. [17] for the explanation of this temperature effect. 


\subsubsection{XPS analysis}

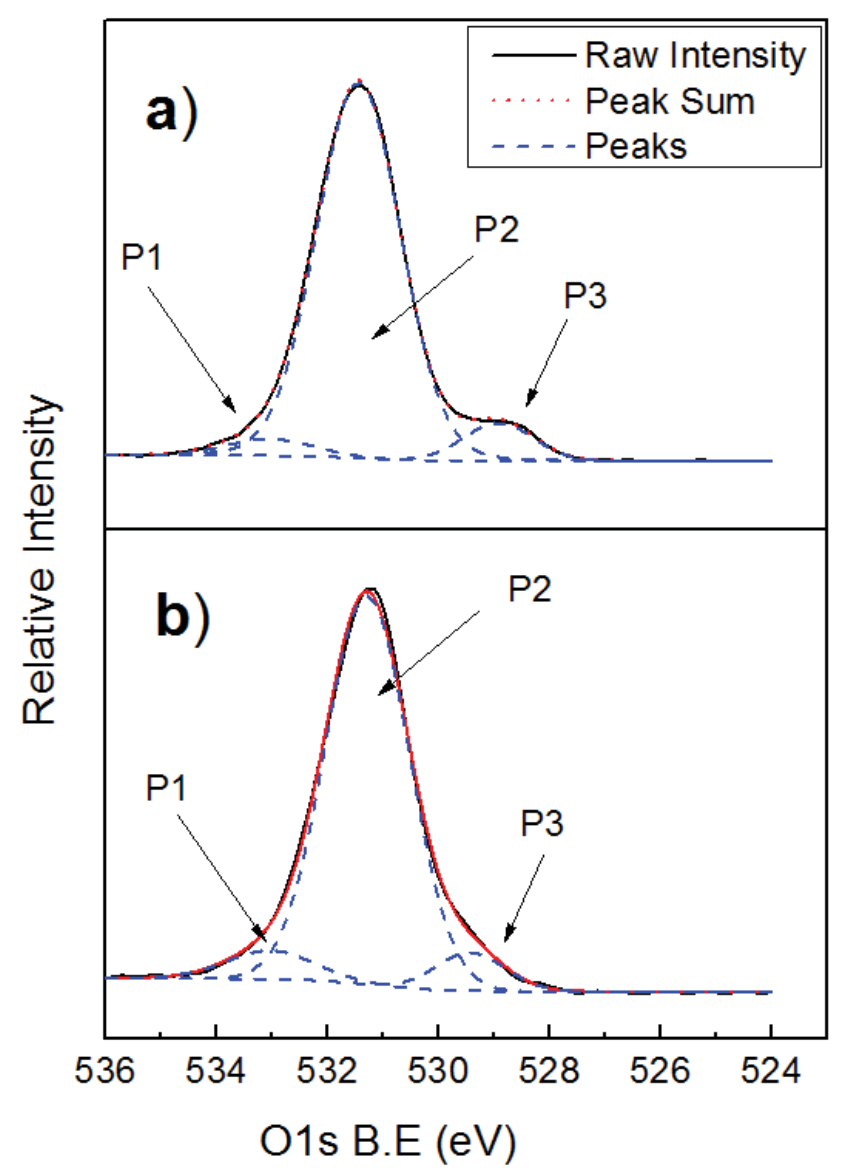

Figure 5.5. O1s binding energy of SCF samples quenched from $950{ }^{\circ} \mathrm{C}$ at different $p \mathrm{O}_{2}$; a) $p \mathrm{O}_{2}=10^{-4}$ bar; b) $p \mathrm{O}_{2}=1.0$ bar; P1: Absorbed water; P2: Absorbed oxygen; P3: Lattice oxygen. (Details about peak position can be found in the Table 5.1)

Table 5.1. Peak positions of the XPS spectrum as given in Fig. 5.5.

\begin{tabular}{cccc}
\hline$p \mathrm{O}_{2}$ (bar) & $\mathrm{P} 1(\mathrm{eV})$ & $\mathrm{P} 2(\mathrm{eV})$ & $\mathrm{P} 3(\mathrm{eV})$ \\
\hline $\begin{array}{c}1 \times 10^{-4} \text { (Fig. } \\
\text { 5a) }\end{array}$ & 533.0 & 531.4 & 528.9 \\
1.0 (Fig. 5b) & 533.0 & 531.4 & 529.5 \\
\hline
\end{tabular}

The inhibition of the reaction between $\mathrm{SCF}$ and $\mathrm{CO}_{2}$ can be explained by the Lewis acid-base theory, where $\mathrm{CO}_{2}$ is regarded as the gas acid and SCF as the solid base [5]. The intensity of this reaction is determined by the basicity of SCF, which 
may be different under different conditions, for example, different temperature or $p \mathrm{O}_{2}$. In general, the basicity of a metal oxide is defined as its ability to donate electrons to an adsorbed molecule (in this case $\left.\mathrm{CO}_{2}\right)$. The O1s binding energy $(\mathrm{O} 1 \mathrm{~s}$ $\mathrm{BE})$, which is related to the charge density around the oxide ions, is usually taken as a measure of the basicity of a metal oxide $[18,19]$. A higher O1s BE means a lower charge density, consequently, it is more difficult for the oxides to donate electrons to the adsorbed molecules [20], indicating a lower basicity of the metal oxide. To check whether the O1s BE for SCF is $p \mathrm{O}_{2}$ dependent, we annealed SCF bulk samples in oxygen $\left(p \mathrm{O}_{2}=1\right.$ bar) and nitrogen $\left(p \mathrm{O}_{2}=10^{-4}\right.$ bar) at $950{ }^{\circ} \mathrm{C}$ for 20 hours and quenched them to room temperature. XPS analysis was used to determine the O1s BE. The raw XPS data were de-convoluted into three Gaussian peaks (Figure 5.5). The peak at $533.0 \mathrm{eV}$ is assigned to absorbed water, $531.4 \mathrm{eV}$ to oxygen in absorbed oxygen, and 528-530 eV to lattice oxygen [21, 22]. For absorbed water and oxygen, the $\mathrm{O} 1 \mathrm{~s} \mathrm{BE}$ has the same value in both $p \mathrm{O}_{2}$ cases. For the lattice oxygen an increase in $\mathrm{O} 1 \mathrm{~s} \mathrm{BE}$ from $528.9 \mathrm{eV}$ to $529.5 \mathrm{eV}$ was observed when $p \mathrm{O}_{2}$ was increased from $10^{-4}$ to 1 bar. This suggests that the basicity of SCF tends to be lower at higher $p \mathrm{O}_{2}$, thus lowers the affinity of reaction between $\mathrm{SCF}$ and $\mathrm{CO}_{2}$. This result is in agreement with the TGA analysis (Figure 5a).

\subsubsection{Oxygen permeation measurements}




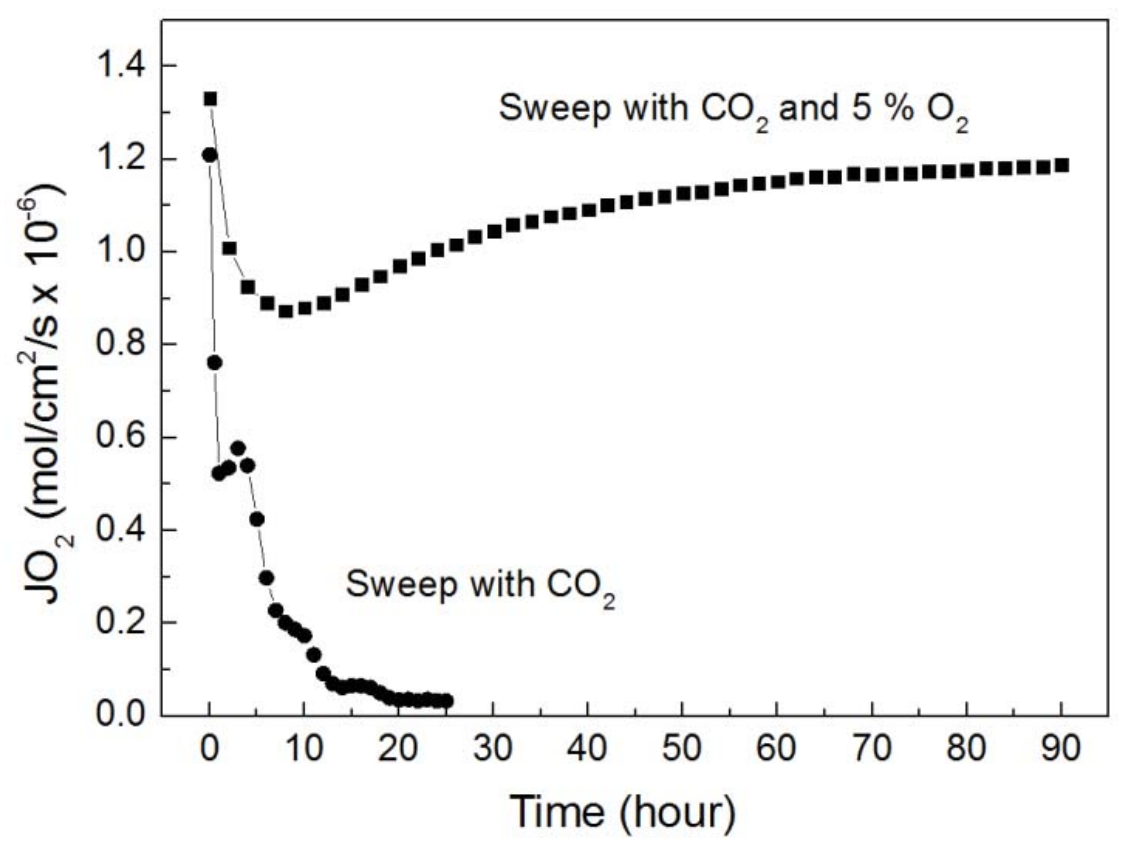

Figure 5.6. Long-term oxygen permeation tests of SCF membranes at $950{ }^{\circ} \mathrm{C}$ by using pure $\mathrm{CO}_{2}$ (circles) or an $\mathrm{O}_{2} / \mathrm{CO}_{2}$ mixture (squares, $\mathrm{O}_{2}$ mole fraction $5 \%$ ) as sweep gas (50 $\mathrm{ml} / \mathrm{min}$ for both cases). Feed gas: air. Membrane thickness: $1 \mathrm{~mm}$.

To check the stability of SCF membranes in $\mathrm{CO}_{2}$ under operating conditions, two long term ( 90 hours) oxygen permeation measurements were performed, at $950{ }^{\circ} \mathrm{C}$, in $\mathrm{CO}_{2}$ atmosphere. In the first experiment synthetic air $\left(\mathrm{O}_{2} 20 \mathrm{ml} / \mathrm{min}\right.$ and $\left.\mathrm{N}_{2} 80 \mathrm{ml} / \mathrm{min}\right)$ was used as feed gas, and pure $\mathrm{CO}_{2}\left(50 \mathrm{ml} / \mathrm{min}, p \mathrm{O}_{2} \approx 10^{-4} \mathrm{bar}\right)$ was used as sweep gas. In the second experiment, a mixture of $\mathrm{O}_{2} / \mathrm{CO}_{2}\left(\mathrm{O}_{2} 2.5 \mathrm{ml} / \mathrm{min}\right.$ and $\mathrm{CO}_{2} 47.5 \mathrm{ml} / \mathrm{min}$ ) was used as sweep gas, and the feed gas was partly changed $\left(\mathrm{O}_{2} 50 \mathrm{ml} / \mathrm{min}\right.$ and $\left.\mathrm{N}_{2} 50 \mathrm{ml} / \mathrm{min}\right)$ to ensure a comparable $p \mathrm{O}_{2}$ gradient across the membrane for both experiments. The results of oxygen permeation measurements, as given in Figure 5.6, show that the SCF membranes behaved quite differently in pure $\mathrm{CO}_{2}$ than in the $\mathrm{CO}_{2} / \mathrm{O}_{2}$ mixture. If pure $\mathrm{CO}_{2}$ is used as sweep gas, the oxygen flux decreased quickly to zero within 25 hours. A similar result has also been reported by Zeng et al. [5]. By using an $\mathrm{O}_{2} / \mathrm{CO}_{2}$ mixture $\left(p \mathrm{O}_{2}=0.05\right.$ bar $)$ as sweep gas, the oxygen flux decreased by $34 \%$ in the first 10 hours, and slowly recovered to $90 \%$ of its original value in the following 50 hours, and then became constant. Although it is 
still not clear what caused the oxygen flux decrease in the first 10 hours, it is obvious that the addition of some oxygen to the sweep gas indeed enhances the $\mathrm{CO}_{2}$ tolerance of SCF membranes in a $\mathrm{CO}_{2}$ atmosphere under operating conditions, and thus prevented the oxygen flux from decreasing in the long run. However, as shown in Figure 5.5, the reaction between SCF powder and $\mathrm{CO}_{2}$ could not be prevented at a temperature of $950{ }^{\circ} \mathrm{C}$ by increasing $p \mathrm{O}_{2}$ up to 0.20 bar, which seems to be in conflict with the oxygen permeation results. This "conflict" is attributed to the dynamic process occurring at the permeate side of the membrane. During an oxygen permeation experiment, oxygen is released from the membrane surface at the permeate side in the form of oxygen molecules, creating a higher oxygen activity at the membrane interface than in the gas bulk phase [23, 24]. This dynamic process, which is different from the stationary environment in the TGA experiments, is beneficial for the membrane stability.

5.3.4 Process design and membrane area calculation

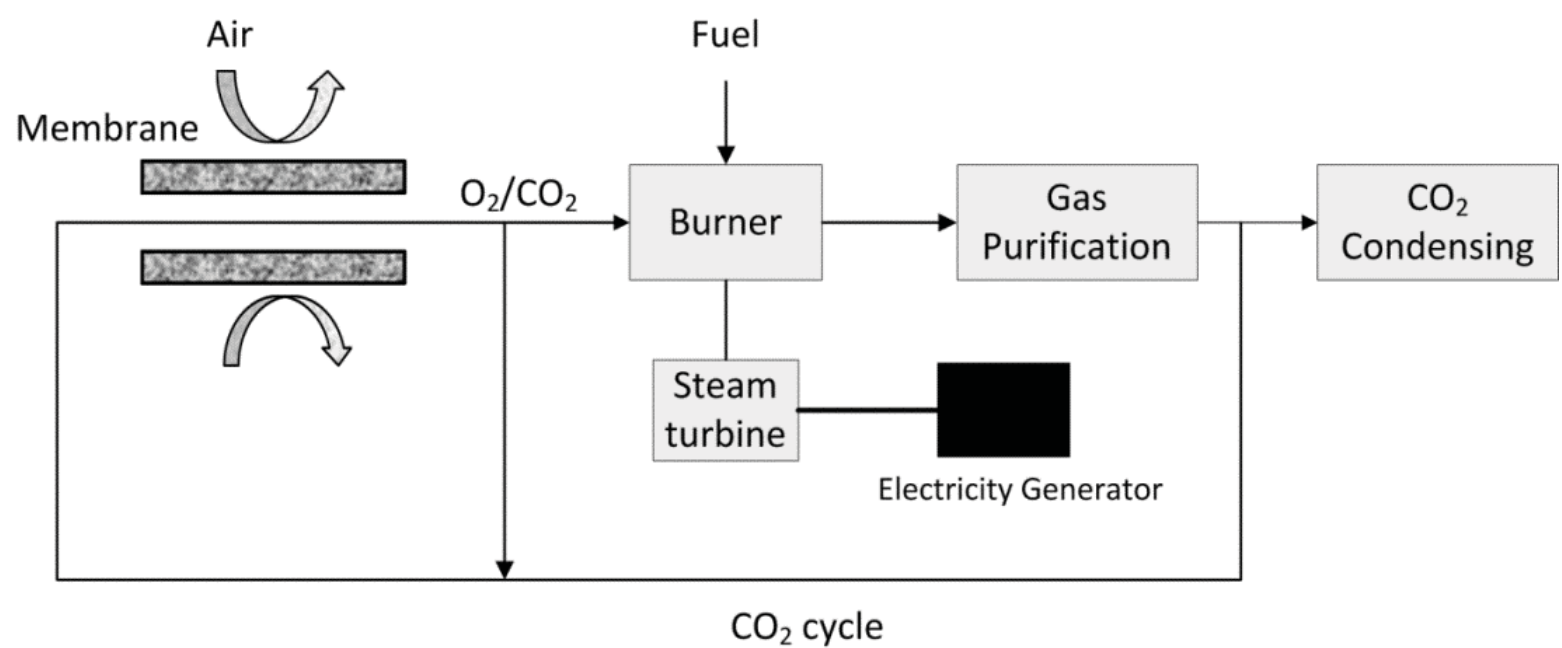

Figure 5.7. A modified process scheme for the membrane integrated oxy-fuel combustion.

Based on these experimental results we propose a new design for a membrane integrated oxy-fuel combustion process (Figure 5.7). In this concept an extra $\mathrm{CO}_{2} / \mathrm{O}_{2}$ recycle is introduced to increase the $p \mathrm{O}_{2}$ in the $\mathrm{CO}_{2}$ sweep gas. This modification 
ensures that the $p \mathrm{O}_{2}$ in the $\mathrm{CO}_{2}$ sweep gas at the inlet of the membrane module is high enough to protect SCF from degradation by carbonation. However, this modification also leads to an increase of needed membrane area because part of $\mathrm{CO}_{2} / \mathrm{O}_{2}$ gas stream is used for recycling and the driving force for oxygen permeation is also slightly decreased. In order to quantitatively study this effect, a calculation was performed of the total membrane area needed for a $50 \mathrm{MW}$ coal-fired power plant using $\mathrm{O}_{2}$ mole fractions in the $\mathrm{CO}_{2}$ sweep varying from 0.005 to 0.1 (details about this calculation can be found in the experimental procedure and methodology section). The membrane geometry and operating conditions are listed in Table 5.2.

Table 5.2. Membrane geometry and operating conditions of oxygen permeation in a single membrane tube.

\begin{tabular}{lll}
\hline Variable & Value & Units \\
\hline Membrane length $(L)$ & 100 & $\mathrm{~cm}$ \\
Membrane outer diameter & 1.0 & $\mathrm{~cm}$ \\
Membrane inner diameter & 0.8 & $\mathrm{~cm}$ \\
Ionic conductivity & 1.0 & $\mathrm{~S} / \mathrm{cm}$ \\
Feed side pressure & 10 & $\mathrm{bar}$ \\
Sweep side pressure & $1.7^{*}$ & $\mathrm{bar}$ \\
Temperature & 1223 & $\mathrm{~K}$ \\
Diffusion coefficient of $\mathrm{O}_{2} / \mathrm{N}_{2}$ & $2.19^{* *}$ & $\mathrm{~cm} / \mathrm{s}$ \\
Diffusion coefficient of $\mathrm{O}_{2} / \mathrm{CO}_{2}$ & $1.55^{* *}$ & $\mathrm{~cm} / \mathrm{s}$ \\
& 0.209 & - \\
$\mathrm{O}_{2}$ mole fraction of feed gas at inlet $\left(f_{\mathrm{f}}^{\mathrm{i}}\right)$ & $0.005-0.1$ & - \\
$\mathrm{O}_{2}$ mole fraction of sweep gas at inlet $\left(f_{\mathrm{s}}^{\mathrm{i}}\right)$ & 0.02 & - \\
$\mathrm{O}_{2}$ mole fraction of feed gas at outlet $\left(f_{\mathrm{f}}^{0}\right)$ & 0.35 & - \\
$\mathrm{O}_{2}$ mole fraction of sweep gas at outlet $\left(f_{\mathrm{s}}^{\mathrm{o}}\right)$ & & \\
\hline
\end{tabular}

*: Typical pressure for oxy-fuel application [1].

**: The binary diffusion coefficients of $\mathrm{O}_{2} / \mathrm{N}_{2}$ and $\mathrm{O}_{2} / \mathrm{CO}_{2}$ at $950{ }^{\circ} \mathrm{C}$ were calculated with Chapman-Enskog's theory [25]. 
The results of calculation are given in Figure 5.8. When $f_{\mathrm{s}}^{\mathrm{i}}\left(\mathrm{O}_{2}\right.$ mole fraction in $\mathrm{CO}_{2}$ sweep gas) is increased to 0.05 , which has been proven to be sufficient to protect $\mathrm{SCF}$ membranes against $\mathrm{CO}_{2}$ degradation, the total needed membrane area increases from $4.97 \times 10^{4}$ to $5.81 \times 10^{4} \mathrm{~m}^{2}$, so only by $\sim 17 \%$ compared with the (theoretical) case of using pure $\mathrm{CO}_{2}$ as sweep gas.

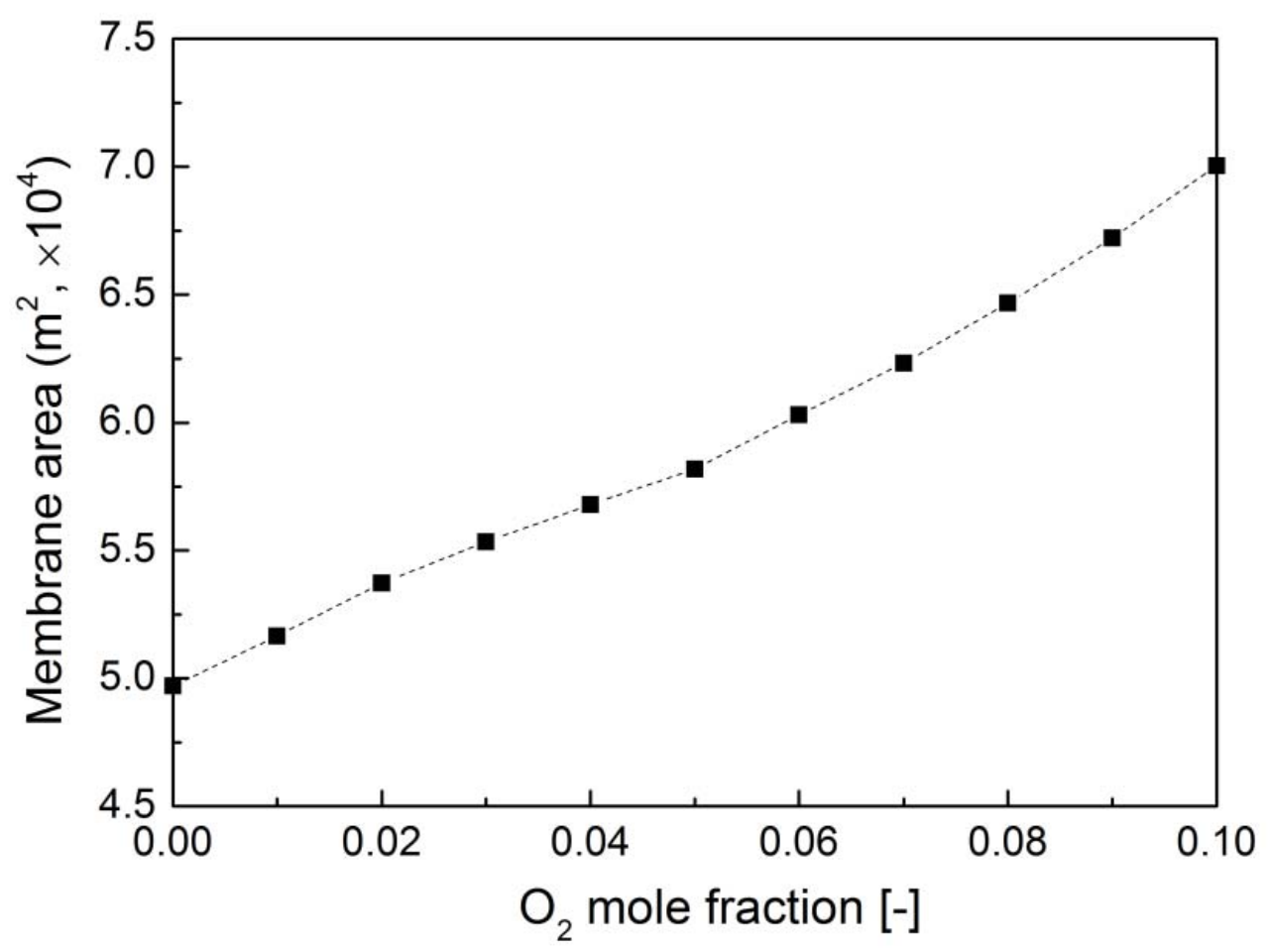

Figure 5.8. Calculated SCF membrane area for a $50 \mathrm{MW}$ coal-fired power plant with different $\mathrm{O}_{2}$ mole fractions of $\mathrm{CO}_{2}$ in the sweep gas.

\subsection{Conclusion}

This study demonstrates that degradation of $\mathrm{SrCo}_{0.8} \mathrm{Fe}_{0.2} \mathrm{O}_{3-\delta}$ (SCF) perovskite, oxygen-selective, membranes in a $\mathrm{CO}_{2}$ atmosphere is affected by the oxygen partial pressure in the $\mathrm{CO}_{2}$ sweep gas. Increasing the oxygen partial pressure enhances the $\mathrm{CO}_{2}$ tolerance of these membranes. Long term oxygen permeation tests at $950{ }^{\circ} \mathrm{C}$ showed that mixing $5 \%$ of oxygen to the $\mathrm{CO}_{2}$ sweep gas can prevent the SCF membrane from degradation without sacrificing its high oxygen permeability. Based on these experimental results a modified membrane integrated oxy-fuel combustion 
process is proposed. A simple membrane area calculation shows that $17 \%$ of additional membrane area is necessary for achieving the same oxygen yield compared with pure $\mathrm{CO}_{2}$ as sweep gas.

\section{References}

[1] B. Metz, O. Davidson, H.d. Coninck, M. Loos, L. Meyer, IPCC Special Report on Carbon Dioxide Capture and Storage, Intergovernmental Panel on Climate Change, (2005).

[2] M.A. Habib, H.M. Badr, S.F. Ahmed, R. Ben-Mansour, K. Mezghani, S. Imashuku, G.J. la O, Y. Shao-Horn, N.D. Mancini, A. Mitsos, P. Kirchen, A.F. Ghoneim, A review of recent developments in carbon capture utilizing oxy-fuel combustion in conventional and ion transport membrane systems, International Journal of Energy Research, 35 (2011) 741-764.

[3] S. Engels, F. Beggel, M. Modigell, H. Stadler, Simulation of a membrane unit for oxyfuel power plants under consideration of realistic BSCF membrane properties, Journal of Membrane Science, 359 (2010) 93-101.

[4] Y. Teraoka, H.-M. Zhang, S. Furukawa, N. Yamazoe, Oxygen permeation through perovskite-type oxides, Chemistry Letter, 14 (1985) 1743-1746.

[5] Q. Zeng, Y.B. Zu, C.G. Fan, C.S. Chen, $\mathrm{CO}_{2}$-tolerant oxygen separation membranes targeting $\mathrm{CO}_{2}$ capture application, Journal of Membrane Science, 335 (2009) 140-144.

[6] T. Klande, O. Ravkina, A. Feldhoff, Effect of A-site lanthanum doping on the $\mathrm{CO}_{2}$ tolerance of $\mathrm{SrCo}_{0.8} \mathrm{Fe}_{0.2} \mathrm{O}_{3-\delta}$ oxygen-transporting membranes, Journal of Membrane Science, 437 (2013) 122130.

[7] W. Chen, C.-s. Chen, L. Winnubst, Ta-doped $\mathrm{SrCo}_{0.8} \mathrm{Fe}_{0.2} \mathrm{O}_{3-\delta}$ membranes: Phase stability and oxygen permeation in $\mathrm{CO}_{2}$ atmosphere, Solid State Ionics, 196 (2011) 30-33.

[8] G. Zhang, Z. Liu, N. Zhu, W. Jiang, X. Dong, W. Jin, A novel $\mathrm{Nb}_{2} \mathrm{O}_{5}$-doped $\mathrm{SrCo}_{0.8} \mathrm{Fe}_{0.2} \mathrm{O}_{3-\delta}$ oxide with high permeability and stability for oxygen separation, Journal of Membrane Science, 405406 (2012) 300-309.

[9] J.W. Stevenson, T.R. Armstrong, R.D. Carneim, L.R. Pederson, W.J. Weber, Electrochemical properties of mixed conducting perovskites $\mathrm{La}_{1-\mathrm{x}} \mathrm{M}_{\mathrm{x}} \mathrm{Co}_{1-\mathrm{y}} \mathrm{Fe}_{\mathrm{y}} \mathrm{O}_{3-\delta}(\mathrm{M}=\mathrm{Sr}, \mathrm{Ba}, \mathrm{Ca}), \mathrm{J}$ Electrochem Soc, 143 (1996) 2722-2729.

[10] J.X. Yi, S.J. Feng, Y.B. Zuo, W. Liu, C.S. Chen, Oxygen permeability and stability of $\mathrm{Sr}_{0.95} \mathrm{Co}_{0.8} \mathrm{Fe}_{0.2} \mathrm{O}_{3-\delta}$ in a $\mathrm{CO}_{2}$ - and $\mathrm{H}_{2} \mathrm{O}$-containing atmosphere, Chem Mater, 17 (2005) 5856-5861.

[11] B. Bird, W. E.Stewart, E. N.Lightfoot, Transport Phenomena, 2 ed ., John Wiley\&Sons, 2001.

[12] Y.S. Lin, W.J. Wang, J.H. Han, Oxygen Permeation through thin mixed-conducting solid oxide membranes, Aiche J, 40 (1994) 786-798. 
[13] P.V. Danckwerts, Continuous flow systems: Distribution of residence times, Chem Eng Sci, 2 (1953) 1-13.

[14] E. Croiset, K. Thambimuthu, A. Palmer, Coal combustion in $\mathrm{O}_{2} / \mathrm{CO}_{2}$ mixtures compared with air, The Canadian Journal of Chemical Engineering, 78 (2000) 402-407.

[15] J. Black, Cost and performance baseline for fossil energy plants. Volume 1: Bituminous coal and natural gas to electricity final report, in: National Energy Technology Laboratory, 2007, pp. 626.

[16] N. Zakowsky, S. Williamson, J.T.S. Irvine, Elaboration of $\mathrm{CO}_{2}$ tolerance limits of $\mathrm{BaCe}_{0.9} \mathrm{Y}_{0.1} \mathrm{O}_{3-\delta}$ electrolytes for fuel cells and other applications, Solid State Ionics, 176 (2005) 3019-3026.

[17] A. Brandão, J.F. Monteiro, A.V. Kovalevsky, D.P. Fagg, V.V. Kharton, J.R. Frade, Guidelines for improving resistance to $\mathrm{CO}_{2}$ of materials for solid state electrochemical systems, Solid State Ionics, 192 (2011) 16-20.

[18] H. Vinek, H. Noller, M. Ebel, K. Schwarz, X-ray photoelectron spectroscopy and heterogeneous catalysis, with elimination reactions as an example, Journal of the Chemical Society, Faraday Transactions 1: Physical Chemistry in Condensed Phases, 73 (1977) 734-746.

[19] H. Noller, J.A. Lercher, H. Vinek, Acidic and basic sites of maim group mixed metal oxides, Materials Chemistry and Physics, 18 (1988) 577-593.

[20] H.J.M. Bosman, A.P. Pijpers, A.W.M.A. Jaspers, An X-ray photoelectron spectroscopy study of the acidity of $\mathrm{SiO}_{2}-\mathrm{ZrO}_{2}$ mixed oxides, J Catal, 161 (1996) 551-559.

[21] C.M. Pradier, C. Hinnen, K. Jansson, L. Dahl, M. Nygren, A. Flodstrom, Structural and surface characterization of perovskite-type oxides; influence of A and B substitutions upon oxygen binding energy, Journal of Materials Science, 33 (1998) 3187-3191.

[22] N.A. Merino, B.P. Barbero, P. Eloy, L.E. Cadús, $\mathrm{La}_{1-\mathrm{x}} \mathrm{Ca}_{\mathrm{x}} \mathrm{CoO}_{3}$ perovskite-type oxides: Identification of the surface oxygen species by XPS, Applied Surface Science, 253 (2006) 14891493.

[23] J. Sunarso, S. Baumann, J.M. Serra, W.A. Meulenberg, S. Liu, Y.S. Lin, J.C.D. da Costa, Mixed ionic-electronic conducting (MIEC) ceramic-based membranes for oxygen separation, Journal of Membrane Science, 320 (2008) 13-41.

[24] H.J.M. Bouwmeester, H. Kruidhof, A.J. Burggraaf, Importance of the surface exchange kinetics as rate limiting step in oxygen permeation through mixed-conducting oxides, Solid State Ionics, 72 (1994) 185-194.

[25] E.L.Cussler, Diffusion: mass transfer in fluid system, 1ed., Cambridge University Press, Cambridge, 1984. 
Chapter 5 


\title{
Chapter 6 Membrane-integrated oxy-fuel combustion: process design and simulation
}

\begin{abstract}
:
In this chapter a membrane-integrated oxy-fuel combustion process is designed and simulated in UniSim ${ }^{\circledR}$. The results show that a net efficiency of $32.1 \%$ is obtained for a coal-fired power plant where 20 tonne/h of coal is burned for electric power generation, which is higher than that of an oxy-fuel combustion process using oxygen from cryogenic distillation of air (29.6\%). The specific electrical energy demand for $\mathrm{CO}_{2}$ capture in this oxy-fuel process, including oxygen production and $\mathrm{CO}_{2}$ compression (to $100 \mathrm{bar}$ ), is calculated to be $\sim 159 \mathrm{kWh}_{\mathrm{e}} / \mathrm{t}_{\mathrm{CO}_{2}}$. The required membrane area for the power plant is approximately $71,000 \mathrm{~m}^{2}$ based on Ta-doped $\mathrm{SrCo}_{0.8} \mathrm{Fe}_{0.2} \mathrm{O}_{3-\delta}$ (SCF) membranes. Inspired by the research as described in chapter 4 , a modified process is proposed, in which un-doped SCF membranes are used for air separation and an extra $\mathrm{O}_{2} / \mathrm{CO}_{2}$ loop is introduced to protect the SCF membranes. The modified process shows a similar net efficiency of $31.9 \%$, but a considerably lower amount of membrane area $\left(49,000 \mathrm{~m}^{2}\right)$ is necessary.
\end{abstract}

This chapter has been submitted for a journal publication. 


\section{List of symbols}

\begin{tabular}{ll}
\hline$A$ & Surface area of an heat exchanger $\left(\mathrm{m}^{2}\right)$ \\
$A_{\mathrm{m}}$ & Total needed membrane area $\left(\mathrm{m}^{2}\right)$ \\
$d$ & Membrane thickness (cm) \\
$D_{\mathrm{i}}$ & Membrane inner diameter (cm) \\
$D_{\mathrm{o}}$ & Membrane outer diameter (cm) \\
$E_{\text {out }}$ & electric power output (MW) \\
$E_{\mathrm{t}}$ & thermal power released from the coal combustion (MW) \\
$E_{\mathrm{O}_{2}}$ & Power for oxygen production (MW) \\
$E_{\mathrm{CO}}^{\mathrm{COM}}$ & Power for CO ${ }_{2}$ compression to 100 bar (MW) \\
$f_{\mathrm{f}}^{\mathrm{i}}$ & Oxygen mole fraction of the feed gas at inlet \\
$f_{\mathrm{f}}^{\circ}$ & Oxygen mole fraction of the feed gas at outlet \\
$f_{\mathrm{s}}^{\mathrm{i}}$ & Oxygen mole fraction of the sweep gas at inlet \\
$f_{\mathrm{s}}^{\circ}$ & Oxygen mole fraction of the sweep gas at outlet \\
$F_{\mathrm{f}}^{\mathrm{i}}$ & Feed gas flow rate in a single membrane tube at inlet (mole/h) \\
$F_{\mathrm{f}}^{\circ}$ & Feed gas flow rate in a single membrane tube at outlet (mole/h) \\
$F_{\mathrm{s}}^{\mathrm{i}}$ & Sweep gas flow rate in a single membrane tube at inlet (mole/h) \\
$F_{\mathrm{s}}^{\circ}$ & Sweep gas flow rate in a single membrane tube at outlet (mole/h) \\
$F_{\mathrm{f}}^{\mathrm{i}}(\mathrm{T})$ & Total feed gas flow rate of the membrane module at inlet (mole/h) \\
$F_{\mathrm{f}}^{\circ}(\mathrm{T})$ & Total feed gas flow rate of the membrane module at outlet $(\mathrm{mole} / \mathrm{h})$ \\
$F_{\mathrm{s}}^{\mathrm{i}}(\mathrm{T})$ & Total sweep gas flow rate of the membrane module at inlet (mole/h) \\
$F_{\mathrm{s}}^{\circ}(\mathrm{T})$ & Total sweep gas flow rate of the membrane module at outlet (mole/h) \\
$F_{\mathrm{O}_{2}}^{\mathrm{i}}$ & Oxygen produced by a single membrane tube (mole/h) \\
$F_{\mathrm{O}_{2}}^{\mathrm{T}}$ & Oxygen produced by the whole membrane module (mole/h) \\
$j_{\mathrm{O}_{2}}$ & Oxygen flux (mole/cm²/s) \\
$L$ & Length of the membrane tube (cm) \\
$\dot{m}_{\mathrm{O}_{2}}$ & Oxygen mass flow rate (tonne/h) \\
\hline &
\end{tabular}




\begin{tabular}{ll}
\hline$\dot{m}_{\mathrm{CO}_{2}}$ & $\mathrm{CO}_{2}$ capturing mass flow rate (tonne/h) \\
$F_{\mathrm{CO}_{2}}$ & $\mathrm{CO}_{2}$ molar flow rate (mole/h) \\
$N_{\mathrm{m}}$ & Total needed membrane tube number \\
$P_{\mathrm{f}}$ & Operating pressure of the feed gas (bar) \\
$P_{\mathrm{s}}$ & Operating pressure of the sweep gas (bar) \\
$P_{\mathrm{O}_{2}}$ & Oxygen partial pressure (bar) \\
$P_{\mathrm{O}_{2}}^{\prime \prime}$ & Oxygen partial pressure at feed side (bar) \\
$P_{\mathrm{O}_{2}}^{\prime}$ & Oxygen partial pressure at sweep side (bar) \\
$Q$ & Heat transferred per unit time in a heat exchanger (MW) \\
$R$ & Gas constant (J/mole/K) \\
$S E_{\mathrm{CO}_{2}}$ & Specific energy for CO $\mathrm{M}_{2}$ capture ( $\mathrm{kWh} \mathrm{h}_{\mathrm{e}} / \mathrm{t}_{\mathrm{CO}_{2}}$ ) \\
$S E_{\mathrm{O}_{2}}$ & Specific energy for $\mathrm{O}_{2}$ production ( $\mathrm{kWh} \mathrm{h}_{\mathrm{e}} / \mathrm{t}_{\mathrm{O}_{2}}$ ) \\
$T$ & Temperature (K) \\
$\Delta T_{\mathrm{lm}}$ & Logarithm mean temperature difference between the two fluids (K \\
$U$ & Overall heat transfer coefficient of the heat exchanger (W/m²/C) \\
$\eta_{\mathrm{t} \rightarrow \mathrm{e}}$ & Overall steam turbine efficiency \\
$\eta$ & Power plant net efficiency \\
$\eta_{\mathrm{r}}$ & Power plant net efficiency of the reference case \\
$\eta_{\mathrm{o}}$ & Power plant net efficiency of the oxy-fuel combustion process \\
$\theta$ & Oxygen recovery \\
\hline
\end{tabular}




\subsection{Introduction}

Coal-fired power plants contribute to around $30 \%$ of the total anthropogenic $\mathrm{CO}_{2}$ emission to the atmosphere, which is considered to be one of the main reasons of the global climate change. In the past 20 years several techniques are developed to reduce the $\mathrm{CO}_{2}$ emission and several overviews of these techniques were published [1-3]. Among these techniques post-combustion, combined with amine absorption, is the most mature one. In this technique $\mathrm{CO}_{2}$ in the flue gas from the power plant is chemically absorbed at ambient temperature by an amine and the $\mathrm{CO}_{2}$-enriched amine then flows through a stripper where temperature is increased to $110{ }^{\circ} \mathrm{C}-130$ ${ }^{\circ} \mathrm{C}$ to remove the absorbed $\mathrm{CO}_{2}$ [4]. After $\mathrm{CO}_{2}$ removal, the amine solvent is pumped back to the absorber via an amine lean-rich heat exchanger and a cooler to bring it down to the absorber temperature level. In this technique, large amounts of energy has to be applied for the desorption of $\mathrm{CO}_{2}$ in the stripper because part of the water in the amine solvent (around $70 \mathrm{wt} \%$ ) is also evaporated. The overall energy consumption for $\mathrm{CO}_{2}$ capture in this amine absorption process is approximately 340$450 \mathrm{kWh}_{\mathrm{e}} / \mathrm{t}_{\mathrm{CO}_{2}}$, which results in a net efficiency drop of 30-35\% for the whole postcombustion process [5-7].

Another promising technique for $\mathrm{CO}_{2}$ capture is oxy-fuel combustion where pure oxygen, instead of air, is used for the combustion of coal, resulting in a concentrated $\mathrm{CO}_{2}$ gas stream thus enabling efficient $\mathrm{CO}_{2}$ capture, because no amine absorption/desorption process is required [8]. Pure oxygen, required for the oxy-fuel combustion process, can be produced via cryogenic distillation of air, which is a mature technique for oxygen separation from air, as established around 100 years ago. However, the energy consumption for oxygen production, using this technique, is relatively high. For a standalone cryogenic air separation unit the specific energy for oxygen production is about 200-240 $\mathrm{kWh}_{\mathrm{e}} / \mathrm{t}_{\mathrm{O}_{2}}$ [9] (oxygen under standard conditions), which leads to a net efficiency drop in the power plant of $\sim 10 \%$. This 
efficiency drop is much smaller than that in the amine based post-combustion process. In addition, the energy, necessary for oxygen production by cryogenic distillation, can be further decreased by optimizing this process, but $160 \mathrm{kWh}_{\mathrm{e}} / \mathrm{t}_{\mathrm{O}_{2}}$ seems to be a realistic limit [9]. To overcome this limit, it is proposed to produce the oxygen, required needed for the oxy-fuel combustion process, by using oxygen transport membranes (OTM), which are conductive only to oxygen at elevated temperatures $\left(>700{ }^{\circ} \mathrm{C}\right)[5,10-12]$. A general scheme of this process is shown in Figure 6.1. The oxygen, as separated from air by the membrane, is swept by the $\mathrm{CO}_{2}$, while the $\mathrm{O}_{2} / \mathrm{CO}_{2}$ gas mixture is used for the combustion of the fossil fuels. After purification, the exhaust gas mainly consists of $\mathrm{CO}_{2}$, part of the $\mathrm{CO}_{2}$ is recycled as sweep gas, and the other part is compressed for delivery and storage.

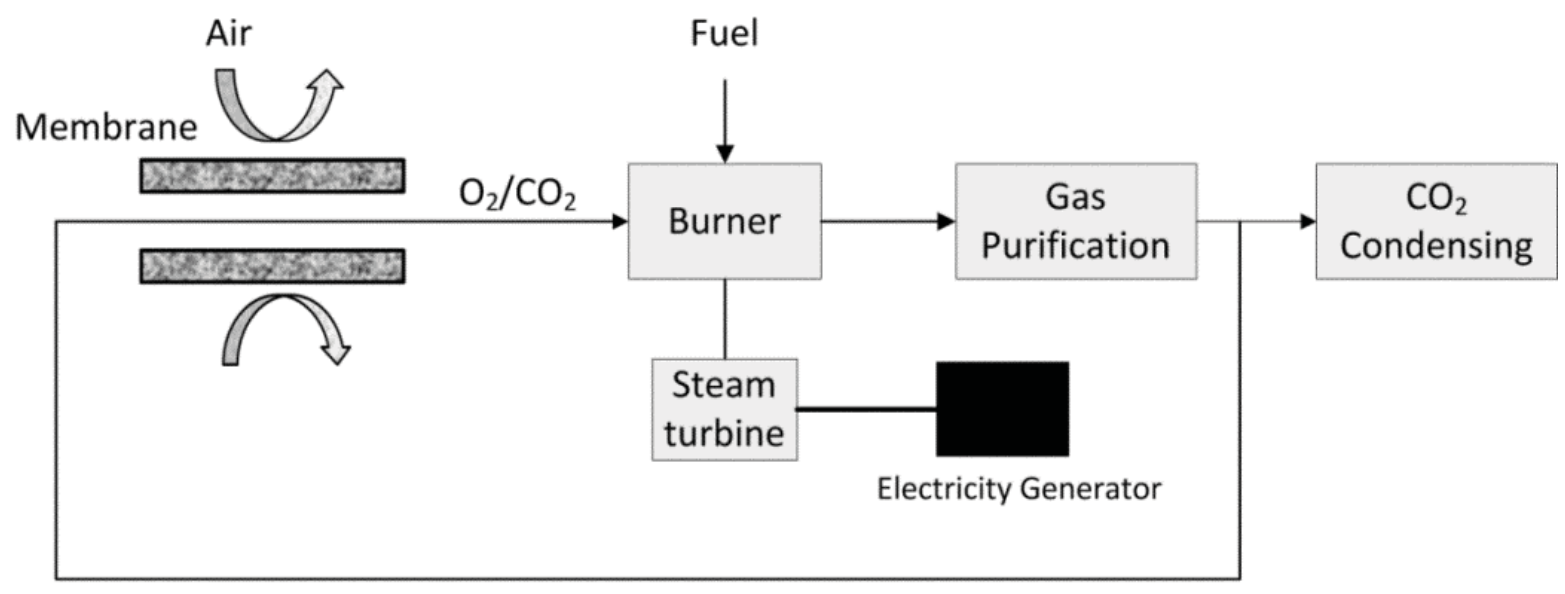

\section{$\mathrm{CO}_{2}$ cycle}

Figure 6.1. A simple illustration of the membrane-integrated oxy-fuel combustion process.

A lot of research is performed in the field of exploring suitable membranes for air separation for this application [11, 13-18]. However, little work has been done on the overall evaluation of a membrane-integrated oxy-fuel combustion process, such as membrane area and energy balance estimation or to show whether the currently developed membranes are sufficient for, or far from, industrial application [19].

In this study, a membrane-integrated oxy-fuel combustion process is designed for a coal-fired power plant, where 20 tonne/h of coal is burned for electric power. 
This process is simulated in UniSim ${ }^{\circledR}$, and the membrane area, necessary for air separation for the power plant, the net efficiency of the power plant and the energy demand for $\mathrm{CO}_{2}$ capture are calculated. For comparison, two other combustion processes are presented: a conventional coal-fired power plant, using air, without $\mathrm{CO}_{2}$ capture and an oxy-fuel combustion process using oxygen from cryogenic distillation of air. The differences among these processes are discussed.

\subsection{Coal-fired power plant without $\mathrm{CO}_{2}$ capture}

In a conventional coal-fired power plant, air is used to combust the coal and the $\mathrm{CO}_{2}$-containing exhaust gas is emitted to the atmosphere. A simple scheme of this process is shown in Figure 6.2. Here air is compressed to 1.7 bar (A1) to carry the pulverized coal to the burner, where combustion occurs. It is assumed that there is only carbon in the coal and the reaction between carbon and oxygen is stoichiometric,

$$
\mathrm{C}+\mathrm{O}_{2} \rightarrow \mathrm{CO}_{2} \quad \Delta H_{\mathrm{r}}^{\circ}=-393.5 \mathrm{~kJ} / \mathrm{mol}
$$

The thermal energy, released from the burner, is used by a steam turbine for electricity generation. It should be noted that the steam turbine system was not drawn in this process because its efficiency varies a lot in different power plants. In this work, we use a parameter called overall steam turbine efficiency $\left(\eta_{\mathrm{t} \rightarrow \mathrm{e}}\right)$ to represent the conversion ratio from thermal power to electric power.

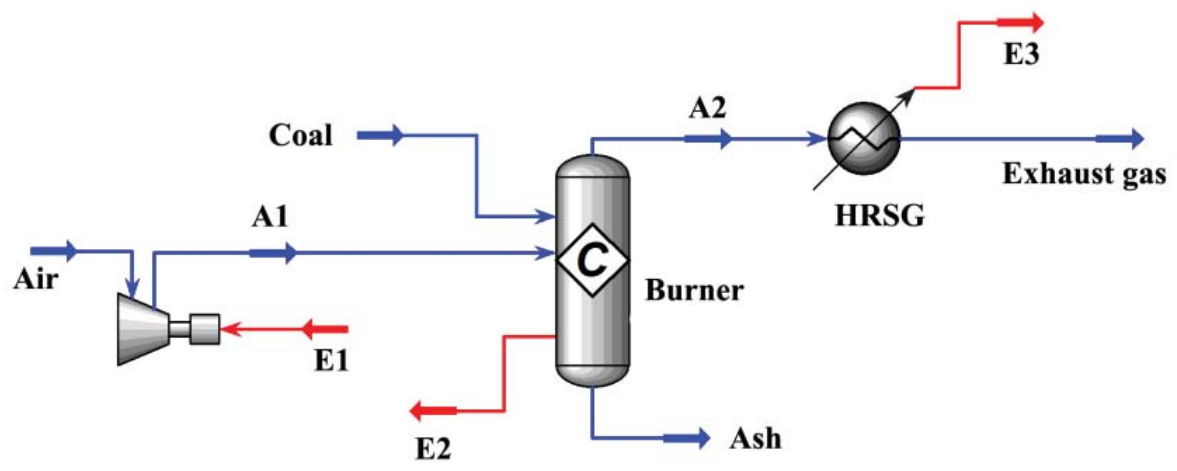

Figure 6.2. Scheme for a conventional coal-fired power plant without $\mathrm{CO}_{2}$ capture (details about the material and power streams are given in table A6.1. in the appendix). 
The temperature of the flue gas (A2) from the burner at $\sim 400{ }^{\circ} \mathrm{C}$ is further decreased to $50{ }^{\circ} \mathrm{C}$ by a Heat-Recovery-Steam-Generator (HRSG), which energy (E3) is also used for the steam turbine system. After the HRSG the exhaust gas consists of some impurity (acid) gases like $\mathrm{SO}_{2}$ and $\mathrm{NO}_{\mathrm{x}}$, which have to be removed in a purification step before emission to the atmosphere is allowed. However, as is mentioned above, it is assumed that there is only carbon in the coal and thus a purification step is omitted. The same strategy holds for all studies in this work.

The electric power output $\left(E_{\text {out }}\right)$ and net efficiency $\left(\eta_{\mathrm{r}}\right)$ of the process were calculated by means of the following equations:

$$
\begin{gathered}
E_{\text {out }}=\left(E_{2}+E_{3}\right) \times \eta_{\mathrm{t} \rightarrow \mathrm{e}}-E_{1} \\
\eta_{\mathrm{r}}=\frac{E_{\text {out }}}{E_{\mathrm{t}}} \times 100 \%
\end{gathered}
$$

where $E_{1}, E_{2}$ and $E_{3}$ are indicated in Figure 6.2 and $E_{\mathrm{t}}$, the total thermal energy released from the combustion, is calculated by the following equation:

$$
E_{\mathrm{t}}=\Delta H_{\mathrm{r}}^{\mathrm{o}} \times F_{\mathrm{CO}_{2}}
$$

where $\Delta H_{\mathrm{r}}^{\circ}$ is the standard enthalpy change in the reaction shown in eq. (6.1), and $F_{\mathrm{CO}_{2}}$ the $\mathrm{CO}_{2}$ molar flow rate.

As can be seen from eq. (6.2) and (6.3), $\eta_{\mathrm{t} \rightarrow \mathrm{e}}$ plays an important role in determining the electric power output and the power plant net efficiency. In principle, $\eta_{\mathrm{t} \rightarrow \mathrm{e}}$ has a theoretical maximum Carnot efficiency of $\sim 64 \%$ assuming the water/steam cycle works between room temperature $\left(25{ }^{\circ} \mathrm{C}\right.$ ) and $565{ }^{\circ} \mathrm{C}$ (creep temperature of stainless steel), but an actual efficiency of up to $42 \%$ for a modern coal-fired power plant is usually expected. In this study $\eta_{\mathrm{t} \rightarrow \mathrm{e}}$ is assumed to be $40 \%$ for all cases [3]. 
Table 6.1. Operating conditions and simulation results for a conventional coal-fired power plant without $\mathrm{CO}_{2}$ capture.

\begin{tabular}{lll}
\hline Variable & Value & Units \\
\hline Coal consumption & 20.0 & tonne $/ \mathrm{h}$ \\
Air mass flow & 230 & tonne/h \\
Air pressure after compression[2] & 1.70 & $\mathrm{bar}$ \\
Compressor adiabatic efficiency & $90.0^{* *}$ & $\%$ \\
Overall steam turbine efficiency $\left(\eta_{\mathrm{t} \rightarrow \mathrm{e}}\right)$ & 40.0 & $\%$ \\
Electric power output $\left(E_{\text {out }}\right)$ & 70.2 & $\mathrm{MW}$ \\
Net efficiency $\left(\eta_{\mathrm{r}}\right)$ & 38.5 & $\%$ \\
\hline
\end{tabular}

**: Compressor adiabatic efficiency is kept at $90 \%$ for all studies in this work

The process, shown in Figure 6.2, was simulated in $\operatorname{UniSim}^{\circledR}$ design, which inherently ensures mass and energy balances across all components, includes thermodynamic data for all chemical species, calculates chemical equilibrium states for the combustion reaction. The simulation results are summarized in table 6.1 (details about the material and power streams are given in table A6.1 in the appendix). The net efficiency of the power plant $\left(\eta_{\mathrm{r}}\right)$ is calculated to be $38.5 \%$ according to eq. (6.2), which is in agreement with the case as treated by J. Black of the National Energy Technology Laboratory [3].

The process shown in Figure 6.2 is used as a reference case for comparison with processes where $\mathrm{CO}_{2}$ capture is applied. The net efficiency of the power plant is expected to be lower when $\mathrm{CO}_{2}$ capture is applied because some power has to be spent on $\mathrm{CO}_{2}$ processing. If one assumes that the net efficiency in this new process is $\eta$ and that the $\mathrm{CO}_{2}$ mass flow rate is $\dot{\mathrm{m}}_{\mathrm{CO}_{2}}$ (assume $100 \% \mathrm{CO}_{2}$ capture), then the energy, necessary to capture one unit of $\mathrm{CO}_{2}$, can be calculated by the following equation, 


$$
S E_{\mathrm{CO}_{2}}=\frac{E_{\mathrm{t}}\left(\eta_{\mathrm{r}}-\eta\right)}{\dot{m}_{\mathrm{CO}_{2}}}
$$

$S E_{\mathrm{CO}_{2}}$ is the specific energy demand for $\mathrm{CO}_{2}$ capture whose unit can be given as $\mathrm{kWh}_{\mathrm{e}} / \mathrm{t}_{\mathrm{CO}_{2}}$.

\subsection{Oxy-fuel combustion process}

In an oxy-fuel combustion process, as depicted in Figure 6.3, oxygen is used instead of air to combust the fuel. $\mathrm{A} \mathrm{CO}_{2}$ recycle (A6, A7) is introduced to avoid extreme high temperatures in the burner [20]. The $\mathrm{O}_{2} / \mathrm{CO}_{2}$ ratio is adjusted to be $0.35 / 0.65(\mathrm{v} / \mathrm{v})$ as it is reported that the combustion of coal with this $\mathrm{O}_{2} / \mathrm{CO}_{2}$ ratio has a similar flame temperature and heat capacity as the combustion of coal in air [21]. This $\mathrm{O}_{2} / \mathrm{CO}_{2}$ mixture (A1) is compressed to 1.7 bar to carry the pulverized coal to the burner for combustion, and the energy, released from combustion, is used for the steam turbine system for electricity generation. The flue gas from the burner (A3) flows through a HRSG for further steam generation and after that it is divided into two parts, one part (A6, identical to A7) is recycled and the other part (A5) is compressed for delivery and storage. The $\mathrm{CO}_{2}$ compression (to $100 \mathrm{bar}$ ) is carried out in 5 stages and after each stage the gas is cooled to $30{ }^{\circ} \mathrm{C}$ before the next compression step.

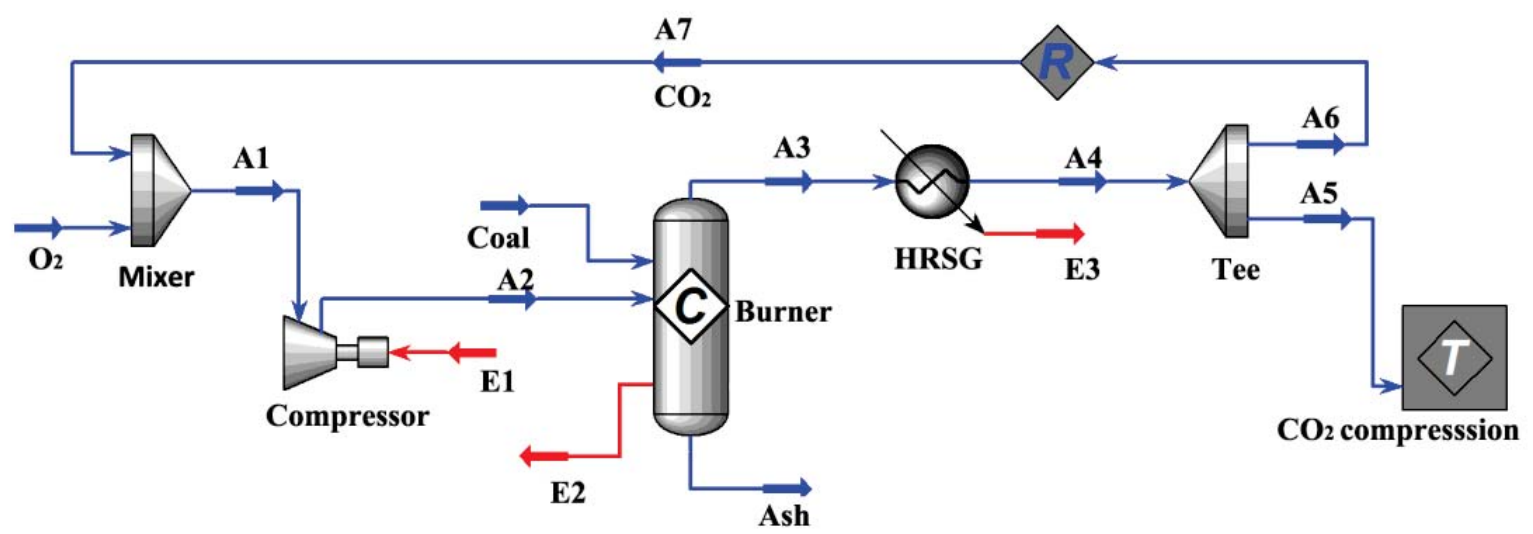

Figure 6.3. Oxy-fuel combustion process with $\mathrm{CO}_{2}$ capture in a coal-fired power plant (details about the material and power streams are given in table A6.2. in the appendix). 
The oxygen, necessary for this process, is produced via cryogenic distillation of air and the energy demand (electric power) for this oxygen production is assumed to be $200 \mathrm{kWh}_{\mathrm{e}} / \mathrm{t}_{\mathrm{O}_{2}}$ [9]. Taking that into consideration, the electric power output and net efficiency of this process can be calculated with the following equations,

$$
\begin{gathered}
E_{\text {out }}=\left(E_{2}+E_{3}\right) \times \eta_{\mathrm{t} \rightarrow \mathrm{e}}-\left(E_{1}+E_{\mathrm{O}_{2}}+E_{\mathrm{CO}_{2}}^{\mathrm{COM}}\right) \\
\eta_{\mathrm{o}}=\frac{E_{\text {out }}}{E_{\mathrm{t}}} \times 100 \%
\end{gathered}
$$

where $E_{\mathrm{O}_{2}}$ and $E_{\mathrm{CO}_{2}}^{\mathrm{COM}}$ represent the power needed for the oxygen production and the $\mathrm{CO}_{2}$ compression (to 100 bar).

The process shown in Figure 6.3 was simulated in UniSim ${ }^{\circledR}$ design and the results are given in table 6.2 (details about the material and power streams are given in table A6.2 in the appendix). The net efficiency is calculated to be $29.6 \%$, which is lower than that of the reference process without $\mathrm{CO}_{2}$ capture $(38.5 \%)$. This is due to the large amount of power, necessary for oxygen production (10.7 MW) and $\mathrm{CO}_{2}$ compression (6.11 MW). According to eq. (6.5), the specific energy demand for $\mathrm{CO}_{2}$ capture is calculated to be $221 \mathrm{kWh}_{\mathrm{e}} / \mathrm{t}_{\mathrm{CO}_{2}}$. 
Table 6.2. Simulation results of the conventional oxy-fuel combustion process with $\mathrm{CO}_{2}$ capture

\begin{tabular}{lll}
\hline Variable & Value & Units \\
Coal consumption & 20.0 & tonne/h \\
$\mathrm{O}_{2}$ mass flow & 53.3 & tonne/h \\
Power for oxygen production $\left(E_{\mathrm{O}_{2}}\right)$ & 10.7 & $\mathrm{MW}$ \\
& & \\
$\mathrm{CO}_{2}$ mass flow (captured part, $\left.\mathrm{A} 5\right)$ & 73.4 & tonne $/ \mathrm{h}$ \\
$\mathrm{Power} \mathrm{CO}_{2}$ compression $\left(E_{\mathrm{CO}}^{\mathrm{COM}}\right)$ & 6.11 & $\mathrm{MW}$ \\
$\mathrm{CO}_{2}$ mass flow $($ recycled part, $\mathrm{A} 6)$ & & \\
Power for $\mathrm{O}_{2} / \mathrm{CO}_{2}$ compression $(\mathrm{E} 1)$ & 138 & tonne $/ \mathrm{h}$ \\
Electric power output $\left(E_{\text {out }}\right)$ & 2.17 & $\mathrm{MW}$ \\
Net efficiency $\left(\eta_{\mathrm{o}}\right)$ & & $\mathrm{MW}$ \\
\hline
\end{tabular}

\subsection{Membrane-integrated oxy-fuel combustion process}

\subsubsection{Membrane module}

\section{Membrane material selection}

The membrane, to be used in the membrane-integrated oxy-fuel combustion (see Figure 6.1) process, should be stable in a $\mathrm{CO}_{2}$ atmosphere, combined with sufficient oxygen permeability. However, for most highly permeable membranes such as $\mathrm{Ba}_{0.5} \mathrm{Sr}_{0.5} \mathrm{Co}_{0.8} \mathrm{Fe}_{0.2} \mathrm{O}_{3-\delta}$ (BSCF) and $\mathrm{SrCo}_{0.8} \mathrm{Fe}_{0.2} \mathrm{O}_{3-\delta}$ (SCF) membranes [22, 23], the stability of these membranes in $\mathrm{CO}_{2}$ atmosphere is a big issue. For example, the oxygen flux of SCF membranes decreases to almost zero after exposing the permeate 
side to a pure $\mathrm{CO}_{2}$ sweep gas stream for 70 hours at $950{ }^{\circ} \mathrm{C}$ [10]. Alternatively, there are some membranes which are very stable in $\mathrm{CO}_{2}$ atmosphere, such as dual phase membranes or $\mathrm{K}_{2} \mathrm{NiF}_{4}$-type membranes [15, 17, 24, 25]. The oxygen fluxes of these membranes, however, are much lower, as compared with BSCF and SCF. In [11] it is found that $\mathrm{SCF}$ remains stable in a $\mathrm{CO}_{2}$ atmosphere when $\mathrm{Co} / \mathrm{Fe}$ (i.e. B) is partly (10\%) substituted by tantalum (called as Ta-doped SCF), while the oxygen flux is not decreased a lot. For reasons of $\mathrm{CO}_{2}$ stability and sufficient oxygen flux, Ta-doped SCF is selected as membrane material for this study.

The oxygen flux of a dense membrane is calculated by using the Wagner equation:

$$
j_{\mathrm{O}_{2}}=-\frac{R T}{(4 F)^{2} d} \sigma_{\text {ion }} \ln \frac{P_{\mathrm{O}_{2}}^{\prime \prime}}{P_{\mathrm{O}_{2}}^{\prime}}
$$

where $j_{\mathrm{O}_{2}}$ is the oxygen flux, $R$ gas constant, $T$ absolute temperature, $F$ Faraday constant, $d$ membrane thickness, $\sigma_{\text {ion }}$ oxygen ionic conductivity and $P_{\mathrm{O}_{2}}$ oxygen partial pressure ( $\mathrm{P}_{\mathrm{O}_{2}}^{\prime \prime}$ at feed side and $\mathrm{P}_{\mathrm{O}_{2}}^{\prime}$ at sweep side). The oxygen ionic conductivity not only depends on the temperature but also on the $P_{\mathrm{O}_{2}}$. In this study, the membrane module works at a fixed temperature $\left(950{ }^{\circ} \mathrm{C}\right)$ but in a changing $P_{\mathrm{O}_{2}}$ environment. In general, the oxygen ionic conductivity increases with increasing $P_{\mathrm{O}_{2}}$, but the change in conductivity as function of $P_{\mathrm{O}_{2}}$ is quite small unless $P_{\mathrm{O}_{2}}$ is less than 0.01 bar [26]. In this study the $P_{\mathrm{O}_{2}}$ in the membrane module is higher than 0.01 bar except at the very beginning of the sweep site of the (tubular) membrane module and therefore it is assumed that the oxygen ionic conductivity is constant in our case. Based on previous oxygen permeation studies at $950{ }^{\circ} \mathrm{C}$ under and $0.21 / 0.04$ bar $P_{\mathrm{O}_{2}}$ gradient [10], the oxygen ionic conductivity of SCF is calculated to be $\sim 1 \mathrm{~S} / \mathrm{cm}$. For Ta-doped SCF, the oxygen flux is around $30 \%$ lower at the same 
temperature and $P_{\mathrm{O}_{2}}$ gradient. Therefore it is assumed that the oxygen ionic conductivity is $0.7 \mathrm{~S} / \mathrm{cm}$ for this system.

\section{$\underline{\text { Membrane area calculation }}$}

Different types of membrane designs are available, like flat, tubular, hollow fiber or monolithic configurations. All designs have advantages and disadvantages in terms of area, sealing and fabrication. A review paper by Vente et al. compared these configurations and it was concluded that a tubular design is the optimal one [27]. In this work a tubular membrane module is chosen for oxygen separation from air. A schematic drawing of the membrane module is shown in chapter 4 (Figure 4.3). In this study the membrane tubes are installed in parallel. Geometrical and operating parameters for one membrane tube are given in table 6.3. 
Table 6.3. Geometry of one tubular membrane and operating conditions.

\begin{tabular}{lll}
\hline Variable & Value & Units \\
\hline Membrane length $(L)$ & 100 & $\mathrm{~cm}$ \\
Membrane outer diameter $\left(D_{\mathrm{o}}\right)$ & 1.0 & $\mathrm{~cm}$ \\
Membrane inner diameter $\left(D_{\mathrm{i}}\right)$ & 0.8 & $\mathrm{~cm}$ \\
Membrane thickness $(d)$ & 0.1 & $\mathrm{~cm}$ \\
Pressure of feed gas $\left(P_{\mathrm{f}}\right)$ & 10 & $\mathrm{bar}$ \\
Pressure of sweep gas $\left(P_{\mathrm{s}}\right)$ & 1.7 & $\mathrm{bar}$ \\
Operating temperature & 950 & ${ }^{\circ} \mathrm{C}$ \\
$\mathrm{O}_{2}$ mole fraction of feed gas at inlet $\left(f_{\mathrm{f}}^{\mathrm{i}}\right)$ & 0.21 & - \\
$\mathrm{O}_{2}$ mole fraction of feed gas at outlet $\left(f_{\mathrm{f}}^{\mathrm{o}}\right)$ & 0.02 & - \\
$\mathrm{O}_{2}$ mole fraction of sweep gas at inlet $\left(f_{\mathrm{s}}^{\mathrm{i}}\right)$ & 0.005 & - \\
$\mathrm{O}_{2}$ mole fraction of sweep gas at outlet $\left(f_{\mathrm{s}}^{\mathrm{o}}\right)$ & 0.35 & - \\
\hline
\end{tabular}

In order to calculate the required amount of membrane area, it is necessary to know how much oxygen is produced by one single membrane tube and then the total needed membrane area can be extrapolated. As is schematically shown in Figure 6.4, it is assumed that the membrane operates in a countercurrent mode, where $F_{\mathrm{s}}^{\mathrm{i}}, F_{\mathrm{f}}^{\mathrm{i}}$ are the sweep and feed gas flow rates at the inlet of the membrane tube, and $F_{\mathrm{s}}{ }^{0}, F_{\mathrm{f}}^{0}$ at the outlet, while $f_{\mathrm{s}}^{\mathrm{i}}, f_{\mathrm{f}}^{\mathrm{i}}, f_{\mathrm{s}}^{0}$ and $f_{\mathrm{f}}^{0}$ the corresponding oxygen mole fractions in these gas streams. 


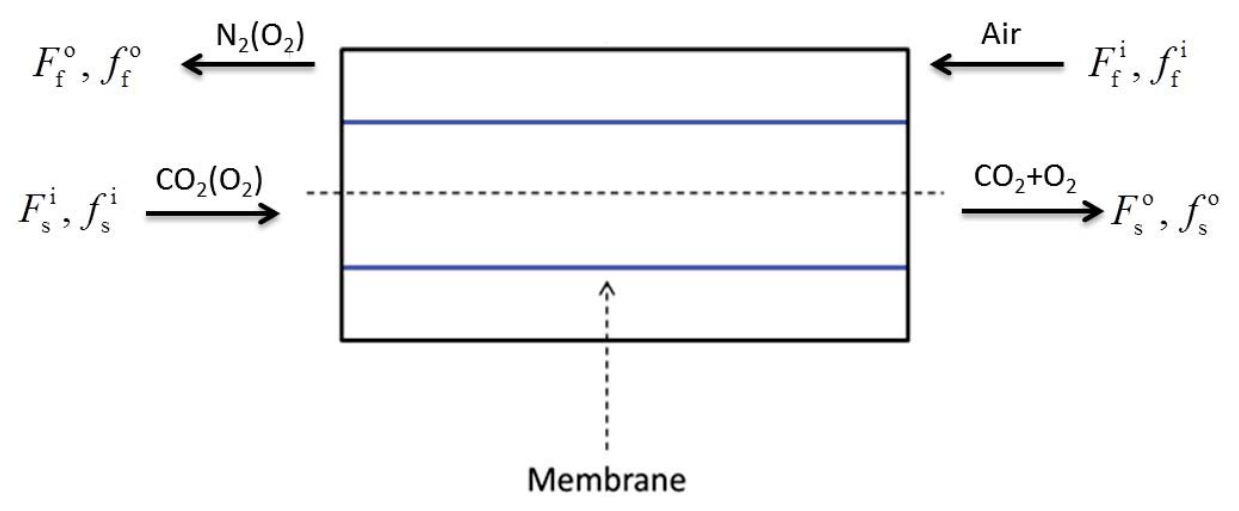

Figure 6.4. Scheme of oxygen flux through a membrane tube, $F$ represents gas flow rate and $f$ is the corresponding oxygen mole fraction in the gas stream.

In this study, $f_{\mathrm{f}}^{\mathrm{i}}$ and $f_{\mathrm{s}}^{0}$ are fixed at 0.21 (oxygen mole fraction of air) and 0.35 (as explained in section 6.3), and the default values of $f_{\mathrm{s}}^{\mathrm{i}}$ and $f_{\mathrm{f}}^{0}$ are 0.005 (residual oxygen in $\mathrm{CO}_{2}$ ) and 0.02 (see table 6.3). With these values, a linear relationship between $F_{s}^{i}$ and $F_{f}^{i}$ is derived according to the conservation of mass for oxygen.

$$
F_{\mathrm{s}}^{\mathrm{i}}=\frac{\left(f_{\mathrm{f}}^{\mathrm{i}}-f_{\mathrm{f}}^{\mathrm{o}}\right) \times\left(1-f_{\mathrm{s}}^{0}\right)}{\left(f_{\mathrm{s}}^{0}-f_{\mathrm{s}}^{\mathrm{i}}\right) \times\left(1-f_{\mathrm{f}}^{0}\right)} F_{\mathrm{f}}^{\mathrm{i}}
$$

Note that eq. (6.9) is necessary rather than sufficient to meet the requirements of oxygen mole fractions. When $F_{\mathrm{s}}^{\mathrm{i}}$ and $F_{\mathrm{f}}^{\mathrm{i}}$ increase simultaneously, by solving the above mentioned problem according to the procedure as described in chapter 4 (section 4.2.5), it is found that both $f_{\mathrm{s}}^{0}$ and $f_{\mathrm{f}}^{0}$ decreases, and there is only one combination of $\left(F_{\mathrm{s}}^{\mathrm{i}}, F_{\mathrm{f}}^{\mathrm{i}}\right)$ that meet the constrains of oxygen mole fractions $\left(f_{\mathrm{s}}^{\mathrm{i}}, f_{\mathrm{f}}^{\mathrm{i}}\right.$, $f_{\mathrm{s}}^{\mathrm{o}}$ and $f_{\mathrm{f}}^{\mathrm{o}}$ ) with given membrane property and operating conditions, i.e., temperature and pressure. With this $\left(F_{\mathrm{s}}^{\mathrm{i}}, F_{\mathrm{f}}^{\mathrm{i}}\right)$ combination, $F_{\mathrm{s}}^{0}$ and $F_{\mathrm{f}}^{0}$ can be calculated. In other words, if $f_{\mathrm{s}}^{\mathrm{i}}, f_{\mathrm{f}}^{\mathrm{i}}, f_{\mathrm{s}}^{0}$ and $f_{\mathrm{f}}^{0}$ are specified, $F_{\mathrm{s}}^{\mathrm{i}}, F_{\mathrm{f}}^{\mathrm{i}}, F_{\mathrm{s}}^{0}$ and $F_{\mathrm{f}}^{0}$ are also fixed, and the oxygen produced by a single membrane tube can be 
calculated by:

$$
F_{\mathrm{O}_{2}}=F_{\mathrm{s}}^{0}-F_{\mathrm{s}}^{\mathrm{i}}
$$

Since the total amount of oxygen, necessary for the process, is known, the number of membrane tubes, $N_{\mathrm{m}}$, can be calculated, as well as the total membrane area $\left(A_{\mathrm{m}}\right)$,

$$
\begin{gathered}
N_{\mathrm{m}}=\frac{F_{\mathrm{O}_{2}}^{\mathrm{T}}}{F_{\mathrm{O}_{2}}} \\
A_{\mathrm{m}}=\frac{\pi}{2}\left(D_{\mathrm{i}}+D_{\mathrm{o}}\right) L N_{\mathrm{m}}
\end{gathered}
$$

where $F_{\mathrm{O}_{2}}^{\mathrm{T}}$ is the amount of total required oxygen, $F_{\mathrm{O}_{2}}$ the amount of oxygen produced by a single membrane tube, $D_{\mathrm{i}}$ and $D_{\mathrm{o}}$ the membrane inner and outer diameter, and $L$ the membrane length.

\subsubsection{Process design}

The design for a membrane-integrated oxy-fuel combustion process is shown in Figure 6.5. In this design air is compressed to $10 \mathrm{bar}$, preheated by a heat exchanger (HEX-1) and further heated (by Heater-1) to the desired temperature $\left(950^{\circ} \mathrm{C}\right)$ before flowing to the membrane module. In the membrane module oxygen is depleted and the (C) gas (A4) is used to preheat the feed gas. After the heat exchanger the $(\mathcal{C}$ gas (A5) is used to operate a gas turbine, where the energy released from gas expansion (E2) is transferred to the air compressors. At the sweep side of the membrane the permeated oxygen is swept by $\mathrm{CO}_{2}$ (A14), and this $\mathrm{O}_{2} / \mathrm{CO}_{2}$ mixture (A7), after passing a heat exchanger (HEX-2) to preheat the recycled $\mathrm{CO}_{2}$ sweep gas (A12), is used for the combustion of coal in the burner. The energy (E4) released from the burner is partly used to heat the air stream (E3) and the recycled $\mathrm{CO}_{2}$ stream (E6), and the remaining part is transferred to a water-steam recycle system for electricity generation. The flue gas (A9) from the burner flows through a HRSG where the energy (E7) is further used for steam generation. After the HRSG the flue gas (A10) 
goes to a gas splitter (TEE), in which one part of it (A11) is recycled as sweep gas for the membrane module and the other part (A15) is compressed (to 100 bar) for delivery and storage.

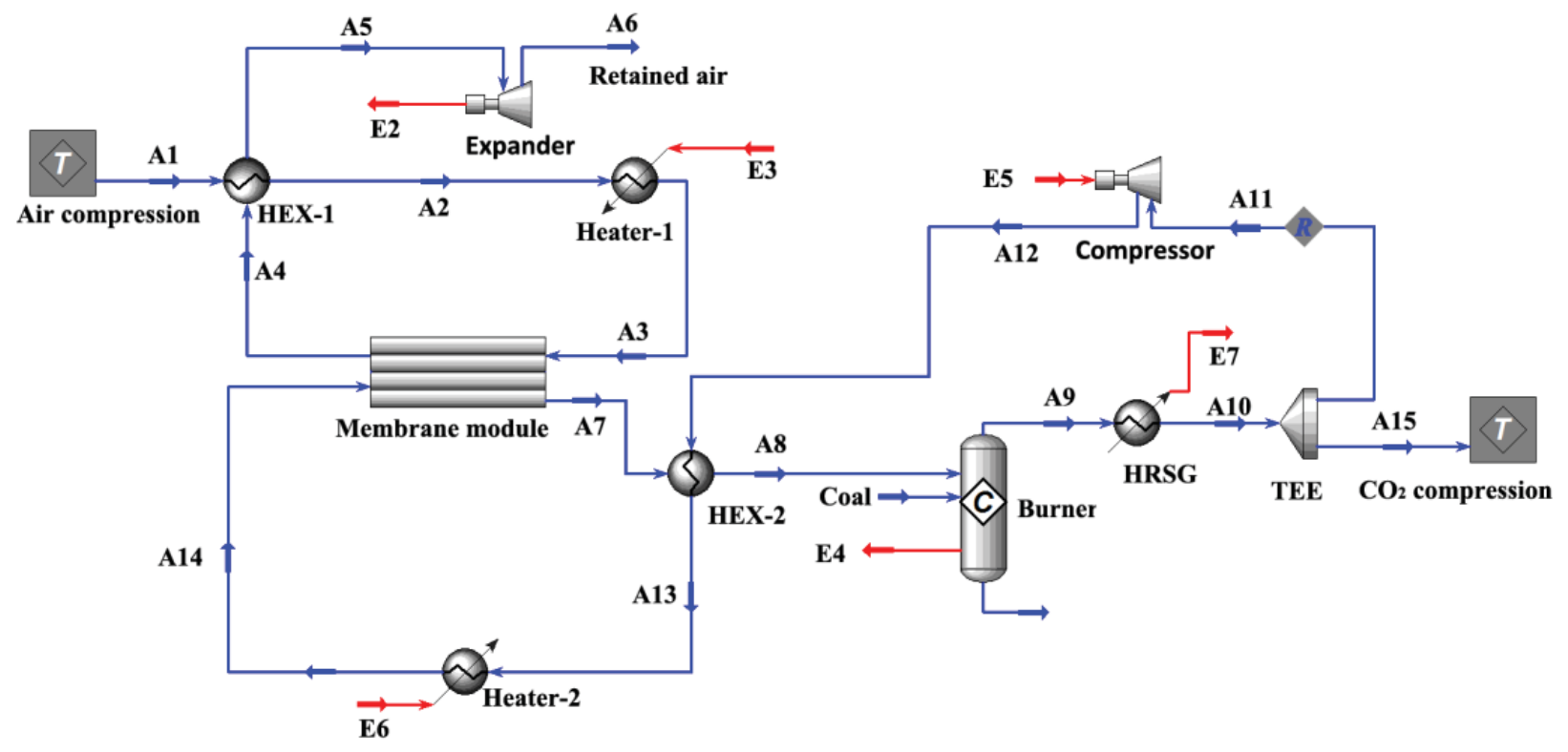

Figure 6.5. Flow sheet of membrane-integrated oxy-fuel combustion process (details about the material and power streams are given in table A6.3. in the appendix).

In this design the gas compressors (all compressors) play an important role in the efficiency of the power plant. A key parameter for gas compressors is the maximum discharge temperature, which strongly depends on the materials and sealants used for the compressor. As a general rule the discharge temperature should be lower than 200 ${ }^{\circ} \mathrm{C}$ for most gas compressors [28]. Multistage compression with intermediate cooling is therefore usually applied in order to reach the desired pressure. In this study a three-stage air and a five-stage $\mathrm{CO}_{2}$ compressor is used and the discharge temperature is kept below $150{ }^{\circ} \mathrm{C}$, while the compressed gas is cooled down to $30{ }^{\circ} \mathrm{C}$ between the compressing stages.

The design includes two heat exchangers, a heat exchanger between compressed air and $(\mathbb{C}$ air from the membrane module (HEX-1) and a heat exchanger between the recycled $\mathrm{CO}_{2}$ and the $\mathrm{O}_{2} / \mathrm{CO}_{2}$ mixture from the membrane module (HEX-2). The general equation for heat transfer across a surface $A$ in a heat exchanger is [29]: 


$$
Q=U A \Delta T_{\mathrm{lm}}
$$

where $Q$ is the heat transfer per unit time, $U$ the overall heat transfer coefficient and $\Delta T_{\operatorname{lm}}$ the logarithm mean temperature difference between the two fluids. In general, a heat exchanger shows a higher efficiency at smaller values of $\Delta T_{\mathrm{lm}}$. However, a smaller $\Delta T_{\operatorname{lm}}$ leads to a smaller driving force for heat transfer and therefore a larger area of the heat exchanger is necessary. As a general rule, $\Delta T_{\operatorname{lm}}$ should be more than $20{ }^{\circ} \mathrm{C}$, and the temperature approach (the temperature difference between outlet temperature of hot fluid and inlet temperature of cold fluid) should be more than 10 ${ }^{\circ} \mathrm{C}$ to avoid an extremely large heat exchanger [29]. In this study, $\Delta T_{\mathrm{lm}}$ in both heat exchangers is kept at $\sim 150{ }^{\circ} \mathrm{C}$ and the temperature approach is kept at $\sim 100{ }^{\circ} \mathrm{C}$. These high values in $\Delta T_{\mathrm{lm}}$ and temperature approach are designed due to the low gas-gas heat transfer coefficient.

\subsubsection{Process simulation}

The process simulation was performed in UniSim ${ }^{\circledR}$. The main assumptions such as coal consumption rate, compressor/expander efficiency and steam turbine efficiency are kept the same with the previous studies in this chapter (see table 6.1). Since there is no membrane unit in $\mathrm{UniSim}^{\circledR}$, the flow rates and compositions of A3, A4, A7 and A14 (see Figure 6.5) were calculated with a dedicated membrane module solved by Matlab. The values were then transferred to UniSim ${ }^{\circledR}$ simulation. The power output and the net efficiency of the power plant were calculated as below:

$$
\begin{gathered}
E_{\text {out }}=\left(E_{4}-E_{6}-E_{3}+E_{7}\right) \times \eta_{\mathrm{t} \rightarrow \mathrm{e}}-\left(E_{\text {com }}-E_{2}\right) \\
\eta_{\mathrm{m}}=\frac{E_{\text {out }}}{E_{\mathrm{t}}} \times 100 \%
\end{gathered}
$$

where $E_{\text {com }}$ is the electric power necessary for all gas compressors (power for air compression + power for $\mathrm{CO}_{2}$ compression to 100 bar for stream $\left.\mathrm{A} 15+E 5\right)$.

The simulation results are given in table 6.4. Details on material and power 
streams are given in table A6.3 of the appendix. A net efficiency of $32.1 \%$ is obtained, which is lower than the reference process, without $\mathrm{CO}_{2}$ capture (38.5\%), but higher than the conventional oxy-fuel combustion process $(29.6 \%)$.

Table 6.4. Simulation results for the membrane based oxy-fuel combustion process.

\begin{tabular}{lll}
\hline Variable & Value & Units \\
\hline Air mass flow & 250 & tonne/h \\
Power for air compression & 17.2 & $\mathrm{MW}$ \\
Power from retentive air expansion (E2) & 12.0 & $\mathrm{MW}$ \\
$\mathrm{CO}_{2}$ mass flow (captured part) & 73.4 & tonne/h \\
Power for $\mathrm{CO}_{2}$ compression (to 100 bar) & 6.11 & $\mathrm{MW}$ \\
$\mathrm{CO}_{2}$ mass flow (recycled part) & 138 & tonne/h \\
Power for recycled CO 2 compression $(\mathrm{E} 5)$ & 1.75 & $\mathrm{MW}$ \\
& & \\
Total membrane area $\left(A_{\mathrm{m}}\right)$ & 71,000 & $\mathrm{~m}{ }^{2}$ \\
Electric power output $\left(E_{\text {out }}\right)$ & 58.5 & $\mathrm{MW}$ \\
Net efficiency $\left(\eta_{\mathrm{m}}\right)$ & $32.1 \%$ & - \\
\hline
\end{tabular}

\subsubsection{Specific energy demand for $\mathrm{CO}_{2}$ capture and oxygen production}

According to eq. (6.5), the specific energy demand for $\mathrm{CO}_{2}$ capture (so for $\mathrm{CO}_{2}$ compression and oxygen production) is calculated to be $\sim 159 \mathrm{kWh}_{\mathrm{e}} / \mathrm{t}_{\mathrm{CO}_{2}}$, which is lower than that in the oxy-fuel combustion process where oxygen is supplied by cryogenic distillation of air $\left(221 \mathrm{kWh}_{\mathrm{e}} / \mathrm{t}_{\mathrm{CO}_{2}}\right.$ see section 6.3). In the oxy-fuel combustion process, described in section 6.3 , the specific energy demand for oxygen production can easily be determined, as it is a stand-alone process. For the membrane-integrated oxy-fuel combustion process, the oxygen production (by 
membrane separation) is coupled with other processes in the power plant. It is therefore difficult to distinguish the power, necessary for oxygen production from other power demanding processes in this design. In order to calculate this and make a comparison with the cryogenic distillation of air process, the following assumption is made:

The total reduction of power plant capacity due to $\mathrm{CO}_{2}$ capture consists of the powers, necessary for $\mathrm{CO}_{2}$ compression and oxygen production.

$$
S E_{\mathrm{O}_{2}}=\frac{E_{\mathrm{t}}\left(\eta_{\mathrm{r}}-\eta\right)-E_{\mathrm{CO}_{2}}^{\mathrm{COM}}}{\dot{m}_{\mathrm{O}_{2}}}
$$

Since the power for $\mathrm{CO}_{2}$ compression is known (table 6.4), the power needed for oxygen production is subsequently obtained. The specific energy for oxygen production (104 $\left.\mathrm{kWh}_{\mathrm{e}} / \mathrm{t}_{\mathrm{O}_{2}}\right)$, calculated according to eq. (6.16), is significantly lower than that of cryogenic distillation process $\left(200 \mathrm{kWh}_{\mathrm{e}} / \mathrm{t}_{\mathrm{O}_{2}}\right)$ [9].

\subsubsection{Parametric study}

In this section, the effect of oxygen recovery, operating pressure at membrane feed side and membrane thickness on the performance of the power plant are discussed. When one process parameter is varied, the other parameters are kept constant, having the values as used for the 'standard case' (see table 6.1 and 6.3).

\section{Effect of oxygen recovery}

In this design oxygen recovery $(\theta)$ is defined as the ratio of oxygen, permeated through the membrane, and total oxygen in the feed gas. This recovery is a function of the oxygen mole fractions of the feed gas at the in- and outlet of the membrane module.

$$
\theta=\frac{F_{\mathrm{f}}^{\mathrm{i}} f_{\mathrm{f}}^{\mathrm{i}}-F_{\mathrm{f}}^{\mathrm{o}} f_{\mathrm{f}}^{\mathrm{o}}}{F_{\mathrm{f}}^{\mathrm{i}} f_{\mathrm{f}}^{\mathrm{i}}}=\frac{f_{\mathrm{f}}^{\mathrm{i}}-f_{\mathrm{f}}^{\mathrm{o}}}{f_{\mathrm{f}}^{\mathrm{i}}\left(1-f_{\mathrm{f}}^{\mathrm{o}}\right)}
$$


As air is used as the feed gas, $f_{\mathrm{f}}^{\mathrm{i}}$ is 0.21 , then eq. (6.17) can be rewritten,

$$
\theta=\frac{0.21-f_{\mathrm{f}}^{0}}{0.21 \times\left(1-f_{\mathrm{f}}{ }^{0}\right)}
$$

For the standard case of the membrane-integrated oxy-fuel combustion process, as described in section 6.4 .3 , the oxygen recovery has a value of 0.92 . It is obvious that $\theta$ decreases with $f_{\mathrm{f}}^{0}$ in the range of 0 to 0.21 , meaning that a lower $f_{\mathrm{f}}^{0}$ results in a higher $\theta$. Since the total amount of oxygen, necessary for the power plant is a constant, a lower feed flow rate is needed at lower $f_{\mathrm{f}}^{0}$. Consequently, in that case the energy for compression and heating the feed gas will decrease, which possibly affects the net efficiency of the power plant. In Figure 6.6 the effect of oxygen recovery on several process parameters and power plant efficiency are given. Figure 6.6a shows the effect of oxygen recovery (or oxygen mole fraction at the feed gas outlet: $f_{\mathrm{f}}^{0}$ ) on the amount of oxygen produced by a single membrane tube. It is clear that when $f_{\mathrm{f}}^{0}$ decreases, the mean $P_{\mathrm{O}_{2}}$ at the air side also decreases, implying that the driving force for oxygen permeation is smaller, thus the oxygen produced by one single membrane tube decreases. Figure $6.6 \mathrm{~b}$ indicates that by decreasing $f_{\mathrm{f}}^{0}$ from 0.10 to 0.01 , the required feed gas flow rate $\left(F_{\mathrm{f}}^{\mathrm{i}}\right)$ decreases from 13.8 to $8.3\left(\times 10^{6} \mathrm{~mole} / \mathrm{h}\right)$. This also means that the total membrane area, required for the production of a fixed amount of oxygen, increases from $61,000 \mathrm{~m}^{2}$ to $73,000 \mathrm{~m}^{2}$ (Figure 6c), meaning an increase of $20 \%$ in required membrane area. However the net efficiency of the power plant increases from $30.4 \%$ to $32.2 \%$ with decreasing $f_{\mathrm{f}}{ }^{\circ}$. 

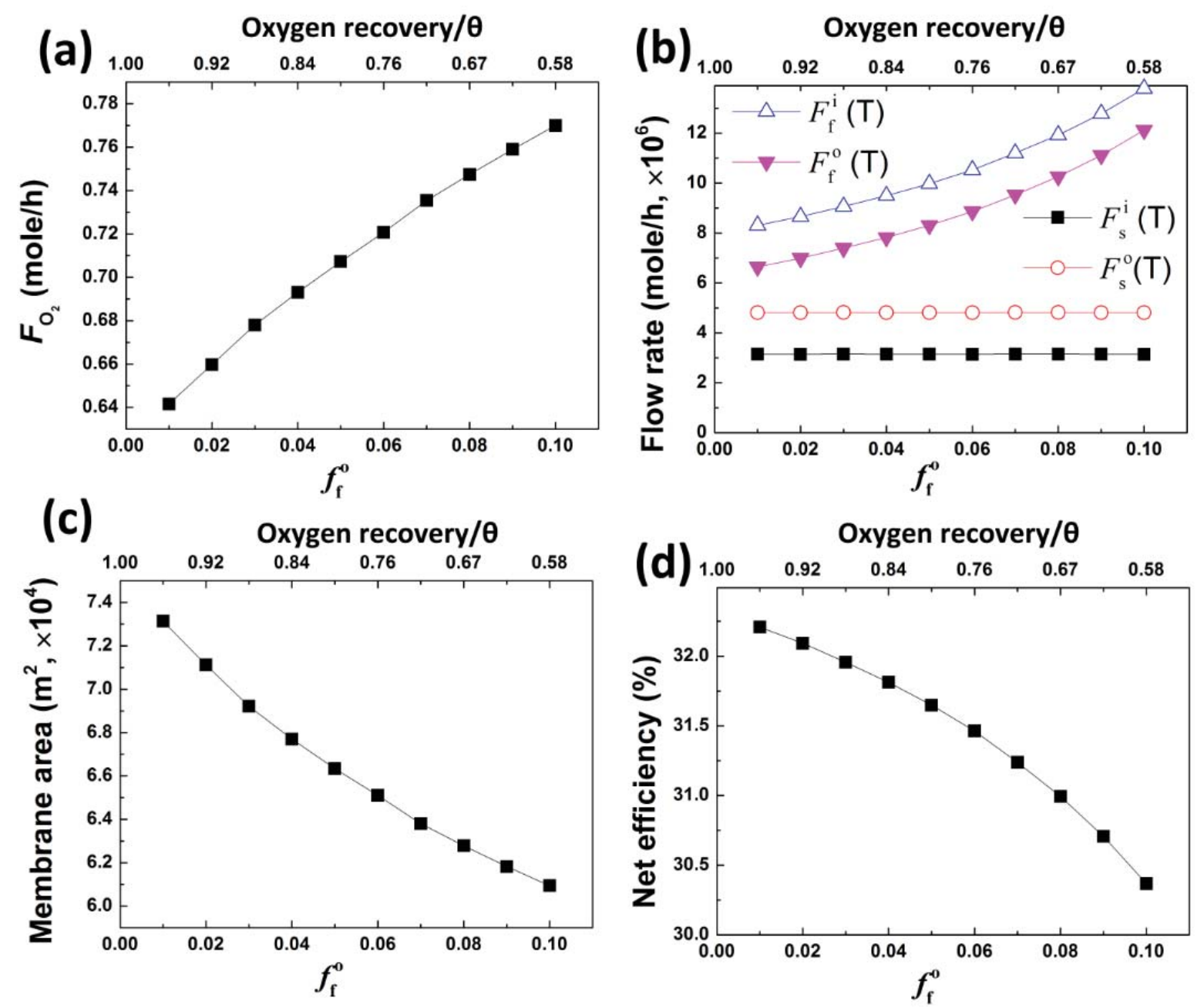

Figure 6.6. Effect of oxygen recovery on several process parameters (a) Oxygen produced by one membrane tube; (b) Gas flow rate in the whole membrane module; (c) Total membrane area needed and (d) Net efficiency of the power plant. ( $f_{\mathrm{f}}^{\mathrm{i}}$ remains constant in this parametric study).

\section{Effect of membrane feed side operating pressure}

Varying the operating pressure at the feed side of the membrane $\left(P_{\mathrm{f}}\right)$ has two major impacts on the characteristics of the power plant: (1) the total required membrane area and (2) the net efficiency of the power plant (see Figure 6.7). Figure 6.7a shows that a decrease in $P_{\mathrm{f}}$ from 13 bar to 4 bar results in a reduction in oxygen production by one single membrane tube from 0.79 to $0.24 \mathrm{~mole} / \mathrm{h}$. This can be explained by the fact that by decreasing in $P_{\mathrm{f}}$ the driving force for oxygen transport 
through the membrane decreases and thus the amount of oxygen produced by one single membrane tube is reduced. This reduced oxygen production per membrane tube leads to an increase of the required amount of membranes from $59,000 \mathrm{~m}^{2}$ to $195,000 \mathrm{~m}^{2}$ (Figure 6.7b), meaning an increase by more than a factor of 3 . Finally, a decrease in $P_{\mathrm{f}}$ leads to a decrease in power, necessary for air compression, which causes an increase of the net efficiency of the power plant. It can be seen from Figure 6.7c, when $P_{\mathrm{f}}$ decreases from 13 bar to 4 bar, the power plant net efficiency increases from $31.6 \%$ to $33.6 \%$.

The change in the amount of required membrane area as function of oxygen mole fraction at the outlet of the feed gas $\left(f_{\mathrm{f}}{ }^{0}\right)$ and as function of operating pressure at the feed side of the membrane $\left(P_{\mathrm{f}}\right)$ will now be discussed. It is found that the influence of $P_{\mathrm{f}}$ is more pronounced than that of $f_{\mathrm{f}}^{0}$ (compare resp. Figure 6.7b and 6.6c). This can be explained by the fact that changing $P_{\mathrm{f}}$ has an overall effect of $P_{\mathrm{O}_{2}}$ at the feed side of the membrane, i.e. an increase/decrease in $P_{\mathrm{f}}$ leads to an entire shift of $P_{\mathrm{O}_{2}}$ over the feed side, while a change in $f_{\mathrm{f}}^{0}$ only affects $P_{\mathrm{O}_{2}}$ near the outlet of the feed side, leaving $P_{\mathrm{O}_{2}}$ at the inlet of the feed side constant. 
(a)

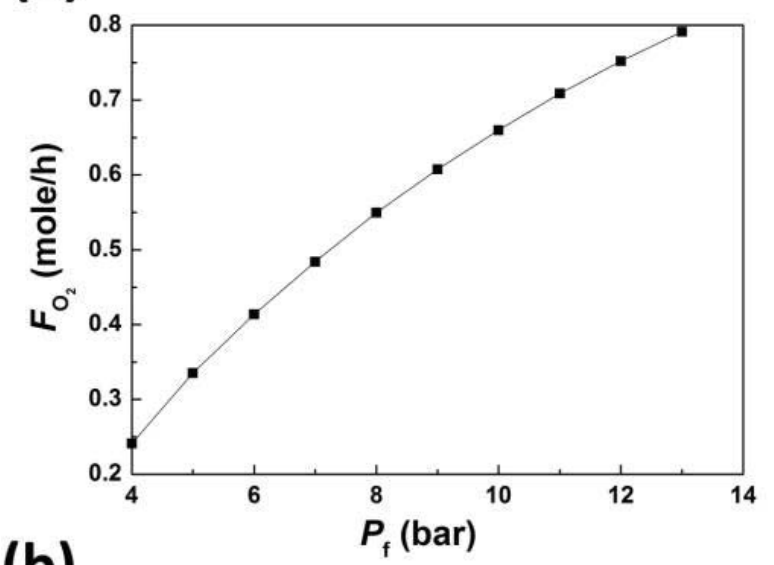

(b)

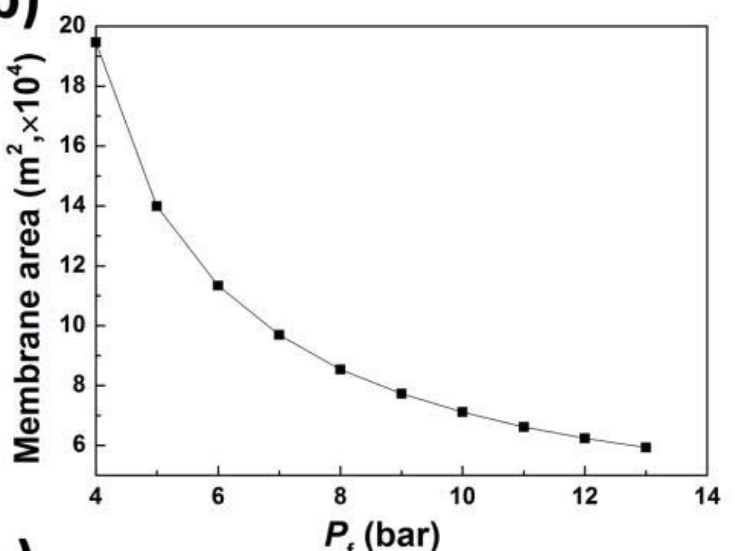

(c)

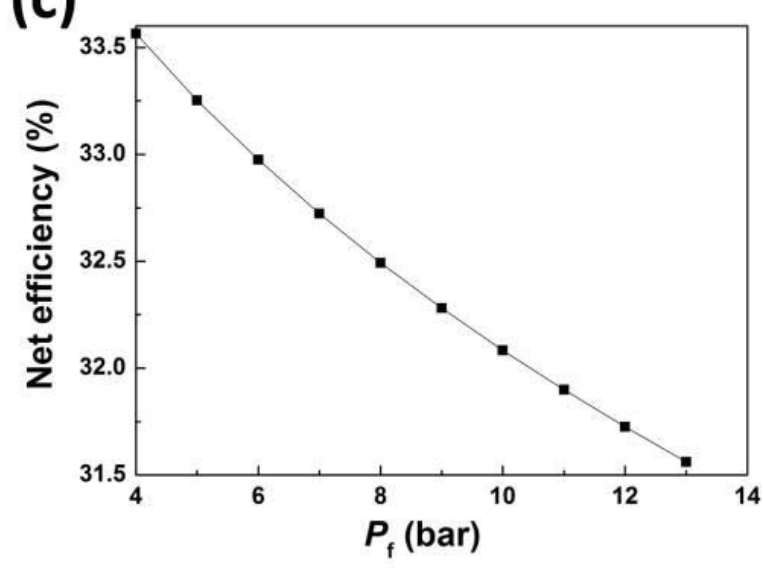

Figure 6.7. Effect of membrane feed side pressure $\left(P_{\mathrm{f}}\right)$ on: (a) Oxygen produced by one membrane tube, (b) Total membrane area need and (c) The net efficiency of the power plant.

\section{Effect of membrane thickness}

According to eq. (6.8), the oxygen flux increases when the membrane thickness decreases (assuming membrane bulk diffusion as the rate determining step for oxygen permeation), which means that more oxygen is produced by one single 
membrane tube. Since the total oxygen, necessary in this study is constant, less membrane area is needed. The influence of membrane thickness on the required amount of membrane area (under 'standard' operating conditions) is shown in Figure 6.8. If the membrane thickness is reduced from 1.0 to $0.6 \mathrm{~mm}$, the amount of membrane area decreases from $71,000 \mathrm{~m}^{2}$ to $42,600 \mathrm{~m}^{2}$. However, it should be noted that the membrane thickness cannot be reduced without limitations. This is not only because of manufacturing problems, but also because of the fragility of the membranes, which is very common for ceramics. A possible solution to this problem is to use supported thin films where a porous support is used to maintain the mechanical strength of the membrane, while a dense oxygen permeable layer/film is coated on top of it. In this way the membrane thickness can be reduced to as low as $20 \mu \mathrm{m}$, and the oxygen flux will be significantly increased [30, 31]. Another issue which should be mentioned in this parametric study on membrane thicknesses is that all process parameters, as given in tables 6.1 and 6.3 (i.e.: the oxygen mole fractions, $f_{\mathrm{s}}^{\mathrm{i}}, f_{\mathrm{f}}^{\mathrm{i}}, f_{\mathrm{s}}^{\mathrm{o}}$ and $f_{\mathrm{f}}^{\mathrm{o}}$, and the operating pressures, $P_{\mathrm{f}}$ and $P_{\mathrm{s}}$ ), are constant, which implies that $F_{\mathrm{s}}^{\mathrm{i}}, F_{\mathrm{f}}^{\mathrm{i}}, F_{\mathrm{s}}^{0}$ and $F_{\mathrm{f}}^{0}$ are also constant. Therefore, the variation in membrane thickness only affects the total amount of membrane area and not the net efficiency of the power plant. 


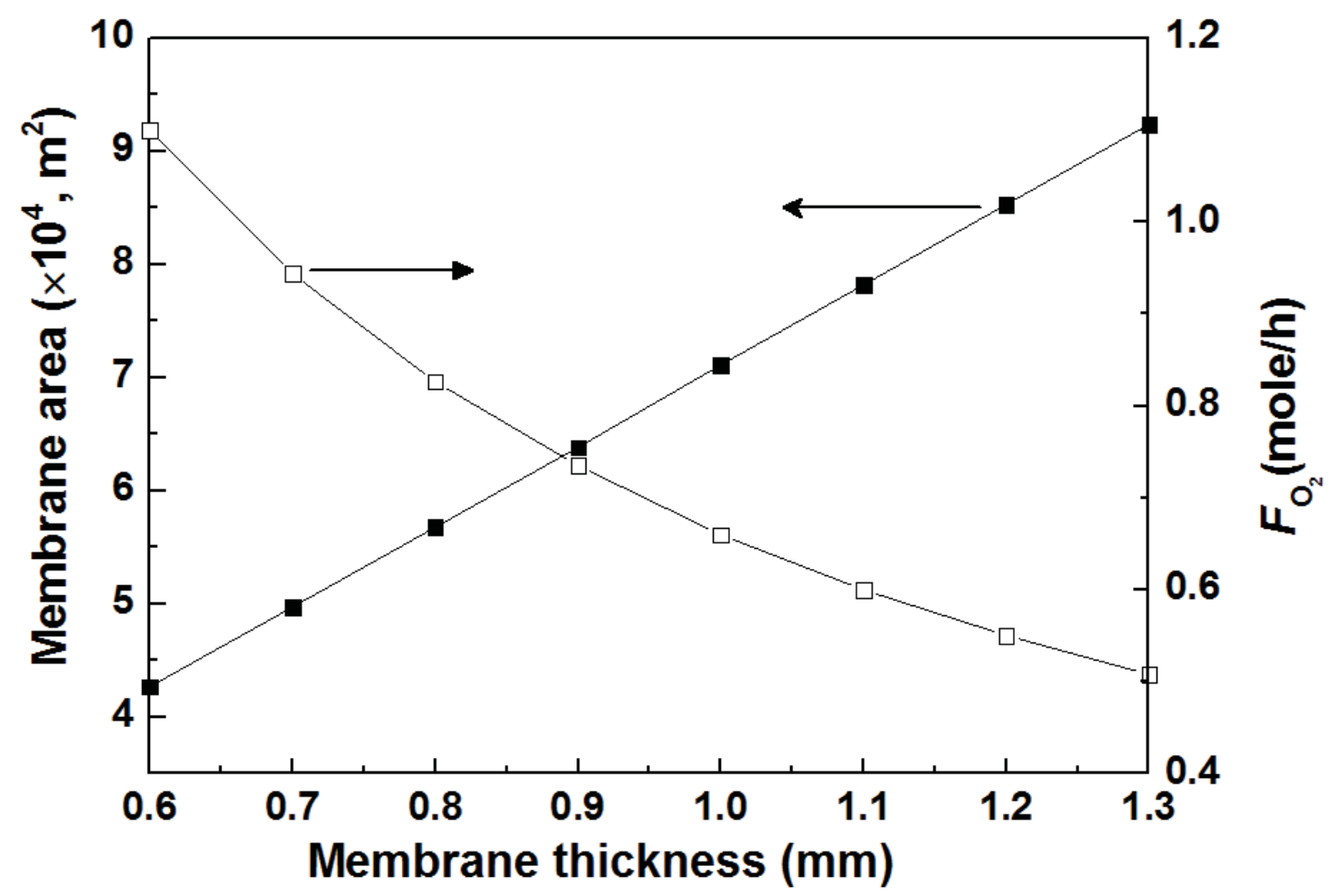

Figure 6.8. Effect of membrane thickness on the amount of oxygen produced by one single membrane tube and total needed membrane area.

\subsubsection{Process modification}

As discussed in chapter 4, the $\mathrm{CO}_{2}$ resistance of high oxygen-permeable SCF membranes is largely improved by increasing $P_{\mathrm{O}_{2}}$ in the $\mathrm{CO}_{2}$ sweep gas. Adding $5 \%$ of oxygen in the sweep gas can protect $\mathrm{SCF}$ membranes from $\mathrm{CO}_{2}$ poisoning. This observation inspired us to propose a modified process, which is shown in Figure 6.9. In this modified process undoped SCF membranes are used for air separation and an extra $\mathrm{O}_{2} / \mathrm{CO}_{2}$ loop (A18) is introduced to increase $P_{\mathrm{O}_{2}}$ in the $\mathrm{CO}_{2}$ sweep gas $\left(f_{\mathrm{s}}^{\mathrm{i}}\right)$ in order to protect the SCF membranes against $\mathrm{CO}_{2}$ poisoning. Due to the pressure drop in the membrane module, the extra $\mathrm{O}_{2} / \mathrm{CO}_{2}$ loop has to be recompressed (COM-2) before being mixed with recycled $\mathrm{CO}_{2}$. Since the temperature of the $\mathrm{O}_{2} / \mathrm{CO}_{2}$ mixture from the heat exchanger (HEX-2) is too high $\left(473{ }^{\circ} \mathrm{C}\right)$, the $\mathrm{O}_{2} / \mathrm{CO}_{2}$ loop has to be cooled (to $150{ }^{\circ} \mathrm{C}$ in this study) before compression, and after the compression it is heated again to $950^{\circ} \mathrm{C}$. 


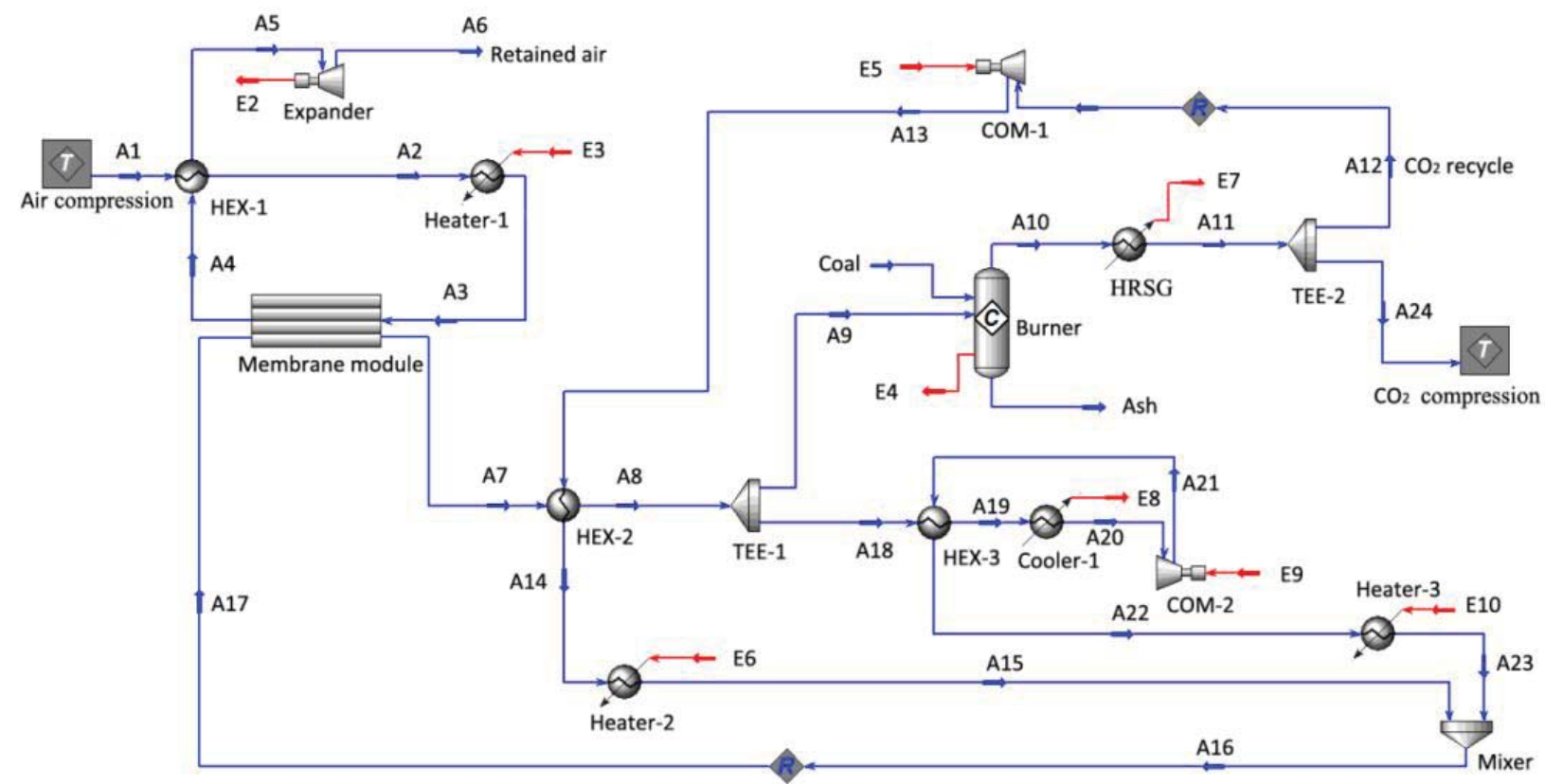

Figure 6.9. A modified membrane-integrated oxy-fuel combustion process (details about the material and power streams are given in table A6.4. in the appendix).

In this modified process the membrane geometry and operating conditions are kept constant (see table 6.1 and 6.3 except $f_{\mathrm{s}}^{\mathrm{i}}$, which latter now has a value from 0.05). The simulation results are given in table 6.5. Details about the material and power streams are given in table A6.4 of the appendix. This modified process almost has the same net efficiency (31.9\%) as the unmodified one (32.1\%). However, the required amount of membrane area in this modified process $\left(49,000 \mathrm{~m}^{2}\right)$ is much less than that in the unmodified one $\left(71,000 \mathrm{~m}^{2}\right)$, namely a reduction of more than $30 \%$. This is due to the fact that the SCF membrane used in the modified process has a higher oxygen permeability if compared with the Ta doped-SCF (see 6.4.1). 
Table 6.5. Simulation results for the modified membrane-integrated oxy-fuel combustion process.

\begin{tabular}{lll}
\hline Variable & Value & Units \\
\hline Total needed membrane area & 49,000 & $\mathrm{~m}^{2}$ \\
Electric power output & 58.1 & $\mathrm{MW}$ \\
Net efficiency $\left(\eta_{\mathrm{m}}\right)$ & 31.9 & $\%$ \\
Specific energy for $\mathrm{CO}_{2}$ capture & 164 & $\mathrm{kWh}_{\mathrm{e}} / \mathrm{t}_{\mathrm{CO}_{2}}$ \\
Specific energy for $\mathrm{O}_{2}$ production & 111 & $\mathrm{kWh}_{\mathrm{e}} / \mathrm{t}_{\mathrm{O}_{2}}$ \\
\hline
\end{tabular}

\subsection{Conclusion}

The integration of oxygen transport membranes into the oxy-fuel combustion process can decrease the energy demand for $\mathrm{CO}_{2}$ capture, as compared to a typical oxy-fuel combustion process where cryogenic distillation is used for oxygen production. In the present study, based on a power plant where 20 tonne/h of coal is burned for electric power generation, a net efficiency of $32.1 \%$ is obtained for the membrane-integrated oxy-fuel combustion process (including $\mathrm{CO}_{2}$ compression to 100 bar), which is higher than that of typical oxy-fuel combustion process $(29.6 \%$ including $\mathrm{CO}_{2}$ compression). The required membrane area is approximately 71,000 $\mathrm{m}^{2}$. The specific energy demand for $\mathrm{CO}_{2}$ capture in this study is $185 \mathrm{kWh}_{\mathrm{e}} / \mathrm{t}_{\mathrm{CO}_{2}}$, and the specific energy demand for $\mathrm{O}_{2}$ production is $104 \mathrm{kWh} / \mathrm{h}_{\mathrm{O}} / \mathrm{t}_{2}$. A modified process design is also proposed, in which higher oxygen permeable membranes (SCF) are used and an extra $\mathrm{CO}_{2} / \mathrm{O}_{2}$ loop is introduced to protect $\mathrm{SCF}$ from $\mathrm{CO}_{2}$ poisoning. The modified process shows a similar net efficiency of $31.9 \%$, but a significantly lower amount of required membrane area $\left(49,000 \mathrm{~m}^{2}\right)$. 


\section{References}

[1] J.D. Figueroa, T. Fout, S. Plasynski, H. Mcllvried, R.D. Srivastava, Advances in $\mathrm{CO}_{2}$ capture technology-The U.S. Department of Energy's Carbon Sequestration Program, Int J Greenh Gas Con, 2 (2008) 9-20.

[2] B. Metz, O. Davidson, H.d. Coninck, M. Loos, L. Meyer, IPCC Special Report on Carbon Dioxide Capture and Storage, Intergovernmental Panel on Climate Change, (2005).

[3] J. Black, Cost and performance baseline for fossil energy plants. Volume 1: Bituminous coal and natural gas to electricity final report, in, National Energy Technology Laboratory, 2007, pp. 626.

[4] L. Dumée, C. Scholes, G. Stevens, S. Kentish, Purification of aqueous amine solvents used in post combustion $\mathrm{CO}_{2}$ capture: A review, Int J Greenh Gas Con, 10 (2012) 443-455.

[5] H. Stadler, F. Beggel, M. Habermehl, B. Persigehl, R. Kneer, M. Modigell, P. Jeschke, Oxyfuel coal combustion by efficient integration of oxygen transport membranes, Int J Greenh Gas Con, 5 (2011) 7-15.

[6] J. Oexmann, C. Hensel, A. Kather, Post-combustion $\mathrm{CO}_{2}$-capture from coal-fired power plants: Preliminary evaluation of an integrated chemical absorption process with piperazine-promoted potassium carbonate, Int J Greenh Gas Con, 2 (2008) 539-552.

[7] M.R.M. Abu-Zahra, J.P.M. Niederer, P.H.M. Feron, G.F. Versteeg, $\mathrm{CO}_{2}$ capture from power plants: Part II. A parametric study of the economical performance based on mono-ethanolamine, Int J Greenh Gas Con, 1 (2007) 135-142.

[8] T. Wall, Y. Liu, C. Spero, L. Elliott, S. Khare, R. Rathnam, F. Zeenathal, B. Moghtaderi, B. Buhre, C. Sheng, R. Gupta, T. Yamada, K. Makino, J. Yu, An overview on oxyfuel coal combustionState of the art research and technology development, Chemical Engineering Research and Design, 87 (2009) 1003-1016.

[9] A. Darde, R. Prabhakar, J.-P. Tranier, N. Perrin, Air separation and flue gas compression and purification units for oxy-coal combustion systems, Energy Procedia, 1 (2009) 527-534.

[10] Q. Zeng, Y.B. Zu, C.G. Fan, C.S. Chen, $\mathrm{CO}_{2}$-tolerant oxygen separation membranes targeting $\mathrm{CO}_{2}$ capture application, Journal of Membrane Science, 335 (2009) 140-144.

[11] W. Chen, C.-s. Chen, L. Winnubst, Ta-doped $\mathrm{SrCo}_{0.8} \mathrm{Fe}_{0.2} \mathrm{O}_{3-\delta}$ membranes: Phase stability and oxygen permeation in $\mathrm{CO}_{2}$ atmosphere, Solid State Ionics, 196 (2011) 30-33.

[12] S. Engels, F. Beggel, M. Modigell, H. Stadler, Simulation of a membrane unit for oxyfuel power plants under consideration of realistic BSCF membrane properties, Journal of Membrane Science, 359 (2010) 93-101.

[13] X. Zhu, H. Liu, Y. Cong, W. Yang, Novel dual-phase membranes for $\mathrm{CO}_{2}$ capture via an oxyfuel route, Chem Commun, 48 (2012) 251-253. 
[14] Y.Y. Wei, J. Tang, L.Y. Zhou, J. Xue, Z. Li, H.H. Wang, Oxygen separation through U-shaped hollow fiber membrane using pure $\mathrm{CO}_{2}$ as sweep gas, Aiche J, 58 (2012) 2856-2864.

[15] Y. Wei, O. Ravkina, T. Klande, H. Wang, A. Feldhoff, Effect of $\mathrm{CO}_{2}$ and $\mathrm{SO}_{2}$ on oxygen permeation and microstructure of $\left(\mathrm{Pr}_{0.9} \mathrm{La}_{0.1}\right)_{2}\left(\mathrm{Ni}_{0.74} \mathrm{Cu}_{0.21} \mathrm{Ga}_{0.05}\right) \mathrm{O}_{4+\delta}$ membranes, Journal of Membrane Science, 429 (2013) 147-154.

[16] H. Luo, H. Jiang, T. Klande, F. Liang, Z. Cao, H. Wang, J. Caro, Rapid glycine-nitrate combustion synthesis of the $\mathrm{CO}_{2}$-stable dual phase membrane $40 \mathrm{Mn}_{1.5} \mathrm{Co}_{1.5} \mathrm{O}_{4-\delta}-60 \mathrm{Ce}_{0.9} \mathrm{Pr}_{0.1} \mathrm{O}_{2-\delta}$ for $\mathrm{CO}_{2}$ capture via an oxy-fuel process, Journal of Membrane Science, 423-424 (2012) 450-458.

[17] W. Li, J.J. Liu, C.S. Chen, Hollow fiber membrane of yttrium-stabilized zirconia and strontiumdoped lanthanum manganite dual-phase composite for oxygen separation, Journal of Membrane Science, 340 (2009) 266-271.

[18] M. Arnold, H.H. Wang, A. Feldhoff, Influence of $\mathrm{CO}_{2}$ on the oxygen permeation performance and the microstructure of perovskite-type $\left(\mathrm{Ba}_{0.5} \mathrm{Sr}_{0.5}\right)\left(\mathrm{Co}_{0.8} \mathrm{Fe}_{0.2}\right) \mathrm{O}_{3-\delta}$ membranes, Journal of Membrane Science, 293 (2007) 44-52.

[19] R. Castillo, Thermodynamic analysis of a hard coal oxyfuel power plant with high temperature three-end membrane for air separation, Appl Energ, 88 (2011) 1480-1493.

[20] L. Chen, S.Z. Yong, A.F. Ghoniem, Oxy-fuel combustion of pulverized coal: Characterization, fundamentals, stabilization and CFD modeling, Progress in Energy and Combustion Science, 38 (2012) 156-214.

[21] E. Croiset, K. Thambimuthu, A. Palmer, Coal combustion in $\mathrm{O}_{2} / \mathrm{CO}_{2}$ mixtures compared with air, The Canadian Journal of Chemical Engineering, 78 (2000) 402-407.

[22] Z.P. Shao, W.S. Yang, Y. Cong, H. Dong, J.H. Tong, G.X. Xiong, Investigation of the permeation behavior and stability of a $\mathrm{Ba}_{0.5} \mathrm{Sr}_{0.5} \mathrm{Co}_{0.8} \mathrm{Fe}_{0.2} \mathrm{O}_{3-\delta}$ oxygen membrane, Journal of Membrane Science, 172 (2000) 177-188.

[23] L. Qiu, T.H. Lee, L.M. Liu, Y.L. Yang, A.J. Jacobson, Oxygen Permeation Studies of $\mathrm{SrCo}_{0.8} \mathrm{Fe}_{0.2} \mathrm{O}_{3-\delta}$, Solid State Ionics, 76 (1995) 321-329.

[24] H. Luo, H. Jiang, T. Klande, Z. Cao, F. Liang, H. Wang, J. Caro, Novel cobalt-free, noble metalfree oxygen-permeable $40 \mathrm{Pr}_{0.6} \mathrm{Sr}_{0.4} \mathrm{FeO}_{3-\delta}-60 \mathrm{Ce}_{0.9} \mathrm{Pr}_{0.1} \mathrm{O}_{2-\delta}$ dual-phase membrane, Chem Mater, 24 (2012) 2148-2154.

[25] W. Li, T.-F. Tian, F.-Y. Shi, Y.-S. Wang, C.-S. Chen, $\mathrm{Ce}_{0.8} \mathrm{Sm}_{0.2} \mathrm{O}_{2-\delta}-\mathrm{La}_{0.8} \mathrm{Sr}_{0.2} \mathrm{MnO}_{3-\delta}$ Dual-Phase Composite Hollow Fiber Membrane for Oxygen Separation, Ind Eng Chem Res, 48 (2009) 57895793.

[26] H.J.M. Bouwmeester, M.W. Otter, B.A. Boukamp, Oxygen transport in $\mathrm{La}_{0.6} \mathrm{Sr}_{0.4} \mathrm{Co}_{1-\mathrm{y}} \mathrm{Fe}_{\mathrm{y}} \mathrm{O}_{3-\mathrm{d}}$, J Solid State Electr, 8 (2004).

[27] J.F. Vente, W.G. Haije, R. Ijpelaan, F.T. Rusting, On the full-scale module design of an air 
separation unit using mixed ionic electronic conducting membranes, Journal of Membrane Science, 278 (2006) 66-71.

[28] Seider, Seader, Lewin, Widagdo, Product and process design principles, Third ed., John Wiley\&Sons, Inc., 2010.

[29] R.K.Sinnott, Chemical engineering design, 4 ed., Elsevier, 2005.

[30] S. Baumann, J.M. Serra, M.P. Lobera, S. Escolástico, F. Schulze-Küppers, W.A. Meulenberg, Ultrahigh oxygen permeation flux through supported $\mathrm{Ba}_{0.5} \mathrm{Sr}_{0.5} \mathrm{Co}_{0.8} \mathrm{Fe}_{0.2} \mathrm{O}_{3-\delta}$ membranes, Journal of Membrane Science, 377 (2011) 198-205.

[31] J.M. Serra, J. Garcia-Fayos, S. Baumann, F. Schulze-Küppers, W.A. Meulenberg, Oxygen permeation through tape-cast asymmetric all-La0.6 $\mathrm{Sr}_{0.4} \mathrm{Co}_{0.2} \mathrm{Fe}_{0.8} \mathrm{O}_{3-\delta}$ membranes, Journal of Membrane Science, 447 (2013) 297-305. 


\subsection{Appendix:}

Table A6.1. Material and power streams for the coal-fired power plant without $\mathrm{CO}_{2}$ capture (see Figure 6.2)

\begin{tabular}{lccccc}
\hline Material streams & Air & A1 & A2 & Coal & Exhaust gas \\
Temperature $\left({ }^{\circ} \mathrm{C}\right)$ & 25 & 79 & 400 & 25 & 50 \\
Pressure $($ bar $)$ & 1 & 1.7 & 1 & 1 & 1 \\
Mole flow $(\mathrm{kmole} / \mathrm{h})$ & 7976 & 7976 & 7976 & 1667 & 7976 \\
Mass flow (tonne/h) & 230 & 230 & 250 & 20 & 250 \\
Power streams & $\mathbf{E 1}$ & $\mathbf{E 2}$ & $\mathbf{E 3}$ & & \\
$(\mathrm{MW})$ & 3.49 & 158.5 & 25.6 & & \\
\hline
\end{tabular}

Table A6.2. Material and power streams for the oxy-fuel combustion process with $\mathrm{CO}_{2}$ capture (see Figure 6.3)

\begin{tabular}{|c|c|c|c|c|c|c|c|c|c|}
\hline Material streams & A1 & A2 & $\mathbf{A 3}$ & A4 & A5 & A6 & A7 & $\mathbf{O 2}$ & Coal \\
\hline Temperature $\left({ }^{\circ} \mathrm{C}\right)$ & 40 & 85 & 373 & 50 & 50 & 50 & 50 & 15 & 25 \\
\hline Pressure (bar) & 1 & 1.7 & 1.7 & 1 & 1 & 1 & 1 & 1 & 1.7 \\
\hline Mole flow (kmole/h) & 4763 & 4763 & 4763 & 4763 & 1667 & 3096 & 3096 & 1667 & 1667 \\
\hline Mass flow (tonne/h) & 190 & 190 & 210 & 210 & 73 & 136 & 136 & 53 & 20 \\
\hline Power streams & E1 & E2 & E3 & \multicolumn{3}{|c|}{$\mathrm{CO}_{2}$ compression } & & & \\
\hline (MW) & 2.2 & 165.4 & 18.6 & \multicolumn{3}{|c|}{6.11} & & & \\
\hline
\end{tabular}


Membrane-integrated oxy-fuel combustion: process design and simulation

Table A6.3. Material and power streams for the membrane-integrated oxy-fuel combustion process (see Figure 6.5)

\begin{tabular}{|c|c|c|c|c|c|c|c|c|c|c|}
\hline Material streams & A1 & $\mathbf{A 2}$ & $\mathbf{A 3}$ & A4 & A5 & A6 & A7 & A8 & A9 & A10 \\
\hline Temperature $\left({ }^{\circ} \mathrm{C}\right)$ & 112 & 716 & 950 & 950 & 212 & 4 & 950 & 435 & 435 & 50 \\
\hline Pressure (bar) & 10 & 10 & 10 & 9.99 & 9.99 & 1 & 1.7 & 1.7 & 1.2 & 1 \\
\hline Mole flow (kmole/h) & 8659 & 8659 & 8659 & 6992 & 6992 & 6992 & 4815 & 4815 & 4815 & 4815 \\
\hline Mass flow (tonne/h) & 250 & 250 & 250 & 196 & 196 & 196 & 192 & 192 & 212 & 212 \\
\hline Material streams & A11 & A12 & A13 & A14 & A15 & Coal & & & & \\
\hline Temperature $\left({ }^{\circ} \mathrm{C}\right)$ & 50 & 101 & 850 & 950 & 50 & 25 & & & & \\
\hline Pressure (bar) & 1 & 1.7 & 1.7 & 1.7 & 1 & 1.2 & & & & \\
\hline Mole flow $(\mathrm{kmole} / \mathrm{h})$ & 3148 & 3148 & 3148 & 3148 & 1666 & 1659 & & & & \\
\hline Mass flow (tonne/h) & 138 & 138 & 138 & 138 & 73 & 20 & & & & \\
\hline Power streams & E2 & $\mathbf{E 3}$ & E4 & E5 & E6 & E7 & \multicolumn{2}{|c|}{$\mathrm{CO}_{2}$ compression } & \multicolumn{2}{|c|}{ Air compression } \\
\hline (MW) & 11.97 & 18.85 & 179.9 & 1.75 & 4.89 & 22.81 & \multicolumn{2}{|c|}{6.11} & \multicolumn{2}{|c|}{17.2} \\
\hline
\end{tabular}


Table A6.4. Material and power streams for the modified membrane-integrated oxy-fuel combustion process (see Figure 6.9)

\begin{tabular}{|c|c|c|c|c|c|c|c|c|c|c|}
\hline Material streams & A1 & A2 & A3 & A4 & A5 & A6 & A7 & A8 & A9 & A10 \\
\hline Temperature $\left({ }^{\circ} \mathrm{C}\right)$ & 112 & 716 & 950 & 950 & 212 & 4 & 950 & 486 & 486 & 486 \\
\hline Pressure (bar) & 10 & 10 & 10 & 9.99 & 9.99 & 1 & 1.7 & 1.7 & 1.7 & 1.7 \\
\hline Mole flow (kmole/h) & 8659 & 8659 & 8659 & 6992 & 6992 & 6992 & 5280 & 5280 & 4763 & 4763 \\
\hline Mass flow (tonne/h) & 249.8 & 249.8 & 249.8 & 196.4 & 196.4 & 196.4 & 210.2 & 210.2 & 189.6 & 209.6 \\
\hline Material streams & A11 & A12 & A13 & A14 & A15 & A16 & A17 & A18 & A19 & A20 \\
\hline Temperature $\left({ }^{\circ} \mathrm{C}\right)$ & 50 & 50 & 92 & 850 & 950 & 950 & 950 & 486 & 260 & 150 \\
\hline Pressure (bar) & 1 & 1 & 1.7 & 1.7 & 1.7 & 1.7 & 1.7 & 1.7 & 1.695 & 1.695 \\
\hline Mole flow (kmole/h) & 4763 & 3096 & 3096 & 3096 & 3096 & 3613 & 3613 & 517 & 517 & 517 \\
\hline Mass flow (tonne/h) & 209.6 & 136.2 & 136.3 & 136.3 & 136.3 & 156.9 & 156.9 & 20.6 & 20.6 & 20.6 \\
\hline Material streams & A21 & A22 & A23 & A24 & Coal & & & & & \\
\hline Temperature $\left({ }^{\circ} \mathrm{C}\right)$ & 150 & 387 & 950 & 50 & 25 & & & & & \\
\hline Pressure (bar) & 1.7 & 1.695 & 1.7 & 1 & 1.7 & & & & & \\
\hline Mole flow (kmole/h) & 517 & 517 & 517 & 1667 & 1667 & & & & & \\
\hline Mass flow (tonne/h) & 20.6 & 20.6 & 20.6 & 73.4 & 20.0 & & & & & \\
\hline Power streams & E2 & $\mathbf{E 3}$ & $\mathbf{E} 4$ & E5 & E6 & E7 & E8 & E9 & E10 & \\
\hline$(\mathrm{MW})$ & 11.97 & 18.85 & 179.3 & 1.44 & 4.82 & 25.93 & 0.62 & 0.002 & 3.76 & \\
\hline Power streams & \multicolumn{2}{|c|}{$\mathrm{CO}_{2}$ compression } & \multicolumn{2}{|c|}{ Air compression } & & & & & & \\
\hline$(\mathrm{MW})$ & \multicolumn{2}{|c|}{6.11} & \multicolumn{2}{|c|}{17.2} & & & & & & \\
\hline
\end{tabular}




\section{Chapter 7 Conclusions and recommendations}


This thesis describes several fundamental aspects on the membrane-integrated oxy-fuel combustion process and can be divided in two parts: 1) The development and characterization of membrane materials; 2) The design, simulation and evaluation of a coal-fired power plant, coupled with a membrane module.

A simple and easy method to measure the oxygen nonstoichiometry of a perovskite material is described in chapter 2. A Computing Fluid Dynamic (CFD) model is developed in chapter 3 to describe the oxygen gradient in a commonly used oxygen permeation set-up, as used to determine the oxygen ionic conductivity of a membrane. Chapter 4 provides the development of a $\mathrm{CO}_{2}$-stable membrane ( $\mathrm{Ta}$ doped $\mathrm{SrCo}_{0.8} \mathrm{Fe}_{0.2} \mathrm{O}_{3-\delta}(\mathrm{SCF})$ ) as can be used for the membrane-integrated oxy-fuel combustion process. In chapter 5 it is found that the $\mathrm{CO}_{2}$ tolerance of the SCF membrane is affected by the ambient oxygen partial pressure: mixing $5 \%$ oxygen to $\mathrm{CO}_{2}$ can prevent the membrane from degradation. In chapter 6 of this thesis a membrane-integrated oxy-fuel combustion process is designed, and this process is simulated in Unisim for evaluation.

In this final chapter, some general conclusions are drawn from the previous chapters, and some recommendations are given for future work.

\subsection{Incomplete gas mixing in a lab-scale permeation set-up}

Oxygen permeation measurements are performed to determine membrane properties like the oxygen flux through a membrane at a given oxygen partial pressure gradient and the (ionic) conductivity. These measurements are usually performed in lab-scale equipment as schematically given in Figure 3.1 (Chapter 3). By varying the oxygen partial pressure $\left(P_{\mathrm{O}_{2}}\right)$ at the feed/sweep side of the membrane, it is possible to calculate the oxygen ionic conductivity using Wagner's equation (see eq.1.6 in chapter 1) [1]. However, an ideal gas mixing has to be assumed in such a permeation set-up, i.e.: the oxygen partial pressure $\left(P_{\mathrm{O}_{2}}\right)$ is homogeneous on the membrane surface and is identical with the value measured at the outlet of the set-up. 
It is then assumed that the set-up functions as a Continuous Ideally Stirred Tank Reactor (CISTR). However, with the aid of a CFD model, it is found in chapter 3 that this assumption is not completely valid. The $P_{\mathrm{O}_{2}}$ on the membrane surface at the permeate is not homogeneous over the surface, while there might be also a difference between $P_{\mathrm{O}_{2}}$ as measured at the outlet of the set-up and the (average) $P_{\mathrm{O}_{2}}$ at the membrane surface. This incomplete gas mixing is affected by the set-up geometry as well as operating conditions like flow rate and type of sweep gas. It is shown that especially the type of sweep gas has great influence on the gas mixing, e.g. using helium as sweep gas results in better mixing with oxygen than argon. If using helium as sweep gas in the set-up as used in our Inorganic Membranes laboratory, there is only a slight deviation in the CISTR assumption.

Due to incomplete gas mixing, calculation of the oxygen ionic conductivity based on the $P_{\mathrm{O}_{2}}$ measured at the outlet is not accurate. A way to overcome this problem is to use a CFD model, as described in chapter 3. With this CFD model, no ideal gas mixing assumption is required, and the oxygen ionic conductivity can be obtained by fitting the experimental results.

\subsection{Chemical stability of MIEC membranes in a $\mathrm{CO}_{2}$-containing atmosphere}

The chemical stability of mixed ion-electron conducting (MIEC) membranes in a $\mathrm{CO}_{2}$-containing atmosphere is of relevance in a number of processes where $\mathrm{CO}_{2}$ is in contact with the membrane, e.g. when these membranes are applied in a 4-end mode operation, where $\mathrm{CO}_{2}$ is used as sweep gas. This chemical stability is affected by factors like membrane material, operation temperature and oxygen partial pressure in the $\mathrm{CO}_{2}$-rich sweep gas.

The type of membrane material has a major effect on the chemical stability. For example, $\mathrm{Ba}_{0.5} \mathrm{Sr}_{0.5} \mathrm{Co}_{0.8} \mathrm{Fe}_{0.2} \mathrm{O}_{3-\delta}$ ( $\mathrm{BSCF}$ ) has a very low tolerance to $\mathrm{CO}_{2}$. The introduction of $\mathrm{CO}_{2}$ in the sweep/feed gas causes an immediate decline in oxygen 
flux $[2,3] . \mathrm{La}_{0.6} \mathrm{Sr}_{0.4} \mathrm{Co}_{0.8} \mathrm{Fe}_{0.2} \mathrm{O}_{3-\delta}$ (LSCF) has a relatively high $\mathrm{CO}_{2}$ tolerance, and it is found that a stable oxygen flux is obtained when $\mathrm{CO}_{2}$ is used as sweep gas $[4,5]$. $\mathrm{SrCo}_{0.8} \mathrm{Fe}_{0.2} \mathrm{O}_{3-\delta}(\mathrm{SCF})$ is somewhere in the middle, and using $\mathrm{CO}_{2}$ as sweep gas leads to a slow decrease in oxygen flux [6]. So a general order of $\mathrm{CO}_{2}$ tolerance for $\mathrm{BSCF}$, $\mathrm{SCF}$ and LSCF is: $\mathrm{LSCF}>\mathrm{SCF}>\mathrm{BSCF}$. However, it has also been found that the oxygen permeability of BSCF, SCF and LSCF is in reversed order of $\mathrm{LSCF}<\mathrm{SCF}<\mathrm{BSCF}$, and it seems there is a trade-off between $\mathrm{CO}_{2}$ tolerance and oxygen permeability. In chapter 4 it is proven that $10 \%$ Ta doping at the $\mathrm{Co} / \mathrm{Fe}(\mathrm{B}-)$ site of SCF leads to an increase in $\mathrm{CO}_{2}$ tolerance, and a stable oxygen flux is obtained at $900{ }^{\circ} \mathrm{C}$ using $\mathrm{CO}_{2}$ as sweep gas, although the oxygen permeability is $\sim 30 \%$ smaller than that of the SCF membrane. It is found that the increase in the $\mathrm{CO}_{2}$ tolerance is caused by a decrease in the Lewis basicity of the membrane, as revealed by XPS studies.

Beside the type of membrane material, the operation temperature also plays an important role on the stability of the membrane in a $\mathrm{CO}_{2}$ atmosphere. Yi et al. reported [10] that the oxygen flux of SCF membranes decreases at $810{ }^{\circ} \mathrm{C}$ but remains almost unchanged at $900{ }^{\circ} \mathrm{C}$ when $5 \%$ of $\mathrm{CO}_{2}$ is introduced to the feed gas (air). In chapter 5 isothermal gravimetric analyses were performed at $900{ }^{\circ} \mathrm{C}, 950{ }^{\circ} \mathrm{C}$ and $1000{ }^{\circ} \mathrm{C}$ using a sweep gas containing $67 \% \mathrm{CO}_{2}, 10 \% \mathrm{O}_{2}$ and $23 \%$ nitrogen. It is found that the reaction of SCF with $\mathrm{CO}_{2}$ is completely restrained when the temperature is raised to $1000{ }^{\circ} \mathrm{C}$, compared to fast reactions with $\mathrm{CO}_{2}$ at $900{ }^{\circ} \mathrm{C}$ and $950{ }^{\circ} \mathrm{C}$. In principle, it is possible to use a MIEC membrane at a high temperature to avoid $\mathrm{CO}_{2}$ poisoning. However, some practical problems may arise if the temperature is too high. For example, the melting temperature of BSCF is $\sim 1150{ }^{\circ} \mathrm{C}$ to $1200{ }^{\circ} \mathrm{C}$. It is better not to operate MIEC membranes at a temperature that is very close to the melting temperature of the material.

The effect of $P_{\mathrm{O}_{2}}$ on the stability of SCF membranes in a $\mathrm{CO}_{2}$-containing atmosphere has been intensively discussed in chapter 5. It is found that the chemical 
stability of the membrane in a $\mathrm{CO}_{2}$-containing sweep gas is improved by increasing the oxygen partial pressure in the sweep gas. Long term oxygen permeation experiments, at $950{ }^{\circ} \mathrm{C}$, showed that mixing $5 \%$ of oxygen into the $\mathrm{CO}_{2}$ sweep gas effectively prevents degradation of the SCF membrane. Here it is also observed that the increase in $\mathrm{CO}_{2}$ tolerance is due to a decrease in the Lewis basicity of the membrane, similar to the results of Ta-doped SCF as described in chapter 4. It should be noted that although the work was only focused on SCF, it is expected that similar Lewis acid/base effects on $\mathrm{CO}_{2}$-stability are valid for other perovskite systems.

\subsection{Evaluation of the membrane-integrated oxy-fuel combustion process}

The integration of MIEC membranes in the oxy-fuel combustion process is evaluated in chapter 6 . It is found that the integration of oxygen transport membranes decreases the energy demand for $\mathrm{CO}_{2}$ capture, as compared to a conventional oxyfuel combustion process where cryogenic distillation is used for oxygen production. In a case study, based on a power plant where 20 tonne/h of coal is burned for electric power generation, a net efficiency of $32.1 \%$ is obtained for the membraneintegrated oxy-fuel combustion process (including $\mathrm{CO}_{2}$ compression to $100 \mathrm{bar}$ ), which is higher than that of a conventional oxy-fuel combustion process $(29.6 \%$ including $\mathrm{CO}_{2}$ compression). The required membrane area for the power plant is approximately $71,000 \mathrm{~m}^{2}$ based on Ta-doped $\mathrm{SrCo}_{0.8} \mathrm{Fe}_{0.2} \mathrm{O}_{3-\delta}$ membranes. The specific energy demand for $\mathrm{CO}_{2}$ capture in this study is $185 \mathrm{kWh}_{\mathrm{e}} / \mathrm{t}_{\mathrm{CO}_{2}}$, and the specific energy demand for oxygen production is $104 \mathrm{kWh}_{\mathrm{e}} / \mathrm{t}_{\mathrm{O}_{2}}$. A modified process design is also proposed, in which higher oxygen permeable membranes (SCF) are used and an extra $\mathrm{CO}_{2} / \mathrm{O}_{2}$ loop is introduced to protect $\mathrm{SCF}$ from $\mathrm{CO}_{2}$ poisoning. The modified process shows a similar net efficiency of $31.9 \%$, but a significantly lower amount of required membrane area $\left(49,000 \mathrm{~m}^{2}\right)$. However, it should be noted that in the modified process, extra cost has to be spent on the heat exchangers and gas compressors (see figure 6.9). 


\subsection{Some recommendations for future work}

\section{Membrane stability in a $\mathrm{SO}_{2}$-containing atmosphere}

In the 4-end mode operation of membranes as used in e.g. the oxy-fuel combustion process, the permeate side of the membrane is exposed to the recycled flue gas, which mainly contains $\mathrm{CO}_{2}$. However, depending on the fuel used and the gas purification technique applied, there might be some traces of other gases present in the flue gas which is partly recycled as a sweep gas. These species may affect the membrane performance, even at a very low concentration. An example of a strong membrane-poisoning gas is $\mathrm{SO}_{2}$. Wei et al. [11] have reported that $\left(\operatorname{Pr}_{0.9} \mathrm{La}_{0.1}\right)_{2}\left(\mathrm{Ni}_{0.74} \mathrm{Cu}_{0.21} \mathrm{Ga}_{0.05}\right) \mathrm{O}_{4+\delta}$ (PLNCG) shows very high $\mathrm{CO}_{2}$ tolerance but rather low $\mathrm{SO}_{2}$ tolerance. The oxygen flux of a PLNCG membrane remains almost the same when the sweep gas was switched from helium to pure $\mathrm{CO}_{2}$, however, when the sweep gas was switched to helium containing $84 \mathrm{ppm} \mathrm{SO}_{2}$, the oxygen flux drops to half of its original value within 2 hours and keeps decreasing. Engels et al. [3] have also found similar results with $\mathrm{Sr}_{0.5} \mathrm{Ca}_{0.5} \mathrm{Mn}_{0.8} \mathrm{Fe}_{0.2} \mathrm{O}_{3-\delta}$ (SCMF). SCMF shows

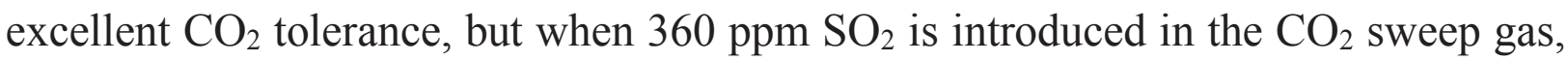
the oxygen flux is immediately stopped. In both cases, it is found that metal sulfates were formed, resulting in a membrane which is impermeable for oxygen. Since the decomposition temperature of metal sulfates is usually much higher than carbonates due to their high formation energy [12-14], $\mathrm{SO}_{2}$ might be a more severe problem compared with $\mathrm{CO}_{2}$. Thus, it might be of interesting to consider the 3-end mode operation for the oxy-fuel combustion process, because no sweep gas is required in such a case.

\section{Membrane stability in a water vapor containing atmosphere}

Water vapor may also exist in the recycled flue gas. Bucher et al. [15] have reported that adding $\sim 1 \%$ water vapor to an $\mathrm{Ar}-\mathrm{O}_{2}$ mixture in the feed gas decreases the oxygen surface reaction rate of $\mathrm{La}_{0.6} \mathrm{Sr}_{0.4} \mathrm{Co}_{0.2} \mathrm{Fe}_{0.8} \mathrm{O}_{3-\delta}$ by a factor of 10 at 600 ${ }^{\circ} \mathrm{C}$. Similar effects has also been found for $\mathrm{La}_{0.6} \mathrm{Sr}_{0.4} \mathrm{Co}_{0.8} \mathrm{O}_{3-\delta}$ [16]. It is interpreted 
that the decrease in surface reaction rate is caused by the coverage of the whole sample surface with silicon. The quartz reactor acted as a silicon source, and volatile $\mathrm{Si}(\mathrm{OH})_{4}(\mathrm{~g})$, which forms in humid atmospheres, was transported via the gas phase to the reactive sample surface. In practice, there are various $\mathrm{Si}$-sources such as glass seals and thermal insulation in the membrane module system. For operating these membranes in water vapor containing atmospheres it is important to avoid the use $\mathrm{SiO}_{2}$-containing materials for sealing etc.

\section{Process development for the 3-end mode}

The work described in this thesis is focused on the 4-end mode operation with regard to the application of the membrane in the membrane-integrated oxy-fuel process. For the 3-end mode (see Figure 1.6a) there is a less strong demand on chemical stability as compared with the 4-end mode, because the membrane is not exposed to any "poisoning" gas like $\mathrm{CO}_{2}$ or $\mathrm{SO}_{2}$. Although the 3-end mode might be more promising in oxy-fuel combustion process, not a lot of research has been done on the development of a process where a membrane is applied in the 3-end mode. In future, simulation experiments on the 3 -end mode must be regarded as well in making an estimation of the energy requirement for oxygen production, i.e. how much energy is needed to produce 1 tonne of oxygen in such a case.

\section{References}

[1] C.H. Chen, H. Kruidhof, H.J.M. Bouwmeester, A.J. Burggraaf, Ionic conductivity of perovskite $\mathrm{LaCoO}_{3}$ measured by oxygen permeation technique, Journal of Applied Electrochemistry, 27 (1997) 71 75.

[2] M. Arnold, H.H. Wang, A. Feldhoff, Influence of $\mathrm{CO}_{2}$ on the oxygen permeation performance and the microstructure of perovskite-type $\left(\mathrm{Ba}_{0.5} \mathrm{Sr}_{0.5}\right)\left(\mathrm{Co}_{0.8} \mathrm{Fe}_{0.2}\right) \mathrm{O}_{3-\delta}$ membranes, Journal of Membrane Science, 293 (2007) 44-52.

[3] S. Engels, T. Markus, M. Modigell, L. Singheiser, Oxygen permeation and stability investigations on MIEC membrane materials under operating conditions for power plant processes, Journal of Membrane Science, 370 (2011) 58-69.

[4] X. Tan, N. Liu, B. Meng, J. Sunarso, K. Zhang, S. Liu, Oxygen permeation behavior of 
La0.6 $\mathrm{Sr}_{0.4} \mathrm{Co}_{0.8} \mathrm{Fe}_{0.2} \mathrm{O}_{3}$ hollow fibre membranes with highly concentrated $\mathrm{CO}_{2}$ exposure, Journal of Membrane Science, 389 (2012) 216-222.

[5] T. Klande, O. Ravkina, A. Feldhoff, Effect of A-site lanthanum doping on the $\mathrm{CO}_{2}$ tolerance of $\mathrm{SrCo}_{0.8} \mathrm{Fe}_{0.2} \mathrm{O}_{3-\delta}$ oxygen-transporting membranes, Journal of Membrane Science, 437 (2013) 122-130.

[6] Q. Zeng, Y.B. Zu, C.G. Fan, C.S. Chen, $\mathrm{CO}_{2}$-tolerant oxygen separation membranes targeting $\mathrm{CO}_{2}$ capture application, Journal of Membrane Science, 335 (2009) 140-144.

[7] J.W. Stevenson, T.R. Armstrong, R.D. Carneim, L.R. Pederson, W.J. Weber, Electrochemical properties of mixed conducting perovskites $\mathrm{La}_{1-\mathrm{x}} \mathrm{M}_{\mathrm{x}} \mathrm{Co}_{1-\mathrm{y}} \mathrm{Fe}_{\mathrm{y}} \mathrm{O}_{3-\delta}(\mathrm{M}=\mathrm{Sr}, \mathrm{Ba}, \mathrm{Ca}), \mathrm{J}$ Electrochem Soc, 143 (1996) 2722-2729.

[8] J. Sunarso, S. Baumann, J.M. Serra, W.A. Meulenberg, S. Liu, Y.S. Lin, J.C.D. da Costa, Mixed ionic-electronic conducting (MIEC) ceramic-based membranes for oxygen separation, Journal of Membrane Science, 320 (2008) 13-41.

[9] J.A. Lane, S.J. Benson, D. Waller, J.A. Kilner, Oxygen transport in $\mathrm{La}_{0.6} \mathrm{Sr}_{0.4} \mathrm{Co}_{0.2} \mathrm{Fe}_{0.8} \mathrm{O}_{3-\delta}$, Solid State Ionics, 121 (1999) 201-208.

[10] J.X. Yi, S.J. Feng, Y.B. Zuo, W. Liu, C.S. Chen, Oxygen permeability and stability of $\mathrm{Sr} 0.95 \mathrm{Co}_{0.8} \mathrm{Fe}_{0.2} \mathrm{O}_{3-\delta}$ in a $\mathrm{CO}_{2}$ - and $\mathrm{H}_{2} \mathrm{O}$-containing atmosphere, Chem Mater, 17 (2005) 5856-5861.

[11] Y. Wei, O. Ravkina, T. Klande, H. Wang, A. Feldhoff, Effect of $\mathrm{CO}_{2}$ and $\mathrm{SO}_{2}$ on oxygen permeation and microstructure of $\left(\mathrm{Pr}_{0.9} \mathrm{La}_{0.1}\right)_{2}\left(\mathrm{Ni}_{0.74} \mathrm{Cu}_{0.21} \mathrm{Ga}_{0.05}\right) \mathrm{O}_{4+\delta}$ membranes, Journal of Membrane Science, 429 (2013) 147-154.

[12] M.W. Nathans, W.W. Wendlandt, The thermal decomposition of the rare-earth sulphates: Thermogravimetric and differential thermal analysis studies up to $1400^{\circ} \mathrm{C}$, Journal of Inorganic and Nuclear Chemistry, 24 (1962) 869-879.

[13] A.G. Ostroff, R.T. Sanderson, Thermal stability of some metal sulphates, Journal of Inorganic and Nuclear Chemistry, 9 (1959) 45-50.

[14] J.A. Poston Jr, R.V. Siriwardane, E.P. Fisher, A.L. Miltz, Thermal decomposition of the rare earth sulfates of cerium(III), cerium(IV), lanthanum(III) and samarium(III), Applied Surface Science, 214 (2003) 83-102.

[15] E. Bucher, W. Sitte, F. Klauser, E. Bertel, Oxygen exchange kinetics of $\mathrm{La}_{0.58} \mathrm{Sr}_{0.4} \mathrm{Co}_{0.2} \mathrm{Fe}_{0.8} \mathrm{O}_{3}$ at $600^{\circ} \mathrm{C}$ in dry and humid atmospheres, Solid State Ionics, 191 (2011) 61-67.

[16] E. Bucher, W. Sitte, F. Klauser, E. Bertel, Impact of humid atmospheres on oxygen exchange properties, surface-near elemental composition, and surface morphology of $\mathrm{La}_{0.6} \mathrm{Sr}_{0.4} \mathrm{CoO}_{3-\delta}$, Solid State Ionics, 208 (2012) 43-51. 


\section{Summary}

Dense ceramic oxygen transport membranes (OTMs) have an infinite selectivity for oxygen because oxygen is transported in the form of ions. This feature makes it of great potential in air separation and other oxygen related processes. This thesis describes original research on OTMs, including fundamental material studies as well as process engineering design and simulation.

A general introduction is given in chapter $\mathbf{1}$, which includes a brief review of $\mathrm{CO}_{2}$ capturing techniques and the basic concept of using OTMs in the oxy-fuel process of a fossil fuel fired power plant.

Chapter 2 and 3 are focused on the development of experimental and mathematical approaches for membrane characterization. In chapter 2 a new and easy method is described to determine the oxygen non-stoichiometry of perovskite materials, which are the most commonly used materials for OTMs. The method is based on the complete decomposition of the powder to stoichiometric metal oxides and/or metal carbonates by using $\mathrm{CO}_{2}$ as reacting gas. The oxygen non-stoichiometry is calculated from the mass change caused by this reaction. Its applicability is demonstrated by using $\mathrm{SrCoO}_{3-\delta}, \mathrm{BaCoO}_{3-\delta}, \mathrm{BaFeO}_{3-\delta}$ and $\mathrm{BaCeO}_{3-\delta}$ as representative materials.

Oxygen permeability of the OTMs is another important membrane property for oxygen transport. Analysis of the oxygen permeability of dense ceramic membranes is usually performed with a lab-scale oxygen permeation set-up where feed and sweep gas are directly flushed over the membrane surface. Due to concentration gradients within the experimental setup, the oxygen partial pressure $\left(P_{\mathrm{O}_{2}}\right)$ measured at the outlet of the set-up does not always have to be the same as the $P_{\mathrm{O}_{2}}$ on the membrane surface. This leads to an inaccurate calculation of the oxygen ionic conductivity (an intrinsic material property) of the membrane. In order to overcome 
this problem, a computational fluid dynamics (CFD) model is developed and described in Chapter 3. In the description of this model special attention is paid to the exact oxygen partial pressures on the membrane surface at the permeate side. With this CFD model, the oxygen ionic conductivity of a selected model membrane, $\mathrm{SrCo}_{0.8} \mathrm{Fe}_{0.2} \mathrm{O}_{3-\delta}$ (SCF), is calculated. In addition, the influence is studied of several set-up parameters on the oxygen partial pressure distribution in the setup such as the distance from sweep gas inlet to the membrane surface, the type of sweep gas used and the sweep gas flow rate. The following results were found:

(1) The distance from sweep gas inlet to the membrane surface affects the $P_{\mathrm{O}_{2}}$ in both radial direction and axial direction. At increasing distance the $P_{\mathrm{O}_{2}}$ on the membrane surface becomes more homogenous due to the lower sweep gas velocity at the surface, causing less convection. However, when the distance is too large, the overall $P_{\mathrm{O}_{2}}$ on the membrane surface will be much higher than that measured at the outlet of the set-up.

(2) The binary diffusion coefficient in the oxygen-sweep gas mixture has a strong influence on the concentration distribution in the setup. Higher diffusion coefficients lead to a better mixing and therefore a faster transport of the oxygen away from the membrane surface. Faster mixing leads to a more homogeneous oxygen partial pressure distribution in the setup. Helium as sweep gas gives the highest diffusion coefficient and results in the most homogeneous oxygen partial pressure distribution in the setup, if compared with gases like $\mathrm{N}_{2}, \mathrm{Ar}$ of $\mathrm{CO}_{2}$.

(3) A higher sweep gas flow rate decreases the overall $P_{\mathrm{O}_{2}}$ at the permeate side of the membrane, thus increasing the oxygen flux, which makes the $P_{\mathrm{O}_{2}}$ on the membrane surface less homogenous. This influence is relatively small compared with the geometry change of the setup and sweep gas composition.

The study in Chapter $\mathbf{4}$ and $\mathbf{5}$ is focused on the development of $\mathrm{CO}_{2}$ tolerant 
membranes. $\mathrm{CO}_{2}$ tolerance is very important in a membrane-integrated fossil fuel fired oxy-fuel combustion process, because highly concentrated $\mathrm{CO}_{2}$ is used as sweep gas for the membrane module. Chapter 4 describes the development of a $\mathrm{CO}_{2}$ stable membrane, namely $\mathrm{Sr}\left(\mathrm{Co}_{0.8} \mathrm{Fe}_{0.2}\right)_{0.9} \mathrm{Ta}_{0.1} \mathrm{O}_{3-\delta}$ (SCFTa), which is derived from $\mathrm{SrCo}_{0.8} \mathrm{Fe}_{0.2} \mathrm{O}_{3-\delta}(\mathrm{SCF})$. SCF is a high oxygen permeable membrane with very low $\mathrm{CO}_{2}$ tolerance. The reaction between $\mathrm{SCF}$ and $\mathrm{CO}_{2}$ leads to a decline in oxygen flux to 0 within 100 hours. When $10 \%$ of $\mathrm{Co} / \mathrm{Fe}$ is replaced by $\mathrm{Ta}$, it is shown that the reaction between $\mathrm{SCF}$ and $\mathrm{CO}_{2}$ is almost prevented. XPS analysis shows that the basicity of SCFTa is less than that of SCF, which may be contributed to the enhanced stability of SCFTa in $\mathrm{CO}_{2}$ atmosphere. $\mathrm{Ta}^{5+}$ also increases the perovskite phase stability of SCF at low oxygen partial pressure $\left(\mathrm{pO}_{2}<10^{-2} \mathrm{~atm}\right)$, which was proven by the disappearance of a strong shrinkage signal during thermal expansion measurements. In the oxygen permeation measurement, the oxygen flux of SCFTa was slightly lower than that of SCF when an air/helium gradient was applied over the membrane, but it remained almost the same when pure $\mathrm{CO}_{2}$ was introduced as sweep gas.

A further study on the $\mathrm{CO}_{2}$ tolerance of SCF is given in Chapter 5. It is found that the $\mathrm{CO}_{2}$ tolerance of SCF improves by increasing the oxygen partial pressure in the $\mathrm{CO}_{2}$-containing gas. Long term oxygen permeation experiments, at $950{ }^{\circ} \mathrm{C}$, showed that mixing $5 \%$ of oxygen into the $\mathrm{CO}_{2}$ sweep gas effectively prevents degradation of the SCF membrane. XPS analysis indicates that the increase in $\mathrm{CO}_{2}$ tolerance of SCF is caused by a decrease in basicity of the material with increasing oxygen partial pressure, which is in agreement with the studies as given in chapter 4 . Based on these experimental results, a modified oxy-fuel combustion process is proposed. In this process a mixture of $5 \% \mathrm{O}_{2}$ and $95 \% \mathrm{CO}_{2}$ is used instead of pure $\mathrm{CO}_{2}$ as sweep gas. The required membrane area for operating a $50 \mathrm{MW}$ coal-fired power plant is calculated based on this design, which shows that only $17 \%$ additional membrane area is needed for oxygen production, compared to the case 
where pure $\mathrm{CO}_{2}$ is used as sweep gas. However, it should be pointed out that the latter case is not realistic, because SCF membranes are not stable in a pure $\mathrm{CO}_{2}$ atmosphere.

Chapter 6 discusses the design of the whole process for a membrane-integrated oxy-fuel combustion process. Simulation results, using $\mathrm{UniSim}^{\circledR}$, indicate for this process an overall net efficiency of $32.1 \%$ for a coal-fired power plant where 20 tonne/h of coal is burned for electric power generation. This efficiency is higher than that for an oxy-fuel combustion process using oxygen from cryogenic distillation of air $(29.6 \%)$. The specific electrical energy demand for $\mathrm{CO}_{2}$ capture in this oxy-fuel process, including oxygen production and $\mathrm{CO}_{2}$ compression (to 100 bar), is calculated to be $\sim 159 \mathrm{kWh}_{\mathrm{e}} / \mathrm{t}_{\mathrm{CO}_{2}}$. The required membrane area for the power plant is approximately $71,000 \mathrm{~m}^{2}$ based on Ta-doped $\mathrm{SrCo}_{0.8} \mathrm{Fe}_{0.2} \mathrm{O}_{3-\delta}$ (SCFTa) membranes. Inspired by the results of the research as described in chapter 5, a modified process is proposed, in which un-doped SCF membranes are used for air separation and an extra $\mathrm{O}_{2} / \mathrm{CO}_{2}$ loop is introduced to protect the $\mathrm{SCF}$ membranes from $\mathrm{CO}_{2}$ poisoning. This modified process shows a net efficiency of $31.9 \%$, which is very closed the net efficiency of unmodified process $32.1 \%$, but a considerably lower amount of membrane area $\left(49,000 \mathrm{~m}^{2}\right)$ is necessary.

Finally, in chapter 7, some conclusions are made and recommendations for future research are provided. More research should be done towards: (1) membrane stability in a $\mathrm{SO}_{2}$-containing atmosphere; (2) membrane stability in a water vapor containing atmosphere and (3) process development for a 3-end mode membrane configuration. 


\section{Samenvatting}

In dit proefschrift zijn materiaalkundige studies van keramische, zuurstof selectieve, membranen beschreven en worden proces simulaties gemaakt, waarbij deze membranen gebruikt worden in het verbrandingsproces van steenkool voor elektriciteitsopwekking, geïntegreerd met $\mathrm{CO}_{2}$ opslag. Het zuurstof transport door deze gasdichte membranen is in de vorm van zuurstof ionen. Daarom hebben deze zuurstof transport membranen (OTMs $=$ Oxygen Transport Membranes) een oneindige selectiviteit voor zuurstof en zijn interessant voor het scheiden van zuurstof uit lucht en voor andere zuurstof gerelateerde processen.

In hoofdstuk 1 wordt een algemene inleiding gegeven over OTMs en daarnaast wordt een kort overzicht gegeven van de verschillende methodes om $\mathrm{CO}_{2}$ af te vangen $\left(\mathrm{CO}_{2}\right.$ capture $)$ bij fossiele brandstof gestookte elektriciteitscentrales. Tenslotte wordt het basisconcept behandeld van het gebruik van OTMs in het "oxyfuel process", waarbij zuurstof van lucht wordt gescheiden, voordat het de verbrandingskamer in gaat.

De hoofdstukken 2 en 3 geven zowel experimentele als mathematische beschrijvingen voor het bepalen van de eigenschappen van de membranen. in hoofdstuk 2 wordt een nieuwe en eenvoudige methode beschreven voor het bepalen van de afwijking $(\delta)$ van de (ideale) zuurstof stoichiometrie in de perovskiet kristalstructuur $\mathrm{ABO}_{3}$. De methode is gebaseerd op de volledige ontleding van het perovksiet poeder (met algemene formule: $\mathrm{ABO}_{3-\delta}$ ) tot het stoichiometrisch metaal oxide en/of metaal-carbonaat door deze poeders te laten reageren in $\mathrm{CO}_{2}$. De afwijking $(\delta)$ van de (ideale) zuurstof stoichiometrie kan dan berekend worden aan de hand van de verandering van de massa ten gevolge van deze ontledingsreactie. De toepasbaarheid van deze methode voor het bepalen van $\delta$ is aangetoond door gebruik te maken van $\mathrm{SrCoO}_{3-\delta}, \mathrm{BaCoO}_{3-\delta}, \mathrm{BaFeO}_{3-\delta}$ en $\mathrm{BaCeO}_{3-\delta}$ als zijnde representatieve OTM materialen. 
De zuurstof doorlaatbaarheid (permeabiliteit) van OTMs is een andere belangrijke membraan eigenschap. De zuurstof permeabiliteit van dichte keramische membranen wordt meestal bepaald in een laboratorium opstelling. Door concentratie gradiënten in een dergelijke opstelling kan er aan het oppervlak van het membraan een andere gassamenstelling zijn dan bij de uitlaat/afvoer. Dit houdt in dat de zuurstof partiaaldruk $\left(P_{\mathrm{O}_{2}}\right)$, die gemeten wordt aan de uitlaat van de opstelling niet altijd dezelfde hoeft te zijn als de $P_{\mathrm{O}_{2}}$ aan het oppervlak van het membraan. Dit resulteert in een onnauwkeurige berekening van de zuurstof ionen geleidbaarheid van het membraan, wat een belangrijke intrinsieke parameter is voor deze materialen. Voor het bepalen van concentratie gradiënten in de meetopstelling is een "Computational Fluid Dynamics" (CFD) model ontwikkeld, wat wordt beschreven in hoofdstuk 3. Bij het uitwerken van dit model is met name aandacht besteed aan het exact berekenen van de zuurstof partiaaldruk aan het oppervlak van de permeaat kant van het membraan. Met dit CFD model is de zuurstof ionen geleiding van het $\mathrm{SrCo}_{0.8} \mathrm{Fe}_{0.2} \mathrm{O}_{3-\delta}$ (SCF) membraan berekend. Tevens is de invloed bestudeerd van verschillende aanpassingen in de meetopstelling op de concentratie gradiënt aan de permeaat kant, zoals de afstand van de inlaat van het spoelgas tot het membraan oppervlak, de gas stroom snelheid en het soort spoelgas, wat gebruikt wordt, met de volgende resultaten:

1) Bij toenemende afstand tussen spoelgas inlaat en membraan oppervlak wordt de $P_{\mathrm{O}_{2}}$ aan het membraan oppervlak meer homogeen, maar als de afstand te groot wordt, is de totale $P_{\mathrm{O}_{2}}$ aan het oppervlak veel hoger dan de gemeten zuurstof partiaaldruk aan de uitlaat van de opstelling.

2 ) De binaire diffusie coëfficiënt van het zuurstof-spoelgas mengsel heeft een grote invloed op de variaties van gas samenstelling in de opstelling. Hogere waarden van de diffusie coëfficiënt resulteren in een betere/snellere menging van zuurstof en 
spoelgas en daardoor in een meer homogene $P_{\mathrm{O}_{2}}$ in de opstelling. Helium heeft, in vergelijking met $\mathrm{N}_{2}$, Ar, of $\mathrm{CO}_{2}$, de hoogste diffusie coëfficiënt en resulteert daarom in de meest homogene $P_{\mathrm{O}_{2}}$ in de opstelling.

3) Door gebruik te maken van een hogere spoelgassnelheid neemt de totale $P_{\mathrm{O}_{2}}$ aan de permeaat kant van het membraan af, waardoor ook de $P_{\mathrm{O}_{2}}$ aan het membraanoppervlak minder homogeen word. De invloed van deze procesparameter is relatief klein ten opzichte van de eerder genoemde parameters.

De studie in hoofdstuk 4 en 5 is gericht op de ontwikkeling van membranen die stabiel zijn in een $\mathrm{CO}_{2}$ atmosfeer. Dit is van groot belang voor het membraangeïntegreerde oxy-fuel verbrandingsproces van fossiele brandstoffen, omdat puur $\mathrm{CO}_{2}$, of een gasmengsel met hoge $\mathrm{CO}_{2}$ concentratie, als spoelgas voor de membraan module wordt gebruikt. Hoofdstuk $\mathbf{4}$ beschrijft de ontwikkeling van een $\mathrm{CO}_{2}$ stabiele membraan, $\operatorname{Sr}\left(\mathrm{Co}_{0.8} \mathrm{Fe}_{0.2}\right)_{0.9} \mathrm{Ta}_{0.1} \mathrm{O}_{3-\delta}$ (SCFTa), wat is afgeleid van het bekende membraan materiaal $\mathrm{SrCo}_{0.8} \mathrm{Fe}_{0.2} \mathrm{O}_{3-\delta}$ (SCF). SCF vertoont een hoge zuurstof permeatie, maar in een $\mathrm{CO}_{2}$ atmosfeer neemt de permeatie snel af om na verloop van tijd (ca 100 muur) volledig zuurstof impermeabel te zijn. De reactie tussen SCF en $\mathrm{CO}_{2}$ wordt bijna volledig tegengegaan als $10 \%$ van het $\mathrm{Co}$ of $\mathrm{Fe}$ vervangen wordt door Ta. XPS analyse toont aan dat SCFTa minder basisch is dan SCF, waardoor het minder snel reageert met $\mathrm{CO}_{2}$. Daarnaast verhoogt het doteren van $\mathrm{SCF}$ met $\mathrm{Ta}^{5+}$ de stabiliteit van de perovskiet kristalstructuur bij lagere zuurstof partiaaldruk $\left(P_{\mathrm{O}_{2}}<\right.$ $\left.10^{-2} \mathrm{~atm}\right)$. Bij een lucht/helium gradiënt over het membraan is de zuurstof permeabiliteit van SCFTa iets lager dan die van SCF, maar de SCFTa blijft dezelfde, constante, permeabiliteit houden als $\mathrm{CO}_{2}$ als spoelgas wordt gebruikt.

In hoofdstuk 5 is een verdere studie uitgevoerd naar de tolerantie van SCF in een $\mathrm{CO}_{2}$ rijke atmosfeer. Aangetoond is dat de $\mathrm{CO}_{2}$ tolerantie van SCF beter wordt als er wat zuurstof aan het $\mathrm{CO}_{2}$ wordt toegevoegd. Een SCF membraan blijft stabiel 
wat betreft zuurstof flux inden er $5 \%$ zuurstof aan het $\mathrm{CO}_{2}$ spoelgas wordt toegevoegd. XPS analyses lieten zien dat de toename in $\mathrm{CO}_{2}$ tolerantie veroorzaakt wordt doordat het SCF minder basisch is bij toenemende zuurstof partiaaldruk. Met de kennis, verkregen uit deze experimentele resultaten is een aangepast oxy-fuel verbrandingsproces voorgesteld, waarbij een mengsel van $5 \% \mathrm{O}_{2}$ en $95 \% \mathrm{CO}_{2}$ als spoelgas wordt gebruikt in plaas van puur $\mathrm{CO}_{2}$. Gebaseerd op dit ontwerp is uitgerekend dat slechts $17 \%$ extra membraan oppervlak nodig is voor zuurstof productie voor een $50 \mathrm{MW}$ kolen gestookte elektriciteitscentrales in vergelijking met het gebruik van puur $\mathrm{CO}_{2}$ als spoelgas. Er moet wel op gewezen worden dat dit laatste geval (puur $\mathrm{CO}_{2}$ als spoelgas) niet realistisch is, omdat SCF membranen niet stabiel zijn in een $100 \% \mathrm{CO}_{2}$ atmosfeer.

Hoofdstuk 6 bediscussieerd het volledige proces van een membraangeïntegreerde oxy-fuel verbrandingsproces. Simulatie resultaten, met gebruik making van UniSim ${ }^{\circledR}$, geeft voor dit proces een totale netto efficiëntie van $32.1 \%$ voor een kolen gestookte elecriciteitscentrale waar 20 ton/uur steenkool wordt verbrand voor de opwekking van elektriciteit. Deze efficiëntie is hoger in vergelijking met een oxyfuel proces waarbij zuurstof verkregen wordt door cryogene destillatie van lucht $(29,6 \%)$. De elektrische energie, die noodzakelijk is voor afvangen van $\mathrm{CO}_{2}$, inclusief $\mathrm{CO}_{2}$ compressie tot 100 bar, is berekend op $159 \mathrm{kWh}_{\mathrm{e}} / \mathrm{t}_{\mathrm{CO}_{2}}$. Indien Tagedoteerd $\mathrm{SrCo}_{0.8} \mathrm{Fe}_{0.2} \mathrm{O}_{3-\delta}$ (SCFTa) als membraan gebruikt wordt, is voor deze elektriciteitscentrale een totaal membraan oppervlak van $71.000 \mathrm{~m}^{2}$ nodig. Geïnspireerd door de resultaten, die in hoofdstuk 5 zijn beschreven, is een alternatief proces voorgesteld waarbij niet gedoteerd SCF is gebruikt voor het scheiden van zuurstof van lucht. Hierbij is een extra lus ("loop") van $\mathrm{O}_{2} / \mathrm{CO}_{2}$ geïntroduceerd in het proces schema om de SCF membranen te beschermen tegen degradatie ten gevolge van $\mathrm{CO}_{2}$. Dit gemodificeerde proces geeft dezelfde netto efficiënte als voor het proces zonder "loop" en met SCFTa membranen, maar er is minder membraan oppervlak nodig $\left(49.000 \mathrm{~m}^{2}\right)$. 
Tenslotte worden in hoofdstuk 7 de belangrijkste conclusies samengevat en worden aanbevelingen gegeven voor toekomstig onderzoek. De belangrijkste aanbevelingen zijn, dat er meer onderzoek gedaan moet worden naar de stabiliteit van deze membraan in $\mathrm{SO}_{2}$ en/of water bevattende atmosferen. Daarnaast zal bij een proces design ook nagegaan moeten worden wat de netto efficiëntie en het benodigde membraanoppervlak is bij gebruik making van de zogenaamde 3 -end mode voor de membraan module (in plaats van de in dit proefschrift beschreven 4-end mode). 


\section{Acknowledgements}

When I learnt how to complain about the Dutch weather, it is almost time to leave. Four and half years' living in Enschede, a beautiful small city in the Netherlands, has given me a lot of wonderful memories. At this moment of leaving, it is so emotional.

There are many people that have helped me in the last few years, and I want to thank all of them.

The first person I want to thank is my promotor, Arian Nijmeijer. Arian, thanks very much for giving me the opportunity to carry out the $\mathrm{PhD}$ research in Inorganic Membranes groups. You have given me a lot of valuable advices during my $\mathrm{PhD}$ research, and that really helped me a lot.

I would also like to thank Louis Winnubst, my daily supervisor, for guiding me in the research and taking care of me in all other aspects in the past few years. I still remember that the first day I arrived in the Netherlands, Louis and Shumin pick me up from the Schiphol airport, it was something like yesterday but actually 1630 days ago. Yes, 1630, what a huge number! Louis, thanks a lot.

This thesis cannot be finished without the help from my colleagues/friends in the Inorganic Membranes (IM) group. I want to thank Henny Bouwmeester for many fruitful scientific discussions in material science and electrochemistry, Nieck Benes for the discussion on process simulation, Frank Morssinkhof, Mieke Luiten-olieman, Cindy Huiskes for many technical supports. I would also like to thank all other present/left IM members, Susanne Van Rijn, Bas ten Donkelaar, Marcel ten Hove, Emiel Kappert, Tan Phung, Hammad Qureshi, Michiel Raaijmakers, Saim Saher, Cheryl Tarnadi, Patrick de Wit, Evelien Maaskant, Bo Wang, Can Aran, Chung-yul Yoo, Chunlin Song, Martin Wolf, Roland Blanch Ojea, Shumin Fang, Tingfang Tian, Weihua Zhou. I wish you all the best and we keep in touch in the future.

During the PhD research, I got a lot of help from people outside the IM group. 
Part of the experiments in chapter 4 was performed in University of Science and Technology of China (USTC) with the help of Professor Chusheng Chen, the process design and simulation in chapter 6 was done with a lot of help from Dr. Louis van de ham from Sustainable Process Technology group, here I want to express my gratitude to them.

The life of living abroad becomes easier with my Chinese friends in Twente, I want to thank all of them, Lei Hui, Zhou Di, Wang Min, Liu Haiying and Zhang Chunhong, Zhu Dan, Tian Ye, Fang Shumin and Pan Yan, Zhou Weihua and He Qiwei, Zhao Yingnan and Jiayin, Ni Yunyun, Feng Xueling, Tan Lianghui, Chen Yanting and Liu Fei, Li Xiaohua, Chang Lantian and Du Ying, Zhang Yali and Zhao Jie, Sui Xiaofeng and Gao Yuying, Chen Songyue and He Yifan, Sun Chao and Han Tingting, Gang Tian and Wan Xin, Xu Lixian and Luo Hongping, Zhang Jingwei and Chen zhonghua. Thank you all, my friends, I wish you all the best for your future life.

Finally, I want to express my thanks to my family:

我要感谢父母对我的养育之恩和这么多年来对我的支持和帮助, 父爱如山, 母爱如水, 当我有了自己的孩子之后才真正懂的这份爱。如今常年在外, 不能 陪伴爸妈, 只希望他们能健健康康的我便满足了。我也要感谢我的妻子岳玉梅, 谢谢你辞掉国内的工作来到荷兰团聚, 我们在一起已经十年了, 虽然生活中也 有磕磕碰碰, 但是我们对彼此的爱却是永恒的。最后我要感谢我亲爱的女儿, 谢谢你的到来, 你给爸爸妈妈的生活中增添了无穷的欢乐, 你咿咿呀呀的说话 让家里热闹非凡, 祝你健康快乐成长。

Wei Chen

April 21, 2014

Enschede 


\section{Curriculum Vitae}

Wei Chen was born in on December 19 ${ }^{\text {th }}, 1982$ in Henan province, China. After the graduation from the first high school of Yancheng county in 2002, he started his study in University of Science and Technology of China (USTC), majored in material science and engineering. In 2006, he obtained his bachelor's degree in natural science, and then he continued his study/research in USTC as a master student. The master program was done with the supervision of Professor Chusheng Chen and in 2010 Wei Chen obtained the master degree in material science and engineering. From the end of 2009 he joined the Inorganic Membrane Group, as a PhD student. His research interests are: fundamental researches on solid state ionics, solid state electrochemistry; design and simulation on membrane related chemical process. 
